\title{
Application of NUREG/CR-5999 Interim Fatigue Curves to Selected Nuclear Power Plant Components
}

Manuscript Completed: February 1995

Date Published: March 1995

\section{Prepared by}

A. G. Ware, D. K. Morton, M. E. Nitzel

Idaho National Engineering Laboratory Lockheed Idaho Technologies Company Idaho Falls, ID 83415

\section{DISCLAIMER}

This report was prepared as an account of work sponsored by an agency of the United States Government. Neither the United States Government nor any agency thereof, nor any of their employees, makes any warranty, express or implied, or assumes any legal liability or responsibility for the accuracy, completeness, or usefulness of any information, apparatus, product, or process disclosed, or represents that its use would not infringe privately owned rights. Reference herein to any specific commercial product, process, or service by trade name, trademark, manufacturer, or otherwise does not necessarily constitute or imply its endorsement, recommendation, or favoring by the United States Government or any agency thereof. The views and opinions of authors expressed herein do not necessarily state or reflect those of the United States Government or any agency thereof.

Prepared for

Division of Engineering

Office of Nuclear Reactor Regulation

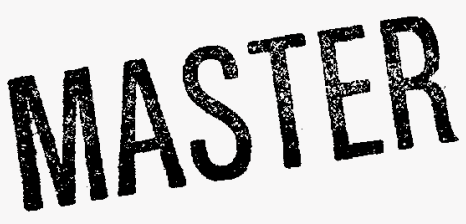

U.S. Nuclear Regulatory Commission

Washington, DC 20555-0001

NRC Job Code J2081 


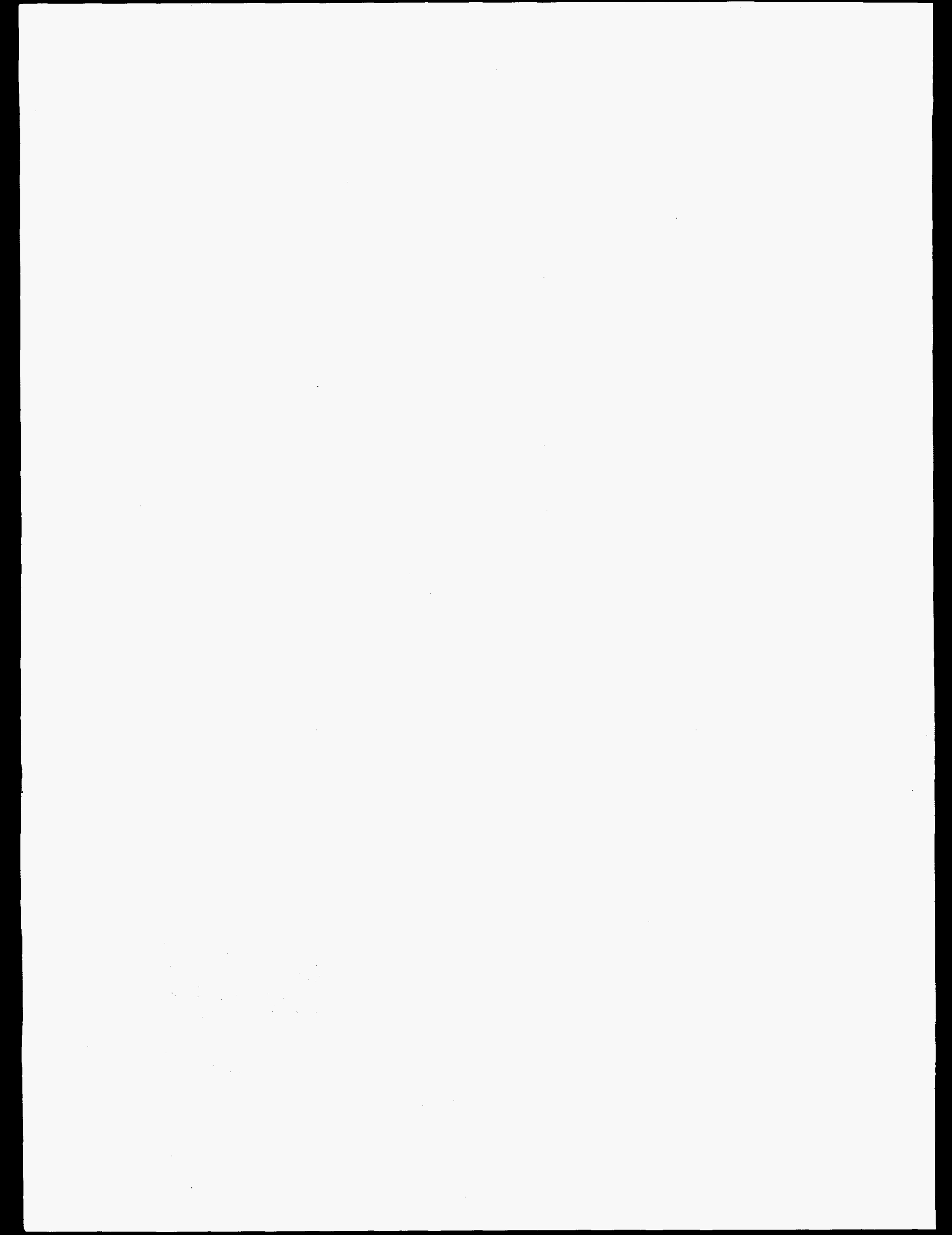




\section{DISCLAIMER}

Portions of this document may be illegible in electronic image products. Images are produced from the best available original document. 


\begin{abstract}
Recent test data indicate that the effects of the light water reactor (LWR) environment could significantly reduce the fatigue resistance of materials used in the reactor coolant pressure boundary components of operating nuclear power plants. Argonne National Laboratory has developed interim fatigue curves based on test data simulating LWR conditions, and published them in NUREG/CR-5999. In order to assess the significance of these interim fatigue curves, fatigue evaluations of a sample of the components in the reactor coolant pressure boundary of LWRs were performed. The sample consists of components from facilities designed by each of the four U.S. nuclear steam supply system vendors. For each facility, six locations were studied, including two locations on the reactor pressure vessel. In addition, there are older vintage plants where components of the reactor coolant pressure boundary were designed to codes that did not require an explicit fatigue analysis of the components. In order to assess the fatigue resistance of the older vintage plants, an evaluation was also conducted on selected components of three of these plants. This report discusses the insights gained from the application of the interim fatigue curves to components of seven operating nuclear power plants.
\end{abstract}




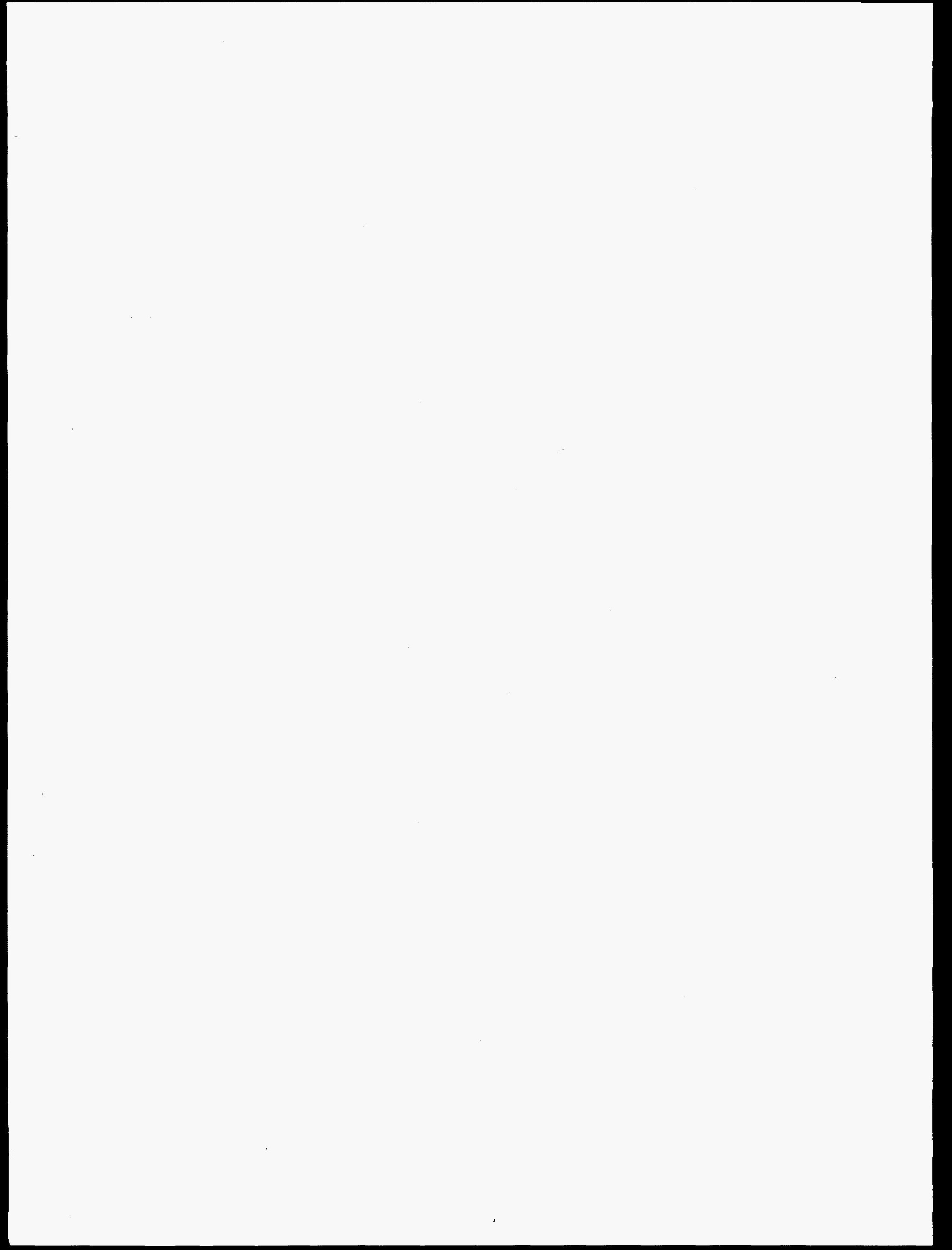




\section{CONTENTS}

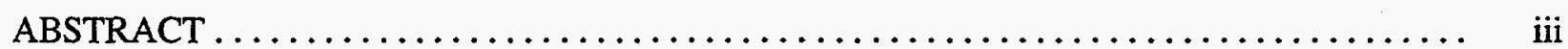

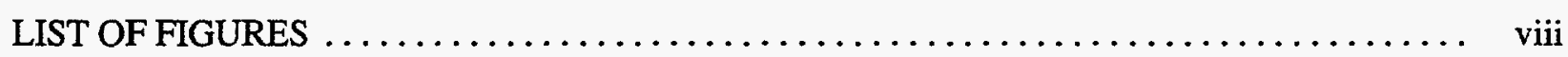

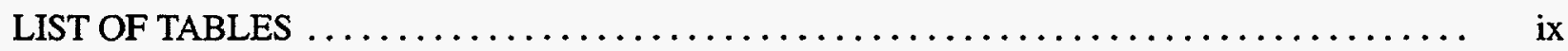

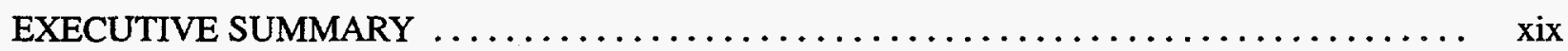

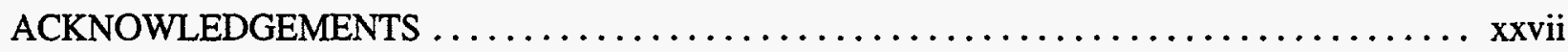

ACRONYMS AND ABBREVIATIONS $\ldots \ldots \ldots \ldots \ldots \ldots \ldots \ldots \ldots \ldots \ldots \ldots \ldots \ldots \ldots \ldots \ldots \ldots$

1. INTRODUCTION $\ldots \ldots \ldots \ldots \ldots \ldots \ldots \ldots \ldots \ldots \ldots \ldots \ldots \ldots \ldots \ldots \ldots \ldots \ldots \ldots \ldots \ldots \ldots, 1-1$

2. ASME CODE SECTION III FATIGUE METHODOLOGY $\ldots \ldots \ldots \ldots \ldots \ldots \ldots \ldots .2-1$

2.1 Background of ASME Code Fatigue Requirements $\ldots \ldots \ldots \ldots \ldots \ldots \ldots \ldots .2-1$

2.1.1 USAS B31.1 and B31.7 $\ldots \ldots \ldots \ldots \ldots \ldots \ldots \ldots \ldots \ldots \ldots \ldots \ldots \ldots \ldots, 2-1$

2.1.2 ASME Code $\ldots \ldots \ldots \ldots \ldots \ldots \ldots \ldots \ldots \ldots \ldots \ldots \ldots \ldots \ldots \ldots \ldots \ldots \ldots \ldots, 2-2$

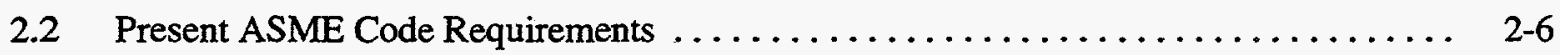

2.2.1 ASME Code NB-3200 Fatigue Analysis Method $\ldots \ldots \ldots \ldots \ldots \ldots \ldots .2-7$

2.2.2 ASME Code NB-3600 Fatigue Analysis Method $\ldots \ldots \ldots \ldots \ldots \ldots \ldots .2-9$

2.2.3 Simplified Elastic-Plastic Multiplier (Ke) $\ldots \ldots \ldots \ldots \ldots \ldots \ldots \ldots, 2-10$

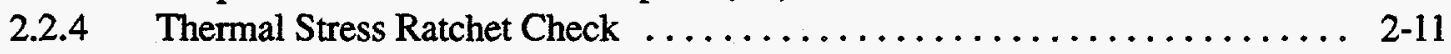

3. NUREG/CR-5999 INTERIM FATIGUE CURVES $\ldots \ldots \ldots \ldots \ldots \ldots \ldots \ldots \ldots \ldots \ldots \ldots \ldots \ldots$

3.1 Curve Descriptions $\ldots \ldots \ldots \ldots \ldots \ldots \ldots \ldots \ldots \ldots \ldots \ldots \ldots \ldots \ldots \ldots \ldots \ldots \ldots \ldots \ldots, 3-1$

3.2 Increase in CUF using Interim Curves $\ldots \ldots \ldots \ldots \ldots \ldots \ldots \ldots \ldots \ldots \ldots \ldots \ldots \ldots \ldots, 3-4$

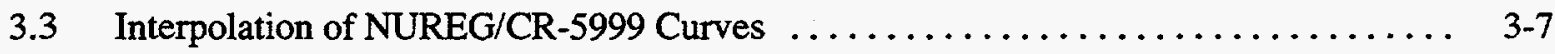

3.4 Revised Interim Fatigue Curves $\ldots \ldots \ldots \ldots \ldots \ldots \ldots \ldots \ldots \ldots \ldots \ldots \ldots \ldots \ldots \ldots \ldots \ldots \ldots \ldots, 12$

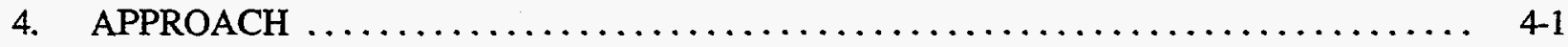

$4.1 \quad$ Selection of Components for Analysis $\ldots \ldots \ldots \ldots \ldots \ldots \ldots \ldots \ldots \ldots \ldots, 4 \ldots \ldots \ldots \ldots$

4.2 Application of NUREG/CR-5999 Fatigue Curves $\ldots \ldots \ldots \ldots \ldots \ldots \ldots \ldots \ldots$.1

4.2.1 Interior and Exterior Surfaces $\ldots \ldots \ldots \ldots \ldots \ldots \ldots \ldots \ldots \ldots \ldots, 4,1$

$4.2 .2 \quad$ Cladding $\ldots \ldots \ldots \ldots \ldots \ldots \ldots \ldots \ldots \ldots \ldots \ldots \ldots \ldots, \quad 4,2$

$4.2 .3 \quad$ Life Extension $\ldots \ldots \ldots \ldots \ldots \ldots \ldots \ldots \ldots \ldots \ldots \ldots \ldots \ldots \ldots \ldots, \quad 4,2$

4.2.4 Extent of Licensee Calculation Review $\ldots \ldots \ldots \ldots \ldots \ldots \ldots \ldots \ldots, 4,3$

4.2.5 Reporting of Stress Results ........................... 4

4.2.6 Significant Digits $\ldots \ldots \ldots \ldots \ldots \ldots \ldots \ldots \ldots \ldots \ldots \ldots \ldots \ldots \ldots \ldots \ldots \ldots \ldots, 4,3$ 


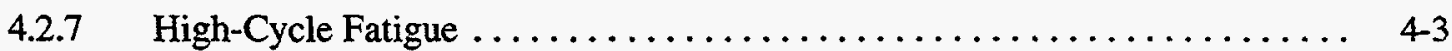

4.2.8 Applicable Temperature and Strain Rate Values ............... $4-3$

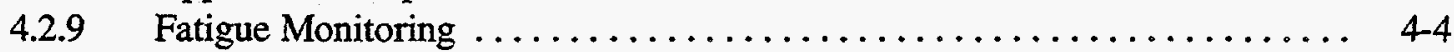

4.3 Potential Adjustments to Licensees' Calculations that Might Reduce the CUF ..... 4-5

4.4 Examples of Code Changes and Adjustments to Cycles/Transients that Might

Increase the CUF in Licensees' Calculations . . . . . . . . . . . . . . . . . . .

5. COMPONENT EVALUATIONS $\ldots \ldots \ldots \ldots \ldots \ldots \ldots \ldots \ldots \ldots \ldots \ldots \ldots \ldots \ldots \ldots \ldots \ldots \ldots \ldots$

5.1 Newer Vintage Combustion Engineering Plant $\ldots \ldots \ldots \ldots \ldots \ldots \ldots \ldots \ldots \ldots$

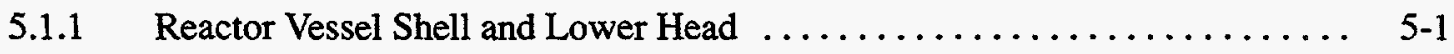

5.1 .2 Reactor Vessel Inlet and Outlet Nozzles $\ldots \ldots \ldots \ldots \ldots \ldots \ldots \ldots \ldots \ldots .5-2$

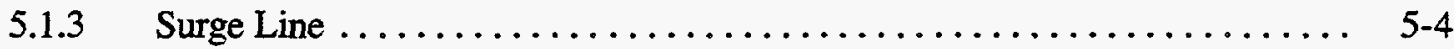

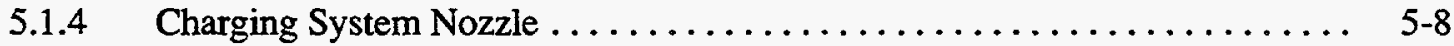

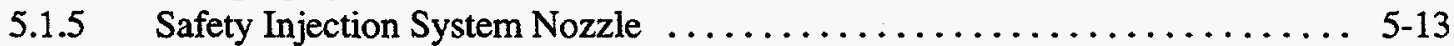

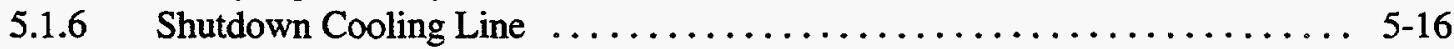

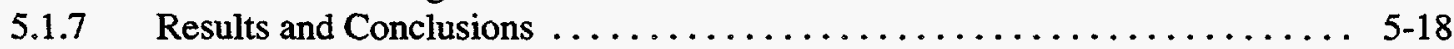

5.2 Older Vintage Combustion Engineering Plant $\ldots \ldots \ldots \ldots \ldots \ldots \ldots \ldots \ldots \ldots$

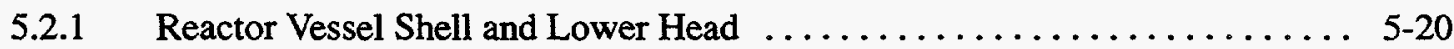

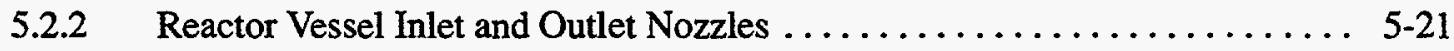

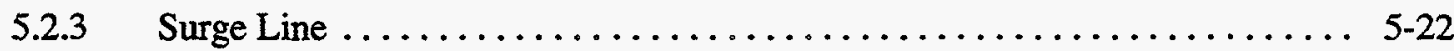

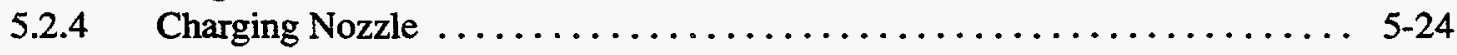

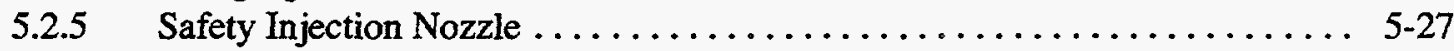

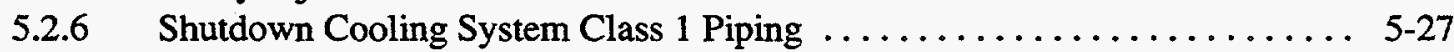

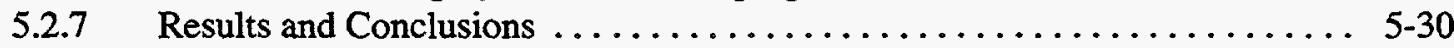

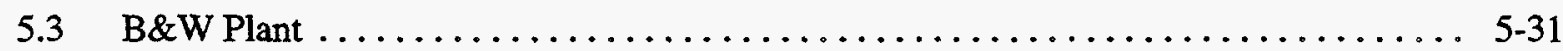

5.3.1 Reactor Vessel Shell and Lower Head $\ldots \ldots \ldots \ldots \ldots \ldots \ldots \ldots \ldots . \ldots \ldots$. 5.33

5.3 .2 Reactor Vessel Inlet and Outlet Nozzles $\ldots \ldots \ldots \ldots \ldots \ldots \ldots \ldots \ldots \ldots . \ldots \ldots \ldots$

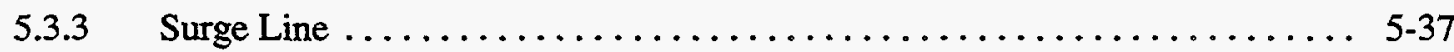

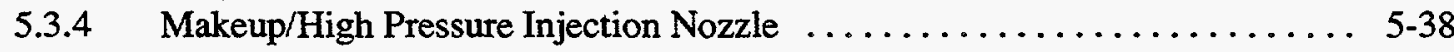

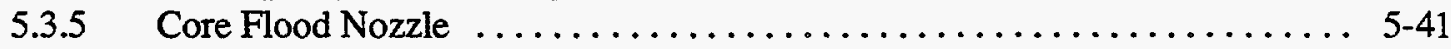

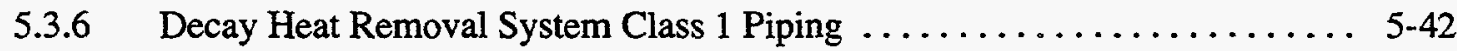

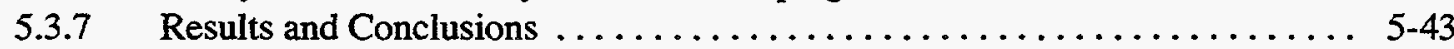

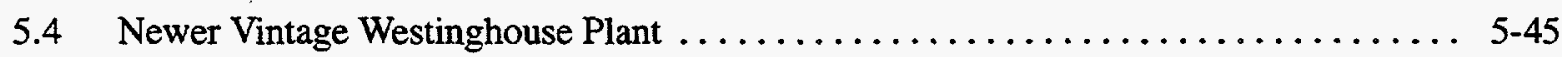

5.4.1 Reactor Vessel Shell and Lower Head $\ldots \ldots \ldots \ldots \ldots \ldots \ldots \ldots \ldots . \ldots \ldots$. $5-47$

$5.4 .2 \quad$ Reactor Vessel Inlet and Outlet Nozzles $\ldots \ldots \ldots \ldots \ldots \ldots \ldots \ldots \ldots \ldots . \ldots \ldots$

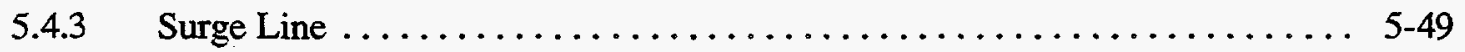

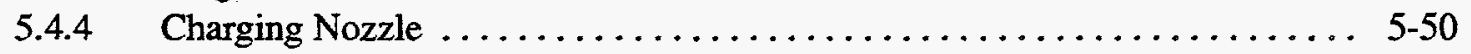

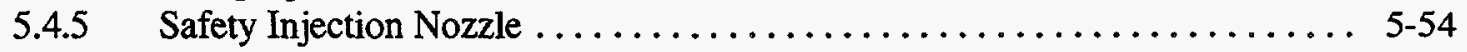

5.4 .6 Residual Heat Removal System Class 1 Piping $\ldots \ldots \ldots \ldots \ldots \ldots \ldots \ldots$

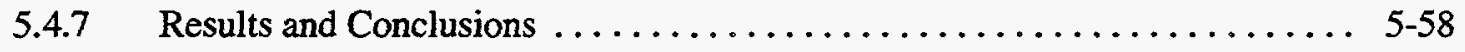


5.5.1 Reactor Vessel Shell and Lower Head $\ldots \ldots \ldots \ldots \ldots \ldots \ldots \ldots \ldots . \ldots \ldots . \ldots \ldots$

5.5 .2 Reactor Vessel Inlet and Outlet Nozzles . . . . . . . . . . . . . . . . . 5-63

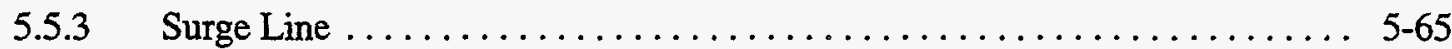

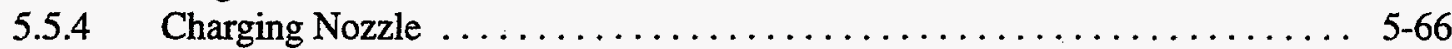

5.5.5 Safety Injection Nozzle . . . . . . . . . . . . . . . . . . . . . . 5-71

5.5.6 Residual Heat Removal System Class 1 Piping $\ldots \ldots \ldots \ldots \ldots \ldots \ldots \ldots$ 5-76

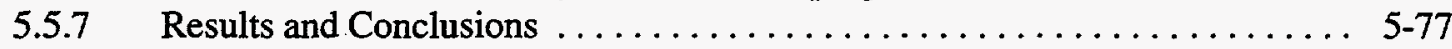

5.6 Newer Vintage General Electric Plant $\ldots \ldots \ldots \ldots \ldots \ldots \ldots \ldots \ldots \ldots \ldots \ldots \ldots$

5.6.1 Reactor Vessel Shell and Lower Head $\ldots \ldots \ldots \ldots \ldots \ldots \ldots \ldots \ldots$ 5-81

5.6 .2 Reactor Vessel Feedwater Nozzle $\ldots \ldots \ldots \ldots \ldots \ldots \ldots \ldots \ldots \ldots \ldots . .64$

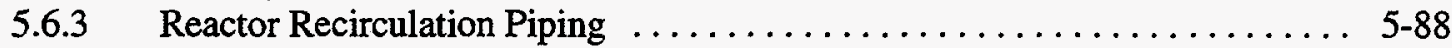

5.6.4 Core Spray Line Reactor Vessel Nozzle and Associated Class 1

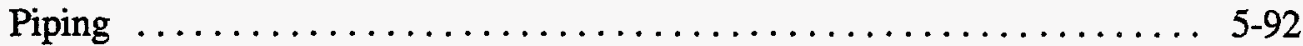

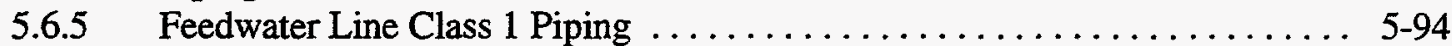

5.6.6 Residual Heat Removal (RHR) Nozzles and Associated Class 1

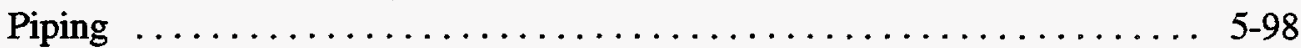

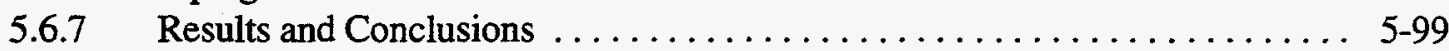

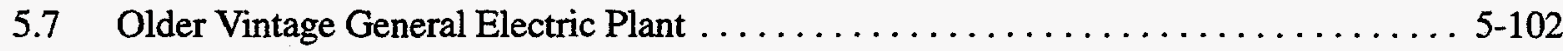

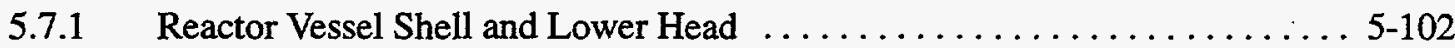

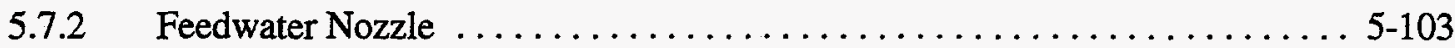

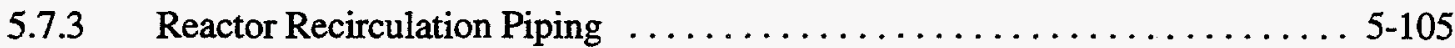

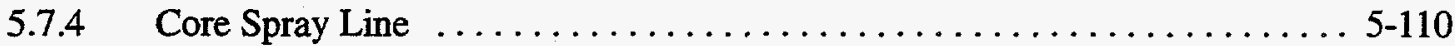

5.7.5 RHR Return Line Piping ...................... 5-115

$5.7 .6 \quad$ Feedwater Piping . . . . . . . . . . . . . . . . . . . . . $5-116$

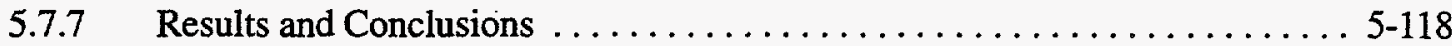

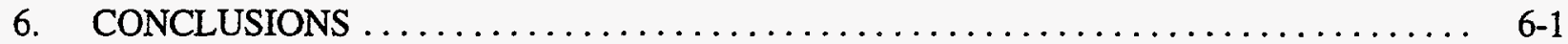

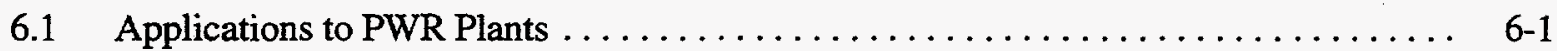

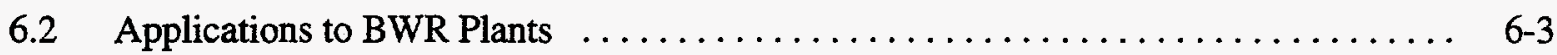

6.3 CUF Evaluations for Piping Components Designed to the B31.1 Piping Code . . . . . 6-4

6.4 Revised Interim Fatigue Curves for Stainless Steel $\ldots \ldots \ldots \ldots \ldots \ldots \ldots \ldots \ldots \ldots$

6.5 Overall Conclusion $\ldots \ldots \ldots \ldots \ldots \ldots \ldots \ldots \ldots \ldots \ldots \ldots \ldots \ldots \ldots \ldots \ldots \ldots$

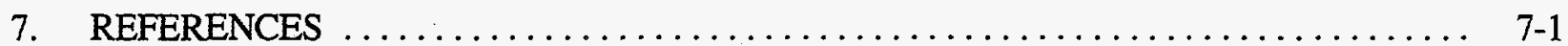




\section{LIST OF FIGURES}

2-1. ASME Code carbon and low-alloy steel fatigue curves (ASME, 1992) ........ 2-3

2-2. ASME Code stainless steel and Alloy 600 fatigue curve (ASME, 1992) ........ 2-4

2-3. ASME Code stainless steel and Alloy 600 high-cycle fatigue curves (ASME, 1992) $\ldots \quad$ 2-5

3-1. Interim fatigue curve for stainless and Alloy 600 steels $\ldots \ldots \ldots \ldots \ldots \ldots \ldots \ldots$

3-2. Interim fatigue curve for carbon and low-alloy steels in low-oxygen water $\ldots \ldots \ldots$

3-3. Interim fatigue curve for carbon and low-alloy steels in high-oxygen water

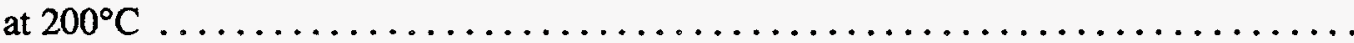

3-4. Interim fatigue curve for carbon and low-alloy steels in high-oxygen water

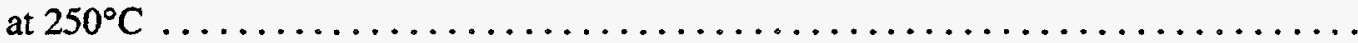

3-5. Interim fatigue curve for carbon and low-alloy steels in high-oxygen water at $288^{\circ} \mathrm{C}$

3-6. Increase in CUF using NUREG/CR-5999 interim fatigue curve for stainless and

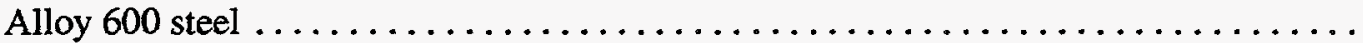

3-7. Increase in CUF using NUREG/CR-5999 interim fatigue curve for carbon and low-alloy steel in low-oxygen environment . . . . . . . . . . . . . . . . . . . . . .

3-8. Increase in CUF using NUREG/CR-5999 interim fatigue curve for carbon and low-alloy steel in high-oxygen environment at $200^{\circ} \mathrm{C}$

3-9. Increase in CUF using NUREG/CR-5999 interim fatigue curve for carbon and low-alloy steel in high-oxygen environment at $250^{\circ} \mathrm{C}$

3-10. Increase in CUF using NUREG/CR-5999 interim fatigue curve for carbon and low-alloy steel in high-oxygen environment at $288^{\circ} \mathrm{C} \ldots \ldots \ldots \ldots \ldots \ldots \ldots \ldots \ldots \ldots \ldots$

3-11. Ratio of strain rate cycles at $200^{\circ} \mathrm{C}$

3-12. Ratio of strain rate cycles at $250^{\circ} \mathrm{C}$

3-13. Ratio of strain rate cycles at $288^{\circ} \mathrm{C}$

3-14. Ratio of cycles on $200^{\circ} \mathrm{C}$ curve to cycles on $250^{\circ} \mathrm{C}$ curve $\ldots \ldots \ldots \ldots \ldots$

3-15. Ratio of cycles on $200^{\circ} \mathrm{C}$ curve to cycles on $288^{\circ} \mathrm{C}$ curve $\ldots \ldots \ldots \ldots \ldots \ldots \ldots$

3-16. Relationship of strain rate and numbers of cycles $\ldots \ldots \ldots \ldots \ldots \ldots \ldots \ldots \ldots \ldots$

3-17. Relationship of temperature and numbers of cycles $\ldots \ldots \ldots \ldots \ldots \ldots \ldots \ldots \ldots$

3-18. Revised stainless steel interim fatigue design curve (computed from

Chopra, 1994) 
3-19. Ratio of revised interim fatigue curve cycles to corresponding ASME Code

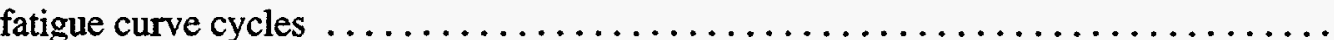

5-1. Shutdown cooling system model isometric view $\ldots \ldots \ldots \ldots \ldots \ldots \ldots \ldots \ldots \ldots$

5-2. Charging system nozzle finite element model $\ldots \ldots \ldots \ldots \ldots \ldots \ldots \ldots \ldots \ldots$

5-3. Charging nozzle axisymmetric finite element model $\ldots \ldots \ldots \ldots \ldots \ldots \ldots \ldots \ldots$

5-4. Safety injection nozzle finite element model $\ldots \ldots \ldots \ldots \ldots \ldots \ldots \ldots \ldots \ldots$

5-5. Safety injection nozzle axisymmetric finite element model $\ldots \ldots \ldots \ldots \ldots \ldots \ldots \ldots$

5-6. Residual heat removal system model isometric view $\ldots \ldots \ldots \ldots \ldots \ldots \ldots \ldots \ldots .5-78$

5-7. BWR/4 recirculation piping system isometric view $\ldots \ldots \ldots \ldots \ldots \ldots \ldots \ldots \ldots$

5-8. Comparison of RHR shutdown cooling transients $\ldots \ldots \ldots \ldots \ldots \ldots \ldots \ldots \ldots$

5-9. BWR/4 feedwater line with RCIC connection $\ldots \ldots \ldots \ldots \ldots \ldots \ldots \ldots \ldots \ldots \ldots \ldots$

\section{LIST OF TABLES}

2-1. Values for $\mathrm{S}(\mathrm{ksi})$ and $\mathrm{N}$ (cycles) [ASME, 1992, Table I-9.0] $\ldots \ldots \ldots \ldots \ldots \ldots \ldots$

2-2. Values for $m$ and $n$ [ASME, 1992, Table NB-3228.5(b)-1] $\ldots \ldots \ldots \ldots \ldots \ldots \ldots$

3-1. Applicable figures from NUREG/CR-5999 $\ldots \ldots \ldots \ldots \ldots \ldots \ldots \ldots \ldots \ldots \ldots \ldots \ldots \ldots$

5-1. Number of selected design basis transients compared to anticipated number of transients

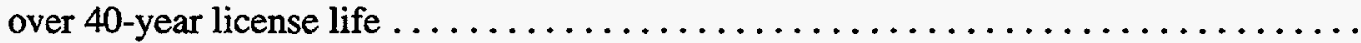

5-2. CUF results for reactor vessel shell/lower head region using NUREG/CR-5999 interim

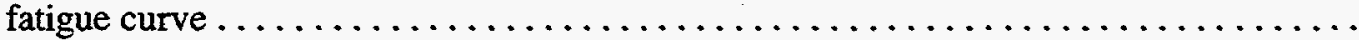

5-3. CUF results for reactor vessel inlet nozzle using NUREG/CR-5999 interim

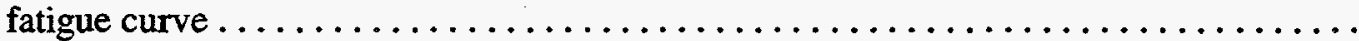

5-4. CUF results for reactor vessel outlet nozzle using NUREG/CR-5999 interim fatigue

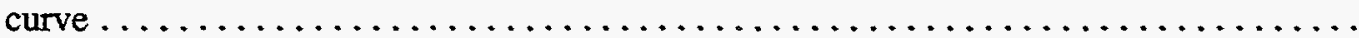

5-5. CUF results for reactor vessel outlet nozzle using NUREG/CR-5999 interim fatigue

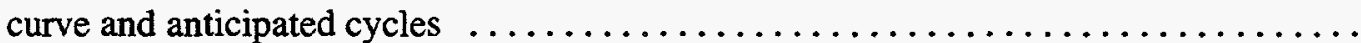

5-6. CUF results for the surge line using NUREG/CR-5999 interim fatigue curve .......

5-7. CUF results for the surge line using NUREG/CR-5999 interim fatigue curve and

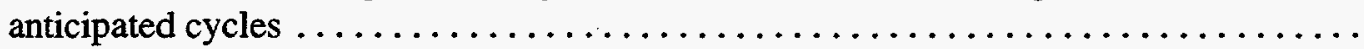

5-8. Potential for elimination of conservative assumptions to reduce CUF for surge line elbow using NUREG/CR-5999 interim fatigue curve 
5-9. CUF results for the surge line using revised interim fatigue curves and anticipated

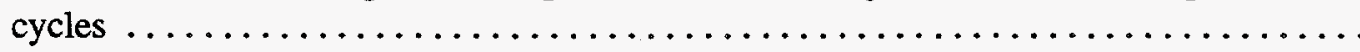

5-10. CUF results for the charging system nozzle forging using NUREG/CR-5999 interim

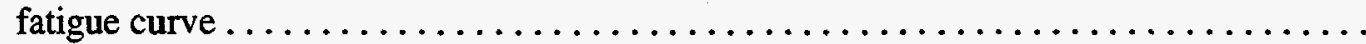

5-11. CUF results for the charging system nozzle safe end using NUREG/CR-5999 interim

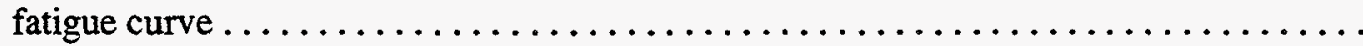

5-12. CUF results for the charging system nozzle safe end using NUREG/CR-5999 interim fatigue curve with conservative assumptions removed

5-13. CUF results for the charging system nozzle safe end using NUREG/CR-5999 interim fatigue curve with conservative assumptions removed and anticipated cycles ........

5-14. Potential for elimination of conservative assumptions to reduce CUF for charging nozzle safe end using NUREG/CR-5999 interim fatigue curve $\ldots \ldots \ldots \ldots \ldots \ldots \ldots$

5-15. CUF results for the charging system nozzle safe end using revised interim fatigue curves with conservative assumptions removed and anticipated cycles $\ldots \ldots \ldots \ldots \ldots$

5-16. CUF results for the safety injection nozzle forging using NUREG/CR-5999 interim

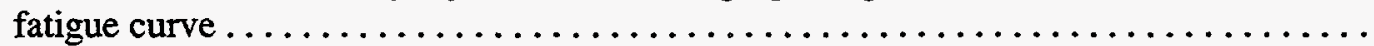

5-17. CUF results for the safety injection nozzle safe end using NUREG/CR-5999 interim

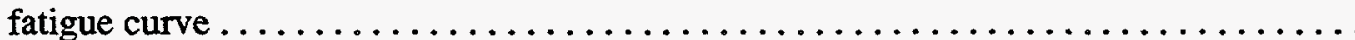

5-18. CUF results for the safety injection nozzle forging using NUREG/CR-5999 interim

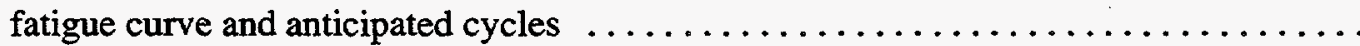

5-19. CUF results for the safety injection nozzle safe end using NUREG/CR-5999 interim fatigue curve with conservative assumptions removed $\ldots \ldots \ldots \ldots \ldots \ldots \ldots$

5-20. CUF results for the safety injection nozzle safe end using NUREG/CR-5999 interim fatigue curves with conservative assumptions removed and anticipated cycles .......

5-21. CUF results for the safety injection nozzle safe end using revised NUREG/CR-5999 interim fatigue curves with conservative assumptions removed and anticipated cycles

5-22. CUF results for the shutdown cooling line using NUREG/CR-5999 interim fatigue curve and licensee's design basis stresses

5-23. CUF results for the shutdown cooling line using NUREG/CR-5999 interim fatigue curve with conservative assumptions removed $\ldots \ldots \ldots \ldots \ldots \ldots \ldots \ldots$

5-24. CUF results for the shutdown cooling line using NUREG/CR-5999 interim fatigue curve with conservative assumptions removed and anticipated cycles ...........

5-25. CUF results for the shutdown cooling line using revised interim fatigue curves with conservative assumptions removed and anticipated cycles $(0.001 \% / \mathrm{s}$ strain rate) $\ldots \ldots$ 
5-26. Summary of newer vintage Combustion Engineering plant CUFs

5-27. Number of selected design basis cycles compared to anticipated number of cycles

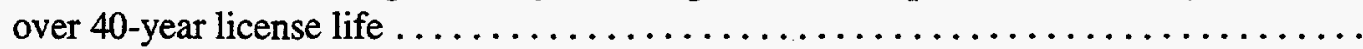

5-28. CUF results for reactor vessel lower head using NUREG/CR-5999 interim

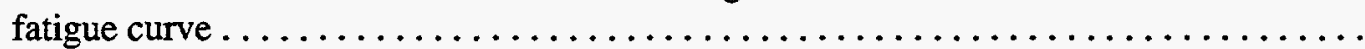

5-29. CUF results for reactor vessel inlet nozzle using NUREG/CR-5999 interim fatigue curve

5-30. CUF results for reactor vessel outlet nozzle using NUREG/CR-5999 interim

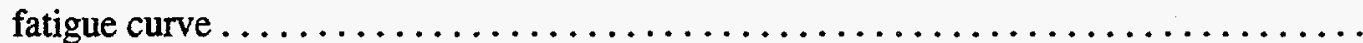

5-31. CUF results for surge line elbow using NUREG/CR-5999 interim fatigue curve

5-32. CUF results for surge line elbow using NUREG/CR-5999 interim fatigue curve and

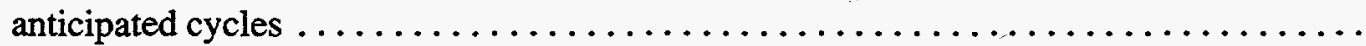

5-33. Potential for elimination of conservative assumptions to reduce CUF for surge line elbow using NUREG/CR-5999 interim fatigue curve $\ldots \ldots \ldots \ldots \ldots \ldots \ldots$

5-34. CUF results for surge line elbow using revised interim fatigue curves with conservative assumptions removed and anticipated cycles

5-35. CUF results for charging nozzle using NUREG/CR-5999 interim fatigue curve ......

5-36. CUF results for charging nozzle using NUREG/CR-5999 interim fatigue curve and

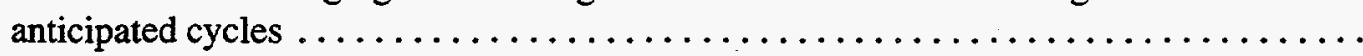

5-37. CUF results for the charging system nozzle safe end using revised interim fatigue curves with conservative assumptions removed and anticipated cycles $\ldots \ldots \ldots \ldots \ldots \ldots$

5-38. CUF results for safety injection nozzle using NUREG/CR-5999 interim fatigue

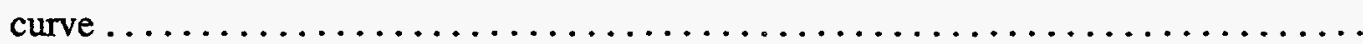

5-39. CUF results for safety injection nozzle using NUREG/CR-5999 interim fatigue curve and anticipated cycles

5-40. CUF results for the safety injection nozzle safe end using revised interim fatigue curves with conservative assumptions removed and anticipated cycles

5-41. CUF results for the shutdown cooling system piping using NUREG/CR-5999 interim fatigue curve

5-42. CUF results for the shutdown cooling system piping using revised interim fatigue curves

5-43. Summary of older vintage Combustion Engineering plant CUFs $\ldots \ldots \ldots \ldots \ldots \ldots$

5-44. Number of selected design basis cycles compared to anticipated number of cycles over

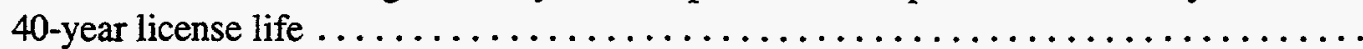


5-45. CUF results for reactor vessel lower head using NUREG/CR-5999 interim fatigue

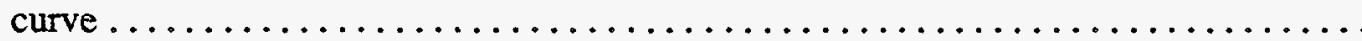

5-46. CUF results for instrumentation penetration weld using NUREG/CR-5999 interim

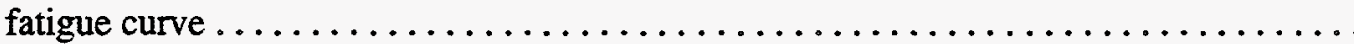

5-47. CUF results for instrumentation penetration weld using NUREG/CR-5999 interim

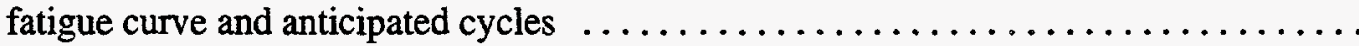

5-48. Potential for elimination of conservative assumptions to reduce CUF for instrumentation penetration weld using NUREG/CR-5999 interim fatigue curve $\ldots \ldots \ldots \ldots \ldots \ldots$

5-49. CUF results for instrumentation penetration weld using revised interim fatigue curves with conservative assumptions removed and anticipated cycles $\ldots \ldots \ldots \ldots \ldots \ldots$

5-50. CUF results for reactor vessel outlet nozzle using NUREG/CR-5999 interim fatigue

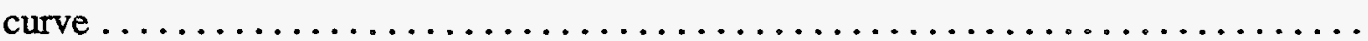

5-51. CUF results for reactor vessel outlet nozzle using NUREG/CR-5999 interim fatigue curve with conservative assumptions removed

5-52. Potential for elimination of conservative assumptions to reduce CUF for surge line using NUREG/CR-5999 interim fatigue curve $\ldots \ldots \ldots \ldots \ldots \ldots \ldots \ldots \ldots \ldots \ldots \ldots \ldots \ldots \ldots$

5-53. CUF results for makeup/HPI nozzle using NUREG/CR-5999 interim fatigue curve . . .

5-54. CUF results for makeup/HPI nozzle using NUREG/CR-5999 interim fatigue curve and anticipated cycles

5-55. CUF results for makeup/HPI nozzle using NUREG/CR-5999 interim fatigue curve based on anticipated numbers of cycles and 1992 Code edition $\mathrm{Ke}$................

5-56. Potential for elimination of conservative assumptions to reduce CUF for makeup/high pressure injection nozzle using NUREG/CR-5999 interim fatigue curve . . . . . . . .

5-57. CUF results for makeup/HPI nozzle using NUREG/CR-5999 interim fatigue curve based on anticipated numbers of cycles and 1992 Code edition $\mathrm{Ke} . \ldots \ldots \ldots \ldots \ldots$

5-58. CUF results for core flood nozzle using NUREG/CR-5999 interim fatigue curve .....

5-59. CUF results for the decay heat removal system piping using NUREG/CR-5999 interim

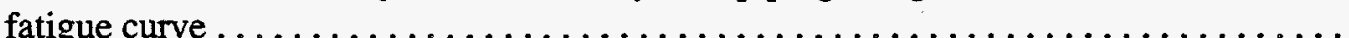

5-60. CUF results for the decay heat removal system piping using NUREG/CR-5999 interim fatigue curve with conservative assumptions removed

5-61. CUF results for the decay heat removal system piping using NUREG/CR-5999 interim fatigue curve with conservative assumptions removed and anticipated cycles ........

5-62. CUF results for the decay heat removal system piping using revised interim fatigue curve with conservative assumptions removed and anticipated cycles 
5-63. Summary of B\&W 177 fuel assembly plant CUFs

5-64. Number of selected design basis cycles compared to anticipated number of cycles over

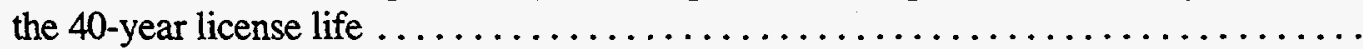

5-65. CUF results for reactor vessel lower head using NUREG/CR-5999 interim fatigue

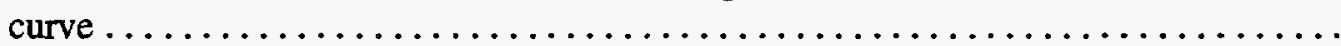

5-66. CUF results for reactor vessel inlet nozzle using NUREG/CR-5999 interim fatigue curve.

5-67. CUF results for reactor vessel outlet nozzle using NUREG/CR-5999 interim fatigue

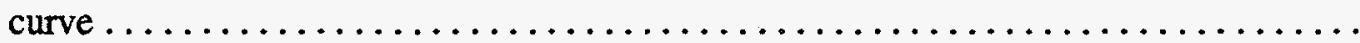

5-68. Potential for elimination of conservative assumptions to reduce CUF for surge line hot leg nozzle using NUREG/CR-5999 interim fatigue curve

5-69. CUF results for charging nozzle using NUREG/CR-5999 interim fatigue curve $\ldots \ldots$

5-70. CUF results for charging nozzle using NUREG/CR-5999 interim fatigue curve with

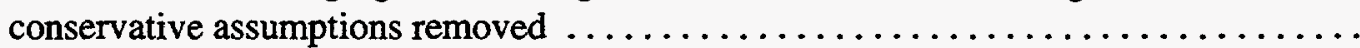

5-71. Potential for elimination of conservative assumptions to reduce CUF for charging nozzle using NUREG/CR-5999 interim fatigue curve $\ldots \ldots \ldots \ldots \ldots \ldots \ldots$

5-72. CUF results for charging nozzle using revised interim fatigue curves with conservative

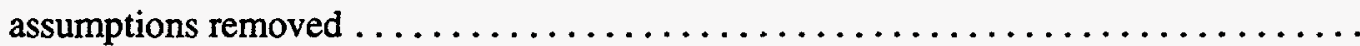

5-73. CUF results for safety injection (BIT) nozzle using NUREG/CR-5999 interim fatigue curve

5-74. CUF results for safety injection (BIT) nozzle using NUREG/CR-5999 interim fatigue curve with conservative assumptions removed

5-75. CUF results for safety injection (BIT) nozzle using NUREG/CR-5999 interim fatigue curve with conservative assumptions removed and anticipated cycles

5-76. Potential for elimination of conservative assumptions to reduce CUF for safety injection (BIT) nozzle using NUREG/CR-5999 interim fatigue curve

5-77. CUF results for safety injection (BIT) nozzle using revised interim fatigue curves with conservative assumptions removed and anticipated cycles $\ldots \ldots \ldots \ldots \ldots \ldots$

5-78. CUF results for the residual heat removal system piping using NUREG/CR-5999

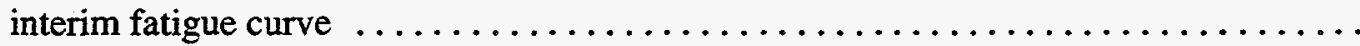

5-79. CUF results for the residual heat removal system piping using NUREG/CR-5999 interim fatigue curve and anticipated cycles $\ldots \ldots \ldots \ldots \ldots \ldots \ldots \ldots \ldots \ldots . . . \ldots \ldots$

5-80. Potential for elimination of conservative assumptions to reduce CUF for residual heat removal system using NUREG/CR-5999 interim fatigue curve $\ldots \ldots \ldots \ldots \ldots$ 
5-81. CUF results for the residual heat removal system piping using revised interim fatigue

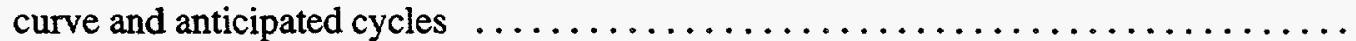

5-82. Summary of newer vintage Westinghouse plant CUFs $\ldots \ldots \ldots \ldots \ldots \ldots \ldots \ldots \ldots .5$

5-83. Number of selected design basis cycles compared to anticipated number of cycles

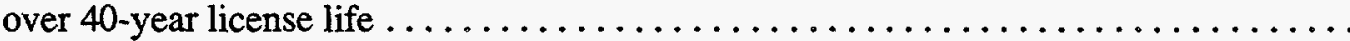

5-84. CUF results for reactor vessel lower head and shell using NUREG/CR-5999 interim

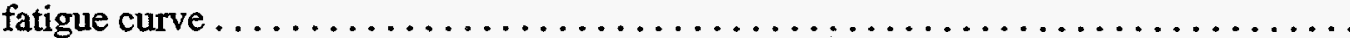

5-85. Potential for elimination of conservative assumptions to reduce CUF for reactor vessel lower head/shell using NUREG/CR-5999 interim fatigue curve . . . . . . . . . . . . .

5-86. CUF results for reactor vessel inlet nozzle using NUREG/CR-5999 interim

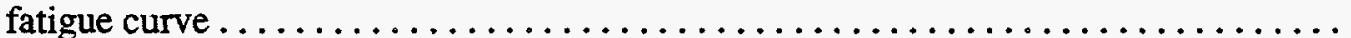

5-87. CUF results for reactor vessel outlet nozzle using NUREG/CR-5999 interim fatigue

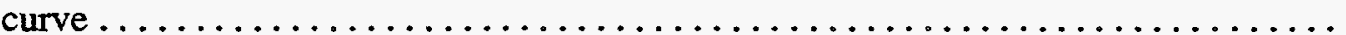

5-88. Potential for elimination of conservative assumptions to reduce CUF for surge line elbow using NUREG/CR-5999 interim fatigue curve $\ldots \ldots \ldots \ldots \ldots \ldots \ldots \ldots$

5-89. Major charging system transients assumed in the analysis

5-90. Results for charging nozzle using NB-3200 and NB-3600 methods and ASME Code

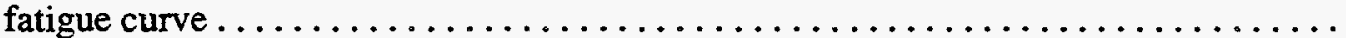

5-91. CUF results for charging nozzle using NUREG/CR-5999 interim fatigue curve ......

5-92. CUF results for charging nozzle using revised interim fatigue curve $\ldots \ldots \ldots \ldots \ldots$

5-93. Results for safety injection nozzle using NB-3200 and NB-3600 methods and ASME Code fatigue curve (safety injection/reactor trip)

5-94. CUF results for safety injection nozzle using NUREG/CR-5999 interim fatigue curve . .

5-95. CUF results for safety injection nozzle using revised interim fatigue curves $\ldots \ldots \ldots$

5-96. CUF results for the residual heat removal system piping using NUREG/CR-5999 interim

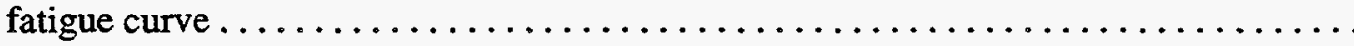

5-97. CUF results for the residual heat removal system piping using revised interim fatigue

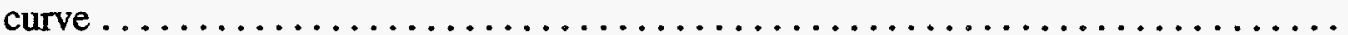

5-98. Summary of older vintage Westinghouse plant CUFs

5-99. Number of selected design basis cycles compared to anticipated number of cycles over 40-year license life

5-100. CUF results for reactor vessel lower head near CRDM penetration weld using NUREG/CR-5999 interim fatigue curve 
5-101. CUF results for CRDM penetration weld using NUREG/CR-5999 interim fatigue

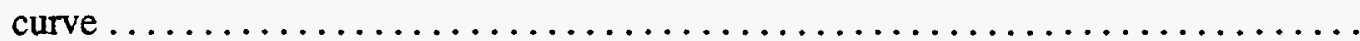

5-102. CUF results for reactor vessel lower head near CRDM penetration weld using NUREG/CR-5999 interim fatigue curve with conservative assumptions removed .....

5-103. CUF results for CRDM penetration weld using NUREG/CR-5999 interim fatigue curve with conservative assumptions removed $\ldots \ldots \ldots \ldots \ldots \ldots \ldots \ldots \ldots \ldots \ldots \ldots \ldots \ldots \ldots$

5-104. CUF results for CRDM penetration weld using revised interim fatigue curve with

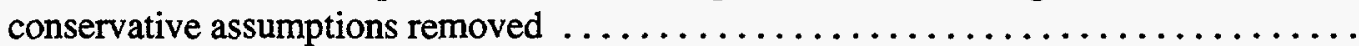

5-105. CUF results for reactor vessel feedwater nozzle thermal sleeve using NUREG/CR-5999 interim fatigue curve

5-106. CUF results for reactor vessel feedwater nozzle safe end using NUREG/CR-5999 interim fatigue curve

5-107. CUF results for reactor vessel feedwater nozzle thermal sleeve using NUREG/CR-5999 interim fatigue curve and anticipated numbers of cycles

5-108. Potential for elimination of conservative assumptions to reduce CUF for feedwater nozzle thermal sleeve using NUREG/CR-5999 interim fatigue curve

5-109. CUF results for reactor vessel feedwater nozzle safe end using NUREG/CR-5999 interim fatigue curve with conservative assumptions removed

5-110. CUF results for reactor vessel feedwater nozzle safe end using NUREG/CR-5999 interim fatigue curves with conservative assumptions removed and anticipated cycles .......

5-111. Potential for elimination of conservative assumptions to reduce CUF for feedwater nozzle safe end using NUREG/CR-5999 interim fatigue curve $\ldots \ldots \ldots \ldots \ldots \ldots \ldots$

5-112. CUF results for reactor vessel feedwater nozzle thermal sleeve using revised interim

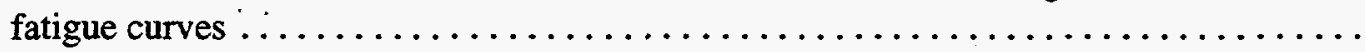

5-113. CUF results for the recirculation system piping using NUREG/CR-5999 interim

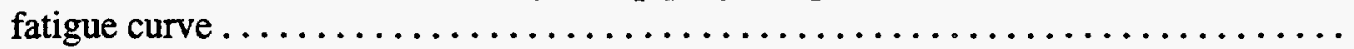

5-114. CUF results for the recirculation system piping using NUREG/CR-5999 interim

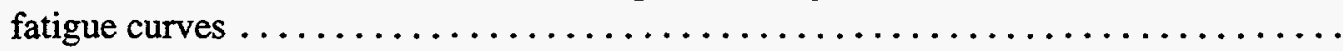

5-115. Potential for elimination of conservative assumptions to reduce CUF for recirculation system using NUREG/CR-5999 interim fatigue curve $\ldots \ldots \ldots \ldots \ldots \ldots \ldots \ldots \ldots \ldots \ldots \ldots \ldots \ldots$

5-116. CUF results for the recirculation system piping using revised interim fatigue curves $\ldots$

5-117. CUF results for core spray nozzle thermal sleeve using NUREG/CR-5999 interim

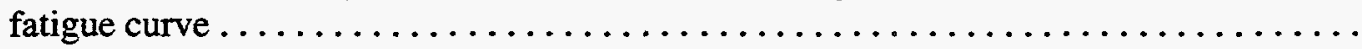

5-118. CUF results for core spray nozzle safe-end extension using NUREG/CR-5999 interim

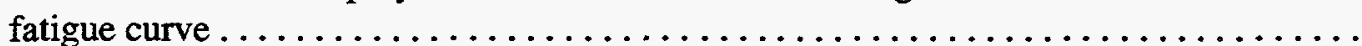


5-119. CUF results for core spray nozzle thermal sleeve using NUREG/CR-5999 interim fatigue

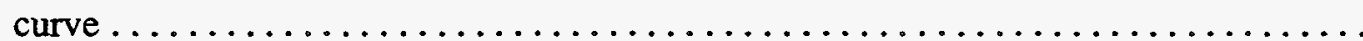

5-120. CUF results for core spray nozzle safe-end extension using NUREG/CR-5999 interim fatigue curve with conservative assumptions removed

5-121. CUF results for core spray nozzle thermal sleeve using revised interim fatigue curves

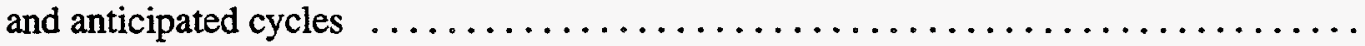

5-122. CUF results for feedwater line piping using NUREG/CR-5999 interim fatigue curve ...

5-123. CUF results for feedwater line piping using NUREG/CR-5999 interim fatigue curve and removing conservative assumptions

5-124. Potential for elimination of conservative assumptions to reduce CUF for feedwater line piping using NUREG/CR-5999 interim fatigue curve $\ldots \ldots \ldots \ldots \ldots \ldots \ldots$

5-125. CUF results for the residual heat removal suction line piping using NUREG/CR-5999 interim fatigue curve

5-126. Potential for elimination of conservative assumptions to reduce CUF for RHR piping using NUREG/CR-5999 interim fatigue curve

5-127. Summary of newer vintage GE plant CUFs

5-128. Number of selected design basis cycles compared to anticipated number of cycles

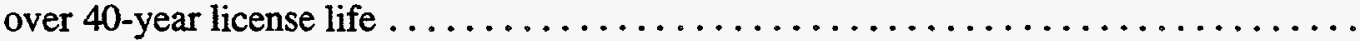

5-129. CUF results for reactor vessel shell and lower head using NUREG/CR-5999 interim fatigue curve.

5-130. CUF results for reactor vessel shell and lower head using NUREG/CR-5999 interim fatigue curve with conservative assumptions removed and based on anticipated cycles

5-131. CUF results for reactor vessel feedwater nozzle using NUREG/CR-5999 interim fatigue curves

5-132. CUF results for reactor vessel feedwater nozzle using NUREG/CR-5999 interim fatigue curves and anticipated cycles

5-133. Potential for elimination of conservative assumptions to reduce CUF for feedwater nozzle using.NUREG/CR-5999 interim fatigue curve $\ldots \ldots \ldots \ldots \ldots \ldots \ldots$

5-134. CUF results for recirculation piping system using NUREG/CR-5999 interim fatigue curve .

5-135. CUF results for recirculation piping system using NUREG/CR-5999 interim fatigue curve and anticipated cycles

5-136. Potential for elimination of conservative assumptions to reduce design CUF for recirculation piping system 
5-137. CUF results for recirculation piping system using revised interim fatigue curves $\ldots \ldots$

5-138. CUF results for core spray nozzle using NUREG/CR-5999 interim fatigue curve .....

5-139. CUF results for core spray nozzle safe end using NUREG/CR-5999 interim fatigue

5-140. CUF results for core spray nozzle safe end using NUREG/CR-5999 interim fatigue curve and anticipated cycles

5-141. Potential for elimination of conservative assumptions to reduce CUF for core spray nozzle safe end using NUREG/CR-5999 interim fatigue curve $\ldots \ldots \ldots \ldots \ldots \ldots$

5-142.. CUF results for core spray nozzle safe end using revised interim fatigue curve and anticipated cycles

5-143. CUF results for RHR piping system using NUREG/CR-5999 interim fatigue curve ... .

5-144. CUF results for RHR piping system using revised interim fatigue curves $\ldots \ldots \ldots \ldots$

5-145. CUF results for feedwater piping using NUREG/CR-5999 interim fatigue curves ....

5-146. CUF results for feedwater piping using NUREG/CR-5999 interim fatigue curves based on anticipated cycles

5-147. Potential for elimination of conservative assumptions to reduce design CUF for feedwater piping

5-148. Summary of older vintage General Electric plant CUFs

6-1. Summary of component CUFs for 40-year life using NUREG/CR-5999 interim fatigue curves 


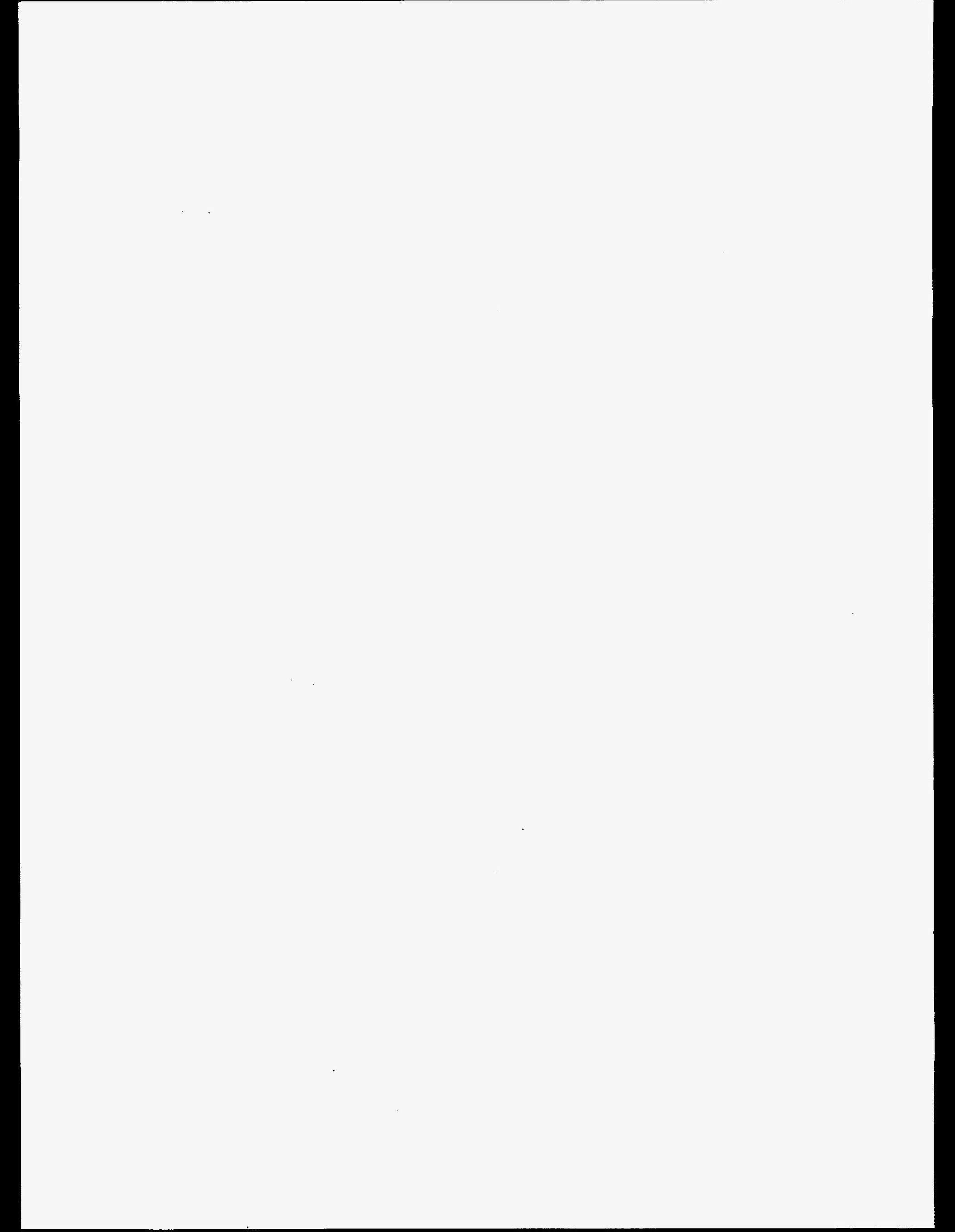




\section{EXECUTIVE SUMMARY}

\section{ES-1. Introduction}

Recent test data indicate that the effects of the light water reactor (LWR) environment could significantly reduce the fatigue resistance of materials used in the reactor coolant pressure boundary components of operating nuclear power plants. The American Society of Mechanical Engineers (ASME) Boiler \& Pressure Vessel Code fatigue curves used for the design of these components were based primarily on strain-controlled fatigue tests of small, polished specimens at room temperature in air. Although adjustment factors were applied to the best-fit curves to account for effects such as size, surface finish, environment, and data scatter, some of the recent test data indicate that these factors may not have been sufficiently conservative to account for environmental effects.

In a separate project funded by the United States Nuclear Regulatory Commission (USNRC), the Argonne National Laboratory (ANL) has developed interim fatigue curves based on test data of small, polished specimens cycled to failure in water simulating LWR conditions, and published them in NUREG/CR-5999. In order to assess the significance of the interim fatigue curves in NUREG/CR-5999, fatigue evaluations of a sample of the components in the reactor coolant pressure boundary were performed. The sample consists of components from facilities designed by each of the four U.S. nuclear steam supply system (NSSS) vendors. For each facility, six locations were studied, including two locations on the reactor pressure vessel.

In addition, there are older vintage plants where components of the reactor coolant pressure boundary were designed to codes, such as United States of America Standard (USAS) B31.1, that did not require an explicit fatigue analysis of the components. Since the Code of Federal Regulations currently references the ASME Boiler and Pressure Vessel Code which includes a fatigue evaluation of the components of the reactor coolant pressure boundary (unless certain exemption requirements are met), this has led to a concern regarding the adequacy of the fatigue resistance of these older vintage plants. In order to assess the fatigue resistance of the older vintage plants, an evaluation was also conducted on selected components of these plants. The components selected were the same as in the newer vintage plants. A comparison of the magnitudes of the cumulative usage factors (CUFs) between older and newer vintage plants, and the results of the application of the NUREG/CR-5999 interim fatigue curves to six components in each of the three older vintage plants are presented in this report.

\section{ES-2. ASME Code Section III Fatigue Methodology}

In the 1960s Codes and Standards specific to nuclear power plants were developed. Section III, Nuclear Vessels, was first issued in 1963 as a separate code. All of the vessel analyses reviewed in this NUREG/CR were performed using the 1965 or later editions of Section III. Prior to 1969, nuclear piping was designed using United States of America Standard (USAS) B31.1; from 1969 to 1971, plants were designed with USAS B31.7-1969 as the standard; and the ASME Code has been used thereafter. The rules of B31.7 were incorporated in NB-3600 of the 1971 edition of Section III.

The ASME Code, Section III, NB-3200 elastic fatigue analysis is applicable to any component, but is generally used exclusively for vessels, fairly frequently for nozzles, but rarely for piping. If neither the elastic or simplified elastic-plastic methods can demonstrate that the ASME Code limits are satisfied, NB-3200 allows a fully plastic analysis. (However, the time and expense needed to perform such an analysis makes this option a last resort.) For Class 1 piping, the ASME Code (Article NB-3600 of Section III) provides for protection against fatigue failures caused by elastic and plastic cycling similar to NB-3200; however, more detailed equations are given leading to a simpler, but generally more conservative, analysis approach. 


\section{ES-3. NUREG/CR-5999 Interim Fatigue Curves}

The NUREG/CR-5999 figures are very small, use a $\log$-log scale, and contain no background grid. This makes the values very difficult to read from the graphs. Dr. W. J. Shack of ANL supplied us with a spreadsheet with the data points used to construct the interim fatigue curves for use in this project. The spreadsheet values were used to perform the CUF calculations in Section 5 of this report.

In order to assess the increase in the CUF using the interim fatigue curves, values for the numbers of cycles on the ASME Code fatigue curve were divided by the numbers of cycles at corresponding stresses on the interim fatigue curves (using the ANL spreadsheet values). The ASME Code method of interpolating between values was used. The factor of increase depends on the alternating stress intensity. The factor of increase for stainless steel is as high as a factor of 17. For carbon and low-alloy steels in low-oxygen environments, the maximum factor of increase is only about 2.75 . For carbon and low-alloy steels in high-oxygen environments at saturated $(0.001 \% / \mathrm{s})$ strain rates, the maximum factors of increase are about 13,30, and 55 at temperatures of 200,250 , and $288^{\circ} \mathrm{C}$, respectively. The lowest maximum increase of about 3.5 occurs at high strain rates $(0.1 \% / \mathrm{s})$ at $200^{\circ} \mathrm{C}$.

In order to be able to accurately interpolate between the temperature and strain rate values on the interim fatigue curves, studies were carried out to determine appropriate interpolation formulas. The ratios of the numbers of cycles for the three strain rates at the three temperatures on the high-oxygen curves were plotted. In addition, the ratio of the values for the three temperatures at the three strain rates were plotted. From these curves we deduced that interpolation relations can be determined irrespective of alternating stress intensity.

Since the ratios were not dependent on the alternating stress intensity, a value of $55 \mathrm{ksi}$ was chosen to determine the relations between strain rate, temperature, and number of cycles. The logarithms of strain rate and numbers of cycles have a linear relationship, and the temperature and the logarithm of the numbers of cycles are linearly related.

Subsequent to the issue of NUREG/CR-5999, ANL transmitted revised best-estimate fatigue curves for stainless steel (in equation form) to the $\mathrm{NRC}$. The revised curves are strain rate-, temperature-, and material-dependent and differ for Type $316 \mathrm{NG}$ and other types of stainless steel. However, none of the stainless steel components investigated as part of this project are Type $316 \mathrm{NG}$ stainless steel.

The ANL best-estimate curves were converted to design curves comparable to ASME Code fatigue design curves by reductions of a factor of 1.5 on stress or 20 on cycles, whichever is less. The revised curves increase the CUF by a factor of about $5(1 \% / \mathrm{s}$ strain rate) to $11(0.001 \% / \mathrm{s}$ strain rate) over CUFs computed using the ASME Code fatigue design curves. The NUREG/ CR-5999 interim fatigue curves increase the CUF by as much as a factor of 17 over the ASME Code design fatigue curves. However, for low strain rates, the revised curves would result in a higher CUF for alternating stress intensities above $90 \mathrm{ksi}$. The $1 \% / \mathrm{s}$ strain rate was achieved during tests in which the specimens were loaded by mechanical cycling. It is highly unlikely that such a high strain rate could be achieved during thermal cycling. No strain rates approaching $1 \% / \mathrm{s}$ were calculated in this study. A $1 \% / \mathrm{s}$ strain rate corresponds to an equivalent elastic stress rate of $283,000 \mathrm{psi} / \mathrm{s}$.

\section{ES-4. Approach}

The components chosen for the evaluation of the five PWR plants [B\&W, Combustion Engineering (one older and one newer vintage), and Westinghouse (one older and one newer vintage)] are as follows:

1. Reactor vessel shell and lower head

2. Reactor vessel inlet and outlet nozzles 
3. Pressurizer surge line (including hot leg and pressurizer nozzles)

4. Reactor coolant piping charging system nozzle

5. Reactor coolant piping safety injection nozzle

6. Residual heat removal (RHR) system Class 1 piping.

The components chosen for the evaluation of the two BWR plants [General Electric (one older and one newer vintage)] are as follows:

1. Reactor vessel shell and lower head

2. Reactor vessel feedwater nozzle

3. Reactor recirculation piping (including inlet and outlet nozzles)

4. Core spray line reactor vessel nozzle and associated Class 1 piping

\section{RHR Class 1 piping}

\section{Feedwater line Class 1 piping.}

For both PWR and BWR plants, these components are not necessarily the locations with the highest design CUFs in the plant, but were chosen to give a representative overview of components that had higher CUFs and/or were important from a risk perspective. For example, the reactor vessel shell (and lower head) was chosen for its risk importance.

NUREG/CR-5999 includes one fatigue curve for stainless steel, but several curves for carbon/ low-alloy steels which are based on the sulfur content of the steel and the oxygen level in the coolant. For the five PWR plants, the curves for high-sulfur steel and a low-oxygen environment (typical for PWRs) were used. For the two BWR plants, the curves for high-sulfur steel and a highoxygen environment were used. The high-oxygen (greater than $100 \mathrm{ppm}$ ) environment considered in the selected curves is consistent with the water chemistry in BWRs without hydrogen water chemistry. Neither of the two BWR plants evaluated have used hydrogen water chemistry.

If the CUF for a component exceeded 1.0 using the NUREG/CR-5999 interim fatigue curves, potential changes that could be used to reduce the CUF were sought. In reviewing the licensees' calculations, we found 17 potential changes that could be used to reduce the CUF. Several changes were found from review of the licensees' calculations that might increase the CUF. These mainly consisted of changes to the ASME Code since the edition of record for the plants' licensing bases, and the anticipated numbers of cycles for some transients exceeding the number of design basis cycles.

\section{ES-5. Component Evaluations}

The stress results from existing analyses were used to determine revised CUFs based on the NUREG/CR-5999 curves. Since the licensees' design basis analyses were based on the ASME Code of record, it was uneconomical for the licensee to attempt to reduce the CUF to lower and lower values by removing conservative assumptions once the Code requirements were met. Given more funding and time, further calculations could have been performed to reduce the existing stress values by using more realistic loadings or more detailed analysis models. These reduced stresses would result in lower CUFs. Therefore, high CUF values obtained using the NUREG/CR-5999 interim fatigue curves do not reflect the lowest CUF, since in every case where the CUF was greater than 1.0, we have listed one, and in most cases several, steps that could be taken to reduce the CUF by additional analyses and monitoring.

The details of the evaluations for six components for each of the seven plants surveyed are described in Sections 5.1 through 5.7 in the body of the report. It appears that the two most difficult areas to reduce the CUF to lower values are PWR surge lines, which are subject to thermal stratification, and BWR tees joining RHR, recirculation, RCIC, RWCU, feedwater, etc. lines where hot and cold coolant mixing occurs. The results and 
conclusions of these evaluations are summarized in ES-6. below.

\section{ES-6. Conclusions}

The conclusions from applying the NUREG/ CR-5999 interim fatigue curves to the fatigue analyses of seven LWRs (five PWRs and two BWRs) are divided into five parts: applications to PWR and BWR plants, comparisons of the CUFs of plants designed to B31.1 versus plants designed to the ASME Code, the revised interim fatigue curves for stainless steel, and the overall conclusion.

\section{ES-6.1 Applications to PWR plants}

1. The anticipated number of cycles are less than the design basis number of cycles for all key transients, notably heatup and cooldown transients and power changes. (For example, the design analyses accounted for load following whereas the plants are being operated as base-loaded.)

2. After removing conservative assumptions and using anticipated numbers of cycles, the CUFs for all the reactor vessel components (shell and lower head, inlet and outlet nozzles) were less than 1.0 for a 40 -year life. In two cases, an Alloy 600 instrumentation nozzle and a lower head core support block, the CUFs (1.113 and 1.337, respectively) were slightly above 1.0 for 60 years.

3. The CUFs for the stainless steel surge lines of all five plants exceeded 1.0 for 40 years. The most significant transient for surge lines is thermal stratification which was not accounted for in the original design basis. The surge lines were reanalyzed for fatigue in response to NRC Bulletin 88-11. Fatigue monitoring was used to determine temperature differences and numbers of cycles during times of thermal stratification. More refined analyses to later (circa 1986) editions of the ASME Code, including removal of conservative assumptions, were used by the licensees to reduce the CUF below 1.0 using ASME Code fatigue curves. However, there remain conservative assumptions that could be used to further reduce the CUF. Four of the five analyses used NB-3600 piping methods. A detailed finite analysis of the regions with high CUFs, and, if needed, plastic analyses, could be used to reduce the CUF. The $B \& W$ plant's analysis already has incorporated an NB-3200 plastic analysis. Probably the best way to reduce the CUF is more precise monitoring of the individual surge lines. The stratification transients used in the analyses are mainly based on owners group submittals that conservatively define a set of enveloping stratification transients that will apply to several plants.

4. After removing conservative assumptions and using anticipated numbers of cycles, the 40-year CUFs for the stainless steel charging and safety injection nozzles were below 1.0 for 7 of the 10 cases. The other three (two charging and one safety injection nozzle) had CUFs ranging from 1.3 to 4.9 for a 40 year life. The numbers of key transients for these two components (for example, loss of letdown and loss of charging) are not counted on a regular basis as are transient cycles important to overall plant operation (for example, heatups and reactor trips); consequently, it was difficult to estimate anticipated numbers of cycles. It appears that the number and severity of these key cycles are conservative and further studies based on plant operation could be used to reduce the CUF. Based on our results of the CUFs for charging and safety injection nozzles of an older vintage plant using the 1992 ASME Code edition NB-3600 and NB-3200 methods, it appears that by using NB-3200 methods contained in the 1992 ASME Code, the CUFs for all nozzles could be reduced than 1.0 .

5. The 40-year CUFs for RHR lines were less than 1.0 for four of the five plants. The fifth plant included cycles for thermal stratification in the RHR line, which were not considered for the other four plants. 
Excluding thermal stratification, the CUF for the fifth plant would have been comparable to the other four plants. The analysis of the fifth plant used NB-3600 piping methods. A detailed finite analysis using NB-3200 methods, and, if needed, a plastic analysis, could be used to reduce the CUF. Probably the best way to reduce the CUF is fatigue monitoring of the RHR line. The stratification transients may conservatively define a set of enveloping stratification transients or valve leakage.

6. For carbon and low-alloy steel components, the NUREG/CR-5999 interim fatigue curves increased the CUF by an average factor of 2.2 times the design basis CUF. This was before any adjustments based on conservative assumptions removal and anticipated cycles were made. For stainless steel and Alloy 600, the average multiplication factor is 9.2 .

\section{ES-6.2 Applications to BWR plants}

1. The anticipated number of cycles exceed the design basis numbers of cycles for some transients, notably startup and shutdowns. However, the anticipated number of cycles is less than the design basis number of cycles for other transients such as power changes (the design analyses accounted for load following whereas the plants are being operated as base-loaded.)

2. After removing conservative assumptions and using anticipated numbers of cycles, the CUFs for the reactor vessel shell and lower head were less than 1.0 for 40 - and 60 -year lives. The core spray nozzle CUF was less than 1.0 for the 40 - and 60 -year lives of the newer vintage $B W R$ plant, but was greater than $1.0(2.305)$ for the safe end of the older vintage BWR plant for 40 years. Although CUFs for the recirculation nozzles were not calculated using NUREG/CR-5999, the design basis CUFs were 0.002 for the newer vintage plant and 0.300 for the older vintage plant (using very conservative lumped tran- sients). No problem would be expected in reducing the CUFs below 1.0 .

3. The 40-year CUF for the feedwater nozzle exceeded 1.0 for both plants. The CUF range was from about 1.9 to 3.2. (The CUF for the thermal sleeve on the BWR/6 plant was about 5). Although we incorporated transient definitions, anticipated cycles, strain rates, and temperatures according to the information available, there remains a great deal of uncertainty concerning these values. There also remain conservative assumptions that could be used to reduce the CUFs. Two studies based on fatigue monitoring of BWR feedwater nozzles in other plants showed that the monitored CUF was a factor of 30 to 50 less than the design basis CUF.

4. The 40-year CUF for the recirculation system is less than 1.0 for the newer vintage BWR, and slightly exceeds 1.0 for 60 years (1.245). The CUF for the older vintage BWR is 3.898. Both CUFs were calculated using NB-3600 methods, and were for tees. Based on our experience with comparing NB-3200 and NB-3600 methods for nozzles, we believe that an NB-3200 analysis and fatigue monitoring would reduce the CUF below 1.0.

5. The CUF for the feedwater lines are 3.688 and 6.980 (at tee locations). The CUF for the tee was calculated using NB-3600 methods. Based on our experience with comparing NB-3200 and NB-3600 methods for nozzles, we believe that an NB-3200 analysis and fatigue monitoring would reduce the CUFs below 1.0 .

6. The CUF for the BWR/6 RHR line is $\mathbf{1 1 . 2 6}$ in a straight run of piping. All transients that contributed to the CUF involved thermal stratification. The analysis used NB-3600 piping methods. A detailed finite analysis using NB-3200 methods, and, if needed, a plastic analysis, could be used to reduce the CUF. Probably the best way to reduce the CUF is more precise monitoring of the RHR 
line. The stratification transients may conservatively define a set of enveloping stratification transients.

\section{ES-6.3 CUF Evaluations for Piping Components Designed to the B31.1 Piping Code}

1. The design of PWR components and the transients to which they are subjected to are similar for older and newer vintage plants. An exception is the Westinghouse 3- and 4-loop plants that we studied, which had different safety injection piping configurations. Consequently, we reviewed transients from both the newer vintage Westinghouse and the Combustion Engineering plants to ensure that the transients we used were representative for the older vintage Westinghouse plant.

The design of some of the BWR systems were not similar for the older vintage (BWR/4) and newer vintage (BWR/6) plants that we reviewed. Several key locations of hot and cold coolant mixing, which on the $B W R / 4$ plant are on piping that would be considered Class 1 today, are included in the Class 2 portions of the BWR/6 piping. We reviewed transients from both a BWR/6 and another BWR $/ 4$ plant to ensure that the transients we used were representative for the older vintage $B W R$ plant.

2. While we did not perform additional fatigue evaluations of PWR surge lines because the licensees had already analyzed these lines for fatigue in response to NRC Bulletin $88-11$, the results of the fatigue evaluations and CUFs for older and newer vintage plants appear comparable.

3. The charging and safety injection nozzles for one older vintage PWR were analyzed using detailed finite element models (both contained thermal sleeves). The CUF using both the ASME Code and NUREG/ CR-5999 curves were less than 1.0 .
4. The design basis CUFs for two older vintage PWR RHR lines that we analyzed, including representative transients from other PWRs, were low and comparable to the other PWRs (not including thermal stratification effects).

5. The design basis CUFs for the older vintage BWR plant recirculation, RHR, and feedwater lines that we analyzed, including representative transients from other BWRs, were less than 1.0. The 40-year CUFs using the NUREG/CR-5999 curves were above 1.0 for the recirculation and feedwater lines. The comparable CUFs were above 1.0 for the newer vintage $B W R$, also, but only about half those computed for the older vintage BWR.

6. The older vintage plants' piping typically has thicker walls than do newer vintage plants. This causes higher thermal stresses in the older vintage plants' piping. Thermal stresses were found to be the major type of stress contributor to the CUF. Some stress indices are a function of the pipe diameter and thickness, but this is expected to have only a minor effect on the CUF.

\section{ES-6.4 Revised Interim Fatigue Curves for Stainless Steel}

Subsequent to the issue of NUREG/CR-5999, Argonne National Laboratory developed a bestestimate $\mathrm{S}-\mathrm{N}$ equation for stainless steel in air and water environments. The fatigue life is dependent on both the applied strain and the strain rate for stainless steels other than Type $316 \mathrm{NG}$ in a water environment. The equation was converted to ASME Code-type curves by applying factors of 1.5 on stress or 20 on cycles, whichever is less. The CUFs using the revised curves were reduced by an average of about $20 \%$ from the CUFs computed using the NUREG/CR-5999 curve. Application of the revised interim curves reduced the CUF for the newer vintage Combustion Engineering plant charging nozzle safe end to below 1.0 for 60 years; reduced the CUF for the older vintage Combustion Engineering plant surge line to below 1.0 for both 40 and 60 years; reduced the $\mathrm{B} \& W$ plant lower head penetration 
weld CUF to below 1.0 for 60 years; and reduced the $\mathrm{B} \& \mathrm{~W}$ plant makeup/high pressure injection nozzle CUF to slightly above 1.0 (1.051) for 40 years.

\section{ES-6.5 Overall Conclusion}

We were able to show that by removing conservative assumptions and using anticipated numbers of cycles, the CUF could be reduced to below 1.0 for most components using the NUREG/CR-5999 interim fatigue curves, both for older and newer vintage plants. Representative CUFs for components on older vintage plants designed to the B31.1 piping code, for which no fatigue analyses were required, were determined to be less than 1.0 using the current ASME Code.

For components which we were not able to reduce the CUF below 1.0 using the NUREG/ CR-5999 interim fatigue curves, several additional steps that could be taken to further reduce the CUF were listed. The two major remaining steps mentioned were (1) more detailed finite element analyses or (2) fatigue monitoring of the transients. Whereas using ASME Code NB-3200 versus NB-3600 analysis methods will assist with regions of axial thermal gradients, we did not find that the CUF could be reduced when the majority of the stress was caused by radial thermal gradients. A problem with NB-3200 analyses is that minimal guidance is provided by the ASME Code regarding fatigue strength reduction factors for welds. Analysts typically do not apply fatigue strength reduction factors for welds on nozzles made in the shop. For field welds, the NB-3600 stress indices can be used, but they may be too conservative. A plastic analysis in which the strains are computed, rather than using the $\mathrm{K}_{e}$ factor to adjust the elastic stresses, will lower the CUF.

The best method to lower the CUF for the few worst locations appears to be fatigue monitoring. For most of the cases where the CUF exceeded 1.0 , neither actual numbers of cycles that the plant is experiencing nor the magnitude of temperature differences or thermal shocks were known. Therefore, worst-case design assumptions were used. By using realistic numbers of cycles and severity of transients, we believe that the CUF could be reduced sufficiently without resorting to more detailed analysis methods. However, in some cases, for example where thermal stratification exists, a combination of fatigue monitoring and more refined analyses may be needed. 


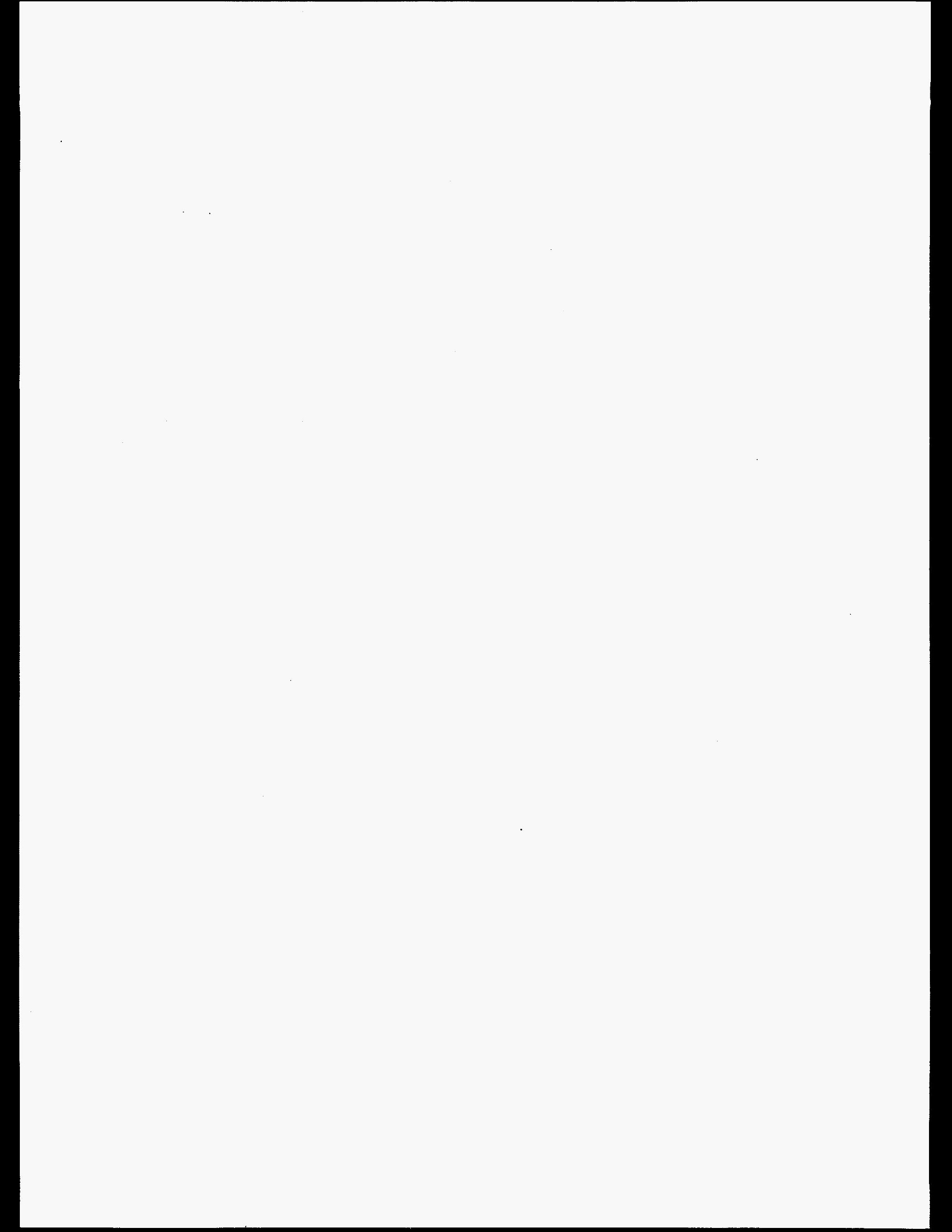




\section{ACKNOWLEDGEMENTS}

The authors acknowledge the significant role played by John R. Fair, the United States Nuclear Regulatory Commission (USNRC) project officer for FIN J2081, in providing programmatic and technical direction for this project. Ronald W. Parkhill of the USNRC was responsible for arranging visits to utility and NSSS vendor facilities and for obtaining the required information from the seven participating utilities. Numerous utility contacts from the staffs of the seven plants studied assisted us in obtaining the detailed information required to complete this project. The staffs of Westinghouse Electric Corporation, Babcock \& Wilcox Nuclear Services Company, Sargent \& Lundy, and the General Electric Company were helpful in providing information and answering questions on design and analyses of these plants. Norman E. Pace of the INEL staff performed the thermal analysis for the systems and components on the three older vintage plants that were analyzed. Rodrigo Ochoa of the California State University at Northridge assisted with graph preparation and performing the CUF calculations. 


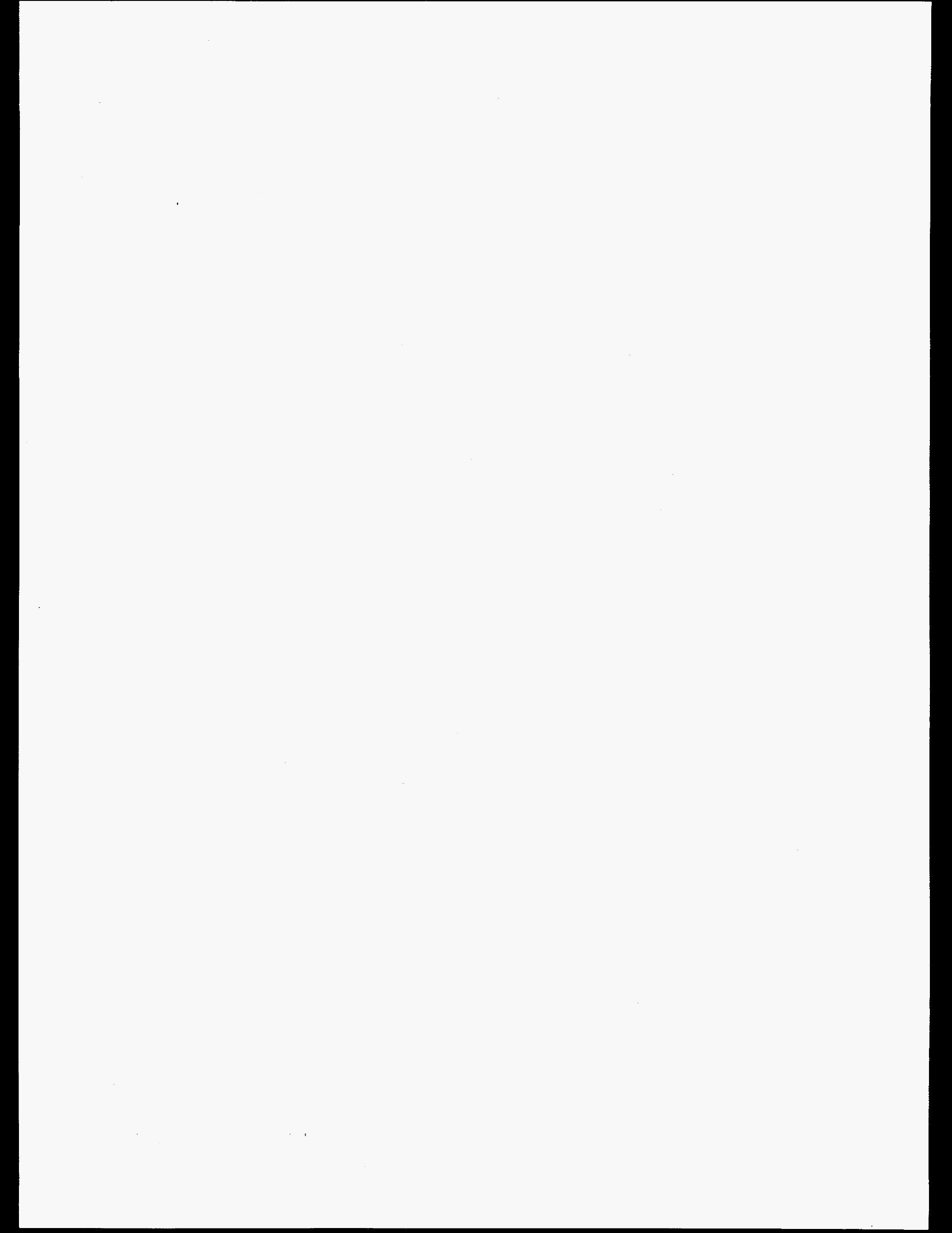




\section{ACRONYMS AND ABBREVIATIONS}

ANL Argonne National Laboratory

ANSI

American National Standards Institute

AOTC Allowable Operating Transient Cycles

ASA American Standards Association

ASME American Society of Mechanical Engineers

ASTM American Society for Testing and Materials

BIT boron injection tank

B\&W Babcock \& Wilcox

BWR boiling water reactor

CC Code case

CRDM control rod drive mechanism

CUF cumulative usage factor

EPRI Electric Power Research Institute

FSRF fatigue strength reduction factor

GE General Electric
HPI high pressure injection

INEL Idaho National Engineering Laboratory

LOCA loss-of-coolant accident

LOFP loss of feedwater pumps

LWR light water reactor

NSSS nuclear steam supply system

OBE operating basis earthquake

OD outside diameter

PWR pressurized water reactor

$\mathrm{RCIC}$ reactor core isolation cooling

RHR residual heat removal

RWCU reactor water cleanup

SCF stress concentration factor

TG turbine generator

USAS United States of America Standard

USNRC United States Nuclear Regulatory Commission

UTS ultimate tensile strength 


\section{Application of NUREG/CR-5999 Interim Fatigue Curves to Selected Nuclear Power Plant Components}

\section{INTRODUCTION}

Recent test data indicate that the effects of the light water reactor (LWR) environment could significantly reduce the fatigue resistance of materials used in the reactor coolant pressure boundary components of operating nuclear power plants. The American Society of Mechanical Engineers (ASME) Boiler \& Pressure Vessel Code fatigue curves used for the design of these components were based primarily on strain-controlled fatigue tests of small, polished specimens at room temperature in air. Although adjustment factors were applied to the best-fit curves to account for effects such as size, surface finish, environment, and data scatter, some of the recent test data indicate that these adjustment factors may not have been sufficiently conservative to account for environmental effects.

In a separate project funded by the United States Nuclear Regulatory Commission (USNRC), the Argonne National Laboratory (ANL) has developed interim fatigue curves based on test data of small, polished specimens cycled to failure in water simulating LWR conditions, and published them in NUREG/ CR-5999 (Majumdar, Chopra, and Shack, 1993). The data that the ANL considered in developing the interim curves consists of the results from tests reported in the open literature, and from tests conducted at ANL. The ANL staff determined that both temperature and oxygen affect fatigue life. For low-oxygen levels characteristic of pressurized water reactors (PWRs) and boiling water reactors (BWRs) with hydrogen water chemistry, environmental effects on fatigue life were reported to be "modest" at all temperatures and strain rates. For high-oxygen levels typical of BWRs without hydrogen water chemistry, NUREG/CR-5999 reports that fatigue life decreases significantly. In high-oxygen environments, fatigue life depends strongly on strain rate and temperature. In order to assess the signifi- cance of the interim fatigue curves in NUREG/ CR-5999, fatigue evaluations of a sample of the components in the reactor coolant pressure boundary were performed. The sample consists of components from facilities from each of the four U.S. nuclear steam supply system (NSSS) types: Babcock \& Wilcox (B\&W), Combustion Engineering, General Electric (GE), and Westinghouse Electric Corporation. For each facility, six locations were studied, including two locations on the reactor pressure vessel. This report discusses the insights gained from the application of the interim fatigue curves to these components.

In addition, there are older vintage plants where components of the reactor coolant pressure boundary were designed to codes, such as United States of America Standard (USAS) B31.1 (ASME, 1967), that did not require an explicit fatigue analysis of the components. Since the Code of Federal Regulations currently references the ASME Code which includes a fatigue evaluation of the components of the reactor coolant pressure boundary (unless certain exemption requirements are met), there is a concern regarding the adequacy of the fatigue resistance of these older vintage plants. In order to assess the fatigue resistance of the older vintage plants, an evaluation was also conducted on selected components from a sample of these plants. The components selected were the same as in the newer vintage plants. These older plants have fatigue analyses of the reactor pressure vessel and a few other components such as PWR surge lines. Therefore, the results of the reactor pressure vessel and available piping assessments were used to determine whether there is any significant difference in the impact of a change in the fatigue curves between the older and newer designs. Since some of the piping system components for these older vintage plants do not have existing fatigue analyses, 
representative fatigue analyses were conducted for the portions of these systems that would be classified as Class 1 systems by today's standards. The piping systems of $B \& W$ plants were considered to be very similar to each other (all are 177 fuel assembly designs), and designed to the ANSI B31.7 Code (ASME, 1969). Therefore, evaluations were performed on older vintage plants from each of the remaining three NSSS vendors. The results of the application of the NUREG/CR-5999 interim fatigue curves to com- ponents in each of the three older vintage plants are reported in this NUREG/CR.

Section 2 briefly describes the ASME Code Section III approach to fatigue analysis. Section 3 discusses the NUREG/CR-5999 interim fatigue curves, Section 4 describes the approach taken in selecting the components for study and in applying the interim fatigue curves, and Section 5 presents the results for the seven plants studied. The major conclusions from the study are listed in Section 6 , followed by a reference section. 


\section{ASME CODE SECTION III FATIGUE METHODOLOGY}

This section provides background information to assist the reader in understanding the methodology used to calculate cumulative usage factors (CUFs) for nuclear vessels and piping in the ASME Code, and the changes to Codes and Standards that have taken place over the years. Section 2.1 briefly describes the history and major changes to the applicable Codes and Standards between the period of time the analyses reviewed in this project were conducted, and the present ASME Code edition. Section 2.2 briefly describes the methods used to compute the CUF for vessels and piping.

\subsection{Background of ASME Code Fatigue Requirements}

In the 1960s Codes and Standards specific to nuclear power plants were developed. Section III, Nuclear Vessels (ASME, 1963), was first issued in 1963 as a separate code. All of the vessel analyses reviewed for this project were performed using the 1965 or later editions of Section III. Prior to 1969 , nuclear piping was designed using United States of America Standard (USAS) B31.1; from 1969 to 1971, plants were designed with USAS B31.7-1969 as the standard; and the ASME Code has been used thereafter. Piping systems purchased for nuclear power plants prior to July 1,1971 , generally meet the rules set forth in B31. Those purchased after July 1, 1971, generally meet the rules of ASME Code, Section III. The rules of B31.7 were incorporated in NB-3600 of the 1971 edition of Section III. A brief history of the development of the requirements related to fatigue follows.

2.1.1 USAS B31.1 and B31.7. The Piping Code of the United States of America National Standards Institute [formerly the American Standards Association (ASA)] was originally published in 1935 as the American Tentative Standard Code for Pressure Piping (ASA B31.1). It was focused on satisfying primary stress limits and did not specifically address fatigue, which was assumed to be covered by design safety factors on primary stresses.
The 1955 issue of ASA B31.1 introduced several new concepts into the piping code. Standard equations for piping design were included; fatigue failures caused by expansion stresses were considered; and the concepts of stress range and maximum shear stress, as pertinent to the fatigue of piping systems, were used. The quantitative evaluation of local expansion stresses was introduced through stress intensification factors. Fatigue usage was addressed by stating that the expansion stress $S_{E}$ could not exceed the allowable stress range $S_{A}$, which included a stress reduction factor $f$, as follows:

$S_{A}=f\left(1.25 S_{c}+0.25 S_{h}\right)$

where

$$
\begin{aligned}
& S_{\mathrm{c}}=\quad \begin{array}{l}
\text { the basic material allowable } \\
\text { stress at the minimum cold } \\
\text { temperature }
\end{array} \\
& S_{\mathrm{h}}=\quad \begin{array}{l}
\text { the basic material allowable } \\
\text { stress at the maximum hot } \\
\text { temperature }
\end{array} \\
& \mathrm{f}=\quad \begin{array}{l}
1.0 \text { for } \leq 7000 \text { cycles, gradually } \\
\text { reducing to } 0.5 \text { at } \leq 100,000 \\
\text { cycles. }
\end{array}
\end{aligned}
$$

This equation is still used by the chemical, petroleum, and power industries, with minor modifications.

When the first generation nuclear power plants were designed in the mid-1950s, the only basis for design and fabrication of piping was the ASA B31.1-1955 Code for Pressure Piping. The plant designers realized that because of the critical nature of nuclear power plant piping, a standard that went beyond the minimum requirements of ASA B31.1-1955 was needed. Designers specified many requirements themselves, such as ordering materials to existing American Society for Testing and Materials (ASTM) specifications. Starting in about 1962, many of these supplemental, but necessary, requirements were eventually incorporated into the Nuclear Code Cases. Much 
of this experience was later consolidated in the USAS B31.1-1967 Power Piping Code which was commonly referenced for early nuclear plants. In 1969 United States of America Standard (USAS) B31.7, Nuclear Power Piping, was issued specifically for nuclear piping. USAS B31.7-1969 provided design rules for three classes of piping. This included a set of rigorous design rules for Class 1 piping, while the designs of Classes 2 and 3 piping were performed in accordance with USAS B31.1, with slight modifications. USAS B31.7-1969 introduced three fatigue curves: curves for carbon and low-alloy steels with metal temperatures not exceeding $700^{\circ} \mathrm{F}$ [one for ultimate tensile strength (UTS) $\leq 80 \mathrm{ksi}$ and one for UTS 115 to $130 \mathrm{ksi}$; ; one for austenitic stainless steels, nickel-iron-chromium, nickel-chromium-iron, and nickel-copper alloys with metal temperatures not exceeding $800^{\circ} \mathrm{F}$; and curves for steel bolting. The USAS B31.7-1969 fatigue analysis methodology (that is, using the alternating stress intensity and the fatigue design curves along with Miner's rule to calculate a CUF) were similar to the existing ASME Section III requirements for nuclear vessels. (However, the methods for calculating the alternating stress intensity were substantially different for nuclear vessels and B31.7 piping). The piping systems for some nuclear plants were designed using USAS B31.7-1969, before piping rules were specifically incorporated into Section III of the ASME Code in 1971.

2.1.2 ASME Code. The ASME set up a committee in 1911 for the purpose of formulating standard rules for the construction of steam boilers and other pressure vessels. In the early $1960 \mathrm{~s}$ the rules and philosophy of ASME Code Section I, Power Boilers, closely paralleled that of the power piping sections of B31. Code Committee members realized that more rigorous requirements were needed for nuclear vessels; consequently, Section III, Nuclear Vessels, was issued in 1963 as a separate code. Guidelines for a formal fatigue analysis for nuclear components were provided in this edition,. Two fatigue curves were included in this version: one for carbon and low-alloy steels for metal temperatures not exceeding $700^{\circ} \mathrm{F}$, and one for $18-8$ stainless steels and nickel-chromium-iron ( $\mathrm{Ni}-\mathrm{Cr}-\mathrm{Fe})$ alloy for metal temperatures not exceeding $800^{\circ} \mathrm{F}$. The range was from 10 to $10^{6}$ cycles.

In the 1968 edition there were three sets of curves: one for carbon, low-alloy, and series $4 \mathrm{XX}$ alloy steel for metal temperatures not exceeding $700^{\circ} \mathrm{F}$ (a curve for UTS $\leq 80 \mathrm{ksi}$ and another for UTS 115 to $130 \mathrm{ksi}$ ); one for series $3 \mathrm{XX}$ high-alloy steels, nickel-chromium-iron alloy, nickel-ironchromium alloy, and nickel-copper alloy for metal temperatures not exceeding $800^{\circ} \mathrm{F}$; and a third graph with curves for high strength steel bolting. In early Code editions, there was no requirement to adjust the alternating stress intensity $\left(S_{\text {alt }}\right)$ values for the modulus of elasticity when performing NB-3200 analyses. With the Summer 1968 Addenda to the Code, the $S_{\text {alt }}$ values were required to be multiplied by the room temperature modulus of elasticity shown on the fatigue curves divided by the modulus of elasticity that was used in the analysis.

The scope was significantly altered in the 1971 Code to approximately its present form. The title was changed from Nuclear Vessels to Nuclear Power Plant Components. Class 1 piping rules were included in Paragraph NB-3600, taken from USAS B31.7-1969. The Class 1 fatigue curves were placed in Appendix I of Section III. The title for the ferritic steel curve (ASME Code Figure I-9.1) was changed to substitute "high tensile" for "series $4 \mathrm{XX}$ alloy", and the next curve (ASME Code Figure I-9.2.1) had "austenitic" substituted for "series $3 \mathrm{XX}$ high alloy." Both curves ranged from 10 to $10^{6}$ cycles (Figures 2-1 and 2-2).

A change was made in the Summer 1979 Addenda to remove the $\Delta T_{1}$ term (see Section 2.2.2) from the primary plus secondary stress intensity range calculation for piping, making it easier to meet the $3 \mathrm{~S}_{\mathrm{m}}$ limit. The Winter 1979 Addenda gave formulas to compute the allowable number of cycles $(\mathrm{N})$ for a given alternating stress (S). In earlier Code editions the allowable number of cycles was visually determined from the fatigue design (S-N) curves. The stainless steel/Alloy 600 curve was altered in the Winter 1982 edition to reflect a change in the modulus of elasticity shown on the curve from $26 \times 10^{6}$ to $28.3 \times 10^{6} \mathrm{psi}$. 


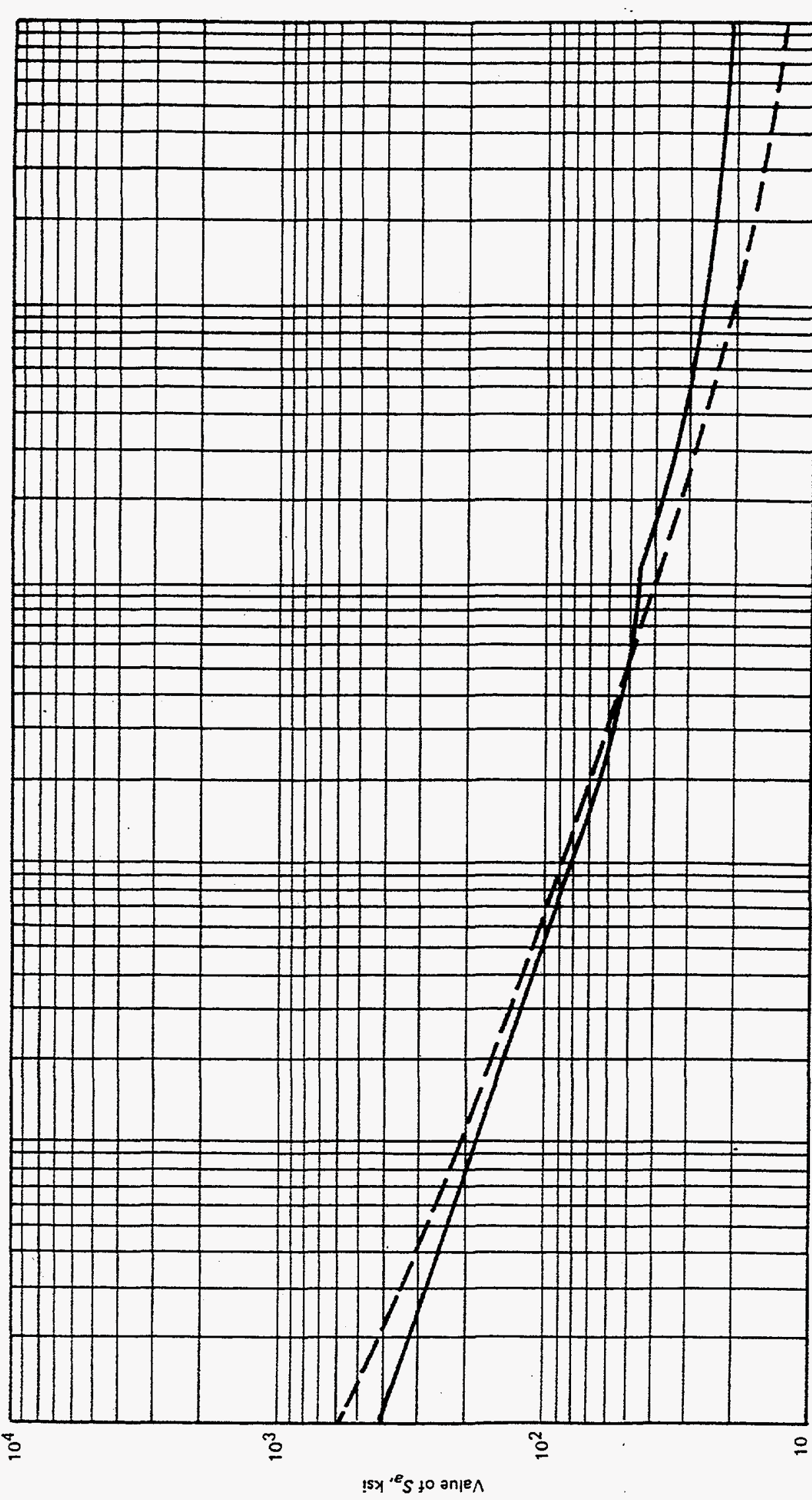

$\stackrel{\circ}{\circ}$

$\stackrel{8}{\circ}$

$\stackrel{+}{\circ}$

$\cong$

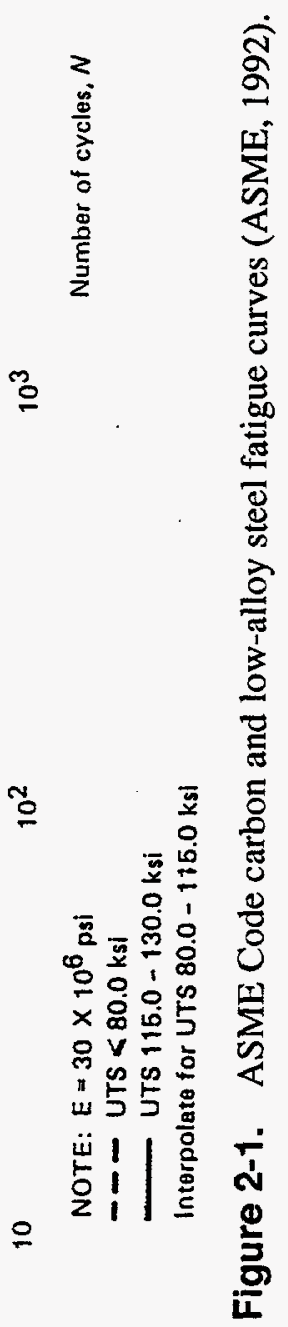


ASME Code Section III Fatigue Methodology

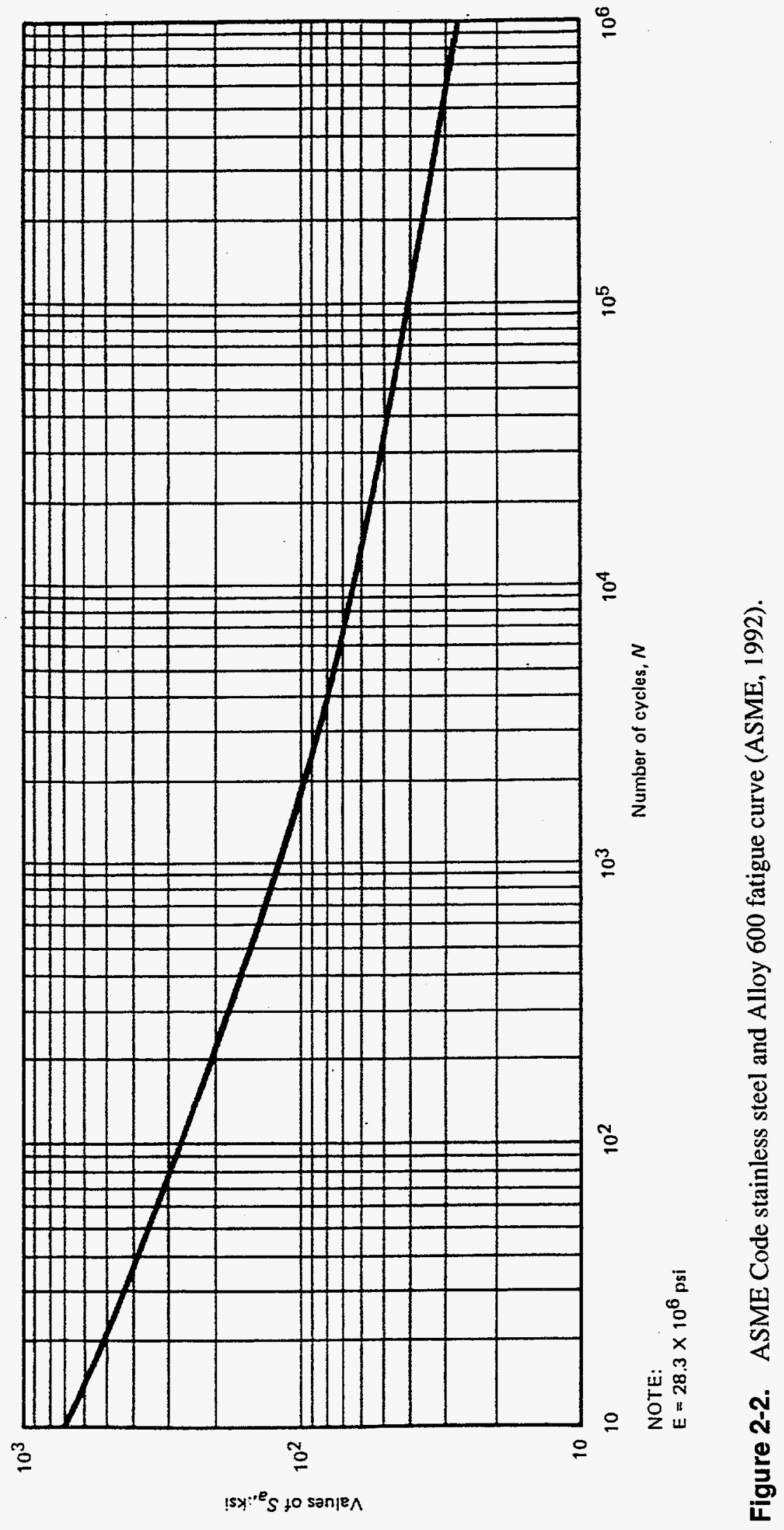


The 1983 revision to Section III extended the fatigue design curve for austenitic steels, nickelchromium-iron alloy, nickel-iron-chromium alloy, and nickel-copper alloy from $10^{6}$ to $10^{11}$ cycles (Figure 2-3). This extension was the first instance in the development of ASME Code fatigue curves to differentiate between base metal and weld zones. The weld zone is defined as the weld and adjacent base metal within three weld thicknesses from the weld center line. This version of the Code gives three design fatigue curves ( $A, B$, and $C$ ) for the base metal outside the weld zone, and two curves ( $B$ and $C$ ) for the weld zone, that account for the values of the primary plus secondary stress intensity range and the mean stress (ASME Code Figure I-9.2.2).

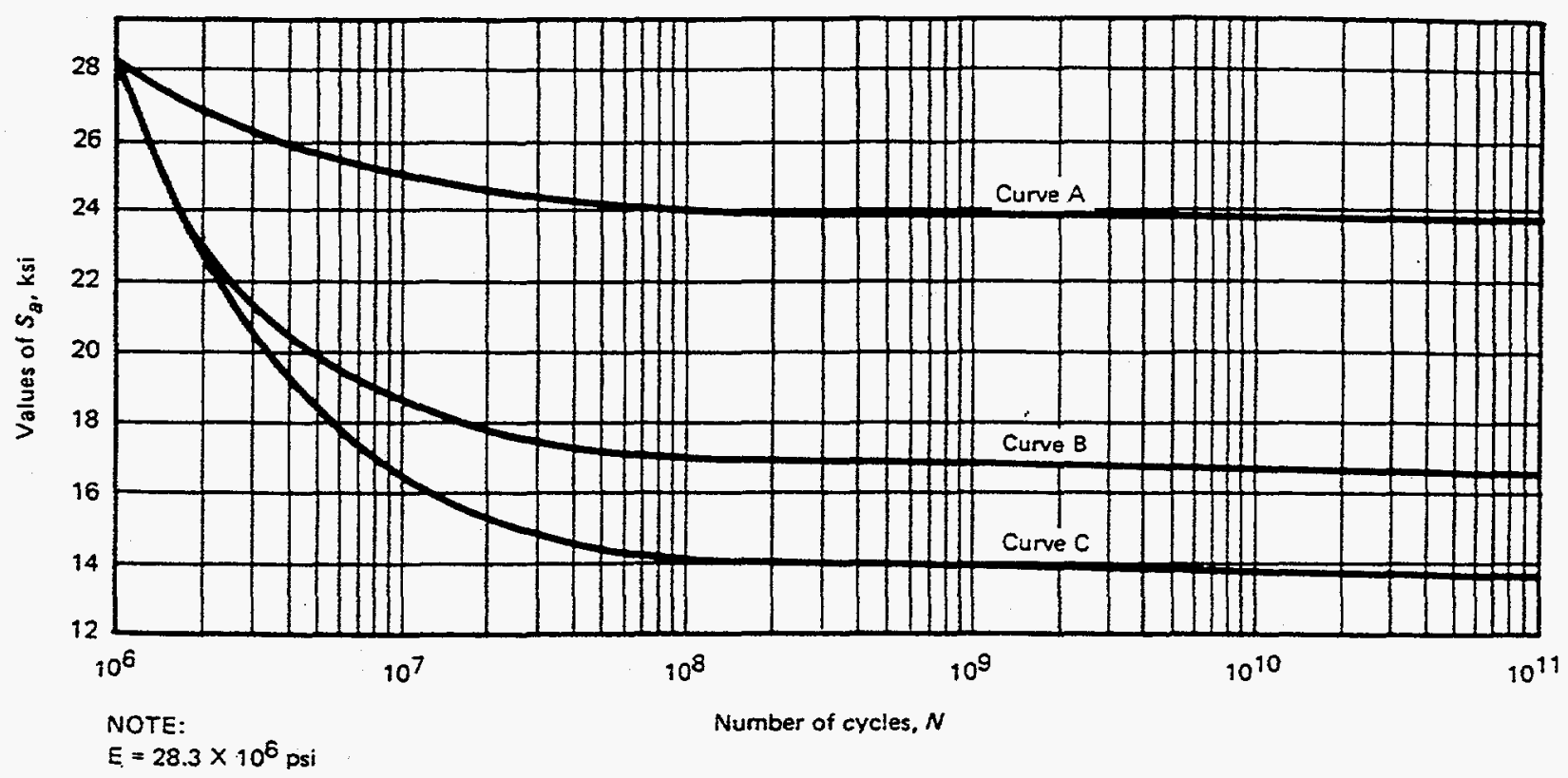

Criteria for the Use of the Curves in This Figure [Notes (1)-(5)]

\begin{tabular}{ccc}
\hline Curve & $\begin{array}{c}\text { Elastic Analysis of Material } \\
\text { Other Than Welds and } \\
\text { Adjacent Base Metal }\end{array}$ & $\begin{array}{c}\text { Elastic Analysis of } \\
\text { Weids and Adjacent } \\
\text { Base Metal }\end{array}$ \\
\hline A & $\left(P_{L}+P_{b}+Q\right)_{\text {Ranse }} \leq 27.2 \mathrm{ksi}$ & $\ldots$ \\
B & $\left(P_{L}+P_{b}+Q\right)_{\text {Range }}>27.2 \mathrm{ksi}$ and \\
$S_{z}$ is corrected for applied mean stress & $\left(P_{L}+P_{b}+Q\right)_{\text {Range }} \leq 27.2 \mathrm{ksi}$ \\
C & $\left(P_{L}+P_{b}+Q\right)_{\text {Range }}>27.2 \mathrm{ksi}$ & $\left(P_{L}+P_{b}+Q\right)_{\text {Range }}>27.2 \mathrm{ksi}$ \\
\hline
\end{tabular}

NOTES:

(1) Range applies to the individual quantities $P_{L}, P_{b}$ and $Q$ and applies to the set of cycies under consideration.

(2) Thermal bending stresses resulting from axial and radial gradients are excluded from $Q$.

(3) Curve $A$ is also to be used with inelastic analysis with $S_{z}=1 / 2 \Delta \epsilon_{t} E_{\text {, wher }} \Delta \epsilon_{t}$ is the total effective strain range.

(4) The maximum effect of retained mean stress is included in Curve $C$.

(5) The adjacent base metal is defined as three wall thicknesses from the center line of the weld.

Figure 2-3. ASME Code stainless steel and Alloy 600 high-cycle fatigue curves (ASME, 1992). 


\subsection{Present ASME Code Requirements}

For Class 1 vessels and piping, the ASME Code provides for protection against two types of fatigue failure, those caused by (1) elastic cycling and (2) plastic cycling. To determine if the material cycles elastically, the shakedown requirement states that the maximum primary plus secondary stress intensity range, which excludes local stress concentration effects, must be less than or equal to $3 \mathrm{~S}_{\mathrm{m}} \cdot\left(\mathrm{S}_{\mathrm{m}}\right.$ is the design stress intensity value given in ASME Code Section II, Part D, Subpart 1, Tables $2 \mathrm{~A}$ and $2 \mathrm{~B}$, and are material and temperature dependent.) The purpose of this criterion is to ensure that after a few stress cycles, the material will cycle within the range of the tensile yield strength and the compressive yield strength. The yield strength in the ASME Code is the minimum specified yield strength, which, with regard to the shakedown criterion, the Code assumes to represent the cyclic yield strength for the material. Using the $3 \mathrm{~S}_{\mathrm{m}}$ criterion, no incremental distortion, other plastic cycling, or ratcheting will occur. The peak stress intensity range $S_{p}$, which includes the effects of stress concentrations, is then calculated and the alternating stress intensity for each pair of load sets $\left(S_{a l t}=1 / 2 S_{p}\right)$ is computed. If the shakedown criterion cannot be met, the Code allows for a penalty factor $\left(\mathrm{K}_{\mathrm{e}}\right)$ to be applied to the stress for fatigue calculations. The alternating stress intensity for each pair of load sets is computed by $S_{\text {alt }}=1 / 2 \mathrm{~K}_{\mathrm{e}} \mathrm{S}_{\mathrm{p}}$. The procedure for calculating $\mathrm{K}_{\mathrm{e}}$ is briefly summarized in Section 2.2.3.

The basic stress $(\mathrm{S})$ versus cycles $(\mathrm{N})$ curves (sometimes referred to as $\mathrm{S}-\mathrm{N}$ curves) follow the relation proposed by Langer:

$$
S=B N^{-\frac{1}{2}}+S_{e}
$$

where $\mathrm{B}$ and $\mathrm{S}_{\mathrm{e}}$ are constants determined using linear, least-squares regression analyses to the data (Jaske and O'Donnell, 1977).

Reduction factors of 2 and 20 on stress and cycles, respectively, whichever is more conserva- tive at each point, were applied to the mean bestfit curve of the data to account for the differences in laboratory test specimens and conditions and actual nuclear components in service. According to Harvey (1980) the factor of 20 covered uncertainties as follows: $(2.0 \times 2.5 \times 4.0=20)$ :

Scatter of data (minimum to maximum)

Size effect

Surface finish, environment, etc.

Manjoine and Tome (1983) assign equal weighting (about $15 \%$ each) to the following:

Surface finish

Size

Material variability

Environment

Residual stress.

Porowski et al. (1988) credit the 2 and 20 factors equally to the following:

Scatter in data

Surface finish

Size effects

Environmental effects.

Large-scale vessel fatigue tests performed at room temperature for the express purpose of checking the ASME Code fatigue design curves (Kooistra et al., 1961) showed that fatigue cracks may initiate below the ASME Code design curves, but that wall penetration is not expected until the fatigue cycles exceed the ASME design curves by about a factor of 3 (Cooper, 1992). These tests did not include environmental effects.

A correction for the maximum effects of mean stress was made when the fatigue curve drops below the cyclic (assumed in the Code to be the minimum specified) yield stress as follows: 


$$
\begin{array}{ll}
S^{\prime}=\left(\frac{S_{u}-S_{m}}{S_{u}-S}\right) S & \text { for } S<S_{m} \\
S^{\prime}=\left(\frac{S_{u}-S_{y}}{S_{u}-S}\right) S & \text { for } S<S_{y} \\
S^{\prime}=S & \text { for } S \geq S_{y}
\end{array}
$$

where

$\mathrm{S}^{\prime}$ is the corrected alternating stress

$S$ is the completely reversed amplitude at the same fatigue life as $S^{\prime}$

$\mathrm{S}_{\mathrm{u}}$ is the ultimate tensile strength.

$S_{\mathrm{y}}$ is the stress amplitude under plastic cyclic conditions (usually approximated by the cyclic yield strength).

The mean stress corrections were used to modify the best-fit curves before the 2 and 20 reduction factors were applied. The mean stress correction occurs at about $10^{4}$ cycles for ferritic steels and about $10^{6}$ cycles for austenitic steels. No correction is necessary if the fatigue curve is above the yield stress, because the component is undergoing plastic cycling, has shaken down to elastic action, and thus the mean stress is zero.

\subsubsection{ASME Code NB-3200 Fatigue Analy-} sis Method. The ASME Code, Section III, NB-3200 (design by analysis) elastically computed fatigue analysis methodology is applicable to any component, but is generally used exclusively for vessels (sometimes augmented by NB-3300), fairly frequently for nozzles, but rarely for piping. The ASME Code NB-3600 methodology used almost exclusively for piping and sometimes for branch nozzles is described in Section 2.2.2. The NB-3200 simplified elasticplastic analysis method is discussed in Section 2.2.3, and the thermal stress ratchet check is summarized in Section 2.2.4. If neither the elastic nor the simplified elastic-plastic methods can demonstrate that the ASME Code limits are satisfied, NB-3200 allows a fully plastic analysis. However, the time and expense needed to perform such an analysis makes this option a last resort. The format presented below to describe the methodology is that of the series of steps that an analyst would go through to determine the CUF.

Step 1. The analyst must obtain a set of loadings for the component. This is generally in the form of a set of design and service level transients in the design specification. These loadings define the temperature and pressure changes that the component is expected to undergo during its lifetime, and the number of cycles $n_{i}$ for each of the i loadings.

Step 2. The analyst needs to determine the stress distribution at the most highly stressed locations in the component. This includes the thermal and pressure stresses, and sometimes the preload stresses and thermal expansion stresses imposed on the component by the connecting piping. Closed form solutions are available for some geometries, but often interaction or finite element models are used. The interaction method was commonly used 25 years ago before modern finite element programs became widely available. Vessels and nozzles were modeled by a series of ring elements, connected at the junctures between the elements, so that the forces, moments, displacements, and rotations of the connecting rings matched at the junctures. The most widely used program was SAVE (stress analysis by virtual energy) SEAL SHELL-2, developed for the U.S. Naval Nuclear Program.

Temperature distributions are necessary to determine stress distributions. Two sources of difficulty in determining the highest stresses are (1) during a heatup or cooldown, the temperatures and therefore the thermal stresses are changing with time, and (2) the analyst must use judgment to determine the locations of maximum stress. Both of these difficulties have one thing in common: it is impractical to investigate each point in time and each location of the component. While the thermal analysis can generate a time-temperature relationship for selected points, no comparable method is available to generate stress-history plots without considerable effort. The process generally involves selecting representative points in time during the heatup and cooldown to 
compute the stresses, and using the analyst's judgment, estimating the time of maximum stress. Similarly, it is unreasonable in many calculations to determine the stresses at each unique point, and again the analyst's judgment is used to determine the locations of highest stress. Color plots are available on modern finite element thermal and stress programs to assist the analyst in determining the maximum stress locations. A stress determination is required for each load set.

Step 3. The three principal primary plus secondary stresses $\left(S_{1}, S_{2}\right.$, and $\left.S_{3}\right)$ for each load set are determined. This sometimes involves separating the peak stress from the total stress, such as by linearizing the thermal stress distribution.

Step 4. From the results of step 3, three stress intensities are calculated by subtracting the principal stresses.

$$
\begin{aligned}
& S_{12}=S_{1}-S_{2} \\
& S_{23}=S_{2}-S_{3} \\
& S_{13}=S_{1}-S_{3}
\end{aligned}
$$

The maximum primary plus secondary stress intensity range is the largest difference between the $S_{12}, S_{23}$, or $S_{13}$ values, determined by comparing the stress intensities of all the load sets. Two values (one with the highest tensile stress intensity and the other with the highest compressive stress intensity of all the load sets) are used to form a load pair that determines the maximum stress intensity range. The maximum stress intensity range must meet the $3 S_{m}$ limit; otherwise, the simplified elastic-plastic method (Section 2.2.3) or a plastic analysis may be used.

Step 5. Using the stress values determined in step 2, the peak stresses are calculated. This may involve the use of stress indices, stress concentration factors, experimental stress analysis, etc. The six components of stress for each time and location of interest are determined for each load set.

Step 6. For each pair of load sets, the six components of stress are subtracted and the three principal stress ranges are computed. The peak stress intensity range for each pair is computed by subtracting the principal stresses as described in step 4 , and choosing the largest.

Step 7. The $S_{\text {alt }}$ for each load set pair is one-half the peak stress intensity range. To adjust for temperature and material, $S_{\text {alt }}$ is multiplied by the ratio of the modulus of elasticity on the appropriate fatigue curve to the modulus of elasticity used in the analysis. The allowable number of cycles $\mathrm{N}_{\mathrm{i}}$ for each load set pair is read from the appropriate design fatigue curve [the ASME Code S-N equation/tables are now normally used (Table 2-1)].

Step 8. The individual fatigue usage factor $u_{i}$ at each location is determined by the ratio of the number of design cycles $\left(\mathrm{n}_{\mathbf{i}}\right)$ to the allowable cycles $\left(\mathrm{N}_{\mathrm{i}}\right)$ for each pair of load sets. Once the individual usage factor for the load set pair with the largest $S_{\text {alt }}$ is computed, the cycles associated with that load set pair are eliminated, and the process is repeated until the cycles associated with all the load sets have been exhausted.

Table 2-1. Values for S (ksi) and N (cycles) [ASME, 1992, Table I-9.0].

\begin{tabular}{lcccccccccccccc}
\hline \multicolumn{1}{c}{ Material } & $1 \mathrm{E} 1$ & $2 \mathrm{E} 1$ & $5 \mathrm{E} 1$ & $1 \mathrm{E} 2$ & $2 \mathrm{E} 2$ & $5 \mathrm{E} 2$ & $1 \mathrm{E} 3$ & $2 \mathrm{E} 3$ & $5 \mathrm{E} 3$ & 1E4 & 2E4 & $5 \mathrm{E} 4$ & 1E5 & 2E5 \\
\hline $\begin{array}{l}\text { Carbon and } \\
\text { low-alloy steel } \\
\text { (UTS < 115 to 130 }\end{array}$ & 420 & 320 & 230 & 175 & 135 & 100 & 78 & 62 & 49 & 44 & 36 & 29 & 26 & 24 \\
ksi) & & & & & & & & & & & & & & \\
$\begin{array}{l}\text { Carbon and } \\
\text { low-alloy steel } \\
\text { (UTS } \leq 80 \mathrm{ksi} \text { ) }\end{array}$ & 580 & 410 & 275 & 205 & 155 & 105 & 83 & 64 & 48 & 38 & 31 & 23 & 20 & 16.5 \\
$\begin{array}{l}\text { Austenitic stainless } \\
\text { steel and Alloy 600 }\end{array}$ & 708 & 512 & 345 & 261 & 201 & 148 & 119 & 97 & 76 & 64 & 55.5 & 46.3 & 40.8 & 35.9 \\
\hline
\end{tabular}


Step 9. The cumulative usage factor (CUF) is the sum of the individual usage factors. Tables in Section 5 of this report show how the individual usage factors and CUFs are calculated from $S_{\text {alt }}$, $\mathrm{n}_{\mathbf{i}}$, and $\mathrm{N}_{\mathbf{i}}$. The ASME Code Section III limit is that the CUF at each location must not exceed 1.0. This assumes a linear damage relationship known as Miner's rule.

\subsubsection{ASME Code NB-3600 Fatigue Analy-} sis Method. For Class 1 piping, the ASME Code (Article NB-3600 of Section III) provides for protection against fatigue failures caused by elastic and plastic cycling similar to NB-3200; however, more detailed equations are given leading to a simpler, but more conservative, analysis approach. Another difference is that NB-3600 does not require an adjustment for the modulus of elasticity before entering the fatigue curves.

The shakedown-to-elastic-action criterion is determined by Equation 10 of NB-3600. If the Equation 10 stress is less than or equal to $3 S_{m}$, then NB-3600 Equation 11 is used to calculate the peak stress, and the CUF is calculated using steps 7, 8, and 9 described in Section 2.2.1.

If the shakedown criterion is not met, the Code allows a penalty factor to be applied to the stress for fatigue calculations. The procedure is briefly summarized as follows:

1. Ensure the stress intensity range caused by moments induced from thermal expansion and thermal anchor movements is $\leq 3 \mathrm{~S}_{\mathrm{m}}$ (Equation 12 of NB-3653.6)

2. Ensure the thermal stress ratchet criterion is met (see Section 2.2.4)

3. Ensure the primary plus secondary membrane plus bending stress intensity, excluding thermal bending and thermal expansion stress, is less than or equal to $3 \mathrm{~S}_{\mathrm{m}}$ (Equation 13 of NB-3653.6)

4. Increase the peak stress intensity value (Equation 11 of NB-3653.2) by a factor $\mathrm{K}_{e}$, based on material parameters $m$ and $n$ (see Section 2.2.3), and calculate the allowable cycles based on the appropriate fatigue curve.

NB-3600 Equations 10 through 13 are repeated in order below, since they are referred to in later discussions in this report.

$$
\begin{aligned}
& S_{n}= \frac{P_{o} D_{o}}{2 t}+C_{2} \frac{D_{o}}{2 I} M_{i}+C_{3} E_{a b} \\
& \times\left|a_{a} T_{a}-a_{b} T_{b}\right| \leq 3 S_{m} \\
& S_{p}= K_{1} C_{1} \frac{P_{o} D_{o}}{2 t}+K_{2} C_{2} \frac{D_{o}}{2 I} M_{i} \\
&+\frac{1}{2(1-v)} K_{3} E a \bigsqcup \Delta T_{1} \mid+K_{3} C_{3} E_{a b} \\
& \times\left|a_{a} T_{a}-a_{b} T_{b}\right|+\frac{1}{1-v} E a\left|\Delta T_{2}\right| \\
& S_{e}= \frac{C_{2} D_{o}}{2 I} M_{i}^{*} \leq 3 S_{m} \\
& C_{1} \frac{P_{o} D_{o}}{2 t}+C_{2} \frac{D_{o} M_{i}}{2 I}+C_{3}^{\prime} E_{a b} \\
& \quad \times\left|a_{a} T_{a}-a_{b} T_{b}\right| \leq 3 S_{m}
\end{aligned}
$$
$\mathrm{D}_{\mathrm{O}} \quad=\quad$ outside diameter of pipe.
$\mathrm{t}=$ nominal wall thick- ness of product.
I = moment of inertia.
$C_{1}, C_{2}, C_{3}, C^{\prime}=$ secondary stress indices.

$\mathrm{M}_{\mathrm{i}} \quad$ = resultant range of moment which occurs when the system goes from one service load set to another.

$\mathrm{S}_{\mathrm{m}} \quad=\quad \begin{aligned} & \text { allowable design } \\ & \text { stress intensity. }\end{aligned}$

$\mathrm{T}_{\mathrm{a}}\left(\mathrm{T}_{\mathrm{b}}\right) \quad=\quad$ range of average temperature on side $a(b)$ of gross structural discontinuity or material discontinuity. 


\begin{tabular}{c|l}
$a_{a}\left(a_{b}\right) \quad \begin{array}{l}\text { coefficient of thermal } \\
\text { expansion on side a(b) } \\
\text { of a gross structural } \\
\text { discontinuity or mate- } \\
\text { rial discontinuity, at } \\
\text { room temperature. }\end{array} \quad S_{e}$ \\
$=\quad \begin{array}{l}\text { average modulus of } \\
\text { elasticity of the two } \\
\text { sides of a gross struc- } \\
\text { tural discontinuity or } \\
\text { material discontinuity } \\
\text { at room temperature. }\end{array} \quad M_{i}^{*} \quad=\begin{array}{l}\text { mal gradient through } \\
\text { the wall thickness not } \\
\text { included in } \Delta T_{1}\end{array}$ \\
nominal value of \\
expansion stress.
\end{tabular}

$P_{0} \quad=$ range of service pressure.
$K_{1}, K_{2}, K_{3}=$ local stress indices for the specific component under investigation.

Ea $=$ modulus of elasticity (E) times the mean coefficient of thermal expansion $(\alpha)$ both at room temperature.

$\Delta T_{1} 1 \quad=\quad$ absolute value of the range of the temperature difference between the temperature of the outside surface $T_{0}$ and the temperature of the inside surface $T_{i}$ of the piping product assuming moment generating equivalent linear temperature distribution.

$\checkmark T_{2} \mathrm{I}=$ absolute value of the range for that portion of the nonlinear ther-

\subsubsection{Simplified Elastic-Plastic Multiplier}

$\left(K_{e}\right)$. The $K_{e}$ factor is a multiplier to the peak stress to adjust for the effects of plasticity in calculating $S_{\text {alt }}$. The alternating stress intensity is calculated using Equation (2-10) (ASME, 1992, NB- 3228.5; Equation 14 of NB-3653.6).

$S_{a l t}=\frac{1}{2} K_{e} S_{p}$

where

$S_{p}=$ peak stress intensity range.

The adjustment is made when the primary plus secondary stress intensity range exceeds $3 S_{m}$. This will occur in instances when the primary plus secondary stress intensity range excluding thermal bending meets the $3 \mathrm{~S}_{\mathrm{m}}$ limit, but the range including thermal bending does not meet the $3 \mathrm{~S}_{\mathrm{m}}$ limit. $\mathrm{K}_{\mathrm{e}}$ is computed as follows:

$$
\begin{aligned}
K_{e}= & 1.0 \text { for } S_{n} \leq 3 S_{m} \\
K_{e}= & 1.0+\frac{(1-n)}{n(m-1)}\left(\frac{S_{n}}{3 S_{m}}-1\right) \\
& \text { for } 3 S_{m}<S_{n}<3 m S_{m} \\
K_{e}= & \frac{1}{n} \text { for } S_{n} \geq 3 m S_{m}
\end{aligned}
$$


where

$\mathrm{S}_{\mathrm{n}}=$ primary plus secondary stress intensity range

$\mathrm{S}_{\mathrm{m}}=$ design stress intensity

and $\mathrm{m}$ and $\mathrm{n}$ are defined in Table 2-2.

2.2.4 Thermal Stress Ratchet Check. Both ASME Code NB-3200 and NB-3600 have thermal stress ratchet checks to prevent progressive distortion for vessels, nozzles, and pipes under internal pressure that are subjected to cyclic thermal loads.

NB-3222.5 states that for an axisymmetric shell loaded by a steady-state internal pressure, the following criteria must be met:

Case 1: For a linear through-wall temperature variation

$$
\begin{array}{ll}
\mathrm{y}^{\prime}=1 / \mathrm{x} & 0<\mathrm{x}<0.5 \\
\mathrm{y}^{\prime}=4(1-\mathrm{x}) & 0.5<\mathrm{x}<1.0
\end{array}
$$

Case 2: For a parabolic through-wall temperature variation

$$
\begin{aligned}
& y^{\prime}=4.65,3.55 .2 .70 \text { for } x=0.3,0.4,0.5 \\
& y^{\prime}=5.2(1-x) \quad 0.615<x<1.0
\end{aligned}
$$

where:

$\mathrm{y}^{\prime}=$ The maximum allowable range of thermal stress computed on an elastic basis divided by the yield stress $\mathrm{x}=$ The maximum general membrane stress due to pressure divided by the yield stress

NB-3653.7 requires a stress ratchet check for piping only if ASME Equation 10 is exceeded. The criterion (which is based on the maximum pressure for the set of conditions under consideration) is:

$$
\Delta T_{1} \text { range } \leq \frac{y^{\prime} S_{y}}{0.7 E \alpha} C_{4}
$$

where

$$
\begin{aligned}
& \mathrm{y}^{\prime}=3.33,2.0,1.2,0.8 \text { for } \mathrm{x}=0.3 \text {, } \\
& 0.5,0.7,0.8 \\
& \mathrm{x}=\left(\mathrm{PD}_{\mathrm{o}} / 2 \mathrm{t}\right)\left(1 / \mathrm{S}_{\mathrm{y}}\right) \\
& \mathrm{P} \quad=\quad \text { the maximum pressure } \\
& \mathrm{C}_{4}=1.1 \text { for ferritic material }
\end{aligned}
$$

\section{3 for austenitic material}

$S_{\mathrm{y}}=$ yield stress at the average fluid temperature

$E a=$ the modulus of elasticity multiplied by the coefficient of thermal expansion at room temperature

$\mathrm{D}_{\mathrm{o}}=$ the pipe outside diameter

$\mathrm{t}=$ the nominal pipe wall thickness.

Table 2-2. Values for $m$ and $n$ [ASME, 1992, Table NB-3228.5(b)-1].

\begin{tabular}{lll}
\hline \multicolumn{1}{c}{ Material } & $\mathrm{m}$ & $\mathrm{n}$ \\
\hline Low-alloy steel & 2.0 & 0.2 \\
Carbon steel & 3.0 & 0.2 \\
Austenitic stainless steel & 1.7 & 0.3 \\
Alloy 600 & 1.7 & 0.3 \\
\hline
\end{tabular}




\section{NUREG/CR-5999 INTERIM FATIGUE CURVES}

A summary of the figures for design in the NUREG/CR-5999 interim fatigue curves is presented in Table 3-1.

Although the caption in Figure 8 of NUREG/ CR-5999 does not state that the curves are also for low-alloy steels, it was assumed that these curves were applicable for low-alloy steels. There are no curves for Alloy 600 in NUREG/CR-5999; therefore, Figure 13 was assumed to be applicable for Alloy 600 since the ASME Code uses the same design fatigue curves for austenitic stainless and Alloy 600 steels.

We did not know the exact sulfur contents of the steels used in the components studied in this project. However, the maximum sulfur contents (wt\%) for some typical carbon and low-alloy steels are:

$\begin{array}{ll}\text { SA-302 Grades A through D } & 0.040 \\ \text { SA-533 Types A through D } & 0.040 \\ \text { SA-106 Grades A through C } & 0.058 \\ \text { SA-508 Classes 1 through 3 } & 0.025 \\ \text { SA-333 Grade 6 } & 0.058 .\end{array}$

Since the NUREG/CR-5999 definition of low sulfur is below $0.008 \mathrm{wt} \%$, it is doubtful that current LWR components were made from lowsulfur carbon or low-alloy steels; therefore,
NUREG/CR-5999 Figure 11 was not used in this study.

NUREG/CR-5999 also gives design fatigue values for the high-cycle, low-stress region $\left(>10^{6}\right.$ cycles). High-cycle fatigue resulted in only miniscule contributions to CUFs for the transients we studied in the design fatigue calculations, so we generally used $10^{6}$ allowable cycles as the endurance limit.

\subsection{Curve Descriptions}

The NUREG/CR-5999 figures are very small, use a log-log scale, and contain no background grid. This makes it very difficult to read the values on the graphs accurately. Dr. W. J. Shack of ANL supplied a spreadsheet with the data points used to construct the interim fatigue curves for use in this project. Using these data, the figures for the five material/oxygen/temperature cases that were used in this project are shown in Figures 3-1 through 3-5. The spreadsheet values also were used to perform the CUF calculations in Section 5 of this report. Figures 3-3 through 3-5 each contain three curves for strain rates of 0.1 , 0.01 and 0.001 (saturated) \%/s (percent per second). Dr. Shack stated that the values of the moduli of elasticity used to convert strain to stress in developing these curves was the same as in the current version of the ASME Code; that is, $30 \times 10^{6}$ psi for carbon and low-alloy steels, and $28.3 \times 10^{6}$ psi for austenitic stainless steel.

Table 3-1. Applicable figures from NUREG/CR-5999.

\begin{tabular}{clcccc}
\hline $\begin{array}{c}\text { NUREG/CR-5999 } \\
\text { Figure number }\end{array}$ & Type of steel & $\begin{array}{c}\text { Oxygen content } \\
(\mathrm{ppb})\end{array}$ & $\begin{array}{c}\text { Temperature } \\
\left({ }^{\circ} \mathrm{C}\right)\end{array}$ & $\begin{array}{c}\text { Strain rate } \\
(\% / \mathrm{s})\end{array}$ & $\begin{array}{c}\text { Sulfur } \\
\text { content }\end{array}$ \\
\hline 8 & Carbon & $>100$ & $200,250,288$ & $0.1,0.01,0.001$ & high \\
10 & $\begin{array}{l}\text { Carbon and } \\
\text { low-alloy }\end{array}$ & $<100$ & all & all & all \\
11 & $\begin{array}{l}\text { Carbon and } \\
\text { low-alloy } \\
\text { Austenitic } \\
\text { stainless }\end{array}$ & $>100$ & all & all & low \\
13 & all & all & all & all \\
\hline
\end{tabular}


NUREG/CR-5999 Interim Fatigue Curves

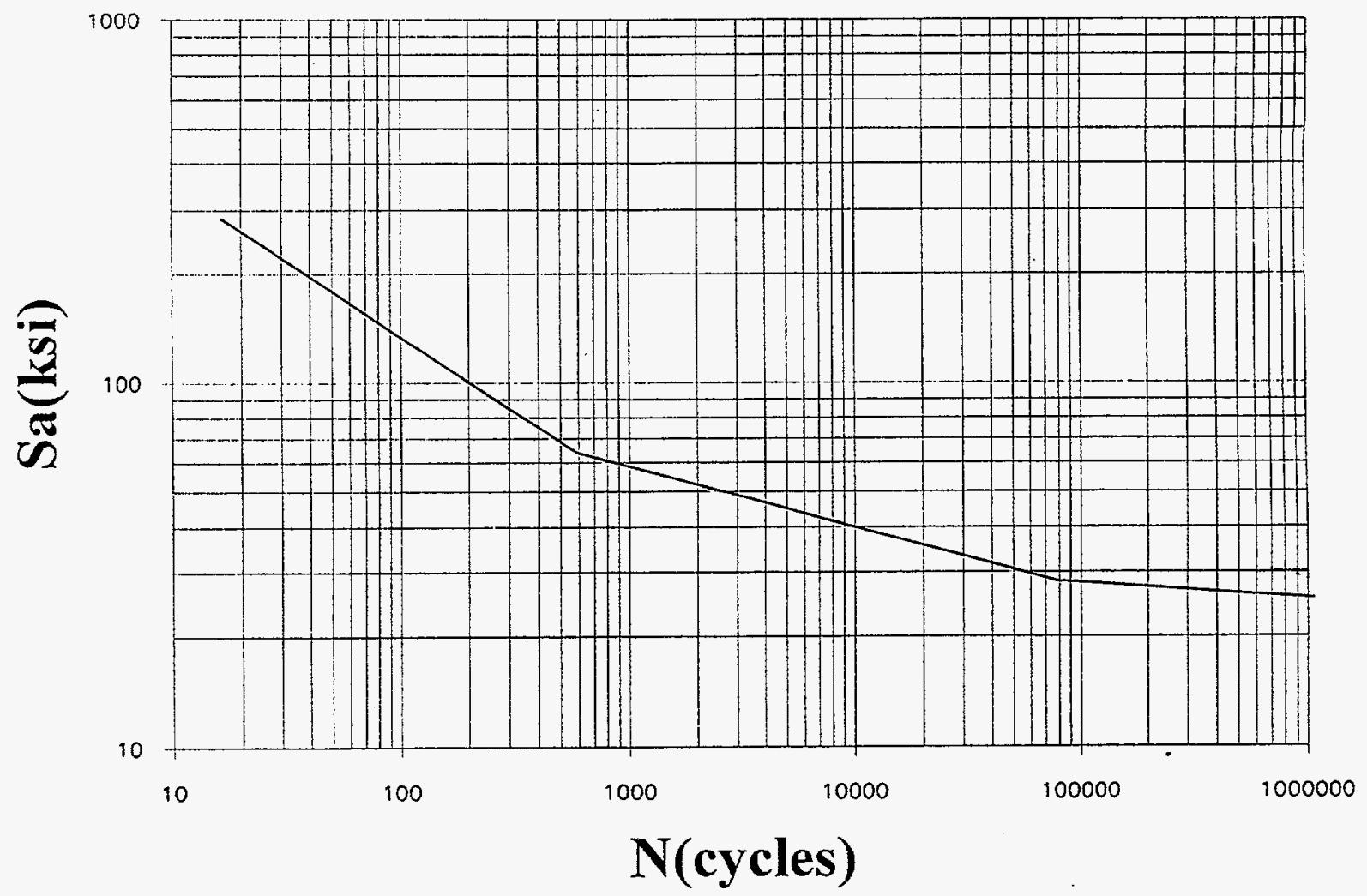

Figure 3-1. Interim fatigue curve for stainless and Alloy 600 steels.

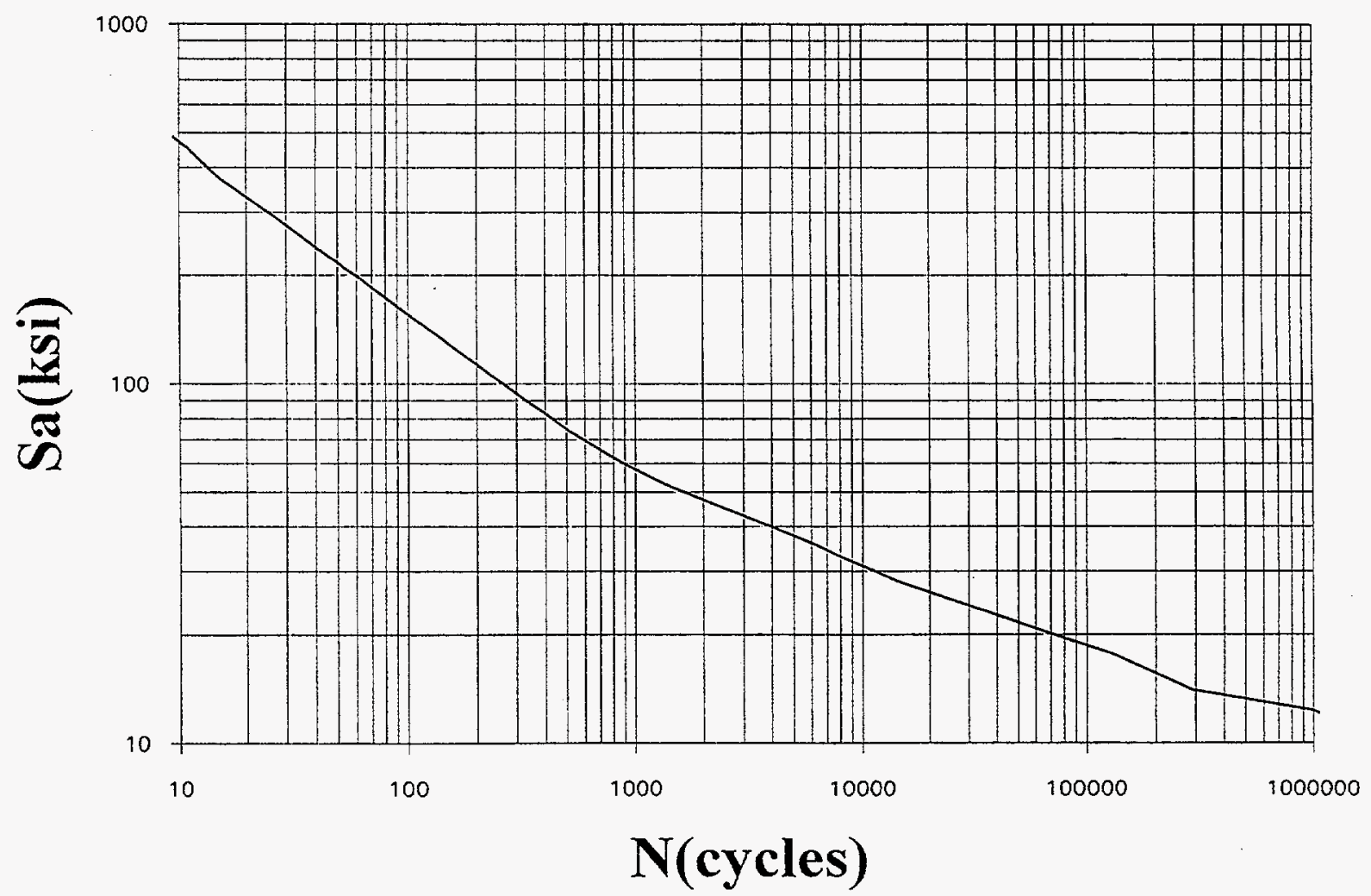

Figure 3-2. Interim fatigue curve for carbon and low-alloy steels in low-oxygen water. 


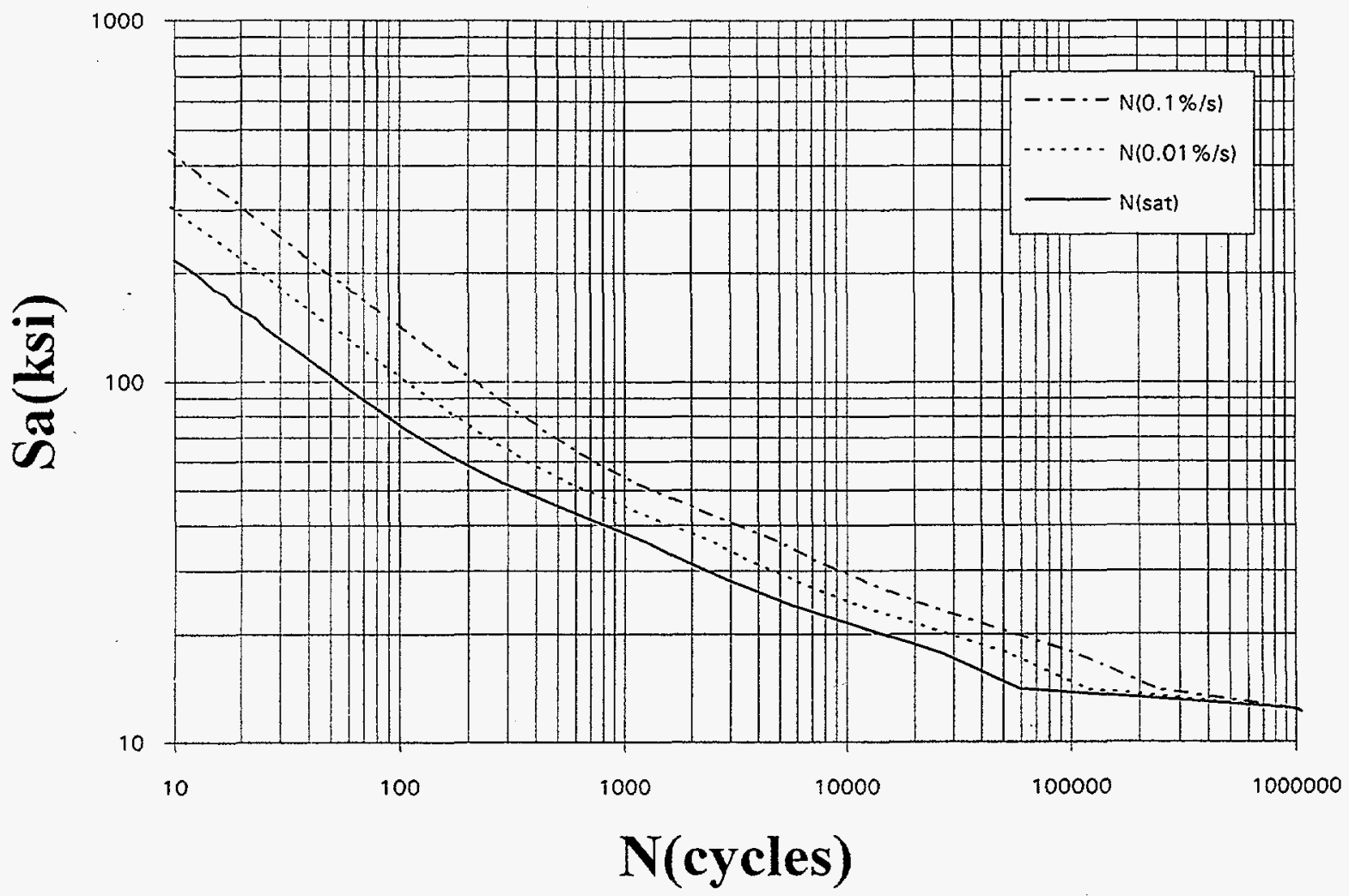

Figure 3-3. Interim fatigue curve for carbon and low-alloy steels in high-oxygen water at $200^{\circ} \mathrm{C}$.

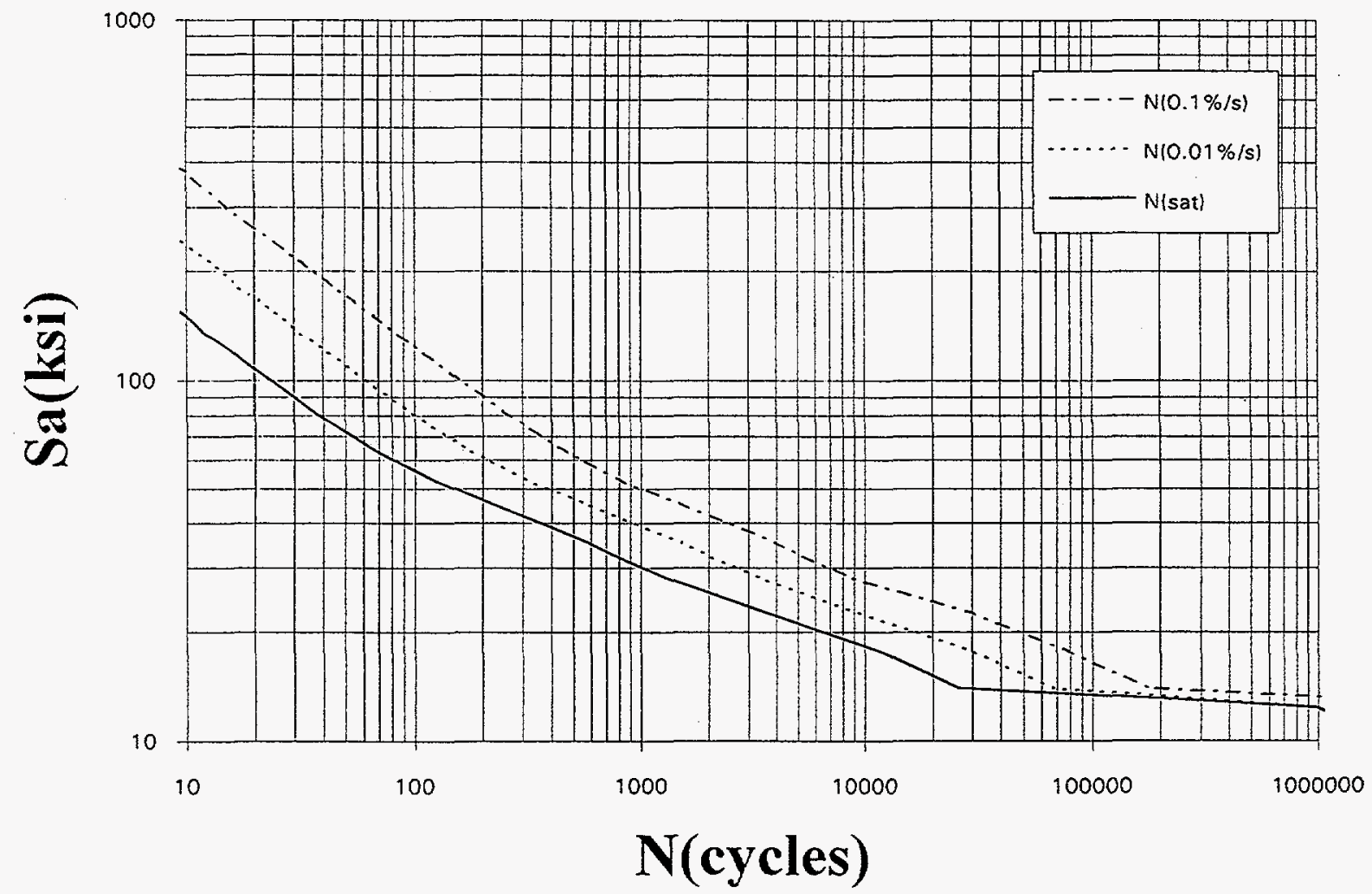

Figure 3-4. Interim fatigue curve for carbon and low-alloy steels in high-oxygen water at $250^{\circ} \mathrm{C}$. 


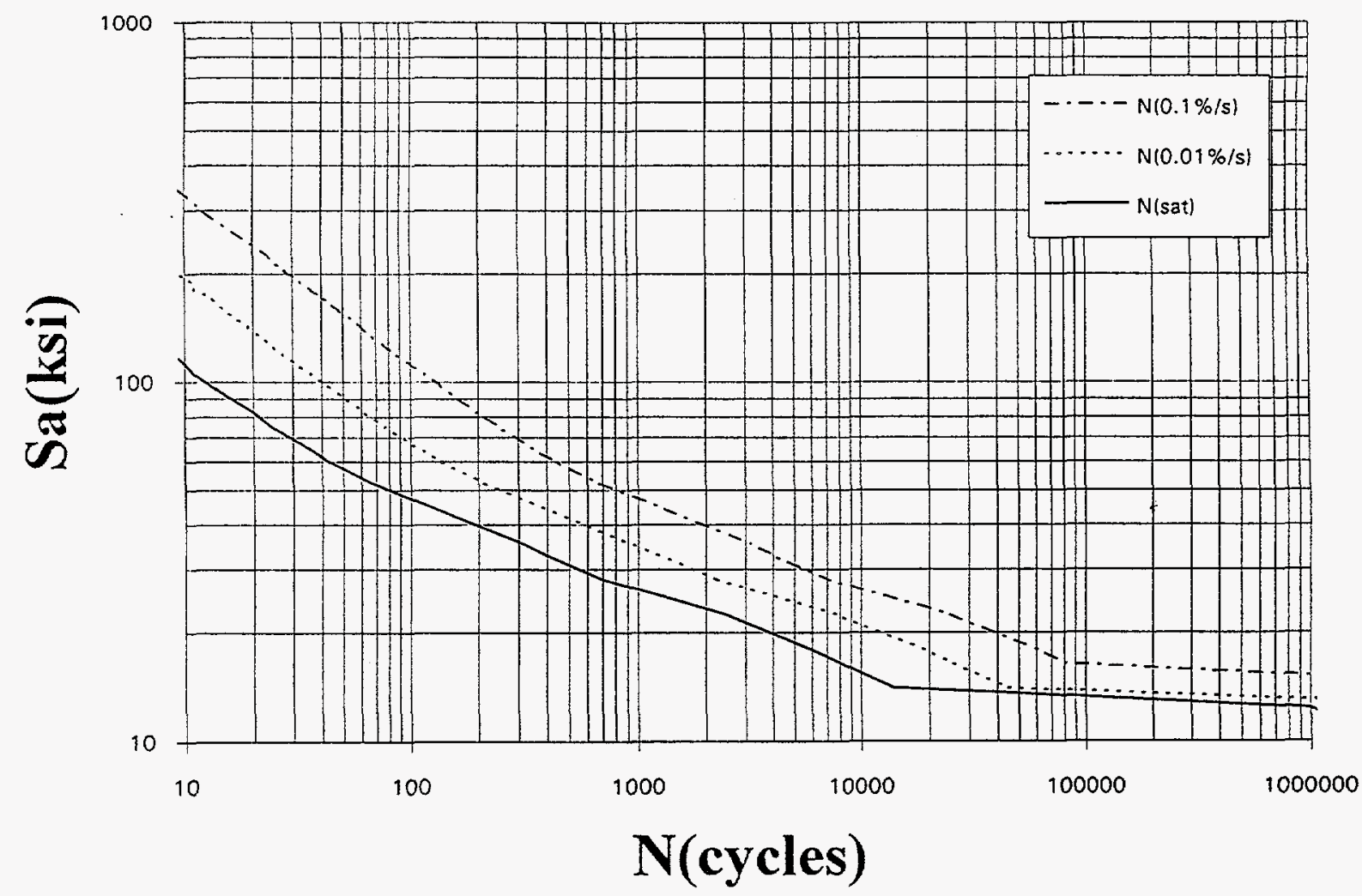

Figure 3-5. Interim fatigue curve for carbon and low-alloy steels in high-oxygen water at $288^{\circ} \mathrm{C}$.

\subsection{Increase in CUF using Interim Curves}

In order to assess the increase in the CUF using the interim fatigue curves, values for the numbers of cycles on the ASME Code design fatigue curve (from Table 2-1) were divided by the numbers of cycles at corresponding stresses on the interim fatigue curves (using the ANL spreadsheet values). The results are shown in Figures 3-6 through 3-10. The ASME Code method of interpolating between values was used. The interpolation formula for stress values $S$ between the values of $S_{i}$ and $S_{j}$ is:

$N=N_{i}\left(\frac{N_{j}}{N_{i}}\right)^{\frac{\log \left(\frac{s_{i}}{s}\right)}{\log \left(\frac{s_{i}}{s_{j}}\right)}}$

where

$\mathrm{N}=$ allowable cycles for stress
$\mathrm{S}=\mathrm{S}_{\mathrm{alt}}$ stress value

$\mathrm{N}_{\mathrm{i}}, \mathrm{N}_{\mathrm{j}}=\quad$ low and high numbers of cycles (at $S_{i}, S_{j}$ )

$S_{i}, S_{j}=$ high and low stress values (at $\mathrm{N}_{\mathrm{i}}, \mathrm{N}_{\mathrm{j}}$ ).

Figures 3-6 through 3-10 show that the factor of increase depends on the alternating stress intensity. From Figure 3-6 for stainless steel and Alloy 600 , the factor of increase is about 11 for low alternating stress intensities, increasing to a factor of 17 at about $63 \mathrm{ksi}$, and then decreasing to a factor of 6 at $160 \mathrm{ksi}$. For carbon and low-alloy steels in low-oxygen environments, the maximum factor of increase is only about 2.75 at $55 \mathrm{ksi}$ (Figure 3-7). For carbon and low-alloy steels in high-oxygen environments at saturated $(0.001 \% / \mathrm{s})$ strain rates, the maximum factors of increase are about 13,30 , and 55 at temperatures of 200,250 , and $288^{\circ} \mathrm{C}$, respectively (Figures 3-8 through 3-10). The lowest 


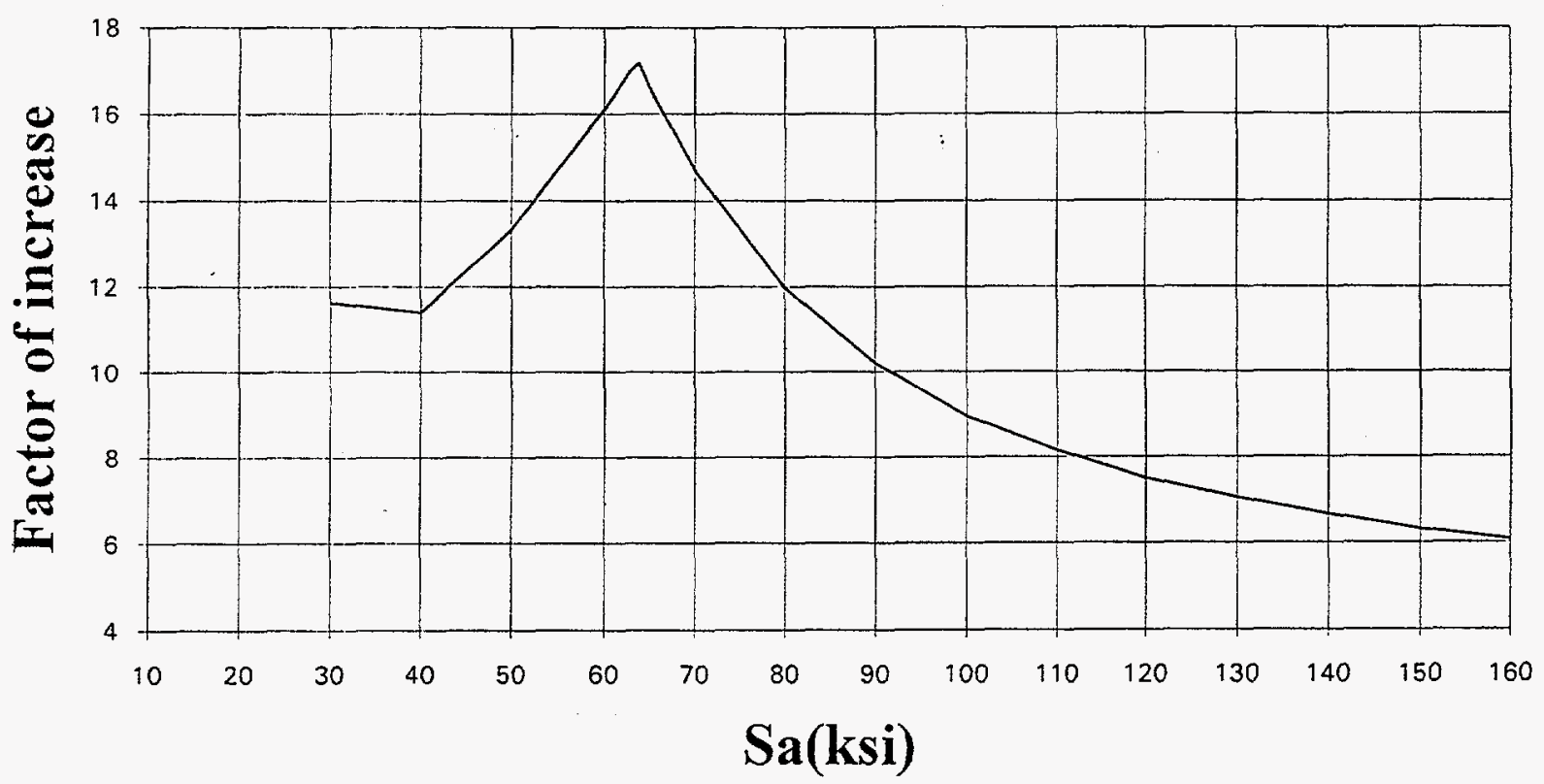

Figure 3-6. Increase in CUF using NUREG/CR-5999 interim fatigue curve for stainless and Alloy 600 steel.

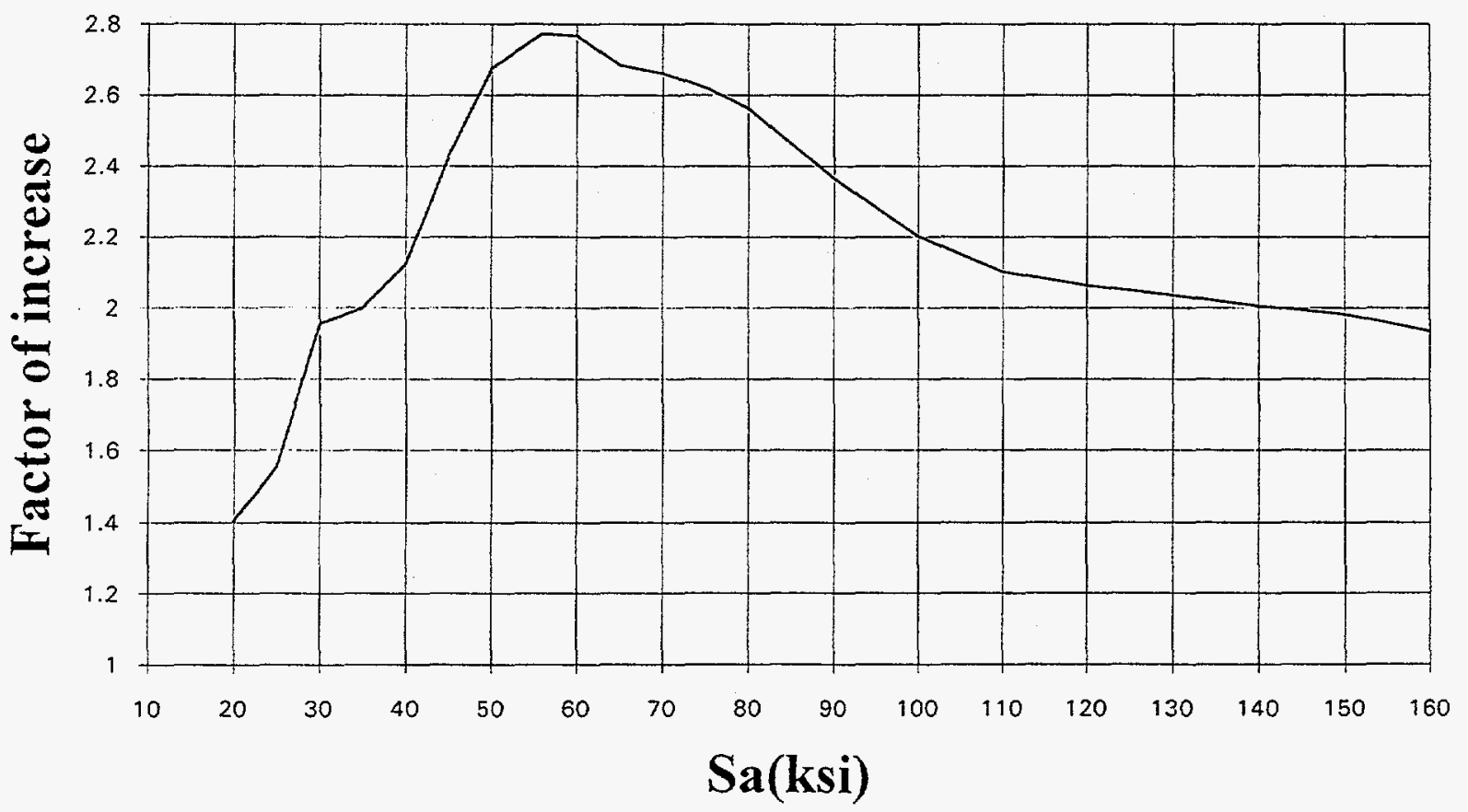

Figure 3-7. Increase in CUF using NUREG/CR-5999 interim fatigue curve for carbon and low-alloy steel in low-oxygen environment. 


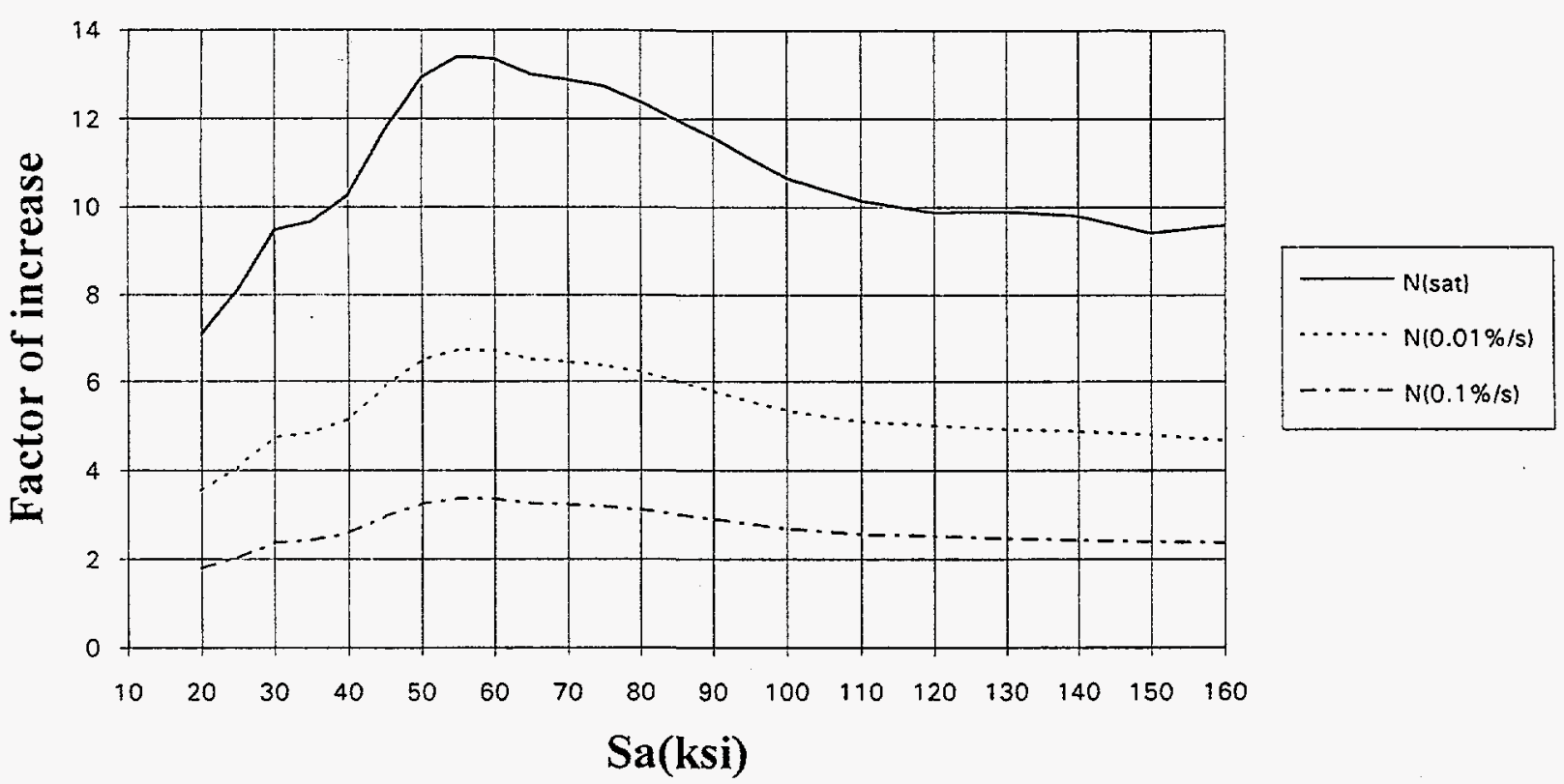

Figure 3-8. Increase in CUF using NUREG/CR-5999 interim fatigue curve for carbon and low-alloy steel in high-oxygen environment at $200^{\circ} \mathrm{C}$.

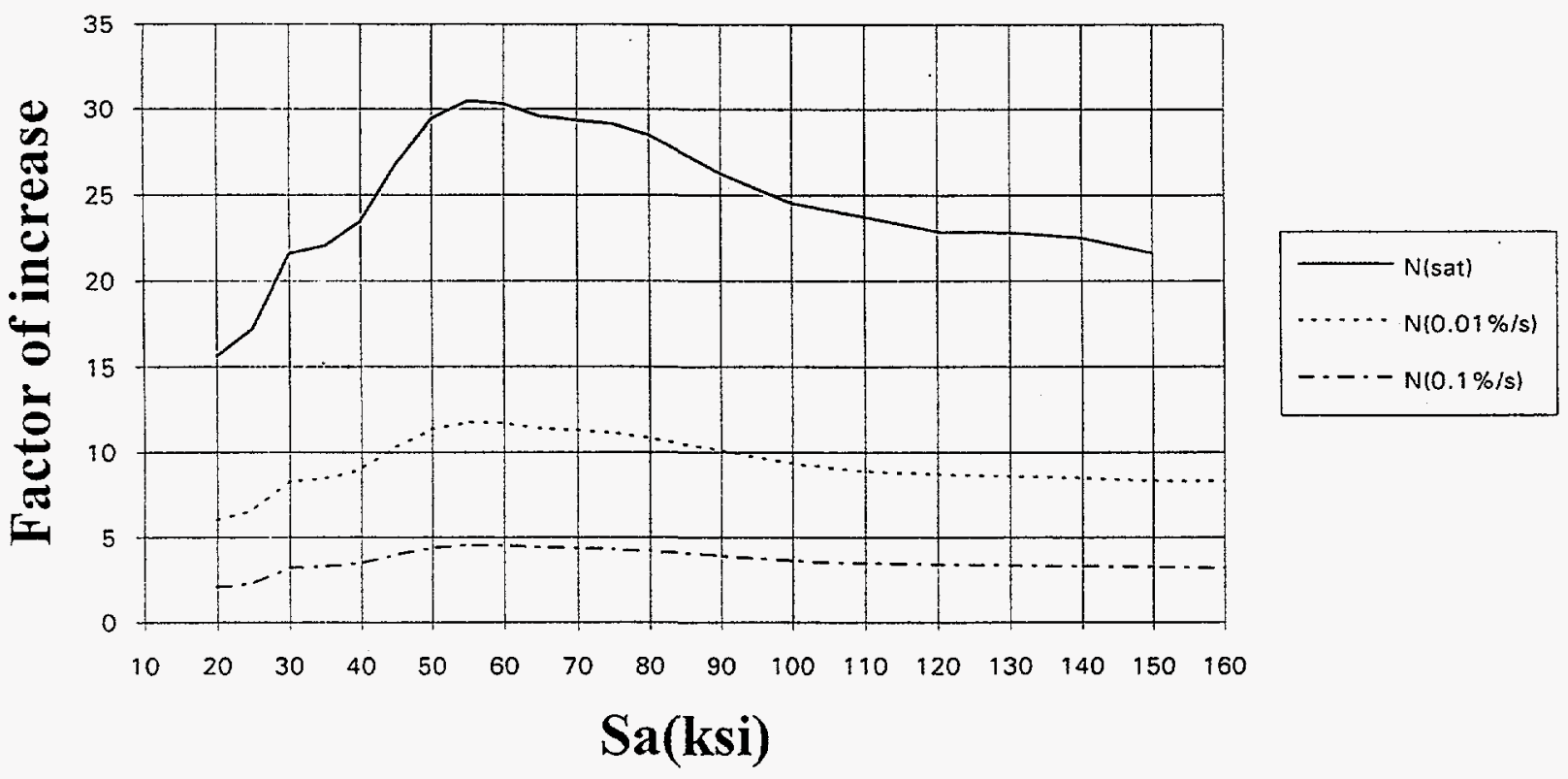

Figure 3-9. Increase in CUF using NUREG/CR-5999 interim fatigue curve for carbon and low-alloy steel in high-oxygen environment at $250^{\circ} \mathrm{C}$. 


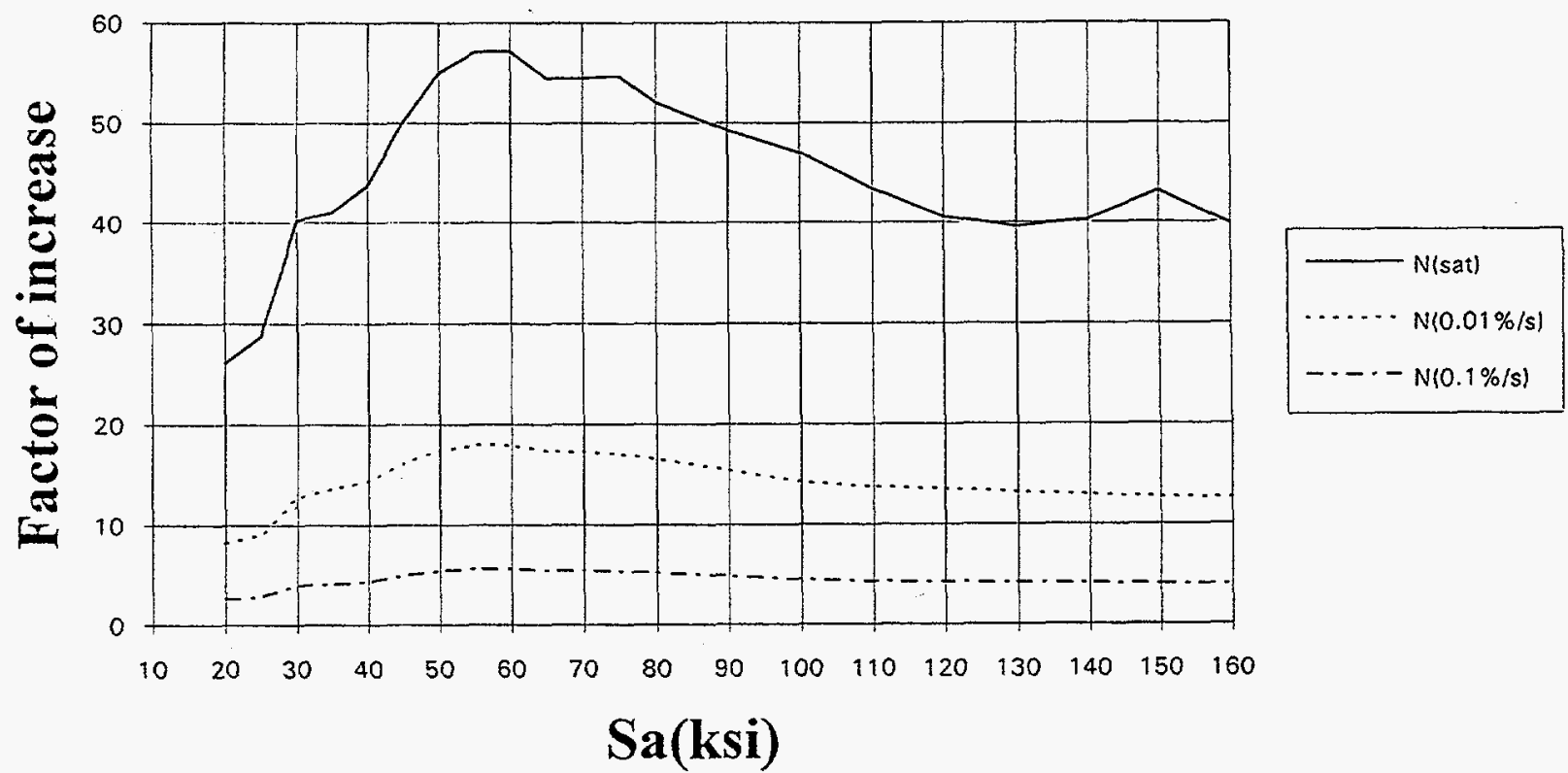

Figure 3-10. Increase in CUF using NUREG/CR-5999 interim fatigue curve for carbon and low-alloy steel in high-oxygen environment at $288^{\circ} \mathrm{C}$.

maximum increase of about 3.5 occurs at high strain rates $(0.1 \% / \mathrm{s})$ at $200^{\circ} \mathrm{C}$.

\subsection{Interpolation of NUREG/CR-5999 Curves}

In order to be able to accurately interpolate between the temperature and strain rate values on the interim fatigue curves, studies were carried out to determine appropriate interpolation formulas. Since it appeared from Figures 3-6 through 3-10 that the relations may be stress dependent, the ratios of the numbers of cycles for the three strain rates at the three temperatures for the high-oxygen curves were plotted. In addition, the ratio of the values for the three temperatures at the three strain rates were plotted. The results are shown in Figures 3-11 through 3-15. These plots show that the ratios are all fairly constant with stress. For example, in Figure 3-11, the ratio of $\mathrm{N}_{\text {sat }}$ to the numbers of cycles $\mathrm{N}_{0.01}$ and $\mathrm{N}_{0.1}$ are 2 and 4 , respectively. From these curves we can deduce that interpolation relations can be determined irrespective of stress.

Since the ratios were not dependent on stress, an alternating stress of $55 \mathrm{ksi}$ was chosen to determine the relations between strain rate, temperature, and number of cycles. This stress level was chosen since from Figures 3-11 through 3-15, the ratios for numbers of cycles for both strain rates and temperatures are at an approximate constant level for all five graphs. Plots of strain rate versus cycles for the three temperatures, and for temperature versus cycles for the three strain rates (at 55 ksi) are shown in Figures 3-16 and 3-17. From Figure 3-16, it can be seen that the logarithms of strain rate and numbers of cycles have a linear relationship. Therefore the interpolation formula is:

$N=N_{i} 10^{\frac{\log \left(\frac{S R}{S R_{j}}\right)}{\log \left(\frac{S R_{i}}{S R_{j}}\right)} \log \frac{N_{i}}{N_{j}}}$ 
NUREG/CR-5999 Interim Fatigue Curves
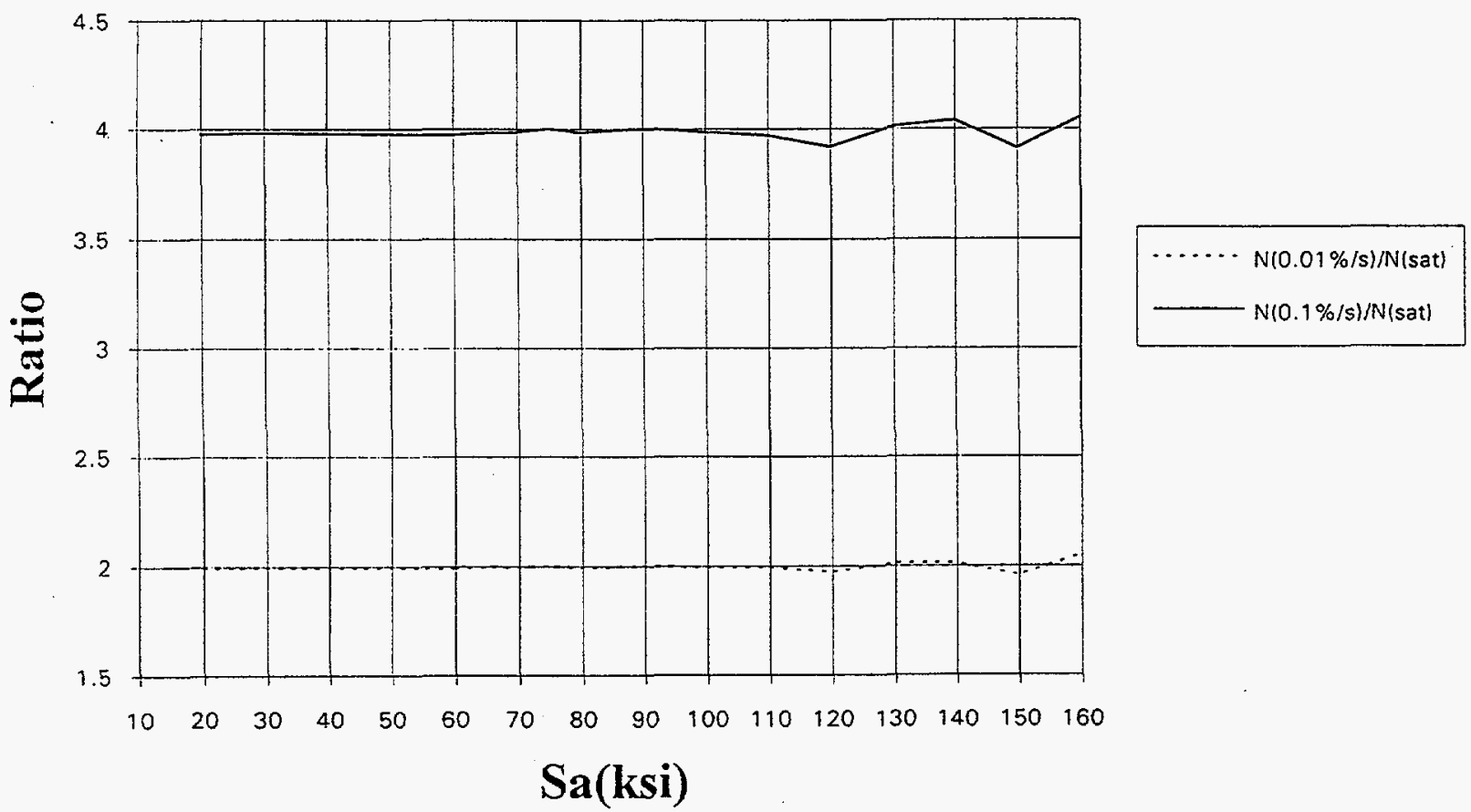

Figure 3-11. Ratio of strain rate cycles at $200^{\circ} \mathrm{C}$.

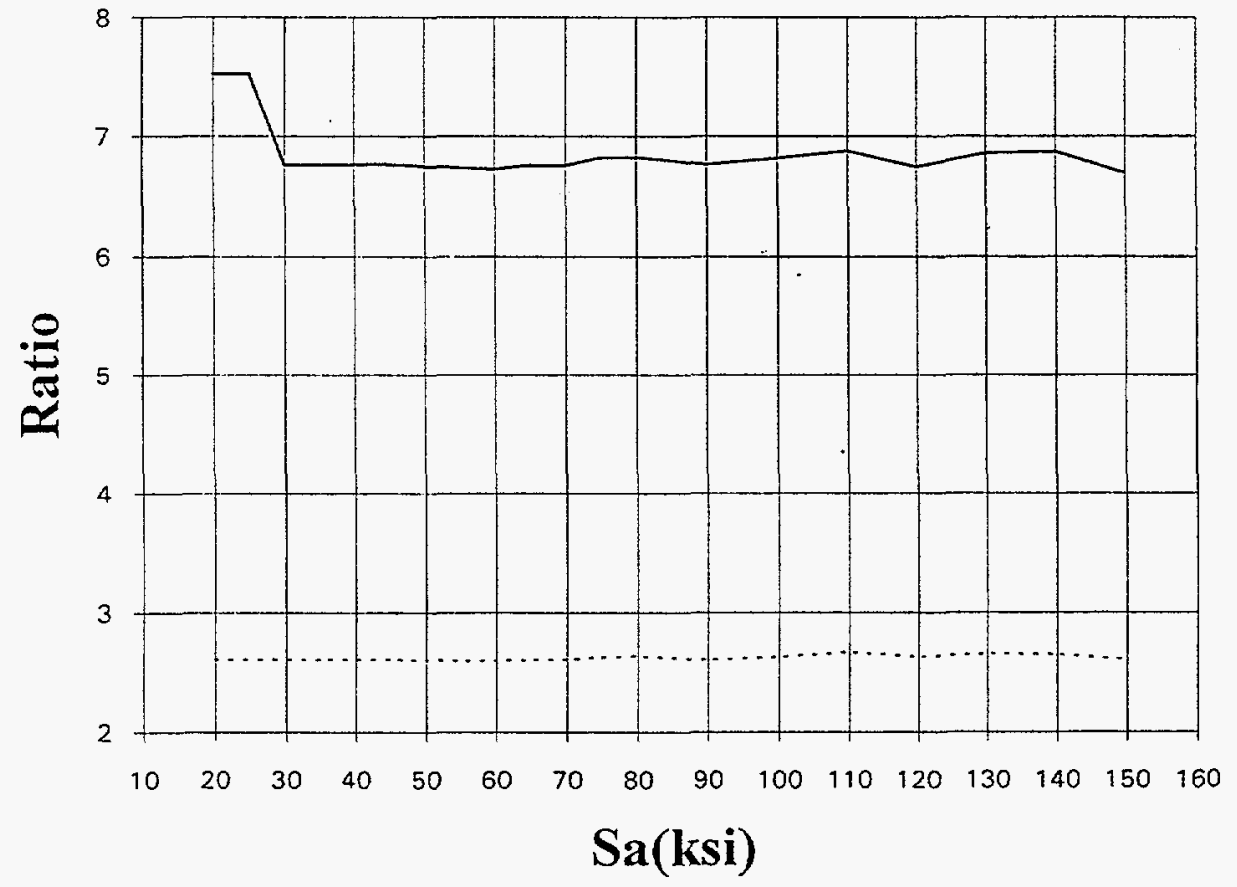

……N N $0.01 \% / \mathrm{s}) / \mathrm{N}(\mathrm{sat})$ N $(0.1 \% / \mathrm{s}) / \mathrm{N}$ (sat)

Figure 3-12. Ratio of strain rate cycles at $250^{\circ} \mathrm{C}$. 

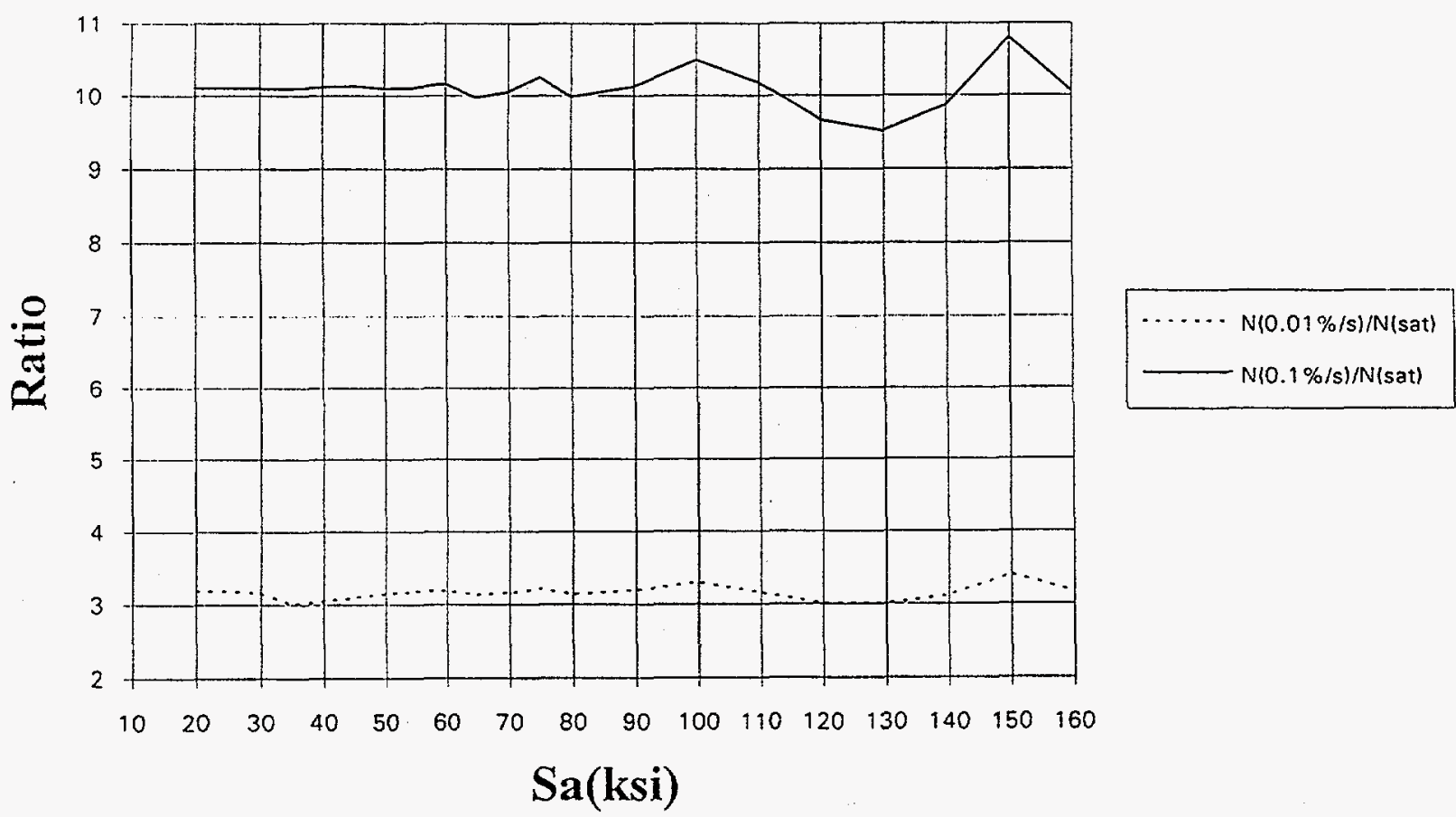

Figure 3-13. Ratio of strain rate cycles at $288^{\circ} \mathrm{C}$.

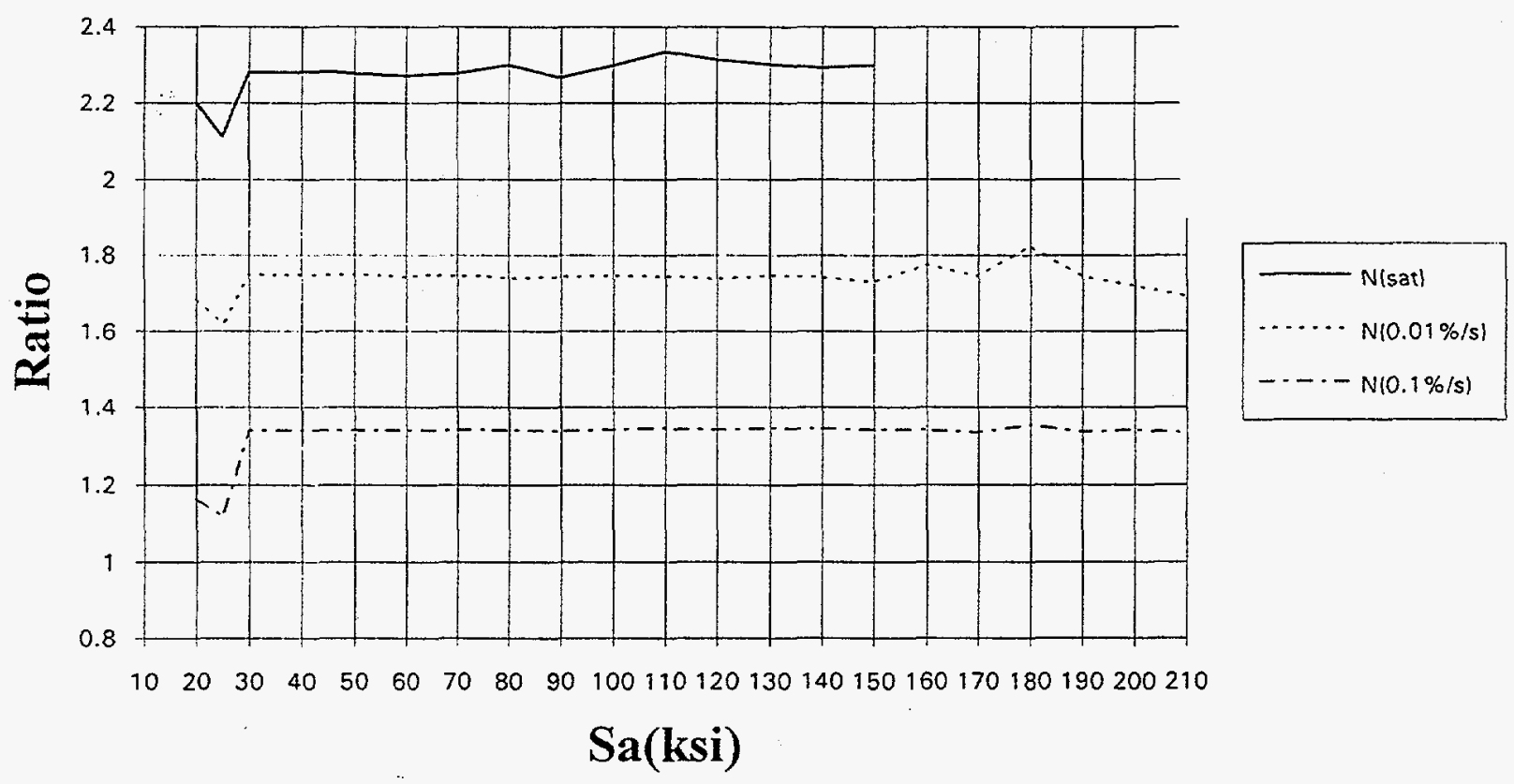

Figure 3-14. Ratio of cycles on $200^{\circ} \mathrm{C}$ curve to cycles on $250^{\circ} \mathrm{C}$ curve. 

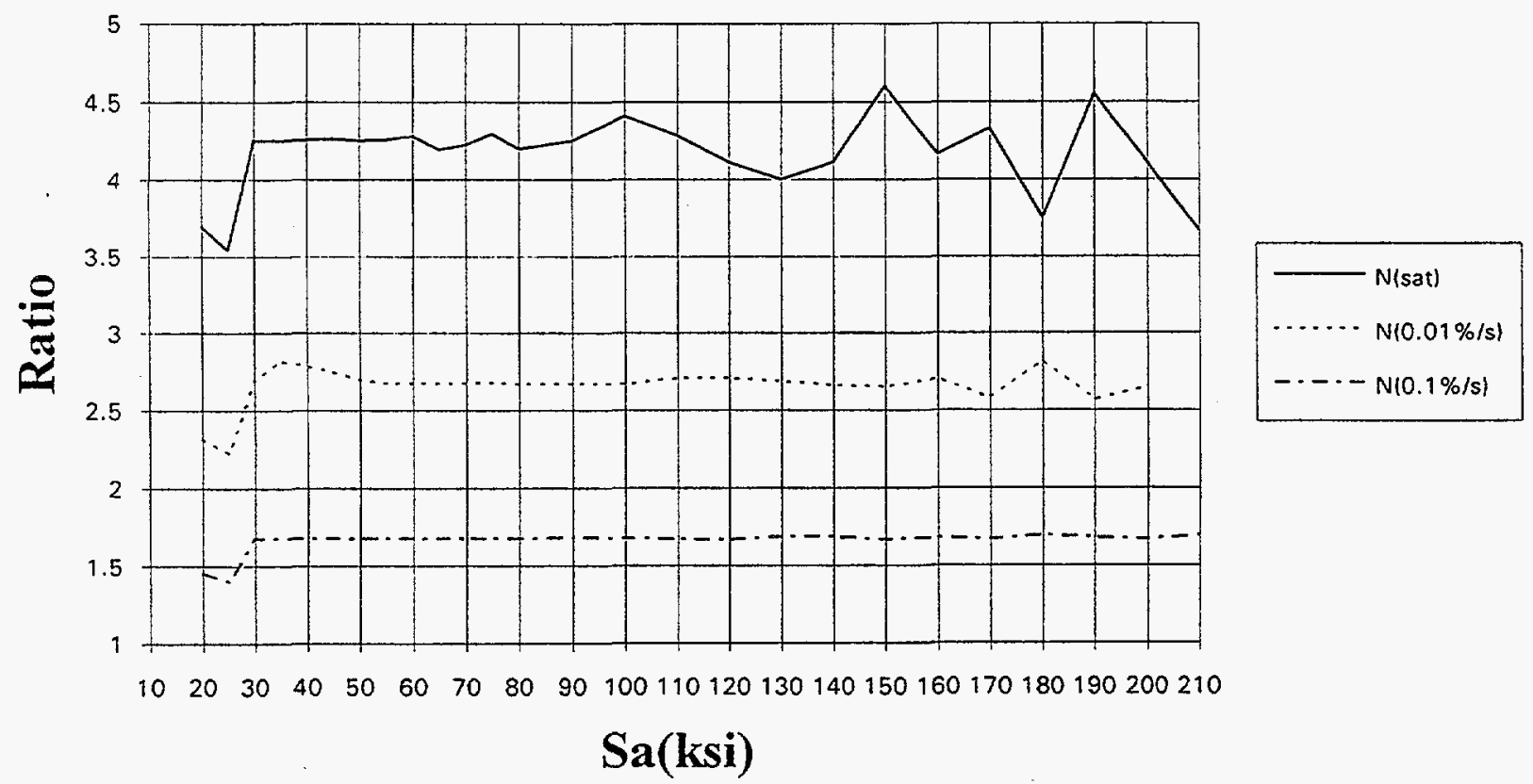

Figure 3-15. Ratio of cycles on $200^{\circ} \mathrm{C}$ curve to cycles on $288^{\circ} \mathrm{C}$ curve.
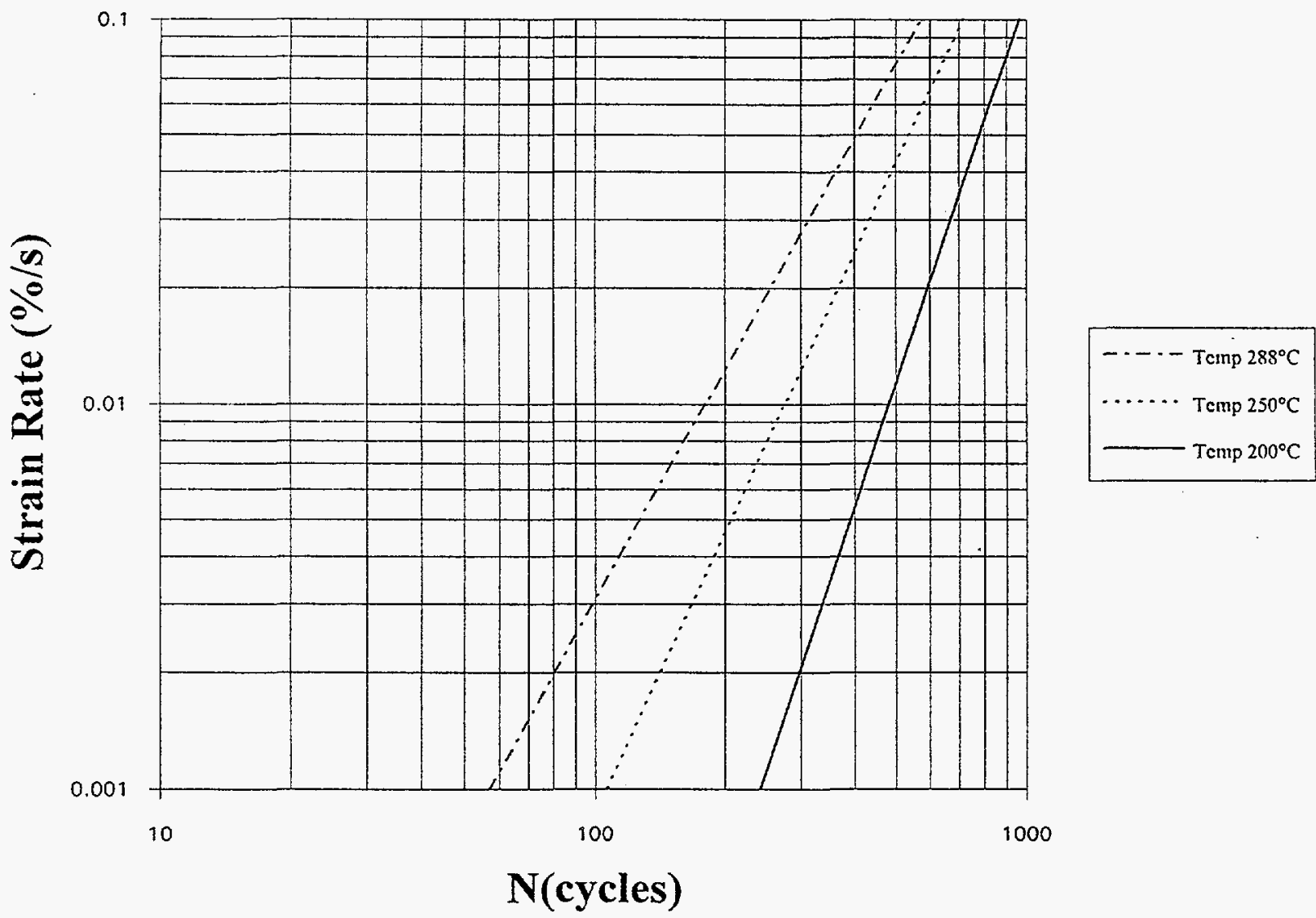

Figure 3-16. Relationship of strain rate and numbers of cycles. 


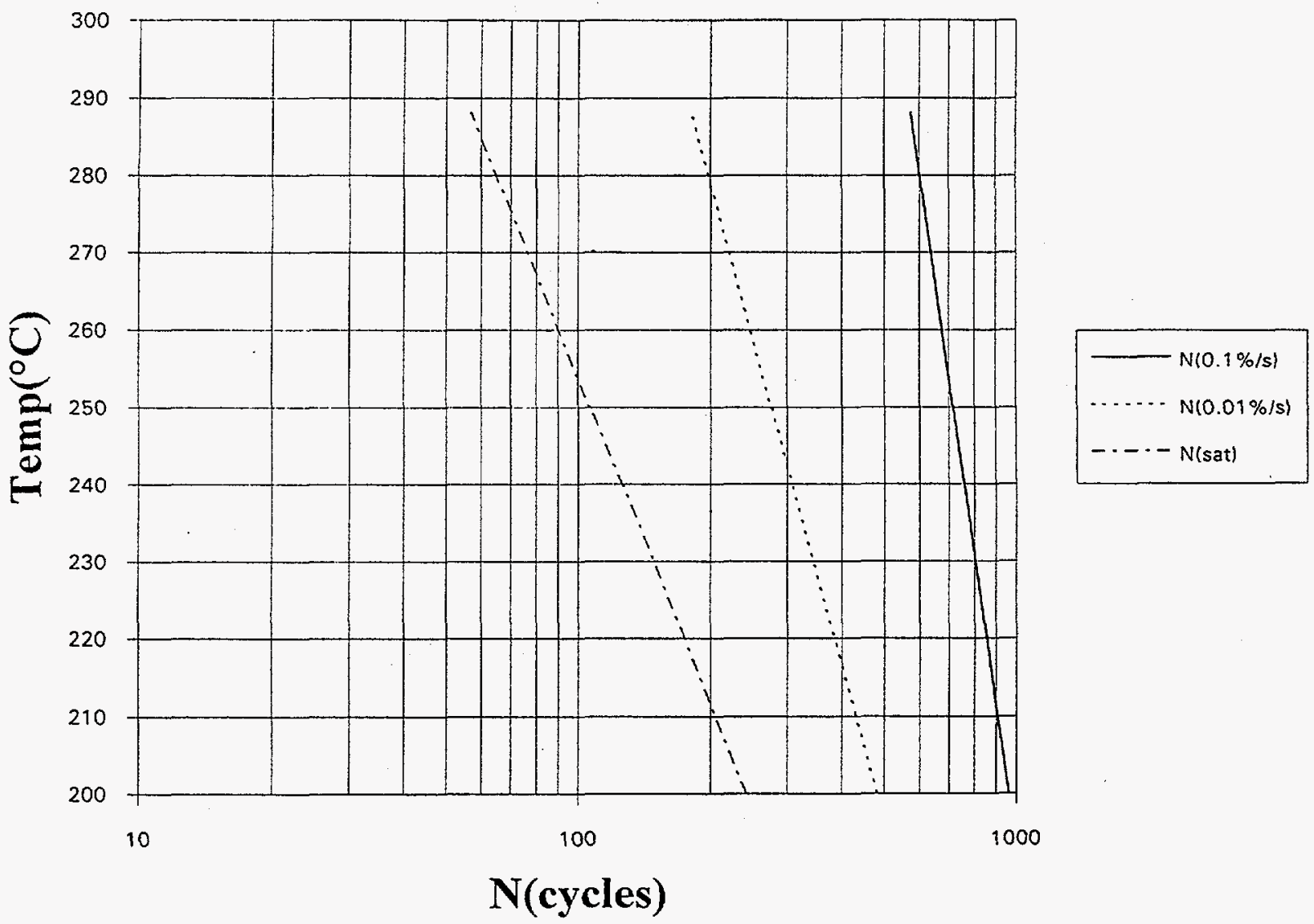

Figure 3-17. Relationship of temperature and numbers of cycles.

where

$$
\begin{aligned}
& \mathrm{N}=\begin{array}{l}
\text { allowable cycles for strain } \\
\text { rate } \mathrm{SR}
\end{array} \\
& \mathrm{SR}=\text { the strain rate value } \\
& \mathrm{N}_{\mathrm{i}}, \mathrm{N}_{\mathrm{j}}=\begin{array}{l}
\text { high and low numbers of } \\
\text { cycles }\left(\text { at } \mathrm{SR}_{\mathrm{i}}, \mathrm{SR}_{\mathrm{j}}\right)
\end{array} \\
& \mathrm{SR}_{\mathrm{i}}, \mathrm{SR}_{\mathrm{j}}=\quad \begin{array}{l}
\text { high and low strain rate } \\
\text { values }\left(\text { at } \mathrm{N}_{\mathrm{i}}, \mathrm{N}_{\mathrm{j}}\right) .
\end{array}
\end{aligned}
$$

Similarly, from Figure 3-17 it can be seen that the temperature and the logarithm of the numbers of cycles are linearly related. Therefore the interpolation formula is:

$$
N=N_{j} 10^{\frac{T-T_{j}}{T_{i} T_{j}}} \log \frac{N_{i}}{N_{j}}
$$

where

$$
\begin{array}{ll}
\mathrm{N} & =\begin{array}{l}
\text { allowable cycles for temp- } \\
\text { erature }
\end{array} \\
\mathrm{T} & =\text { the temperature } \\
\mathrm{N}_{\mathrm{i}}, \mathrm{N}_{\mathrm{j}}=\text { numbers of cycles (at } \mathrm{T}_{\mathrm{i}}, \mathrm{T}_{\mathrm{j}} \text { ) } \\
\mathrm{T}_{\mathrm{i}}, \mathrm{T}_{\mathrm{j}}=\text { low and high temperatures. }
\end{array}
$$

Equations (3-2) and (3-3) were used for interpolating in this report. More recent ANL publications (Chopra, 1994) show that the natural logarithm of the best-estimate number of cycles is proportional to the temperature and strain rate. However, interpolation was used in only a few cases for BWR carbon/low-alloy steel components, and the slight differences in interpolation equations would not result in major changes to these few CUFs. 


\subsection{Revised Interim Fatigue Curves}

Subsequent to the issue of NUREG/CR-5999, ANL (Chopra, 1994) transmitted revised bestestimate fatigue curves for stainless steel (in equation form) to the NRC. The revised curves are strain rate-, temperature-, and material-dependent and differ for Type $316 \mathrm{NG}$ and other types of stainless steel. However, since none of the stainless steel components investigated as part of this project are Type $316 \mathrm{NG}$, the ANL equation can be reduced to:

$$
\begin{gathered}
\operatorname{Ln}\left(N_{25}\right)=6.663-1.957 \operatorname{Ln}\left(\varepsilon_{a}-0.1225\right) \\
+I_{w}(0.12 \dot{\varepsilon} *-0.47)
\end{gathered}
$$

where

$$
\begin{array}{ll}
\mathrm{N}_{25} \quad=\quad \begin{array}{l}
\text { fatigue life defined as the } \\
\text { number of cycles for the peak } \\
\text { tensile stress to drop 25\% } \\
\text { from its initial value (the } \\
\text { best-estimate fatigue life) }
\end{array} \\
\varepsilon_{\mathrm{a}} \quad=\quad \text { applied strain in percent } \\
\mathrm{I}_{\mathrm{W}} \quad=\quad 1 \text { if in water, } 0 \text { otherwise } \\
\dot{\varepsilon}^{*} \quad=\quad \text { strain rate } \\
0 \quad \text { for } \dot{\varepsilon}^{*}>1 \% / s \\
\operatorname{Ln}\left(\dot{\varepsilon}^{*}\right) \text { for } 0.001<\dot{\varepsilon}^{*}<1 \% / s \\
\operatorname{Ln}(0.001) \text { for } \dot{\varepsilon}^{*}<0.001 \% / s
\end{array}
$$

These best-estimate curves were converted to design curves comparable to ASME Code fatigue design curves by reductions of a factor of 1.5 on stress or 20 on cycles, whichever is less (consistent with NUREG/CR-5999). The two bounding curves ( 1 and $0.001 \% / \mathrm{s}$ strain rates) are shown in Figure 3-18. The 20-on-cycles reduction affects the high-stress, low-cycle portions of the curves (above about $40 \mathrm{ksi}$ ), while the factor of 1.5 on stress affects the low-stress, high-cycle portions of the curves (note the cusp on the curves at the intersection of the 1.5-on-stress and 20-on-cycles zones). No adjustment was made for the maximum effect of mean stress. (This adjustment only affects high-cycle fatigue $>10^{5}$ cycles).

As shown in Figure 3-19, the revised curves increase the CUF by a factor of about $5(1 \% / \mathrm{s}$ strain rate) to $11(0.001 \% / \mathrm{s}$ strain rate) over CUFs computed using the ASME Code fatigue design curve. The NUREG/CR-5999 interim fatigue curve increase the CUF by as much as a factor of 17 over the ASME Code design fatigue curve. However, for low strain rates, the revised curves would result in a higher CUF for alternating stress intensities above $90 \mathrm{ksi}$.

For many cases, the high alternating stress intensities result from thermal shocks, which have high strain rates, so the revised curves are expected in general to reduce the CUFs from those calculated using NUREG/CR-5999. Unfortunately, insufficient details are included in most of the licensees' stress analyses to determine the strain rates, although in a few cases the times to maximum strains were included in the stress reports. To get representative strain rates for the cases where times were not reported, we used the times for the maximum through-wall temperature differences to occur in the thermal analyses we performed on piping and nozzles. For cases where large thermal shocks are applied to piping and nozzles, the maximum through-wall temperature differences occur at about 30 to 45 seconds into the transient, but most of the temperature difference has occurred by about 10 to 15 seconds. Therefore, 30 seconds was chosen as a representative time for the buildup of the tensile portion of the stress cycle during thermal shocks.

The $1 \% / \mathrm{s}$ strain rate was achieved during tests in which the specimens were loaded by mechanical cycling. It is unlikely that such a high strain rate could be achieved during thermal cycling. No strain rates approaching $1 \% / \mathrm{s}$ were calculated in this study. A $1 \% / \mathrm{s}$ strain rate corresponds to an equivalent elastic stress rate of $283,000 \mathrm{psi} / \mathrm{s}$. 


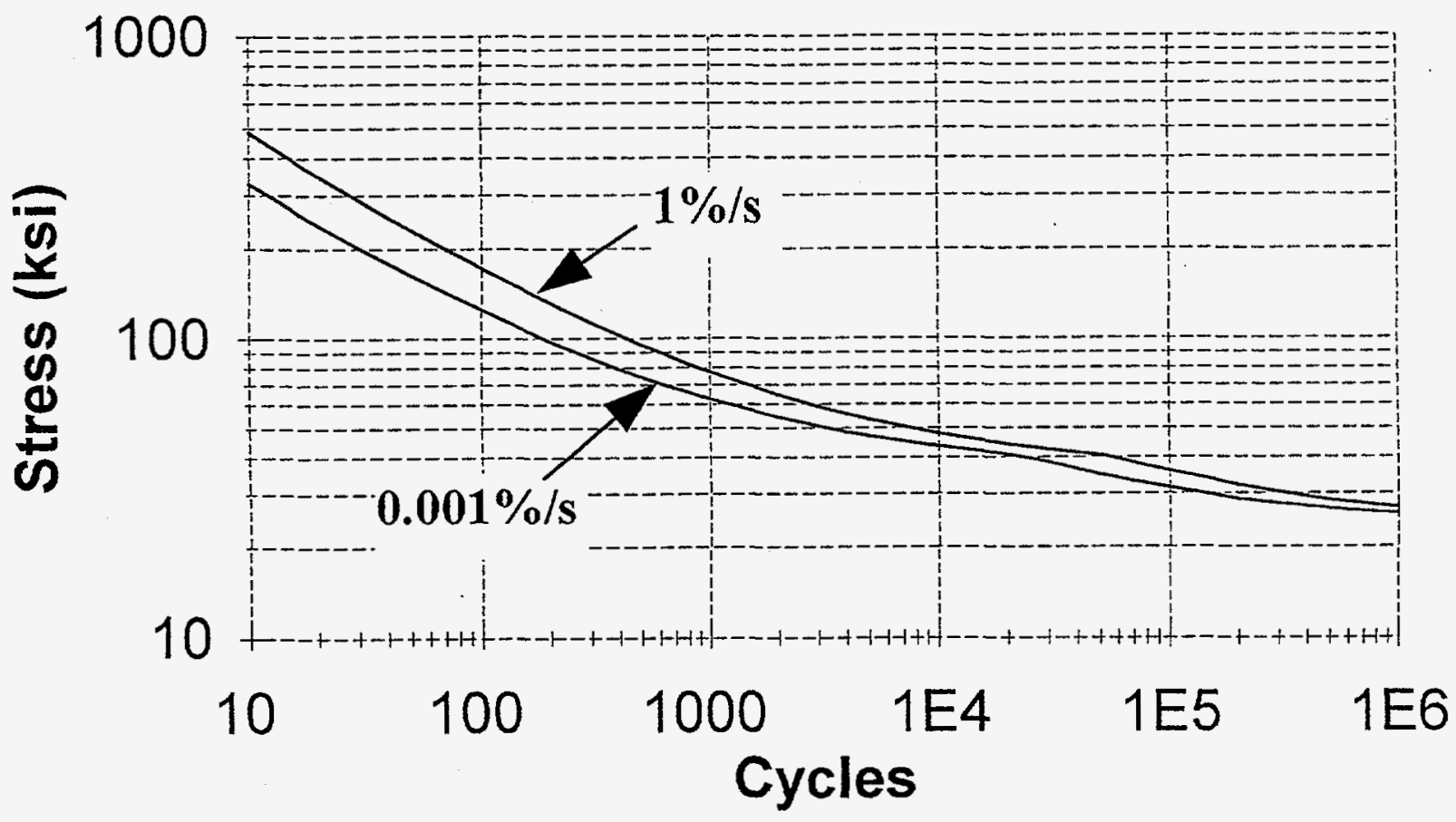

Figure 3-18. Revised stainless steel interim fatigue design curve (computed from Chopra, 1994).

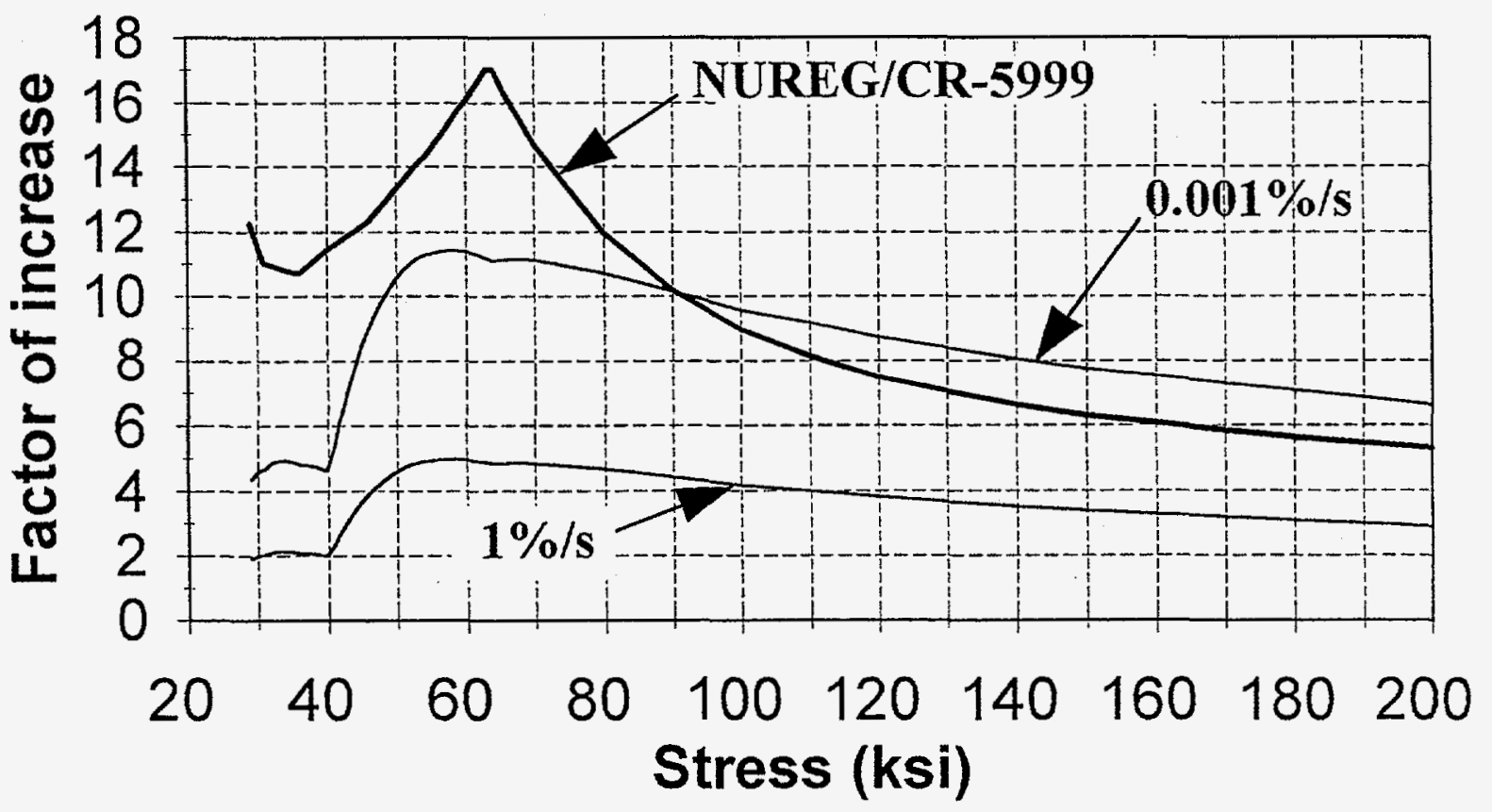

Figure 3-19. Ratio of revised interim fatigue curve cycles to corresponding ASME Code fatigue curve cycles. 


\section{APPROACH}

\subsection{Selection of Components for Analysis}

The components chosen for the evaluation of the five PWR plants [B\&W, Combustion Engineering (one older vintage and one newer vintage), and Westinghouse (one older vintage and one newer vintage)] are as follows:

1. Reactor vessel shell and lower head.

2. Reactor vessel inlet and outlet nozzles.

3. Pressurizer surge line (including hot leg and pressurizer nozzles).

4. Reactor coolant piping charging system nozzle.

5. Reactor coolant piping safety injection nozzle.

6. Residual heat removal (RHR) system Class 1 piping.

The terminology used above is for Westinghouse plants. The first three components are the same for Combustion Engineering and B\&W plants, but the latter three components for the three PWR nuclear steam supply system (NSSS) vendors are different either simply in name or in the routing of the piping. For cases where there is no direct one-for-one correspondence, the location that most nearly corresponded to the Westinghouse component was chosen. These locations are described in Section 5.

The components chosen for the evaluation of the two BWR plants [General Electric (one older vintage and one newer vintage)] are as follows:

1. Reactor vessel shell and lower head.

2. Reactor vessel feedwater nozzle.

3. Reactor recirculation piping (including inlet and outlet nozzles).
4. Core spray line reactor vessel nozzle and associated Class 1 piping.

5. RHR Class 1 piping.

6. Feedwater line Class 1 piping.

For both PWR and BWR plants, these components are not necessarily the locations with the highest design CUFs in the plant, but were chosen to give a representative overview of components that had higher CUFs and/or were important from a risk perspective. For example, the reactor vessel shell and lower head was chosen for its risk importance.

\subsection{Application of NUREG/CR-5999 Fatigue Curves}

NUREG/CR-5999 includes one fatigue curve for stainless steel, but several curves for carbon/ low-alloy steels which are based on the sulfur content of the steel and the oxygen level in the coolant. For the five PWR plants, the curves for high-sulfur steel and a low-oxygen environment (typical for PWRs) were used. For the two BWR plants, the curves for high-sulfur steel and a highoxygen environment were used. The high-oxygen (greater than $100 \mathrm{ppm}$ ) environment considered in the selected curves is consistent with the water chemistry in BWRs without hydrogen water chemistry. Neither of the two BWR plants evaluated have used hydrogen water chemistry.

\subsubsection{Interior and Exterior Surfaces. The} highest CUFs for components in the seven plants evaluated in this fatigue assessment study generally occur on the interior surfaces which experience the full effects of thermal shocks from fluid temperature changes. In a few cases the highest CUF was found to occur on the exterior surface (because of stress concentration effects), and in other cases no differentiation between interior and exterior surfaces was made in the licensee's calculations. Since it is expected that the interior 
surfaces will be more affected by environmental conditions than the exterior surfaces because of their direct contact with the reactor coolant and higher thermal shock stresses, the CUFs for the interior surfaces were chosen for evaluations.

4.2.2 Cladding. The interiors of LWR reactor vessels and nozzles made of carbon/low-alloy steel are clad with stainless steel. Table NB-3217-1 of the ASME Code classifies the cladding stress intensities due to differential expansions as peak stress. Some BWRs have had the cladding removed from feedwater nozzle areas so that the low-alloy steel is in direct contact with the reactor coolant. BWR carbon steel piping is in direct contact with the reactor coolant. Although the carbon/low-alloy steel components that are clad do not directly contact the reactor coolant, they are subjected to high temperatures.

None of the analyses for clad components supplied by the licensees included a fatigue analysis of the cladding, consistent with standard industry practice. None of the components on older vintage plants (for which no licensee analyses were required and for which the INEL staff conducted fatigue analyses) were clad. Consequently, the effect of the NUREG/CR-5999 interim fatigue curves was calculated for the carbon/low-alloy steel base metal material on the interior surfaces of components with cladding, but not for the cladding, for which we had no information.

Although NUREG/CR-5999 makes no differentiation between the environmental effects caused by temperature and by contact with reactor coolant for either carbon/low-alloy steel in low oxygen environments or for stainless steel, it is expected that the temperature effect is significant. As shown in Figures 3-14 and 3-15, the CUF increases (because the number of allowable cycles decreases) as the temperature increases. For example, Figure 3-14 shows that the ratio of the number of allowable cycles on the $200^{\circ} \mathrm{C}$ curve to the number of allowable cycles on the $250^{\circ} \mathrm{C}$ curve is greater than 1 . Therefore, for a given stress there would be a higher number of allowable cycles at $200^{\circ} \mathrm{C}$ than at higher temperatures. Thus we can conclude that the base metal under the cladding is not immune to environmental effects.

For the ASME Code fatigue curves, the fatigue usage for the base metal under the cladding is less than for the cladding for comparable stress intensity levels because the fatigue life for stainless steel is several times greater than for carbon/lowalloy steel (for example, 2000 allowable cycles for carbon/low-alloy steel versus 10,000 cycles for stainless steel at $64 \mathrm{ksi}$ ). Thus, for ASME Code analyses, it is reasonable to neglect fatigue of the cladding and compute the CUF of the base metal.

However, the allowable cycles for PWR components using the NUREG/CR-5999 interim fatigue curves are 587 cycles for stainless steel and 744 cycles for carbon/low-alloy steel at $64 \mathrm{ksi}$. Therefore, it appears that analyses of clad PWR components performed to NUREG/ CR-5999 interim fatigue curves should investigate the effects of fatigue for the cladding. A fatigue crack in the cladding could propagate into the base metal.

For BWR components in plants without hydrogen water chemistry, the allowable cycles at $64 \mathrm{ksi}$ from the NUREG/CR-5999 interim fatigue curves are 153,307 , and 612 at $200^{\circ} \mathrm{C} ; 67,175$, and 457 at $250^{\circ} \mathrm{C}$; and 36,61 , and 365 at $288^{\circ} \mathrm{C}$ for strain rates of $0.001,0.01$ and $0.1 \% / \mathrm{s}$, respectively. All allowable cycles are less for carbon/ low-alloy steel than for stainless steel, with the exception of values at $200^{\circ} \mathrm{C}$. From our review of the licensees' analyses, the only portion of BWRs that has high strain rates at $200^{\circ} \mathrm{C}$ is the feedwater system, which is not clad. The feedwater nozzle area originally had cladding on all plants, but it has been removed on some plants because of fatigue cracking caused partially by the differential thermal expansion between the cladding and base metal. Therefore, when using NUREG/ CR-5999 interim fatigue curves, it appears that fatigue of cladding can be neglected for BWRs without hydrogen water chemistry with the exception of the feedwater nozzle area.

4.2.3 Life Extension. The effect of extending the plant license life to 60 years was calculated by 
multiplying the 40 -year CUF by 1.5 . For cases where the CUF for a 60 -year design life using the NUREG/CR-5999 interim fatigue curves exceeded the ASME Boiler and Pressure Vessel Code, Section III, allowable value of 1.0 , an evaluation was made to remove conservative assumptions in the licensee's analyses, where justifiable, and a revised CUF was calculated using the methods in the latest (1992) edition of the ASME Code. (The 1989 edition of the Code was the last edition officially endorsed by the USNRC, but the 1992 and 1989 editions are essentially identical with respect to fatigue calculations.) Various editions of the ASME Code were used in the licensees' fatigue analyses for component or system qualification depending upon when the calculations were performed.

\subsubsection{Extent of Licensee Calculation}

Review. No attempt was made to check or to recalculate the alternating stress intensities reported in the licensee's design fatigue calculations. In most, if not all, cases there was more than one location on an individual component where the CUF would exceed 1.0 using the NUREG/CR-5999 interim fatigue curves. In these cases only the location with the highest CUF was evaluated. Once sufficient conservative assumptions had been removed to reduce the CUF below 1.0 for 60 years, no attempt was made to repeat the exercise for the remaining locations with relatively high design CUFs.

\subsubsection{Reporting of Stress Results. For} most components, tables that include the $S_{\text {alt }}$ values and design basis cycles are included in this report so that if future fatigue curves are proposed, use of the $S_{\text {alt }}$ values will lead to fairly easy computation of new allowable cycles, individual usage factors, and CUFs. The number of load pairs for surge line thermal stratification transients proved to be too excessive to report for a few plants.

\subsubsection{Significant Digits. The following} approach was taken to present stress and CUF values on a consistent basis regarding the number of significant digits. In reporting stresses from licensee's reports, two places after the decimal were retained. For stresses calculated by the INEL, including modulus of elasticity adjustments, two places after the decimal were reported. For individual usage factor and CUF values, three places after the decimal were used. When computing the allowable cycles, fractions of cycles were truncated.

4.2.7 High-Cycle Fatigue. If the number of allowable cycles exceeded $10^{6}$, the number was generally reported as $>10^{6}$. For the calculations reviewed in this project, the individual usage factors were consistently less than $1 \%$ of the CUF for allowable cycles of $10^{6}$. In general for the calculations we reviewed, high-cycle, low-stress fatigue was considered only for transients that involved thermal stratification.

\subsubsection{Applicable Temperature and Strain} Rate Values. NUREG/CR-5999 includes interim fatigue curves for high-oxygen environments that include temperature and strain rate effects. These curves would be easily applicable if the transients in nuclear power plants occurred at constant temperatures and strain rates. However, the fatigue cycles occur over temperature ranges from as low as about 30 to as high as about $600^{\circ} \mathrm{F}$, and NUREG/CR-5999 does not give guidance on how to apply the curves to transients with varying temperatures and strain rates. The analyst is faced with the questions of whether to use the maximum temperature during the transient, the average temperature during the transient, or try to determine the temperature at the time that the maximum stress occurs. This is further complicated by the fact that the maximum and minimum stress intensities may occur at a low temperature, for example, less than $200^{\circ} \mathrm{C}$; but at some time during the transient between the minimum and maximum stress intensities, the temperature reaches $550^{\circ} \mathrm{F}$. The most conservative approach would be to use the highest operating temperature of the component. On the other hand, one could use the temperature of the component at the times of highest stress. Our approach was to use the maximum temperature calculated for the times of maximum and minimum stresses, if known; otherwise, the maximum temperature for the load pair was used. 
Use of the three strain rate curves presents the same challenges as the temperature curves. In plant operation the strain rate is not constant. For each stress cycle there are strain rates for the increasing tensile portion, for the decreasing tensile portion, for the increasing compressive portion, and for the deceasing compressive portion. Since it is believed that the major fatigue damage occurs during the increasing tensile portion of the stress cycle, the average strain rate from the initiation of the stress cycle to the maximum tensile stress was used to determine the strain rate. None of the calculations that the vendors supplied included strain rates. The strain rate can be estimated using ASME Code NB-3200 methods, although this is time-consuming. Another complication is that the stress calculations do not include strains, only elastically computed stresses. The adjustment for plastic strain is by the simplified-elastic-plastic method using the $\mathrm{K}_{\mathrm{e}}$ factor. In some cases, sufficient information was provided to determine the difference in the peak stress intensity between the initiation of the stress cycle and the time of maximum stress. The strain rate was estimated by dividing this value by the modulus of elasticity and the time, and multiplying by the $\mathrm{K}_{\mathrm{e}}$ factor. Multiplication by the $\mathrm{K}_{\mathrm{e}}$ factor was included to convert the elastically computed peak stress intensity to a strain in which both elastic and plastic components are represented.

The strain rate is even more difficult to determine using ASME Code NB-3650 (piping) analysis methods. Sometimes the stress terms in ASME Code NB-3600 Equations 10 through 13 are calculated at different times and the maximum values are added together. For the piping cases where there was insufficient information to determine the strain rate (without performing the thermal analyses again), we used the saturated curves for the CUF calculations. This is conservative as the higher strain rate curves would lower the CUFs. In a few cases we were provided sufficient information to estimate a strain rate by using the alternating stress intensity divided by the time to maximum stress intensity and the modulus of elasticity.
To get representative strain rates for the cases where times were not reported, we used the times for the maximum through-wall temperature differences to occur in the thermal analyses we performed on piping and nozzles. For cases where large thermal shocks are applied to piping and nozzles, the maximum through-wall temperature differences occur at about 30 to 45 seconds into the transient, but most of the temperature difference has occurred by about 10 to 15 seconds. Therefore, 30 seconds was chosen as a representative time for the buildup of the tensile portion of the stress cycle during thermal shocks.

4.2.9 Fatigue Monitoring. No fatigue monitoring had been performed on most of these systems. Results of monitoring for thermal stratification was included in all five PWR plants' surge line analyses. Surge line monitoring was performed on two of the plants we evaluated, whereas the other plants used information from owners group monitoring by the NSSS vendor on similar plants. The newer vintage Combustion Engineering plant had performed fatigue monitoring of the safety injection and charging system nozzles. The newer vintage Westinghouse plant used monitoring information for thermal stratification in the residual heat removal line, and the results were included in the licensee's analysis of that system. Neither of the BWR plants had performed fatigue monitoring.

The thermal stratification fatigue monitoring results were complicated and no attempt was made to reduce conservative assumptions associated with the monitoring results. The only change that we made was to reduce the number of stratification cycles based on the ratio of the anticipated number of heatups/cooldowns to the design basis number. The anticipated numbers of cycles for some of the charging and safety injection nozzle transients for the newer vintage Combustion Engineering plant were based on the fatigue monitoring results. Although the CUF for the charging nozzle was slightly above 1.0 for 60 years using the NUREG/CR-5999 curves, we did not use actual monitoring transients to remove conservative assumptions because the licensee informed us that the algorithm used in the fatigue monitoring system was not comparable with how the system 
was actually being operated and needed to be changed.

\subsection{Potential Adjustments to Licensees' Calculations that Might Reduce the CUF}

If the CUF for a component exceeded 1.0 using the NUREG/CR-5999 interim fatigue curves, potential changes that could reduce the CUF were sought. The changes fall into two broad categories, conservative assumptions made by the analyst or Code changes that have been made since the edition of the Code of record for the plant. The following list describes these potential conservative assumptions.

1. Correct CUF calculation. Did the analyst correctly determine the number of allowable cycles from the alternating stresses? Although in most cases we did not have sufficient information to verify the licensee's stress calculations, we did examine the licensee's CUF calculation based on the reported $S_{\text {alt }}$. In some cases errors were found (using the incorrect fatigue curve).

2. Detailed load pairs. Were a number of load pairs conservatively enveloped by the worst case load pair? By separating the enveloped load pair with the overall combined number of cycles into more detailed load pairs, each with its own set of cycles, the CUF can sometimes be significantly reduced.

3. SCF/FSRF. Were conservative fatigue strength reduction factors (FSRFs) and stress concentration factors (SCFs) and stress indices for piping used? In some cases the highest SCF for the entire component was applied to all locations on the component rather than just at the affected location.

4. $S_{m}$ value. Was the $K_{e}$ value computed using a conservative $S_{\mathrm{m}}$ value? In many cases the analyst used the $S_{m}$ value at the design temperature in calculating $\mathrm{K}_{\mathrm{e}}$. Note 3 of ASME Code Figure NB-3222-1 states that the $S_{m}$ value at the maximum temperature experienced during the transient can be used, or if no mechanical loads contribute to the secondary stress, then the average $S_{\mathrm{m}}$ value at the high and low temperatures during the transient can be used to determine $3 \mathrm{~S}_{\mathrm{m}}$. Since most of the high peak stresses result from thermal shocks, we assume that the contributions to secondary stresses from mechanical loads are minor (less than $5 \%$ ) in these cases, and therefore the average $S_{m}$ value at the high and low temperatures can be used. The numbers were available to verify this assumption in several cases. For load pairs that contain hydrotests or seismic events [operating basis earthquake (OBE)], this assumption needs to be verified more carefully.

5. Material property changes. Did the values of the modulus of elasticity, coefficient of thermal expansion, or $S_{m}$ change from the ASME Code edition identified with the design basis calculations to the current Code edition? For example, in some later Code editions the coefficient of thermal expansion has been reduced, which will in turn reduce thermal stresses.

6. Fatigue curve modulus of elasticity value. Did the modulus of elasticity $(E)$ on the fatigue curve change from the ASME Code edition identified with the design basis calculations to the current Code edition? For example the 1965 edition of the Code did not require an adjustment for the modulus of elasticity. In the Winter 1982 addenda the value on the stainless steel/Alloy 600 curve was changed from $26.0 \times 10^{6}$ to $28.3 \times 10^{6}$ psi.

7. Code analysis changes. Did fatigue requirements change from the ASME Code edition of record for the design basis calculations to the current Code edition? For example the $\Delta T_{1}$ term was eliminated from the NB-3600 primary plus secondary stress equation (Equation 10) for piping in the 1977 edition, Summer 1979 addenda of the 
Code. A corresponding change was made to Table NB-3217-2.

8. Actual cycles. Based on the actual cycles that the plant has experienced to date, are the numbers of cycles extrapolated to 40 years less than the numbers of design basis cycles?

In all cases, changes associated with items 1 through 7 above were first considered in reducing the CUF. If the CUF was still greater than 1.0, a revised CUF was computed based on the extrapolated number of current cycles.

In some cases there are additional potential conservative assumptions in the licensee's design basis calculations, but these assumptions could not be removed using the thermal/stress analyses provided. Removal of these potential conservative assumptions would require either more detailed analyses than the licensee's design basis calculations, or more plant-specific information, or both. There are cases where the use of some of these potential conservative assumptions [for example changes to the number of OBEs or use of Code Case N-411 damping] might involve licensing issues which would have to be evaluated and resolved on a plant-by-plant basis. Licensing issues are beyond the scope of this study.

The following list describes these potential conservative assumptions.

9. High temperature rates. The design transients specify a $100^{\circ} \mathrm{F} / \mathrm{h}$ heatup/cooldown rate. However, actual transients seldom approach this rate. The use of equivalent partial cycles based on rates or temperature differences, or redefinition of the number of extrapolated cycles based on rates/differences can reduce the CUF.

10. Detailed stress modeling. Early analyses of vessels and nozzles used the interaction method to analyze for stress. Older and even some recent (as a cost saving measure) nozzle analyses have treated the nozzle as a piping branch connection (that is, a NB-3600 analysis) rather than performing a detailed finite element analysis of the nozzle (that is, a NB-3200 analysis). A modern finite element elastic analysis can give more accurate stress results and can reduce the CUF.

11. Conservative thermal parameters. Several conservative assumptions have been used in thermal analyses, such as high (bounding) heat transfer coefficients and step changes in fluid temperature. In the licensee analyses that we reviewed, we found cases where infinite heat transfer coefficients between the fluid and the metal were used. Use of more realistic thermal parameters could lower the CUF. In other cases, a bounding analysis may have been used to conservatively estimate the CUF resulting from thermal striping.

12. Time phasing of stresses. In piping analyses, the maximums of the $\Delta T_{1}, \Delta T_{2}$ and $\mathrm{T}_{\mathrm{a}}-\mathrm{T}_{\mathrm{b}}$ terms are often used to compute the primary plus secondary and peak stress intensity ranges. However, the time phasing of these terms may be such that the maximums occur at different times. By using the values for all three terms at the same times, the stress intensity ranges may be less. Furthermore, the primary plus secondary and the peak stress intensity ranges may not occur at the same time and time phasing might be used to reduce conservatism in the CUF calculations. However, carrying out this process would involve considerable effort on the analyst's part and is not expected to have much of an effect for vessels and nozzles (other than those nozzles analyzed as piping branch connections using NB-3600 methods).

13. Number of OBEs. The number of OBE cycles is inconsistent from plant to plant. Numbers in the analyses range from 10 to 200 to 650 . The Standard Review Plan (NUREG-0800) requires a minimum of 5 OBE events with ten cycles each. Some plants might reduce the number of design basis OBE cycles. 
14. CC N-411 damping. Some analyses used the damping values in Regulatory Guide 1.61 (the same as in Appendix $N$ of the ASME Code) to perform dynamic analysis. ASME Code Case (CC) N-411 allows higher damping values, which when used could significantly reduce the $O B E$ loads.

15. Number of hydrotests. The first 10 hydrotests need not be considered in the fatigue analysis (NB-3226). Furthermore, the 10-year hydrotest may now be replaced by a leak test (Code Case N-498). Therefore, the number of design basis hydrotests assumed in the fatigue analysis may be conservatively high.

16. Fatigue monitoring. Cycle counting and fatigue monitoring could be used to more accurately estimate the CUF. Some transients that are major contributors to the CUFs are not being counted, such as lossof-charging and loss-of-letdown events. Better knowledge of the numbers of occurrences of these events may show that the actual numbers of cycles are less than the design basis numbers. For transients such as thermal stratification of surge lines, analysts have sometimes used the results of one heatup cycle to estimate the numbers of insurges/outsurges and temperature differences. From these measurements they have conservatively developed an enveloping set of transients for use to the end of plant life. However, monitoring the piping top-tobottom temperature differences during each heatup may result in less cumulative fatigue usage than using the enveloping set.

17. Plastic analysis. An elastic-plastic finite element analysis could be conducted to determine the alternating strain range for use with the NUREG/CR-5999 interim fatigue curves. This would eliminate the conservative assumptions associated with the $\mathrm{K}_{\mathrm{e}}$ factor in the simplified elastic-plastic analysis technique in ASME Code NB-3228.5 and NB-3653.6.

\subsection{Examples of Code Changes and Adjustments to Cycles/Transients that Might Increase the CUF in Licensees' Calculations}

In addition to the changes listed in the previous section that might be used to decrease the CUF in the licensee's calculations, several changes were found from review of the licensees' analyses for the seven plants that might increase the CUF when using the 1992 ASME Code and the latest estimates of cycles and transients. Examples are listed below:

1. Correct CUF calculation. The analyst used the ASME Code fatigue curve for high strength carbon/low-alloy steel instead of the appropriate curve for lower strength material. Both curves are on the same figure in the ASME Code.

2. Use of Code fatigue formulas. In early Code editions (for example 1965) there were no formulas to compute the allowable numbers of cycles from the fatigue curves. The numbers of allowable cycles, visually determined using the minor grid lines on these early curves, are greater than the allowable cycle values computed from the formulas in later editions of the Code.

3. Adjustment for modulus of elasticity. In early Code editions (for example 1965), there was no requirement to adjust the $S_{\text {alt }}$ values for the modulus of elasticity when performing NB-3200 analyses. In later Code editions, the $S_{\text {alt }}$ values are required to be multiplied by the room temperature modulus of elasticity shown on the fatigue curve divided by the modulus of elasticity used in the analysis. Since the modulus of elasticity used in analyses is at operating temperature and the modulus of elasticity decreases with temperature, the multiplication factor is greater than 1.0.

4. Changes in modulus of elasticity values. Values of the modulus of elasticity for 
carbon steel have been increased in later editions of the Code. This will result in higher thermal stresses for piping. For example, for SA-333 Grade 6 material:

\begin{tabular}{ccc}
\hline $\begin{array}{c}\text { Modulus of } \\
\text { elasticity } \\
\left({ }^{\circ} \mathrm{F}\right)\end{array}$ & $\begin{array}{c}\text { Modulus of } \\
\text { elasticity } \\
\text { (x 106 } \mathrm{psi}) \\
1979\end{array}$ & 1992 \\
\hline 70 & 27.9 & 29.5 \\
200 & 27.7 & 28.8 \\
300 & 27.4 & 28.3 \\
400 & 27.0 & 27.7 \\
500 & 26.4 & 27.3 \\
600 & 25.7 & 26.7 \\
\hline
\end{tabular}

5. Changes to coefficient of thermal expansion values. Similar to example 4 , the values of the coefficients of thermal expansion $(\alpha)$ have changed in later Code editions. For example, the $\alpha$ for SA-333 Grade B carbon steel at $70^{\circ} \mathrm{F}$ has been increased from $6.07 \times 10^{-6} \mathrm{in} / \mathrm{in} /{ }^{\circ} \mathrm{F}$ in the 1971 edition of the Code to $6.41 \times 10^{-6} \mathrm{in} / \mathrm{in} /{ }^{\circ} \mathrm{F}$ in the current edition. Consequently, E $\alpha$ for SA-333 Grade B carbon steel at $70^{\circ} \mathrm{F}$ is currently 189.1 versus 169.4 in the 1971 Code edition (and 198.1 versus 185.8 at $600^{\circ} \mathrm{F}$ ). This will result in higher thermal stresses for piping.

6. Actual cycles. The number of current cycles extrapolated to 40 years exceeds the design basis numbers for some BWR plant transients.

7. Transient definition. Analyses for older vintage plants do not have the design cycles defined in detail as specifically as newer vintage plants. In addition, some transient assumptions (for example, BWR feedwater system thermal cycling during startup) may not be adequately defined for older vintage plants.

8. Changes in $\mathbf{S}_{\mathbf{m}}$ values. For some materials, the value of $S_{m}$ is lower in later editions of the Code. The $3 S_{m}$ allowable limit for primary plus secondary stress intensity range would be lower; and for cases where a $\mathrm{K}_{\mathrm{e}}$ factor is used, dividing by a lower $3 S_{\mathrm{m}}$ will result in a higher $S_{\text {alt }}$. As an example, for SA-182 F316 stainless steel:

\begin{tabular}{ccc}
\hline $\begin{array}{c}\text { Temperature } \\
\left({ }^{\circ} \mathrm{F}\right)\end{array}$ & $\begin{array}{c}\mathrm{S}_{\mathrm{m}}(\mathrm{ksi}) \\
1968\end{array}$ & $\begin{array}{c}\mathrm{S}_{\mathrm{m}}(\mathrm{ksi}) \\
1992\end{array}$ \\
\hline 70 & 20 & 20 \\
200 & 20 & 20 \\
300 & 20 & 20 \\
400 & 19.4 & 19.3 \\
500 & 18.2 & 18 \\
600 & 17.1 & 17 \\
\hline
\end{tabular}

9. Changes in the $\mathbf{K}_{\mathbf{e}}$ equation for piping calculations. In most analyses that used older versions of NB-3600 and B31.7 for piping, it appears that elimination of the $\Delta T_{1}$ term from the primary plus secondary stress intensity range term for calculating $\mathrm{K}_{\mathrm{e}}$ will significantly reduce $S_{a l t}$. This is because typically the maximum $\Delta T_{1}, \Delta T_{2}$, and $T_{a}-T_{b}$ terms were used regardless of their time phasing. However, in some analyses, particularly recently, we have observed instances where the $\Delta T_{1}, \Delta T_{2}$, and $T_{a}-T_{b}$ terms are taken at the same time; consequently, this conservatism has been eliminated. In some cases the stress associated with the $T_{a}-T_{b}$ term is far greater than the stress associated with the $\Delta T_{1}$ term, so eliminating the $\Delta T_{1}$ term changes the primary plus secondary stress intensity range minimally. The value of $\mathrm{K}_{\mathrm{e}}$ calculated using the current edition of the Code is greater than would be the penalty factor calculated using older versions (see item 10 below). Therefore, in these cases, analyses performed to the earlier Code editions would result in a lower CUF than calculations performed to the current Code edition.

10. Changes in the $K_{e}$ equation for nozzle calculations. Similar to item 9 above, the thermal stresses for a nozzle, analyzed to B31.7-1969, were computed using a finite element analysis. Since the primary plus 
secondary stress intensity range exceeded $3 S_{\mathrm{m}}$, a simplified elastic-plastic analysis was used. The B31.7 penalty factor $\left(K_{f}\right.$ times $K_{e}$ ) for four load pairs ranged from 2.51 to 3.36, whereas the $K_{e}$ factor using the current Code edition would be 3.33 for all four load pairs.

11. Changes in the material constant values in the $K_{e}$ equation. In an analysis in the 1965-1970 time frame, before the current simplified elastic-plastic analysis procedure was incorporated in the ASME Code, the same formulas were used based on technical papers published in the late 1960s. However, a value of $\mathrm{n}=0.5$ for stainless steel was used instead of the value in the ASME Code of $n=0.3$. Consequently, $a K_{e}$ factor of 1.25 was calculated, whereas a value of 1.57 results from using $\mathbf{n}=0.3$.

12. Changes to stress indices. In NB-3683.5(b) of the present Code edition, the $\mathrm{C}_{3}$ index for transitions with a $1: 3$ slope contains a +0.25 term that was not present in earlier (for example 1980) editions. 


\section{COMPONENT EVALUATIONS}

The evaluations for six components for each of the seven plants surveyed are described in Sections 5.1 through 5.7.

\subsection{Newer Vintage Combustion Engineering Plant}

A comparison of the design CUFs from the licensee's design basis calculations and CUFs using the NUREG/CR-5999 interim fatigue curves was carried out for the locations of highest design CUF for the six components listed below:

1. Reactor vessel shell and lower head

2. Reactor vessel inlet and outlet nozzles

3. Surge line

4. Charging system nozzle

5. Safety injection system nozzle

6. Shutdown cooling line.

As of early 1994, the plant has been operated approximately 10 of the 40 years currently approved in its operating license. Table 5-1 shows the design basis cycles for transients that are important from a fatigue standpoint for the six components that were evaluated. The numbers of transients to date (in some cases estimated by the licensee and the INEL staff) have been extrapolated to 40 years by multiplying by $40 / 10$.

A fatigue monitoring system has been installed on the charging and safety injection systems. The results were used to estimate the numbers of loss of letdown, loss of charging, and safety injection test cycles in Table 5-1. The results of a generic Combustion Engineering plant study of thermal stratification in surge lines was included in the licensee's fatigue analysis of the surge line. The licensee supplied no plant specific data to remove conservative assumptions for this particular plant.

\subsubsection{Reactor Vessel Shell and Lower}

Head. The highest usage factor on the shell and lower head is at the lower head support lugs on the outside diameter (OD) of the reactor vessel. However, since this location is on the outer wall, it is not in contact with the primary coolant and thus is not subject to full environmental fatigue effects. There are no lower head penetrations that might result in high stress concentrations causing high CUFs. The location with the highest CUF on the interior wall is at the juncture of the shell and a tapered section joining it to the lower head [the shell (cylindrical shape) must have approximately twice the thickness as that of the lower head (hemispherical shape) for the same pressureinduced stress level]. The CUF at this location

Table 5-1. Number of selected design basis transients compared to anticipated number of transients over 40-year license life.

\begin{tabular}{lcc}
\hline \multicolumn{1}{c}{ Transient } & Design basis cycles & $\begin{array}{c}\text { Anticipated cycles } \\
\text { for 40 years }\end{array}$ \\
\hline Heatup & 500 & 90 \\
Cooldown & 500 & 90 \\
Reactor trip & 480 & 150 \\
Loss of letdown & 100 & 40 \\
Loss of charging & 100 & 12 \\
Safety injection test & 260 & 100 \\
Leak test & 200 & 115 \\
\hline
\end{tabular}


is calculated for the SA-533 Grade B, Class 1 shell, but in reality it is protected from the coolant by a layer of stainless steel cladding. No fatigue analysis is performed for the cladding.

\subsubsection{NUREG/CR-5999 CUF Based on Licensee's Design Calculation} Stresses. The highest CUF on the interior of the reactor vessel shell in the region of interest was determined to be approximately 0.007 from the licensee's design basis calculations. The effect of the NUREG/CR-5999 interim fatigue curves is shown in Table 5-2. As previously discussed, the results shown in Table 5-2 assume that the coolant was in contact with the low-alloy steel base metal underneath the cladding. The licensee's CUF calculations used the ASME Code, Section III, 1971 edition. The $S_{\text {att }}$ values shown in Table 5-2 have already been adjusted in the licensee's analysis for the effect of the modulus of elasticity by multiplying by $30 / 27$ (the ratio of the modulus of elasticity on the fatigue curve to that used in the analysis) as required by the ASME Code.

Application of the NUREG/CR-5999 interim fatigue curve increased the CUF by a factor of 2.00 over the design basis number. If the plant is operated for 60 years, the CUF remains very low (0.021), and would not exceed the ASME Code limit of 1.0.

\subsubsection{NUREG/CR-5999 CUF with Con-} servative Assumptions Removed. Since the CUF would not exceed 1.0 if the plant is operated for 60 years, no additional calculations were performed.

\subsubsection{Reactor Vessel Inlet and Outlet Nozzles}

5.1.2.1 Inlet Nozzle CUF Using
NUREG/CR-5999 and Licensee's Design
Calculation Stresses. The licensee's design calculations show that the highest CUF for the reactor vessel inlet nozzle is located at a thickness discontinuity where the nozzle is welded to the reactor vessel. The design calculations show the CUF for the inner wall (which will be subjected to the reactor coolant fluid environmental effects) is 0.182 . The CUF at the inner wall was calculated for the low-alloy steel (SA-508 Class 2) base metal, but in reality it is protected from the coolant by a layer of stainless steel cladding. As previously discussed, no fatigue analysis was performed for the cladding. The effect of the NUREG/CR-5999 interim fatigue curve was calculated assuming the coolant was in contact with the low-alloy steel base metal underneath the cladding.

The licensee's design CUF calculations used the ASME Code, Section III, 1971 edition. In this case the reported $S_{\text {alt }}$ values were not adjusted for the effect of the modulus of elasticity, ${ }^{a}$ so they were multiplied by $30 / 27$ (the ratio of the modulus of elasticity on the fatigue curve to that used in

a. The licensee's analysis presents the $S_{\text {alt }}$ values before the correction for the modulus of elasticity. The design basis calculations made the correct adjustment for the modulus of elasticity in obtaining the allowable cycles from the ASME Code fatigue curves, but the adjusted $S_{\text {alt }}$ values were not reported.

Table 5-2. CUF results for reactor vessel shell/lower head region using NUREG/CR-5999 interim fatigue curve.

\begin{tabular}{lcrcc}
\hline \multicolumn{1}{c}{ Load pair } & $\mathrm{S}_{\text {alt }}$ & $\mathrm{N}$ & $\mathrm{n}$ & $\mathrm{u}$ \\
\hline Cooldown/step load increase & 27.11 & 17017 & 200 & 0.012 \\
Heatup/cooldown & 16.22 & 171407 & 300 & 0.002 \\
Leak test/heatup & 10.12 & $2.5 \times 10^{6}$ & 200 & 0.000 \\
& & & $\mathrm{CUF}$ & 0.014 \\
\hline
\end{tabular}


the analysis) as required by the ASME Code. The effect of the NUREG/CR-5999 interim fatigue curve (with the adjusted $S_{\text {alt }}$ values) is shown in Table 5-3.

The results indicate that the CUF increased by a factor of 2.61 over the design basis number. If the plant is operated for 60 years, the CUF is 0.712 , and does not exceed the ASME Code limit of 1.0 .

\subsubsection{Outlet Nozzle CUF Using NUREG/CR-5999 and Licensee's Design Calculation Stresses. The licensee's design} calculations indicated that the highest CUF for the reactor vessel outlet nozzle is at a thickness discontinuity where the smaller nozzle end welded to the reactor coolant piping joins the larger nozzle end that is welded to the reactor vessel. The design CUFs for the inner and outer wall at this joint were found to be 0.334 and 0.377 , respectively. The design CUF is highest at the outer wall (a point which is not in contact with the reactor coolant).

The detailed calculations for the CUF, showing individual usages for the various load pairs, are for the point of maximum usage, which is on the outer wall. A detailed usage calculation for the inner wall was not in the report, just the overall CUF (0.334) summed from the individual load pairs. However, the design CUFs for the inner and outer wall were about the same (the inner wall CUF is about $10 \%$ less than the outer wall), so calculating the effect of the NUREG/CR-5999 interim fatigue curve for the outer wall should be representative, and perhaps slightly conservative for the inner wall CUF. The CUF calculations used the ASME Code, Section III, 1971 edition. In this case the reported $S_{\text {alt }}$ values were not adjusted for the effect of modulus of elasticity, ${ }^{b}$ so they were multiplied by $30 / 27$ (the ratio of the modulus of elasticity on the fatigue curve to that used in the analysis) as required by the ASME Code. The effect of the NUREG/CR-5999 interim fatigue curve (with the adjusted $S_{\text {alt }}$ values) is shown in Table 5-4. (Some of the load pairs were difficult to read on the copy of the original analysis).

The results indicate that the CUF increased by a factor of 2.21 over the licensee's design basis number. The CUF is below the ASME Code limit of 1.0 for the 40-year design life, but would exceed the ASME Code limit if the design cycles are extrapolated to 60 years $(\mathrm{CUF}=1.253$ for 60 years). The CUF at the outside surface was used to assess the effect of the NUREG/CR-5999 interim fatigue curves. If the design-basis CUF for the inside surface were used, the CUF using the NUREG/CR-5999 interim fatigue curves is

b. The licensee's analysis presents the $S_{\text {alt }}$ values before the correction for the modulus of elasticity. The design basis calculations made the correct adjustment for the modulus of elasticity in obtaining the allowable cycles from the ASME Code fatigue curve, but the adjusted $S_{\text {alt }}$ values were not reported.

Table 5-3. CUF results for reactor vessel inlet nozzle using NUREG/CR-5999 interim fatigue curve.

\begin{tabular}{lccccc}
\hline \multicolumn{1}{c}{ Load pair } & $\mathrm{S}_{\text {alt }}$ & $\mathrm{S}_{\text {alt }}$ (adjusted) & $\mathrm{N}$ & $\mathrm{n}$ & $\mathrm{u}$ \\
\hline Heatup/leak test & 54.43 & 60.47 & 869 & 200 & 0.230 \\
Heatup/reactor trip & 43.21 & 48.01 & 1928 & 300 & 0.156 \\
Cooldown/reactor trip & 33.27 & 36.96 & 5382 & 180 & 0.033 \\
Cooldown/OBE & 32.82 & 36.46 & 5676 & 320 & 0.056 \\
OBE/OBE & 1.9 & 2.11 & $>10^{6}$ & 200 & 0.000 \\
\cline { 4 - 6 } & & & & CUF & 0.475 \\
\hline
\end{tabular}


Table 5-4. CUF results for reactor vessel outlet nozzle using NUREG/CR-5999 interim fatigue curve.

\begin{tabular}{lccrrr}
\hline \multicolumn{1}{c}{ Load pair } & $\mathrm{S}_{\text {alt }}$ & $\mathrm{S}_{\text {alt }}$ (adjusted) & \multicolumn{1}{c}{$\mathrm{N}$} & \multicolumn{1}{c}{$\mathrm{n}$} & \multicolumn{1}{c}{$\mathrm{u}$} \\
\hline Cooldown/plant load & 46.36 & 51.51 & 1458 & 500 & 0.343 \\
Leak test/plant unload & 45.77 & 50.85 & 1534 & 200 & 0.130 \\
Heatup/plant load & 35.32 & 39.24 & 4263 & 500 & 0.117 \\
Plant load/unload & 18.76 & 20.84 & 58406 & 13800 & 0.236 \\
Plant unload/upset & 17.84 & 19.82 & 73899 & 480 & 0.007 \\
Plant unload/OBE & 12.89 & 14.32 & 265677 & 200 & 0.001 \\
Plant unload/step load & 11.44 & 12.71 & 729360 & 520 & 0.001 \\
& & & & CUF & 0.835 \\
\hline
\end{tabular}

estimated to be $0.738(0.334 \times 2.21),{ }^{\mathrm{c}}$ for which the same general conclusions would be reached.

\subsubsection{Outlet Nozzle CUF Using} NUREG/CR-5999 and Removing Conservative Assumptions. The results described above indicate that the estimated CUF for the outlet nozzle would exceed 1.0 for 60 years. To remove conservatism from these calculations, the number of transient cycles assumed in the licensee's design calculations were examined and compared to the actual number experienced during operation (approximately 10 years) extrapolated to the end of the currently approved 40-year license period. These numbers are compared in Table 5-1 for the transients supplied by the licensee.

If the heatup and cooldown cycles are reduced from 500 to 90 , then 410 cycles are eliminated from both load pairs 1 and 3 (cooldown/plant load and heatup/plant load) and the 820 cycles are added into load pair 4 (plant load/unload). The heatup and cooldown cases represent the thermal transient from room temperature to operating temperature and return. The load and unload cases represent power loading from 0 to $100 \%$ and

c. The design basis CUF for the inside surface is 0.334 and applying the same increase in CUF as was calculated for the outside surface (2.21), the estimated CUF for the inside surface is 0.738 . return. The adjusted CUF is shown in Table 5-5. When projected to 60 years, the CUF shown in Table $5-5$ is 0.708 .

5.1.3 Surge Line. The latest fatigue analyses for the SA-376, Type 316 stainless steel surge line were performed by a consulting firm to assess thermal stratification conditions as required by NRC Bulletin 88-11. The highest design CUFs were 0.993 on the inside diameter of the liquid sample line, 0.767 on the inside diameter of the hot leg nozzle, and 0.981 on the inside diameter of the piping elbow directly above the hot leg nozzle. Thus the highest design CUF on the surge line itself is 0.981 .

\subsubsection{Surge Line CUF Using NUREG/ CR-5999 and Licensee's Design Calcula- tion Stresses. The CUF calculations used the ASME Code, 1986 edition. The $S_{\text {alt }}$ values were not adjusted for the effect of the modulus of elas- ticity, since NB-3653.4 of the ASME Code does not call for an adjustment of the modulus of elas- ticity. The CUF using the NUREG/CR-5999 in- terim fatigue curve is shown in Table 5-6. Transients 8 a through $8 \mathrm{f}, 9 \mathrm{a}$ through $9 \mathrm{f}, 11$ through 18, and 28 in Table 5-6 are associated with heatups and cooldowns.}

Application of the NUREG/CR-5999 interim fatigue curve increased the CUF by a factor of 8.85 over the licensee's design basis number. The CUF exceeds the ASME Code limit of 1.0. 
Table 5-5. CUF results for reactor vessel outlet nozzle using NUREG/CR-5999 interim fatigue curve and anticipated cycles.

\begin{tabular}{lccrrr}
\hline \multicolumn{1}{c}{ Load pair } & $\mathrm{S}_{\text {alt }}$ & $\mathrm{S}_{\text {alt }}$ (adjusted) & \multicolumn{1}{c}{$\mathrm{N}$} & \multicolumn{1}{c}{$\mathrm{n}$} & $\mathrm{u}$ \\
\hline Cooldown/plant load & 46.36 & 51.51 & 1458 & 90 & 0.062 \\
Leak test/plant unload & 45.77 & 50.85 & 1534 & 200 & 0.130 \\
Heatup/plant load & 35.32 & 39.24 & 4263 & 90 & 0.021 \\
Plant load/unload & 18.76 & 20.84 & 58406 & 14620 & 0.250 \\
Plant unload/upset & 17.84 & 19.82 & 73899 & 480 & 0.007 \\
Plant unload/OBE & 12.89 & 14.32 & 265677 & 200 & 0.001 \\
Plant unload/step load & 11.44 & 12.71 & 729360 & 520 & 0.001 \\
& & & & CUF & 0.472 \\
\hline
\end{tabular}

\begin{abstract}
5.1.3.2 Surge Line CUF Using NUREG/ CR-5999 and Removing Conservative Assumptions. The design fatigue calculations were completed only recently, using a later version of the ASME Code. The transients are complicated because of the treatment of thermal stratification. There were no apparent conservative assumptions used in the licensee's analysis methods. However, fatigue monitoring of the surge line on a constant basis would give a more accurate representation of the numbers and severity of thermal stratification cycles. While the licensee's analysis used the number of transients originally assumed for the plant design, use of actual transient data, both numbers of occurrences and temperatures, would no doubt reduce the CUF.
\end{abstract}

Using the anticipated cycles for 40 years shows that the CUF could be reduced. From Table 5-1, the extrapolated number of heatup and cooldown cycles is 90 , and the number of anticipated leak test cycles is 115 . Transients $8 \mathrm{a}$ through $8 \mathrm{f}, 9 \mathrm{a}$ through 9f, 11 through 18, and 28 in Table 5-6 are associated with heatups and cooldowns. The design cycles for each of these transients were multiplied by $0.18(90 / 500)$, to estimate the anticipated usage in 40 years. The number of leak tests was lowered to 115 . Since the complete stress analysis was not available, only a portion of the load pairs could be adjusted, so conservative assumptions remain. For example, the heatup/ cooldown cycles paired with OBE were reduced down to transient $8 \mathrm{~d}-\mathrm{OBE}$, but since this was the lowest stress load pair containing the OBE transient, all 1248 remaining OBE cycles were placed into load pair 8d-OBE, although transient $8 \mathrm{~d}$ does not have this many design cycles.

The results of our CUF calculations using the adjusted numbers of transients are shown in Table 5-7. When projected to 60 years, the CUF is 5.214. The 3.476 CUF could probably be reduced down to about 3.0 if additional conservative assumptions were removed from the load pairs. Further reductions in the numbers of anticipated cycles could probably be made, for example, in the numbers of OBE cycles. However, to reduce the CUF below 1.0, an NB-3200 analysis and/or more extensive fatigue monitoring and precise cycle counting would probably be required. A summary of further actions that could be taken to potentially reduce the CUF is shown in Table 5-8.

\subsubsection{Surge Line CUF Using Revised} Interim Fatigue Curves. From a review of the licensee's stress analysis, it appears that the strain rates from all transients were low with the exception of the upset and slug flow transients. Since the contribution of the individual fatigue usages from these events was less than $1 \%$ of the CUF, the $0.001 \% / \mathrm{s}$ curve was used for all load pairs. The results of applying the revised curves are shown in Table 5-9. The extrapolated CUF for 60 years is 3.896 . 
Component Evaluations

Table 5-6. CUF results for the surge line using NUREG/CR-5999 interim fatigue curve.

\begin{tabular}{|c|c|c|c|c|}
\hline Load pair & $S_{\text {alt }}$ & $\mathrm{N}$ & $\mathrm{n}$ & $\mathbf{u}$ \\
\hline Hydro-extreme & 190.17 & 43 & 6 & 0.140 \\
\hline $8 a-O B E$ & 163.18 & 62 & 75 & 1.210 \\
\hline $9 \mathrm{~b}-\mathrm{OBE}$ & 162.06 & 63 & 75 & 1.187 \\
\hline 9a-hydro & 138.05 & 92 & 4 & 0.043 \\
\hline $8 \mathrm{~b}-\mathrm{OBE}$ & 127.94 & 111 & 75 & 0.673 \\
\hline $9 \mathrm{a}-\mathrm{OBE}$ & 127.04 & 113 & 71 & 0.626 \\
\hline $8 \mathrm{c}-\mathrm{OBE}$ & 64.76 & 571 & 375 & 0.657 \\
\hline $9 \mathrm{f}-\mathrm{OBE}$ & 64.17 & 584 & 375 & 0.642 \\
\hline $8 f-18$ & 63.39 & 611 & 375 & 0.614 \\
\hline $9 c-11$ & 63.38 & 611 & 375 & 0.614 \\
\hline 8d-OBE & 54.02 & 1600 & 394 & 0.246 \\
\hline $8 g-18$ & 52.38 & 1927 & 125 & 0.065 \\
\hline $8 g-17$ & 52.35 & 1933 & 150 & 0.078 \\
\hline $8 g-11$ & 52.35 & 1933 & 125 & 0.065 \\
\hline 8d-leak test & 52.26 & 1953 & 6 & 0.003 \\
\hline 9g-leak test & 52.26 & 1953 & 194 & 0.099 \\
\hline $9 d-17$ & 51.76 & 2070 & 350 & 0.169 \\
\hline 9g-upset 4 & 51.24 & 2200 & 40 & 0.018 \\
\hline $8 h-9 g$ & 51.18 & 2215 & 166 & 0.075 \\
\hline $9 d-12$ & 50.96 & 2273 & 50 & 0.022 \\
\hline $2 a-8 e$ & 40.10 & 9620 & 500 & 0.052 \\
\hline $8 h-9 h$ & 40.09 & 9635 & 334 & 0.035 \\
\hline $9 h-10 a$ & 40.09 & 9635 & 166 & 0.017 \\
\hline $9 e-12$ & 39.91 & 9899 & 450 & 0.045 \\
\hline $9 e-13$ & 39.82 & 10035 & 50 & 0.005 \\
\hline $3 b-13$ & 39.03 & 11321 & 450 & 0.040 \\
\hline 16-slug 2 & 38.94 & 11480 & 500 & 0.044 \\
\hline Upset 3-slug 1 & 38.82 & 11695 & 30 & 0.003 \\
\hline $3 b-10 a$ & 33.10 & 30525 & 3670 & 0.120 \\
\hline $3 a-10 a$ & 33.10 & 30525 & 4120 & 0.135 \\
\hline $6-10 a$ & 33.10 & 30525 & 200 & 0.007 \\
\hline $7-10 a$ & 33.10 & 30525 & 4580 & 0.150 \\
\hline 2a-slug 1 & 32.87 & 31836 & 70 & 0.002 \\
\hline $5-10 a$ & 29.90 & 56289 & 9400 & 0.167 \\
\hline $4 b-10 a$ & 29.90 & 56289 & 17040 & 0.303 \\
\hline $4 a-10 a$ & 29.90 & 56289 & 17040 & 0.303 \\
\hline $2 a-10 a$ & 20.60 & $>10^{8}$ & 14430 & 0.000 \\
\hline $2 b-10 a$ & 20.60 & $>10^{8}$ & 15000 & 0.000 \\
\hline 10a-upset 2 & 20.60 & $>10^{8}$ & 95 & 0.000 \\
\hline $1 b-10 a$ & 20.60 & $>10^{8}$ & 1969 & 0.000 \\
\hline \multirow[t]{2}{*}{$1 b-10 b$} & 20.00 & $>10^{8}$ & 87710 & 0.001 \\
\hline & & & CUF & 8.684 \\
\hline
\end{tabular}


Table 5-7. CUF results for the surge line using NUREG/CR-5999 interim fatigue curve and anticipated cycles.

\begin{tabular}{|c|c|c|c|c|}
\hline Load pair & $S_{\text {alt }}$ & $\mathrm{N}$ & $\mathrm{n}$ & $\mathbf{u}$ \\
\hline Hydro-extreme & 190.17 & 43 & 6 & 0.140 \\
\hline $8 \mathrm{a}-\mathrm{OBE}$ & 163.18 & 62 & 14 & 0.226 \\
\hline $9 b-O B E$ & 162.06 & 63 & 14 & 0.222 \\
\hline 9a-hydro & 138.05 & 92 & 4 & 0.043 \\
\hline $8 \mathrm{~b}-\mathrm{OBE}$ & 127.94 & 111 & 14 & 0.126 \\
\hline $9 a-O B E$ & 127.04 & 113 & 10 & 0.088 \\
\hline $8 c-O B E$ & 64.76 & 571 & 68 & 0.119 \\
\hline $9 f-O B E$ & 64.17 & 584 & 68 & 0.116 \\
\hline $8 f-18$ & 63.39 & 611 & 68 & 0.111 \\
\hline $9 c-11$ & 63.38 & 611 & 68 & 0.111 \\
\hline 8d-OBE & 54.02 & 1600 & 1248 & 0.780 \\
\hline $8 g-18$ & 52.38 & 1921 & 23 & 0.011 \\
\hline $8 g-11$ & 52.35 & 1933 & 23 & 0.011 \\
\hline $8 g-17$ & 52.35 & 1933 & 27 & 0.014 \\
\hline 8d-leak test & 52.26 & 1953 & 6 & 0.003 \\
\hline $9 \mathrm{~g}$-leak test & 52.26 & 1953 & 109 & 0.056 \\
\hline $9 d-17$ & 51.76 & 2070 & 63 & 0.030 \\
\hline 9g-upset 4 & 51.24 & 2200 & 40 & 0.018 \\
\hline $8 h-9 g$ & 51.18 & 2215 & 30 & 0.014 \\
\hline $9 d-12$ & 50.96 & 2273 & 9 & 0.004 \\
\hline $2 a-8 e$ & 40.10 & 9620 & 90 & 0.009 \\
\hline $8 \mathrm{~h}-9 \mathrm{~h}$ & 40.09 & 9635 & 0 & 0.000 \\
\hline $9 \mathrm{~h}-10 \mathrm{a}$ & 40.09 & 9635 & 90 & 0.009 \\
\hline $9 e-12$ & 39.91 & 9899 & 81 & 0.008 \\
\hline $9 e-13$ & 39.82 & 10035 & 9 & 0.001 \\
\hline $3 b-13$ & 39.03 & 11321 & 81 & 0.007 \\
\hline 16-slug 2 & 38.94 & 11480 & 90 & 0.008 \\
\hline Upset 3-slug 1 & 38.82 & 11695 & 30 & 0.003 \\
\hline $3 b-10 a$ & 33.10 & 30525 & 3670 & 0.120 \\
\hline $3 a-10 a$ & 33.10 & 30525 & 4120 & 0.135 \\
\hline $6-10 a$ & 33.10 & 30525 & 200 & 0.007 \\
\hline $7-10 a$ & 33.10 & 30525 & 4580 & 0.150 \\
\hline 2a-slug 1 & 32.87 & 31834 & 70 & 0.002 \\
\hline $5-10 a$ & 29.90 & 56289 & 9400 & 0.167 \\
\hline $4 b-10 a$ & 29.90 & 56289 & 17040 & 0.303 \\
\hline $4 a-10 a$ & 29.90 & 56289 & 17040 & 0.303 \\
\hline $2 a-10 a$ & 20.60 & $>10^{8}$ & 14430 & 0.000 \\
\hline $2 b-10 a$ & 20.60 & $>10^{8}$ & 15000 & 0.000 \\
\hline 10a-upset 2 & 20.60 & $>10^{8}$ & 95 & 0.000 \\
\hline $1 b-10 a$ & 20.60 & $>10^{8}$ & 1969 & 0.000 \\
\hline \multirow[t]{2}{*}{$1 b-10 b$} & 20.00 & $>10^{8}$ & 87710 & 0.001 \\
\hline & & & CUF & 3.476 \\
\hline
\end{tabular}


Table 5-8. Potential for elimination of conservative assumptions to reduce CUF for surge line elbow using NUREG/CR-5999 interim fatigue curve.

\begin{tabular}{lccl}
\hline \multicolumn{1}{c}{$\begin{array}{c}\text { Assumption } \\
\text { Section 4.3) }\end{array}$} & $\begin{array}{c}\text { Potential } \\
\text { for use }\end{array}$ & Used & \multicolumn{1}{c}{ Comments } \\
\hline Correct CUF calculation & No & No & Analysis appear to be correct \\
Detailed load pairs & No & No & Detailed load pairs were used \\
SCF/FSRF & No & No & Values appear reasonable \\
$S_{\mathrm{m}}$ value & No & No & Average $S_{\mathrm{m}}$ values used \\
Material property & No & No & No changes, 1986 Code edition used \\
changes & & & \\
Fatigue curve E value & No & No & Proper adjustment was made \\
Code analysis changes & No & No & No changes, 1986 Code edition used \\
Actual cycles & Yes & Yes & Adjustment was made for projected cycles \\
High temperature rates & Yes & No & Actual rates may be less than design \\
Detailed stress modeling & Yes & No & NB-3600 analysis used \\
Conservative thermal & Yes & No & Insufficient information \\
parameters & & & \\
Time phasing of stresses & Yes & No & Highest moment and thermal stresses may not occur \\
& & & simultaneously \\
Number of OBEs & Yes & No & OBEs contribute to CUF \\
CC N-4l1 damping & Yes & No & Insufficient information \\
Number of hydrotests & Yes & No & Hydrotests contribute to CUF \\
Fatigue monitoring & Yes & No & Actual transients probably less severe than design \\
Plastic analysis & Yes & No & Elastic plastic finite element analysis could be used \\
\hline
\end{tabular}

5.1.4 Charging System Nozzle. The nozzle consists of a low-alloy steel (SA-182, Grade F1) forging and a stainless steel (SA-182, F316) safe end. The highest design CUF for the nozzle forging is 0.050 near the knuckle on the inside surface, and 0.778 for the safe end on the inside surface near the weld to the charging line. The low-alloy steel nozzle is clad with a layer of stainless steel and therefore is not in direct contact with the reactor coolant; however, no fatigue analysis was performed for the cladding. The stainless steel safe end is in direct contact with the reactor coolant.

\subsubsection{Charging System Nozzle Forg-} ing CUF Using NUREG/CR-5999 and Licensee's Design Calculation Stresses. The licensee's design CUF calculations used the ASME Code, Section III, 1971 edition, through
Summer 1972 addenda. The $S_{\text {alt }}$ values were adjusted for the effect of the modulus of elasticity. The CUF results using the NUREG/CR-5999 interim fatigue curve are included in Table 5-10. The null case represents the condition with no load, that is, cold shutdown.

Application of the NUREG/CR-5999 interim fatigue curve increased the CUF by a factor of 2.08 over the licensee's design basis number. If the plant is operated for 60 years, the CUF is 0.156, which does not exceed the ASME Code limit of 1.0 .

\subsubsection{Charging System Safe End CUF} Using NUREG/CR-5999 and Licensee's Design Calculation Stresses. The licensee's design CUF calculations used the ASME Code, Section III, 1971 edition through Summer 1972 addenda. The $S_{\text {alt }}$ values were adjusted for the 
Table 5-9. CUF results for the surge line using revised interim fatigue curves and anticipated cycles.

\begin{tabular}{|c|c|c|c|c|}
\hline Load pair & $S_{\text {alt }}$ & $\mathrm{N}$ & $\mathbf{n}$ & $\mathbf{u}$ \\
\hline Hydro-extreme & 190.17 & 34 & 6 & 0.176 \\
\hline $8 \mathrm{a}-\mathrm{OBE}$ & 163.18 & 50 & 14 & 0.280 \\
\hline $9 b-O B E$ & 162.06 & 50 & 14 & 0.280 \\
\hline 9a-hydro & 138.05 & 76 & 4 & 0.053 \\
\hline $8 b-O B E$ & 127.94 & 93 & 14 & 0.151 \\
\hline $9 a-O B E$ & 127.04 & 95 & 10 & 0.105 \\
\hline $8 c-O B E$ & 64.76 & 857 & 68 & 0.079 \\
\hline $9 f-O B E$ & 64.17 & 891 & 68 & 0.076 \\
\hline $8 f-18$ & 63.39 & 939 & 68 & 0.072 \\
\hline $9 c-11$ & 63.38 & 940 & 68 & 0.072 \\
\hline 8d-OBE & 54.02 & 2034 & 1248 & 0.614 \\
\hline $8 g-18$ & 52.38 & 2420 & 23 & 0.010 \\
\hline $8 g-11$ & 52.35 & 2428 & 23 & 0.009 \\
\hline $8 g-17$ & 52.35 & 2428 & 27 & 0.011 \\
\hline 8d-leak test & 52.26 & 2452 & 6 & 0.002 \\
\hline 9g-leak test & 52.26 & 2452 & 109 & 0.044 \\
\hline $9 d-17$ & 51.76 & 2594 & 63 & 0.024 \\
\hline 9g-upset 4 & 51.24 & 2756 & 40 & 0.015 \\
\hline $8 h-9 g$ & 51.18 & 2776 & 30 & 0.011 \\
\hline $9 d-12$ & 50.96 & 2849 & 9 & 0.003 \\
\hline $2 a-8 e$ & 40.10 & 23752 & 90 & 0.004 \\
\hline $8 h-9 h$ & 40.09 & 23780 & 0 & 0.000 \\
\hline $9 h-10 a$ & 40.09 & 23780 & 90 & 0.004 \\
\hline $9 e-12$ & 39.91 & 24281 & 81 & 0.003 \\
\hline $9 e-13$ & 39.82 & 24538 & 9 & 0.000 \\
\hline $3 b-13$ & 39.03 & 26977 & 81 & 0.003 \\
\hline 16 -slug 2 & 38.94 & 27278 & 90 & 0.003 \\
\hline Upset 3-slug 1 & 38.82 & 27688 & 30 & 0.001 \\
\hline $3 b-10 a$ & 33.10 & 67160 & 3670 & 0.055 \\
\hline $3 a-10 a$ & 33.10 & 67160 & 4120 & 0.061 \\
\hline $6-10 a$ & 33.10 & 67160 & 200 & 0.003 \\
\hline $7-10 a$ & 33.10 & 67160 & 4580 & 0.068 \\
\hline 2a-slug 1 & 32.87 & 70293 & 70 & 0.001 \\
\hline $5-10 a$ & 29.90 & 143008 & 9400 & 0.066 \\
\hline $4 b-10 a$ & 29.90 & 143008 & 17040 & 0.119 \\
\hline $4 a-10 a$ & 29.90 & 143008 & 17040 & 0.119 \\
\hline $2 a-10 a$ & 20.60 & $>10^{8}$ & 14430 & 0.000 \\
\hline $2 b-10 a$ & 20.60 & $>10^{8}$ & 15000 & 0.000 \\
\hline 10a-upset 2 & 20.60 & $>10^{8}$ & 95 & 0.000 \\
\hline $1 \mathrm{~b}-10 \mathrm{a}$ & 20.60 & $>10^{8}$ & 1969 & 0.000 \\
\hline \multirow[t]{2}{*}{$1 b-10 b$} & 20.00 & $>10^{8}$ & 87710 & 0.001 \\
\hline & & & CUF & 2.597 \\
\hline
\end{tabular}


Table 5-14. Potential for elimination of conservative assumptions to reduce CUF for charging nozzle safe end using NUREG/CR-5999 interim fatigue curve.

\begin{tabular}{lccl}
\multicolumn{1}{c}{$\begin{array}{c}\text { Assumption } \\
\text { (Section 4.3) }\end{array}$} & $\begin{array}{c}\text { Potential } \\
\text { for use }\end{array}$ & Used & \multicolumn{1}{c}{ Comments } \\
\hline Correct CUF calculation & No & No & Analysis appear to be correct \\
Detailed load pairs & No & No & Detailed load pairs were used \\
SCF/FSRF & No & No & Values appear reasonable \\
S $\mathrm{m}$ value & Yes & Yes & Average $S_{\mathrm{m}}$ values used \\
Material property & No & No & No changes \\
changes & & & \\
Fatigue curve E value & No & No & Proper adjustment was made \\
Code analysis changes & Yes & No & Table 3217-2 stress classification for linear radial \\
& & & thermal gradient changed to peak stress \\
Actual cycles & Yes & Yes & Adjustment was made for projected cycles \\
High temperature rates & Yes & No & Actual rates probably less than design \\
Detailed stress modeling & No & No & Finite element model used \\
Conservative thermal & Yes & No & Insufficient information \\
parameters & & & \\
Time phasing of stresses & No & No & Time phasing not expected to be particularly effective \\
& & & for nozzle \\
Number of OBEs & No & No & OBEs do not contribute to CUF \\
CC N-411 damping & No & No & Dynamic loads do not contribute to CUF \\
Number of hydrotests & No & No & Hydrotests do not contribute to CUF \\
Fatigue monitoring & Yes & No & Actual transients probably less severe than design \\
Plastic analysis & Yes & No & Elastic plastic finite element analysis could be used \\
\hline & & & \\
\hline
\end{tabular}

separate the stresses caused by a radial thermal gradient from those caused by an axial thermal gradient. However, based on our analysis of the charging system nozzle for the older vintage Westinghouse plant (Section 5.5.4) for the controlling transient (loss of letdown/recovery), most of the stress is caused by the radial thermal gradient. Reclassifying the stress caused by a radial thermal gradient as a peak stress could reduce the primary-plus-secondary stress intensity range below the $3 S_{m}$ limit, reducing the $K_{e}$ factor to 1 . This would lower $S_{\text {alt }}$ and no doubt reduce the CUF below 1.0.
5.1.4.4 Charging System Nozzle Safe
End CUF Using Revised Interim Fatigue Curves. The first two load pairs, which make the most significant contributions to the CUF, contain the loss-of-letdown and the loss-of-charging transients, respectively. During these two transients, the increasing tensile portion of the stress cycles occurs. From the licensee's stress calculations, the strain rates were estimated to be 0.222 and $0.232 \% / \mathrm{s}$, respectively. Using these strain rates, the CUF results are shown in Table 5-15. The extrapolated CUF for 60 years is 0.753 . 
Table 5-15. CUF results for the charging system nozzle safe end using revised interim fatigue curves with conservative assumptions removed and anticipated cycles.

\begin{tabular}{lcrrrr}
\hline \multicolumn{1}{c}{ Load pair } & \multicolumn{1}{c}{$\mathrm{S}_{\text {alt }}$} & $\mathrm{S}_{\text {alt }}$ (adjusted) & $\mathrm{N}$ & $\mathrm{n}$ & $\mathrm{u}$ \\
\hline Loss of letdown/recovery & 151.73 & 165.2 & 92 & 40 & 0.435 \\
Loss of charging/reactor trip & 115.54 & 125.8 & 188 & 12 & 0.064 \\
Reactor trip/cooldown & 31.11 & 33.9 & 26881 & 90 & 0.003 \\
Cooldown/purification & 29.34 & 31.9 & 38255 & 90 & 0.000 \\
Purification/reactor trip & 23.53 & 25.6 & 892249 & 0 & 0.000 \\
& & & & CUF & 0.502 \\
\hline
\end{tabular}

\subsubsection{Safety Injection System Nozzle. This} nozzle consists of a low-alloy steel (SA-182, Grade F1) forging and a Type 316 stainless steel safe end. The latest fatigue analysis was performed in 1993 to reflect new conditions caused by detached thermal sleeves on two of the four safety injection lines. The licensee's calculations indicate the highest CUF for the nozzle is 0.898 near the knuckle on the inside surface, and is 0.360 for the safe end. A finite element model was used to determine the temperature distributions in the nozzle, but the stress and fatigue analyses were conducted using the NB-3600 piping methods. No differentiation is made between the inside and outside surfaces in piping analyses; therefore, it was assumed that the maximum CUF determined for the nozzle forging applied to the inside surface and that the stainless steel cladding of the forging would be neglected. However, the stainless steel safe end is in direct contact with the reactor coolant.

\subsubsection{Safety Injection Nozzle Forging CUF Using NUREG/CR-5999 and Licens-} ee's Design Calculation Stresses. The licensee's design CUF calculations used the ASME Code, 1989 edition. The CUF using the licensee's stress values and the NUREG/CR-5999 interim fatigue curve is included in Table 5-16. The several tests referred to consist of tests of the safety injection tank check valve (test 12 ) and variations of partial tests of the isolation and check valves using charging system flow (tests 14, 15, and 16).

Application of the NUREG/CR-5999 interim fatigue curve increased the CUF by a factor of 2.34 over the design basis number. The CUF exceeds the ASME Code limit of 1.0.

\subsubsection{Safety Injection Nozzle Safe End} CUF Using NUREG/CR-5999 and Licensee's Design Calculation Stresses. The licensee's design CUF calculations used the ASME Code, 1989 edition. The $S_{\text {alt }}$ values were adjusted for the effect of the modulus of elasticity. The CUF using the licensee's stress values and the NUREG/CR-5999 interim fatigue curve is included in Table 5-17.

Application of the NUREG/CR-5999 interim fatigue curve increased the CUF by a factor of 8.93 over the design basis number. The CUF exceeds the ASME Code limit of 1.0.

\subsubsection{Safety Injection System Nozzle Forging CUF Using NUREG/ CR-5999 and} Removing Conservative Assumptions. The CUF can be substantially reduced by using the numbers of anticipated transients from Table 5-1. There are 260 safety injection tests which are represented by transients 14,15 , and 16 . The licensee's analysis shows 40 cycles for transients 15 and 16 , and 220 cycles for transient 14 , but uses 
Table 5-16. CUF results for the safety injection nozzle forging using NUREG/CR-5999 interim fatigue curve.

\begin{tabular}{lrrrc}
\hline \multicolumn{1}{c}{ Load pair } & $\mathrm{S}_{\mathrm{alt}}$ & $\mathrm{N}$ & $\mathrm{n}$ & $\mathrm{u}$ \\
\hline Shutdown cooling A/test 15 & 101.57 & 253 & 260 & 1.028 \\
Shutdown cooling B/test 14 & 79.81 & 432 & 260 & 0.602 \\
Shutdown cooling A/OBE & 54.21 & 1222 & 240 & 0.196 \\
Shutdown cooling B/test 12 & 49.22 & 1746 & 240 & 0.137 \\
Heatup/OBE & 35.14 & 6543 & 500 & 0.076 \\
OBE/null & 32.46 & 8469 & 500 & 0.059 \\
OBE/flow test & 30.92 & 10124 & 20 & 0.002 \\
OBE/OBE & 14.00 & 287660 & 180 & 0.001 \\
& & & CUF & 2.101 \\
\hline
\end{tabular}

Table 5-17. CUF results for the safety injection nozzle safe end using NUREG/CR-5999 interim fatigue curve.

\begin{tabular}{lrrrr}
\hline \multicolumn{1}{c}{ Load pair } & $\mathrm{S}_{\text {alt }}$ & $\mathrm{N}$ & $\mathrm{n}$ & $\mathrm{u}$ \\
\hline Test 14/test 15 & 121.67 & 125 & 260 & 2.080 \\
Shutdown cooling A/B & 72.08 & 441 & 500 & 1.134 \\
Reactor trip/flow test & 23.81 & $>10^{6}$ & 20 & 0.000 \\
Heatup/OBE & 15.82 & $>10^{8}$ & 500 & 0.000 \\
& & & CUF & 3.215 \\
\hline
\end{tabular}

260 cycles for each of transients 14,15 , and 16. The anticipated number of tests is 100 . The anticipated heatup and cooldown transients are 90 , compared to a design assumption of 500 . The licensee's estimated cycles for transient 12 (testing the safety injection tank check valve) is 160 , whereas the analysis used 240 cycles. If the load pairings are adjusted to reduce the numbers of cycles, the CUF would be as shown in Table 5-18. If the plant is operated for 60 years, the CUF is 0.686 .

\subsubsection{Safety Injection System Nozzle} Safe End CUF Using NUREG/CR-5999 and Removing Conservative Assumptions. The licensee's analysis assumed that the check valve tests would be conducted at power $\left(553^{\circ} \mathrm{F}\right)$, whereas the licensee stated that they are actually conducted at around $340^{\circ} \mathrm{F}$. Based on a review of the licensee's analysis, it is estimated that the stresses for the first load pair could be reduced as shown in Table 5-19. For tests 14 and 15, a peak stress of 262 psi per degree of thermal shock was calculated. Reducing the thermal shock by $213^{\circ} \mathrm{F}$ (from 553 to $340^{\circ} \mathrm{F}$ ) for each test reduces $\mathrm{S}_{\text {alt }}$ by $55.81 \mathrm{ksi}$ to $65.86 \mathrm{ksi}$.

If the load pairs are adjusted to reduce the numbers of cycles as described for the nozzle in Section 5.1.5.3, the CUF would be as shown in Table 5-20. If the plant is operated for 60 years, the CUF is 0.581 .

\subsubsection{Safety Injection System Nozzle} Safe End CUF Using Revised Interim Fatigue Curves. Since the CUF extrapolated to 60 years was below 1.0 and the calculations did not contain sufficient information to determine the strain rates, the $0.001 \% / \mathrm{s}$ curve was used. 
Table 5-18. CUF results for the safety injection nozzle forging using NUREG/CR-5999 interim fatigue curve and anticipated cycles.

\begin{tabular}{lrrrr}
\hline \multicolumn{1}{c}{ Load pair } & $\mathrm{S}_{\text {alt }}$ & $\mathrm{N}$ & $\mathrm{n}$ & $\mathrm{u}$ \\
\hline Shutdown cooling A/test 15 & 101.57 & 253 & 40 & 0.158 \\
Shutdown cooling B/test 14 & 79.81 & 432 & 60 & 0.139 \\
Shutdown cooling A/OBE & 54.21 & 1222 & 50 & 0.041 \\
Shutdown cooling B/test 12 & 49.22 & 1746 & $160^{\mathrm{a}}$ & 0.092 \\
Heatup/OBE & 35.14 & 6543 & 90 & 0.014 \\
OBE/null & 32.46 & 8469 & 90 & 0.011 \\
OBE/flow test & 30.92 & 10124 & 20 & 0.002 \\
OBE/OBE & 14.00 & 287660 & 1230 & 0.004 \\
\cline { 2 - 5 } & & & $\mathrm{CUF}$ & 0.457
\end{tabular}

a. This pairing is conservative in that all of the shutdown cooling B cycles have been exhausted, but there was insufficient information in the analysis to determine a different load pairing for test 12 .

Table 5-19. CUF results for the safety injection nozzle safe end using NUREG/CR-5999 interim fatigue curve with conservative assumptions removed.

\begin{tabular}{lcccc}
\hline \multicolumn{1}{c}{ Load pair } & $\mathrm{S}_{\text {alt }}$ & $\mathrm{N}$ & $\mathrm{n}$ & $\mathrm{u}$ \\
\hline Test 14/test 15 & 65.86 & 548 & 260 & 0.475 \\
Shutdown cooling A/B & 72.08 & 441 & 500 & 1.134 \\
Reactor trip/flow test & 23.81 & $>10^{6}$ & 20 & 0.000 \\
Heatup/OBE & 15.82 & $>10^{8}$ & 500 & 0.000 \\
& & & CUF & 1.609 \\
\hline
\end{tabular}

Table 5-20. CUF results for the safety injection nozzle safe end using NUREG/CR-5999 interim fatigue curves with conservative assumptions removed and anticipated cycles.

\begin{tabular}{lcccc}
\hline \multicolumn{1}{c}{ Load pair } & $\mathrm{S}_{\text {alt }}$ & $\mathrm{N}$ & $\mathrm{n}$ & $\mathrm{u}$ \\
\hline Test 14/test 15 & 65.86 & 548 & 100 & 0.183 \\
Shutdown cooling A/B & 72.08 & 441 & 90 & 0.204 \\
Reactor trip/flow test & 23.81 & $>10^{6}$ & 20 & 0.000 \\
Heatup/OBE & 15.82 & $>10^{8}$ & 90 & 0.000 \\
\cline { 4 - 5 } & & & CUF & 0.387 \\
\hline
\end{tabular}


The results are shown in Table 5-21. The extrapolated CUF for 60 years is 0.429 .

5.1.6 Shutdown Cooling Line. The latest fatigue analyses were performed to reflect new conditions caused by a snubber reduction program. The highest design CUF determined by the licensee's analysis was 0.464 for the nozzle and 0.894 for the piping at a 16 -in. short radius elbow on the retum line, so the piping contains the location of the highest design CUF in the system. No differentiation is made between the inside and outside surfaces in piping fatigue analyses.

\subsubsection{Shutdown Cooling Line CUF Using NUREG/CR-5999 and Licensee's Design Calculation Stresses. The licensee's} design CUF calculations for the piping used the ASME Code, Section III, 1980 edition with Winter 1980 addenda. Information from the accompanying computer run was also used. The CUF using the NUREG/CR-5999 interim fatigue curve is shown in Table 5-22. The shutdown cooling transients were broken down into three classifications in the licensee's calculations which are termed 1, 2, and 3 in Table 5-22.

The NUREG/CR-5999 interim fatigue curve increased the CUF by a factor of 6.82 over the design basis number. The CUF exceeds the ASME Code limit of 1.0 .

\subsubsection{Shutdown Cooling Line CUF Using NUREG/CR-5999 and Removing Conservative Assumptions. The location with the highest design CUF is at the junction of}

a short radius piping elbow to the cold leg nozzle (upper end of elbow). The other (lower) end of the elbow is welded to a short piece of straight piping, which is in turn welded to another elbow. Table NB-3681(a)-1 of the ASME Code gives stress indices for use with the piping equations in NB-3650. For curved pipe or butt welded elbows, note 11 applies, which in turn references NB-3683.2(a) (Abutting Products). This paragraph states that unless otherwise specified, it is not required that stress indices for abutting products be multiplied, except for two elbows welded together or connected by a short piece of straight pipe that is less than or equal to one pipe diameter (nominal size) in length. Thus it appears that while the lower end of the elbow should have the stress indices multiplied together, it is not required to multiply the stress indices together for the upper end where the elbow joins the nozzle.

The alternating stresses and CUF were recomputed for the location of highest CUF (the upper end of the elbow). The results are shown in Table 5-23.

The transient with the highest CUF is load pair 2 (heatup/shutdown cooling 3). These consist of 500 cycles of which $450(90 \%)$ are shutdown cooling 3 and 50 (10\%) are shutdown cooling 1 . However, based on actual cycles to date, the anticipated cycles for 40 years is 90 . Using 2 cycles for load pair 1, 81 for load pair 2 , 7 for load pair 3 , and 0 for load pair 4 results in the CUF shown in Table 5-24. The projected CUF for 60 years is 0.753 .

Table 5-21. CUF results for the safety injection nozzle safe end using revised NUREG/CR-5999 interim fatigue curves with conservative assumptions removed and anticipated cycles.

\begin{tabular}{lcccc}
\hline \multicolumn{1}{c}{ Load pair } & $\mathrm{S}_{\text {alt }}$ & $\mathrm{N}$ & $\mathrm{n}$ & $\mathrm{u}$ \\
\hline Test 14/test 15 & 65.86 & 799 & 100 & 0.125 \\
Shutdown cooling A/B & 72.08 & 60 & 90 & 0.161 \\
Reactor trip/flow test & 23.81 & $>10^{6}$ & 20 & 0.000 \\
Heatup/OBE & 15.82 & $>10^{7}$ & 500 & 0.000 \\
& & & CUF & 0.286 \\
\hline
\end{tabular}


Table 5-22. CUF results for the shutdown cooling line using NUREG/CR-5999 interim fatigue curve and licensee's design basis stresses.

\begin{tabular}{lcrrc}
\hline \multicolumn{1}{c}{ Load pair } & $\mathrm{S}_{\text {alt }}$ & $\mathrm{N}$ & $\mathrm{n}$ & $\mathrm{u}$ \\
\hline Heatup/shutdown cooling \& OBE & 170.03 & 56 & 2 & 0.036 \\
Shutdown cooling 1/null & 141.88 & 86 & 2 & 0.023 \\
Heatup/shutdown cooling 3 & 138.88 & 91 & 450 & 4.945 \\
Heatup/shutdown cooling 1 & 138.59 & 92 & 48 & 0.522 \\
Shutdown cooling 2/null & 131.59 & 104 & 50 & 0.481 \\
Reactor trip \& OBE/null & 47.70 & 3385 & 2 & 0.001 \\
Reactor trip/null & 44.07 & 5450 & 446 & 0.082 \\
Leak test/reactor trip & 39.68 & 10250 & 34 & 0.003 \\
Leak test/step in power & 35.00 & 21815 & 166 & 0.008 \\
& & & $\mathrm{CUF}$ & 6.100 \\
\hline
\end{tabular}

Table 5-23. CUF results for the shutdown cooling line using NUREG/CR-5999 interim fatigue curve with conservative assumptions removed.

\begin{tabular}{lcrrr}
\hline \multicolumn{1}{c}{ Load pair } & $\mathrm{S}_{\text {alt }}$ & $\mathrm{N}$ & $\mathrm{n}$ & $\mathrm{u}$ \\
\hline Heatup/shutdown cooling \& OBE & 108.71 & 164 & 2 & 0.012 \\
Heatup/shutdown cooling 3 & 88.63 & 269 & 450 & 1.673 \\
Heatup/shutdown cooling 1 & 87.69 & 276 & 48 & 0.174 \\
Shutdown cooling 1/null & 87.56 & 277 & 2 & 0.007 \\
Shutdown cooling 2/null & 83.31 & 312 & 50 & 0.160 \\
Reactor trip \& OBE/null & 30.03 & 54838 & 2 & 0.000 \\
Reactor trip/null & 28.01 & 100687 & 446 & 0.004 \\
Leak test/reactor trip & 25.08 & $>10^{6}$ & 34 & 0.000 \\
Leak test/step in power & 22.07 & $>10^{6}$ & 166 & 0.000 \\
& & & $\mathrm{CUF}$ & 2.030 \\
\hline
\end{tabular}

Table 5-24. CUF results for the shutdown cooling line using NUREG/CR-5999 interim fatigue curve with conservative assumptions removed and anticipated cycles.

\begin{tabular}{lcrrc}
\hline \multicolumn{1}{c}{ Load pair } & \multicolumn{1}{c}{$\mathrm{S}_{\text {alt }}$} & $\mathrm{N}$ & $\mathrm{n}$ & $\mathrm{u}$ \\
\hline Heatup/shutdown cooling \& OBE & 108.71 & 164 & 2 & 0.012 \\
Heatup/shutdown cooling 3 & 88.63 & 269 & 81 & 0.301 \\
Heatup/shutdown cooling 1 & 87.69 & 276 & 7 & 0.025 \\
Shutdown cooling 1/null & 87.56 & 277 & 0 & 0.000 \\
Shutdown cooling 2/null & 83.31 & 312 & 50 & 0.160 \\
Reactor trip \& OBE/null & 30.03 & 54838 & 2 & 0.000 \\
Reactor trip/null & 28.01 & 100687 & 446 & 0.004 \\
Leak test/reactor trip & 25.08 & $>10^{6}$ & 34 & 0.000 \\
Leak test/step in power & 22.07 & $>10^{6}$ & 166 & 0.000 \\
\cline { 3 - 5 } & & & CUF & 0.502 \\
\hline
\end{tabular}


5.1.6.3 Shutdown Cooling Line CUF Using Revised Interim Fatigue Curves. The licensee's calculation did not contain sufficient detail to determine the strain rates, so the worst-case $(0.001 \% / \mathrm{s})$ curve was used. This is probably representative since the first three load pairs are various heatups and shutdown cooling events, and the increasing tensile stress occurs during the cooldown at $75^{\circ} \mathrm{F} / \mathrm{hr}$. The results are shown in Table 5-25. The extrapolated CUF for 60 years is 0.731 .

\subsubsection{Results and Conclusions. We} obtained the latest design basis fatigue calculations for six components on a newer vintage Combustion Engineering plant. The design CUF obtained from the licensee's calculations for the location with the highest calculated fatigue usage on each component was recomputed using the NUREG/CR-5999 interim fatigue curves. The results are summarized in Table 5-26. The increases in the magnitudes of the design CUFs are as follows:

\section{Stainless Steel}

Surge Line

Charging nozzle safe end
Safety injection nozzle

safe end

Shutdown cooling line

6.82

7.50 average

Carbon/Low-alloy Steel

Reactor vessel shell/bottom

head

Reactor vessel inlet nozzle

2.61

Reactor vessel outlet nozzle

2.21

Charging nozzle

2.08

Safety injection nozzle

\subsection{4}

2.25 average

Conservative assumptions were identified, and where justifiable, the design CUFs were recomputed with certain conservative assumptions removed. Additionally, the design CUFs were further reduced based on the anticipated number of cycles that the plant will be subjected to during its 40-year life. These CUFs are also shown in Table 5-26.

Table 5-25. CUF results for the shutdown cooling line using revised interim fatigue curves with conservative assumptions removed and anticipated cycles $(0.001 \% / \mathrm{s}$ strain rate).

\begin{tabular}{lcrrr}
\hline \multicolumn{1}{c}{ Load pair } & \multicolumn{1}{c}{$\mathrm{S}_{\mathrm{alt}}$} & $\mathrm{N}$ & $\mathrm{n}$ & $\mathrm{u}$ \\
\hline Heatup/shutdown cooling \& OBE & 108.71 & 147 & 2 & 0.014 \\
Heatup/shutdown cooling 3 & 88.63 & 273 & 81 & 0.297 \\
Heatup/shutdown cooling 1 & 87.69 & 283 & 7 & 0.025 \\
Shutdown cooling 1/null & 87.56 & 284 & 0 & 0.000 \\
Shutdown cooling 2/null & 83.31 & 335 & 50 & 0.149 \\
Reactor trip \& OBE/null & 30.03 & 137796 & 2 & 0.000 \\
Reactor trip/null & 28.01 & 280829 & 446 & 0.002 \\
Leak test/reactor trip & 25.08 & $>10^{6}$ & 34 & 0.000 \\
Leak test/step in power & 22.07 & $>10^{6}$ & 166 & 0.000 \\
& & & $\mathrm{CUF}$ & 0.487 \\
\hline
\end{tabular}


Table 5-26. Summary of newer vintage Combustion Engineering plant CUFs.

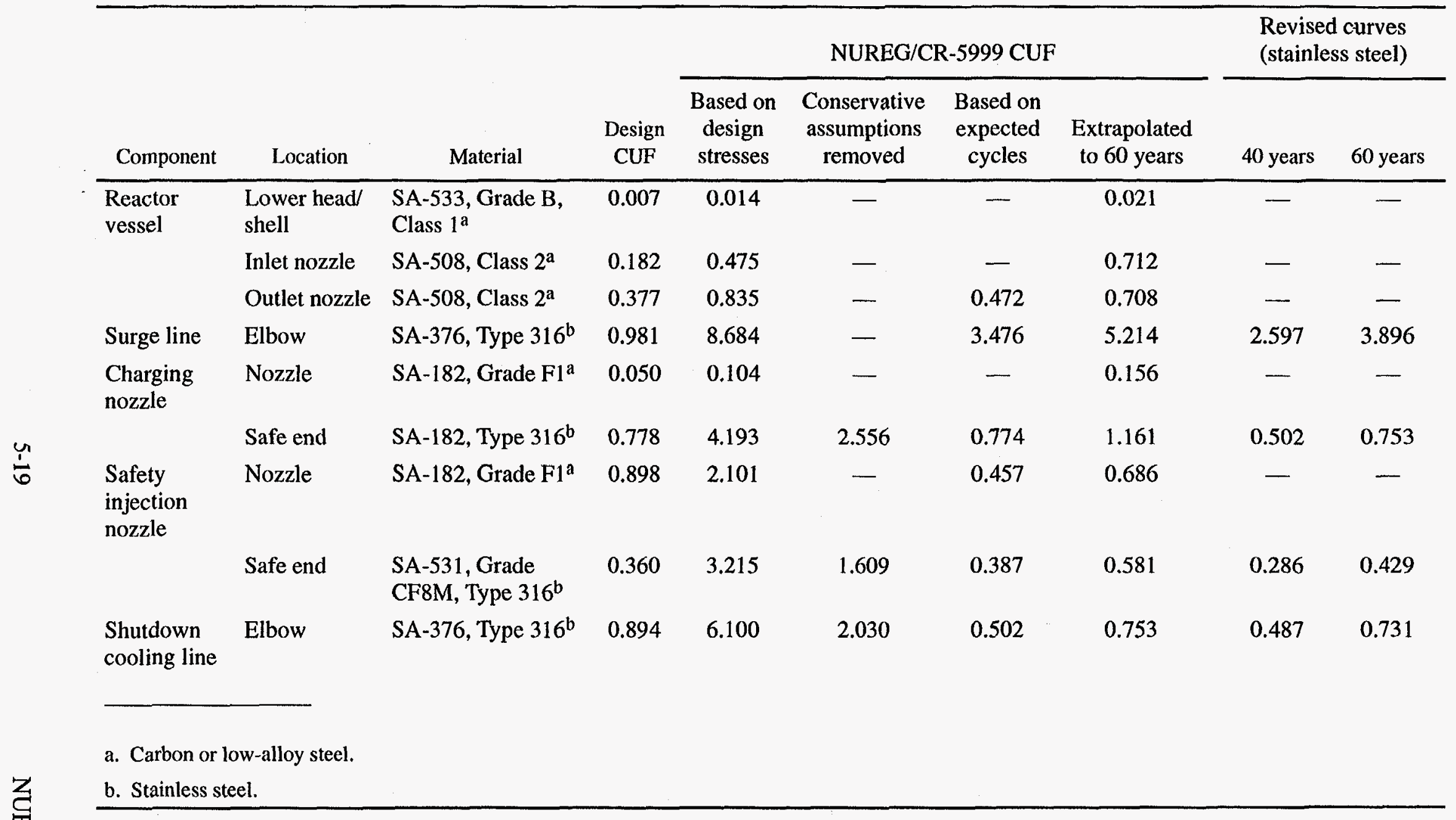


It appears that the CUFs resulting from applying the NUREG/CR-5999 interim fatigue curves, can be reduced below 1.0 for most components comparatively easily by removing conservative assumptions and utilizing the number of anticipated cycles. The charging system nozzle CUF is slightly over 1.0 for 60 years using NUREG/CR-5999, but less than 1.0 using the revised interim curves. Reclassifying the stress caused by the radial thermal gradient as a peak stress (a change from the ASME Code edition used in the analysis to the present edition) could reduce the primary-plus-secondary stress intensity range below the $3 \mathrm{~S}_{\mathrm{m}}$ limit, and no doubt reduce the NUREG/ CR-5999 CUF below 1.0. However, for the surge line piping, our judgment is that a more detailed (that is, ASME Code NB-3200) stress analysis or fatigue monitoring and cycle counting would have to be used to reduce the CUF below 1.0. As listed in Table 5-8, there remain a number of options available to further reduce the CUF.

\subsection{Older Vintage Combustion Engineering Plant}

A comparison of the design CUFs from the licensee's design basis calculations and CUFs using the NUREG/CR-5999 interim fatigue curves was carried out for the locations of highest design CUF for the six components listed below:

1. Reactor vessel shell and lower head

2. Reactor vessel inlet and outlet nozzles

3. Surge line

4. Charging system nozzle

5. Safety injection system nozzle

6. Shutdown cooling system Class 1 piping (representative design basis fatigue calculation performed by INEL).

As of early 1994, the plant has been operated approximately 21 of the 40 years currently approved in its operating license. Table 5-27 shows the design basis cycles for transients that are important from a fatigue standpoint for the six components that were evaluated. The numbers of transients to date(in some cases estimated by the licensee and the INEL staff) have been extrapolated to 40 years by multiplying by $40 / 21$.

Fatigue monitoring of the surge line had been performed on this plant and the results were included in the licensee's calculations. The results were not used except to adjust the number of anticipated stratification cycles based on the expected number of heatups and cooldowns in Table 5-27.

\subsubsection{Reactor Vessel Shell and Lower} Head. The highest CUF on the shell and lower head is 0.008 for inside surface of the lower head at the shell-to-head transition. The SA-533 Grade $\mathrm{B}$ Class 1 head is protected from the coolant by a layer of stainless steel cladding. No fatigue analysis is performed for the cladding.

\subsubsection{NUREG/CR-59g9 CUF Based on Licensee's Design Calculation Stresses.} The licensee's CUF calculations used the ASME Code, Section III, 1965 edition, with Code Cases through June 21,1966 . No interpolation equations were available in this edition of the Code, so the analyst used the minor grid marks on the fatigue curve to determine the allowable numbers of cycles.

The effect of the NUREG/CR-5999 interim fatigue curve is shown in Table 5-28. As previously discussed, the results shown in Table 5-28 assume that the coolant is in contact with the low-alloy steel base metal underneath the cladding. The $S_{\text {alt }}$ values were adjusted for the effect of the modulus of elasticity by multiplying by $30 / 27$, the ratio of the modulus of elasticity in the current edition of the Code to the value commonly used in analyses in the 1965-1970 time period (the actual value used in the analysis was not reported). The 1965 Code edition did not require an adjustment for the effect of the modulus of elasticity. 
Table 5-27. Number of selected design basis cycles compared to anticipated number of cycles over 40-year license life.

\begin{tabular}{lcc}
\hline \multicolumn{1}{c}{ Transient } & Design basis cycles & $\begin{array}{c}\text { Anticipated cycles } \\
\text { for } 40 \text { years }\end{array}$ \\
\hline Heatup/cooldown & 500 & 101 \\
Reactor trip & 400 & 92 \\
Hydrotest & 10 & 2 \\
Power load/unload & 15000 & 202 \\
Heat exchanger isolations & 1400 & 115 \\
\hline
\end{tabular}

Table 5-28. CUF results for reactor vessel lower head using NUREG/CR-5999 interim fatigue curve.

\begin{tabular}{lccrrr}
\hline \multicolumn{1}{c}{ Load pair } & $\mathrm{S}_{\text {alt }}$ & $\mathrm{S}_{\text {alt }}$ (adjusted) & $\mathrm{N}$ & \multicolumn{1}{c}{$\mathrm{n}$} & $\mathrm{u}$ \\
\hline Loss of secondary pressure $\mathrm{A} / \mathrm{B}$ & 63.5 & 70.56 & 580 & 5 & 0.009 \\
Hydrotest/null & 20.1 & 22.33 & 42251 & 10 & 0.000 \\
Leak test/null & 20.0 & 22.22 & 43241 & 40 & 0.001 \\
Loss of flow/null & 16.8 & 18.67 & 97802 & 40 & 0.000 \\
Reactor trip/null & 16.5 & 18.33 & 106603 & 400 & 0.003 \\
Plant unload/null & 16.2 & 18.00 & 116081 & 20 & 0.000 \\
& & & & CUF & 0.013 \\
\hline
\end{tabular}

Application of the NUREG/CR-5999 interim fatigue curve increased the CUF by a factor of 1.63 over the licensee's design basis number. If the plant is operated for 60 years, the CUF is 0.020 and would not exceed the ASME Code limit of 1.0 .

\subsubsection{NUREG/CR-5999 CUF with Con-} servative Assumptions Removed. Since the CUF did not exceed the ASME Code limit of 1.0 for 60 years, no further calculations were performed.

\subsubsection{Reactor Vessel Inlet and Outlet}

Nozzles. The CUFs for the inlet and outlet nozzles are 0.073 and 0.284 , respectively. Each of the SA-336 low-alloy steel nozzles is protected from the coolant by a layer of stainless steel cladding. No fatigue analysis is performed for the cladding. Each nozzle also has a SA-182 F316 stainless steel safe end, but the CUFs for the safe ends are less than 0.001 and therefore were not evaluated.

\subsubsection{NUREG/CR-5999 CUF Based on} Licensee's Design Calculation Stresses for Inlet NozzJe. The licensee's design CUF calculations used the ASME Code, Section III, 1965 edition, with Code Cases through June 21, 1966. The licensee's analysis report showed the fatigue analysis calculations only for the exterior surface of the nozzle, since this location has a higher CUF than the interior surface. Therefore, this exterior location was used to asses the effect of the NUREG/CR-5999 fatigue curves, and the results will upper bound the CUF on the interior surface. The $S_{\text {alt }}$ values were adjusted for the effect of the modulus of elasticity by multiplying by $30 / 27$, the ratio of the modulus of elasticity in the current edition of the Code to the value commonly used in analyses in the 1965-1970 time period (the actual value used in the analysis was not reported). The effect of the NUREG/CR-5999 interim fatigue curve is shown in Table 5-29. 
Table 5-29. CUF results for reactor vessel inlet nozzle using NUREG/CR-5999 interim fatigue curve.

\begin{tabular}{|c|c|c|c|c|c|}
\hline Load pair & $\mathrm{S}_{\mathrm{alt}}$ & $\mathrm{S}_{\mathrm{alt}}($ adjusted) & $\mathrm{N}$ & $\mathrm{n}$ & $\mathbf{u}$ \\
\hline $\begin{array}{l}\text { Loss of secondary } \\
\text { pressure/cooldown }\end{array}$ & 66.12 & 73.47 & 525 & 5 & 0.010 \\
\hline Heatup/cooldown & 35.78 & 39.76 & 4048 & 495 & 0.122 \\
\hline Leak test $A /$ leak test $B$ & 33.62 & 37.36 & 5165 & 200 & 0.039 \\
\hline \multirow[t]{2}{*}{ Heatup/hydrotest } & 24.97 & 27.74 & 15279 & 10 & 0.001 \\
\hline & & & & CUF & 0.172 \\
\hline
\end{tabular}

The Table 5-29 results indicate that the CUF increased by a factor of 2.36 over the licensee's design basis number. The CUF does not exceed the ASME Code limit of 1.0. If the plant is operated for 60 years, the CUF is 0.258 .

\subsubsection{NUREG/CR-5999 CUF Based on Licensee's Design Calculation Stresses for Outlet Nozzle. The licensee's design CUF} calculations used the ASME Code, Section III, 1965 edition, with Code Cases through June 21, 1966. The location with the highest CUF was on the inside surface of the nozzle near the nozzleto-shell juncture. The $S_{\text {alt }}$ values were adjusted for the effect of the modulus of elasticity by multiplying by $30 / 27$, the ratio of the modulus of elasticity in the current edition of the Code to the value commonly used in analyses in the 1965-1970 time period (the actual value used in the analysis was not reported). The effect of the NUREG/CR-5999 interim fatigue curve is shown in Table 5-30.

The Table 5-30 results indicate that the CUF increased by a factor of 1.95 over the licensee's design basis number. The CUF does not exceed the ASME Code limit of 1.0. If the plant is operated for 60 years, the CUF is 0.831 .

\subsubsection{NUREG/CR-5999 CUF with Con-} servative Assumptions Removed. Since the CUFs for both nozzles did not exceed the ASME Code limit of 1.0 for 60 years, no further calculations were performed.

5.2.3 Surge Line. The highest CUF for the surge line piping and nozzles was 0.705 at an
SA-376 Type 316 stainless steel 10-inch Schedule 160 long radius elbow. The latest fatigue analyses were performed by the licensee to assess thermal stratification conditions as required by NRC Bulletin 88-11.

\subsubsection{NUREG/CR-5999 CUF Based on Licensee's Design Calculation Stresses.} The licensee's design CUF calculations used the ASME Code, Section III, 1983 edition, through Winter 1985 addenda. The $S_{\text {alt }}$ values in the licensee's calculations were based on a modulus of elasticity of $26 \times 10^{6} \mathrm{psi}$, so the values were adjusted by multiplying by a factor of $28.3 / 26$, the ratio of the moduli of elasticity for the NUREG/CR-5999 interim fatigue curves and the licensee's calculations. The CUF using the NUREG/CR-5999 interim fatigue curve is shown in Table 5-31. Various states of thermal stratification were defined in the licensee's calculations, but all are simply termed stratification in Table 5-31.

The Table 5-31 results indicate that the CUF increased by a factor of 11.45 over the licensee's design basis number. The CUF exceeds the ASME Code limit of 1.0 .

\subsubsection{NUREG/CR-5999 CUF with Con- servative Assumptions Removed. Since} the analysis was performed relatively recently, few of the areas in the first group of potential conservative assumptions that possibly could be removed are applicable to the surge line. The CUF results almost entirely from the heatup/cooldown (including thermal stratification), and load/ unload cycles. From Table 5-27, the number of 
Table 5-30. CUF results for reactor vessel outlet nozzle using NUREG/CR-5999 interim fatigue curve.

\begin{tabular}{lcccrc}
\hline \multicolumn{1}{c}{ Load pair } & $\mathrm{S}_{\text {alt }}$ & $\mathrm{S}_{\text {alt }}$ (adjusted) & $\mathrm{N}$ & $\mathrm{n}$ & $\mathrm{u}$ \\
\hline $\begin{array}{l}\text { Loss of secondary } \\
\text { pressure/hydrotest }\end{array}$ & 67.01 & 74.46 & 508 & 5 & 0.010 \\
Hydrotest A/hydrotest B & & & & & \\
Heatup/loss of load & 34.61 & 38.46 & 4610 & 5 & 0.001 \\
Heatup/loss of flow & 29.62 & 32.41 & 8518 & 40 & 0.005 \\
Heatup/cooldown & 28.56 & 31.73 & 9207 & 40 & 0.004 \\
Cooldown/plant loading & 28.38 & 31.53 & 9423 & 420 & 0.045 \\
Reactor trip/plant loading & 26.73 & 29.70 & 11737 & 80 & 0.007 \\
Reactor trip/plant unloading & 23.25 & 25.83 & 21348 & 400 & 0.019 \\
& 21.41 & 23.79 & 31396 & 14520 & 0.462 \\
\hline
\end{tabular}

Table 5-31. CUF results for surge line elbow using NUREG/CR-5999 interim fatigue curve.

\begin{tabular}{|c|c|c|c|c|c|}
\hline Load pair & $S_{\text {alt }}$ & $\mathrm{S}_{\mathrm{alt}}($ adjusted) & $\mathrm{N}$ & $\mathbf{n}$ & u \\
\hline $\begin{array}{l}\text { Stratification/loss of flow with } \\
\text { reactor trip }\end{array}$ & 54.72 & 59.56 & 889 & 2 & 0.002 \\
\hline $\begin{array}{l}\text { Stratification/loss of flow with } \\
\text { loss of load }\end{array}$ & 53.55 & 58.29 & 1012 & 1 & 0.001 \\
\hline $\begin{array}{l}\text { Stratification/loss of flow } \\
\text { without loss of load }\end{array}$ & 52.38 & 57.01 & 1157 & 37 & 0.032 \\
\hline Stratification/loss of load & 50.94 & 55.45 & 1367 & 40 & 0.029 \\
\hline Stratification/reactor trip & 49.84 & 54.25 & 1560 & 70 & 0.045 \\
\hline Stratification/stratification & 46.34 & 50.44 & 2418 & 350 & 0.145 \\
\hline Stratification/reactor trip & 45.19 & 49.19 & 2812 & 330 & 0.117 \\
\hline Stratification/low pressure & 41.77 & 45.47 & 4515 & 5 & 0.001 \\
\hline Stratification/plant unloading & 41.24 & 44.89 & 4878 & 15000 & 3.075 \\
\hline Stratification/stratification & 33.98 & 36.99 & 15639 & 72025 & 4.605 \\
\hline Stratification/leak test A & 30.60 & 33.31 & 29385 & 150 & 0.005 \\
\hline Stratification/hydrotest & 30.01 & 32.66 & 33086 & 10 & 0.000 \\
\hline Stratification/leak test B & 26.72 & 29.08 & 66544 & 200 & 0.003 \\
\hline Stratification/null & 26.34 & 28.67 & 72482 & 750 & 0.010 \\
\hline \multirow[t]{2}{*}{ Stratification/null } & 22.57 & 24.57 & $>10^{6}$ & 800 & 0.000 \\
\hline & & & & CUF & 8.070 \\
\hline
\end{tabular}


anticipated heatup cycles for 40 years is 101 , whereas 500 design cycles were used in the licensee's design CUF calculation (applicable to load pairs 6,7 , and 10). The number of anticipated power load/unload cycles for 40 years is 202 , whereas 15000 design cycles were used in the licensee's design CUF calculation (applicable to load pair 9). The load pairs for which significant contributions to the CUF were made by these cycles were adjusted based on the anticipated numbers of cycles in Table 5-27. The CUF after 40 years was estimated by using the anticipated numbers of cycles, and is shown in Table 5-32. If the plant is operated for 60 years, the CUF is 2.018 .

There are a number of other potential conservative assumptions that could be removed, as shown in Table 5-33. For example, performing a detailed finite element analysis using ASME Code
NB-3200 methods might reduce the CUF calculated using NB-3600 piping rules. The stratification temperature differences assumed in the analysis may be conservative. If removing the conservative assumptions did not reduce the CUF below 1.0, then fatigue monitoring or plastic analyses could be used.

\subsubsection{CUF Based on Revised Interim} Fatigue Curves. From a review of the licensee's stress analysis, it appears that the strain rates from all transients were low, so the $0.001 \% / \mathrm{s}$ curve was used for all load pairs. The results of applying the revised curves are shown in Table 5-34. The extrapolated CUF for 60 years is 0.992 .

5.2.4 Charging Nozzle. The highest CUF for the SA-351 Type 316 stainless steel nozzle is 0.266 on the inside surface at a nozzle taper region.

Table 5-32. CUF results for surge line elbow using NUREG/CR-5999 interim fatigue curve and anticipated cycles.

\begin{tabular}{lccrrr}
\hline \multicolumn{1}{c}{ Load pair } & $\mathrm{S}_{\text {alt }}$ & $\begin{array}{c}\mathrm{S}_{\text {alt }} \\
\text { (adjusted) }\end{array}$ & $\mathrm{N}$ & $\mathrm{n}$ & $\mathrm{u}$ \\
\hline $\begin{array}{l}\text { Stratification/loss of flow with } \\
\text { reactor trip }\end{array}$ & 54.72 & 59.56 & 889 & 2 & 0.002 \\
Stratification/loss of flow with & 53.55 & 58.29 & 1012 & 1 & 0.001 \\
loss of load & & & & & \\
Stratification/loss of flow without & 52.38 & 57.01 & 1157 & 37 & 0.032 \\
loss of load & & & & & \\
Stratification/loss of load & 50.94 & 55.45 & 1367 & 40 & 0.029 \\
Stratification/reactor trip & 49.84 & 54.25 & 1560 & 70 & 0.045 \\
Stratification/stratification & 46.34 & 50.44 & 2418 & 71 & 0.029 \\
Stratification/reactor trip & 45.19 & 49.19 & 2812 & 67 & 0.024 \\
Stratification/low pressure & 41.77 & 45.47 & 4515 & 5 & 0.001 \\
Stratification/plant unloading & 41.24 & 44.89 & 4878 & 202 & 0.041 \\
Stratification/stratification & 33.98 & 36.99 & 15639 & 17570 & 1.123 \\
Stratification/leak test A & 30.60 & 33.31 & 29385 & 150 & 0.005 \\
Stratification/hydrotest & 30.01 & 32.66 & 33086 & 2 & 0.000 \\
Stratification/leak test B & 26.72 & 29.08 & 66544 & 200 & 0.003 \\
Stratification/null & 26.34 & 28.67 & 72482 & 750 & 0.010 \\
Stratification/null & 22.57 & 24.57 & $>10^{6}$ & 800 & 0.000 \\
& & & & CUF & 1.345 \\
\hline
\end{tabular}


Table 5-33. Potential for elimination of conservative assumptions to reduce CUF for surge line elbow using NUREG/CR-5999 interim fatigue curve.

\begin{tabular}{lccl}
\hline \multicolumn{1}{c}{$\begin{array}{c}\text { Assumption } \\
\text { (Section 4.3) }\end{array}$} & $\begin{array}{c}\text { Potential } \\
\text { for use }\end{array}$ & Used & \multicolumn{1}{c}{ Comments } \\
\hline Correct CUF calculation & No & No & Analysis appear to be correct \\
Detailed load pairs & No & No & Detailed load pairs were used \\
SCF/FSRF & Yes & No & Insufficient information \\
$S_{\mathrm{m}}$ value & No & No & $\mathrm{K}_{\mathrm{e}}=1$ for all load pairs \\
Material property changes & No & No & No changes, Winter 1985 addenda used \\
Fatigue curve E value & No & No Proper adjustment was made \\
Code analysis changes & No & No & No changes, Winter 1985 addenda used \\
Actual cycles & Yes & Yes & Adjustment was made for projected cycles \\
High temperature rates & Yes & No Actual cooldown rates probably less than design \\
Detailed stress modeling & Yes & No & NB-3600 analysis used \\
Conservative thermal & Yes & No & Insufficient information \\
parameters & & & \\
Time phasing of stresses & Yes & No & Highest moment and thermal stresses may not occur \\
& & & simultaneously \\
Number of OBEs & No & No OBE cycles not significant contributor to CUF \\
CC N-411 damping & No & No Dynamic loads not significant contributor to CUF \\
Number of hydrotests & No & No Hydrotests did not contribute to CUF \\
Fatigue monitoring & Yes & No Actual transients probably less severe than design \\
Plastic analysis & Yes & No Elastic plastic finite element analysis could be used \\
\hline
\end{tabular}

Table 5-34. CUF results for surge line elbow using revised interim fatigue curves with conservative assumptions removed and anticipated cycles.

\begin{tabular}{lccccc}
\hline \multicolumn{1}{c}{ Load pair } & $\mathrm{S}_{\text {alt }}$ & $\begin{array}{c}\text { S } \\
\text { (adjusted) }\end{array}$ & $\mathrm{N}$ & $\mathrm{n}$ & $\mathrm{u}$ \\
\hline $\begin{array}{l}\text { Stratification/loss of flow with } \\
\text { reactor trip }\end{array}$ & 54.72 & 59.56 & 1243 & 2 & 0.002 \\
$\begin{array}{l}\text { Stratification/loss of flow with loss } \\
\text { of load }\end{array}$ & 53.55 & 58.29 & 1377 & 1 & 0.001 \\
Stratification/loss of flow without & 52.38 & 57.01 & 1536 & 37 & 0.024 \\
loss of load & & & & & \\
Stratification/loss of load & 50.94 & 55.45 & 1769 & 40 & 0.023 \\
Stratification/reactor trip & 49.84 & 54.25 & 1988 & 70 & 0.035 \\
Stratification/stratification & 46.34 & 50.44 & 3036 & 71 & 0.023 \\
Stratification/reactor trip & 45.19 & 49.19 & 3569 & 67 & 0.019 \\
Stratification/low pressure & 41.77 & 45.47 & 6369 & 5 & 0.001 \\
Stratification/plant unloading & 41.24 & 44.89 & 7095 & 202 & 0.028 \\
Stratification/stratification & 33.98 & 36.99 & 35238 & 17570 & 0.498 \\
Stratification/leak test A & 30.60 & 33.31 & 64480 & 150 & 0.002 \\
Stratification/hydrotest & 30.01 & 32.66 & 73350 & 10 & 0.000 \\
Stratification/leak test B & 26.72 & 29.08 & 183982 & 200 & 0.001 \\
Stratification/null & 26.34 & 28.67 & 211477 & 750 & 0.004 \\
Stratification/null & 22.57 & 24.57 & $2.9 \times 10^{6}$ & 800 & 0.000 \\
& & & & CUF & 0.661 \\
\hline
\end{tabular}


5.2.4.1 NUREG/CR-5999 CUF Based on Licensee's Design Calculation Stresses. The licensee's design CUF calculations used the ASME Code, Section III, 1965 edition, through Winter 1967 addenda. The $S_{\text {alt }}$ values in the licensee's calculations were based on a modulus of elasticity of $26 \times 10^{6} \mathrm{psi}$, so the values were adjusted by multiplying by a factor of $28.3 / 26$, the ratio of the moduli of elasticity for the NUREG/CR-5999 interim fatigue curves and the licensee's calculations. The CUF using the NUREG/CR-5999 interim fatigue curves is shown in Table 5-35. Application of the NUREG/CR-5999 interim fatigue curve increased the CUF by a factor of 14.73 over the licensee's design basis number.
5.2.4.2 NUREG/CR-5999 CUF with Conservative Assumptions Removed. The actual numbers of anticipated heat exchanger isolation (applicable to load pair 3), plant load/ unload (applicable to load pair 6), and reactor trip (applicable to load pair 5) transients in Table 5-27 are less than the corresponding numbers in the licensee's design basis calculations. When the anticipated numbers of cycles are used, the CUF is below 1.0, as shown in Table 5-36. If the plant is operated for 60 years, the CUF is 0.999 . The CUF still contains a conservative number of plant unload B cycles, but since the CUF was below 1.0 for 60 years, no further efforts to reduce the CUF were undertaken.

Table 5-35. CUF results for charging nozzle using NUREG/CR-5999 interim fatigue curve.

\begin{tabular}{lccrrr}
\hline \multicolumn{1}{c}{ Load pair } & $\mathrm{S}_{\text {alt }}$ & $\mathrm{S}_{\text {alt }}$ (adjusted) & $\mathrm{N}$ & $\mathrm{n}$ & $\mathrm{u}$ \\
\hline $\begin{array}{l}\text { Loss of secondary pressure/loss } \\
\text { of letdown B }\end{array}$ & 115.70 & 125.93 & 115 & 5 & 0.043 \\
$\begin{array}{l}\text { Loss of letdown A/ } \\
\text { loss of letdown B }\end{array}$ & 78.96 & 85.94 & 289 & 95 & 0.329 \\
$\begin{array}{l}\text { Heat exchanger isolation/plant } \\
\text { unload B }\end{array}$ & 58.48 & 63.65 & 596 & 1400 & 2.349 \\
Loss of load/plant unload B & 54.27 & 59.07 & & & \\
Reactor trip/plant unload B & 47.05 & 51.21 & 2207 & 440 & 0.043 \\
$\begin{array}{l}\text { Plant unload A/plant unload B } \\
\text { Purification A/purification B }\end{array}$ & 34.72 & 37.79 & 13749 & 13120 & 0.199 \\
& 20.23 & 22.02 & $4.2 \times 10^{7}$ & 43500 & 0.001 \\
\hline
\end{tabular}

Table 5-36. CUF results for charging nozzle using NUREG/CR-5999 interim fatigue curve and anticipated cycles.

\begin{tabular}{lccrrc}
\hline \multicolumn{1}{c}{ Load pair } & $\mathrm{S}_{\text {alt }}$ & $\mathrm{S}_{\text {alt }}$ (adjusted) & $\mathrm{N}$ & $\mathrm{n}$ & $\mathrm{u}$ \\
\hline $\begin{array}{l}\text { Loss of secondary } \\
\text { pressure/loss of letdown B }\end{array}$ & 115.70 & 125.93 & 115 & 5 & 0.043 \\
$\begin{array}{l}\text { Loss of letdown A } \\
\text { loss of letdown B }\end{array}$ & 78.96 & 85.94 & 289 & 95 & 0.329 \\
$\begin{array}{l}\text { Heat exchanger isolation/plant } \\
\text { unload B }\end{array}$ & 58.48 & 63.65 & 596 & 115 & 0.193 \\
Loss of load/plant unload B & 54.27 & 59.07 & 934 & 40 & 0.043 \\
Reactor trip/plant unload B & 47.05 & 51.21 & 2207 & 92 & 0.042 \\
Plant unload A/plant unload B & 34.72 & 37.79 & 13749 & 202 & 0.015 \\
Purification A/purification B & 20.23 & 22.02 & $4.2 \times 10^{7}$ & 43500 & 0.001 \\
\hline & & & & $\mathrm{CUF}$ & 0.666 \\
\hline
\end{tabular}


5.2.4.3 CUF Based on Revised Interim Fatigue Curves. Since the CUF extrapolated to 60 years was below 1.0 and the calculations did not contain sufficient information to determine the strain rates, the $0.001 \% / \mathrm{s}$ curve was used. Using this strain rate, the CUF results are shown in Table 5-37. The extrapolated CUF for 60 years is 0.843 .

5.2.5 Safety Injection Nozzle. The highest CUF for the SA-351 Type 316 stainless steel safety injection nozzle is 0.088 on the inside surface at a nozzle taper location.

\subsubsection{NUREG/CR-5999 CUF Based on} Licensee's Design Calculation Stresses. The licensee's design CUF calculations used the ASME Code, Section III, 1965 edition, through Winter 1967 addenda. The $S_{\text {alt }}$ values in the licensee's calculations were based on a modulus of elasticity of $26 \times 10^{6} \mathrm{psi}$, so the values were adjusted by multiplying by a factor of $28.3 / 26$, the ratio of the moduli of elasticity for the NUREG/CR-5999 interim fatigue curves and the licensee's calculations. The CUF using the NUREG/CR-5999 interim fatigue curve is shown in Table 5-38.

Application of the NUREG/CR-5999 interim fatigue curve increased the CUF by a factor of 15.00 over the design basis number. The CUF exceeds the ASME Code limit of 1.0 .

\subsubsection{NUREG/CR-5999 CUF with Con-} servative Assumptions Removed. Most of the CUF is contributed by the cooldown transient (applicable to load pair 1). If 101 cycles are used for this transient instead of 500 (see Table 5-27), the CUF is lowered below 1.0 as shown in Table 5-39. If the plant is operated for 60 years, the CUF is 0.621 .

\subsubsection{CUF Based on Revised Interim} Fatigue Curves. Since the CUF extrapolated to 60 years was below 1.0 and the calculations did not contain sufficient information to determine the strain rates, the $0.001 \% / \mathrm{s}$ curve was used. The results are shown in Table 5-40. The extrapolated CUF for 60 years is 0.476 .

\subsubsection{Shutdown Cooling System Class 1}

Piping. No CUF analyses have been performed by the licensee for the shutdown cooling system. Consequently, system drawings were supplied by the licensee and a representative fatigue analysis was performed by the INEL staff.

\subsubsection{Shutdown Cooling System Class 1 Piping CUF Based on NUREG/ CR-5999 Interim Fatigue Curve. Before a} fatigue analysis could be conducted, a set of representative transients for the plant had to be defined. The postulated set of transients used in the analysis was based on the plant operation and numbers of cycles defined by the licensee for other components, and the definition of transients

Table 5-37. CUF results for the charging system nozzle safe end using revised interim fatigue curves with conservative assumptions removed and anticipated cycles.

\begin{tabular}{lccccc}
\hline \multicolumn{1}{c}{ Load pair } & $\mathrm{S}_{\text {alt }}$ & $\mathrm{S}_{\text {alt }}$ (adjusted) & $\mathrm{N}$ & $\mathrm{n}$ & $\mathbf{u}$ \\
\hline $\begin{array}{l}\text { Loss of secondary pressure/loss } \\
\text { of letdown B }\end{array}$ & 115.70 & 125.93 & 97 & 5 & 0.052 \\
$\begin{array}{l}\text { Heat exchanger isolation/plant } \\
\text { unload B }\end{array}$ & 78.96 & 85.94 & 302 & 95 & 0.315 \\
$\begin{array}{l}\text { Heat exchanger isolation/plant } \\
\text { unload B }\end{array}$ & 58.48 & 63.65 & 923 & 115 & 0.125 \\
$\begin{array}{l}\text { Loss of load/plant unload B } \\
\text { Reactor trip/plant unload B }\end{array}$ & 54.27 & 59.07 & 1292 & 40 & 0.031 \\
Plant unload A/plant unload B & 47.05 & 51.21 & 2766 & 92 & 0.033 \\
& 34.72 & 37.79 & 31618 & 202 & 0.006 \\
\hline
\end{tabular}


Table 5-38. CUF results for safety injection nozzle using NUREG/CR-5999 interim fatigue curve.

\begin{tabular}{lccrrc}
\hline \multicolumn{1}{c}{ Load pair } & $\mathrm{S}_{\text {alt }}$ & $\mathrm{S}_{\text {alt }}$ (adjusted) & $\mathrm{N}$ & $\mathrm{n}$ & $\mathrm{u}$ \\
\hline Cooldown A/null & 66.30 & 72.17 & 440 & 500 & 1.136 \\
Cooldown B/leak test & 50.01 & 54.53 & 1512 & 200 & 0.132 \\
Cooldown B/hydrotest & 48.08 & 52.33 & 1938 & 10 & 0.005 \\
Cooldown B/heatup & 39.72 & 43.23 & 6120 & 290 & 0.047 \\
Cooldown C/heatup & 19.88 & 21.64 & $>10^{6}$ & 210 & 0.000 \\
Cooldown C/steady state & 18.77 & 20.43 & $>10^{6}$ & 290 & 0.000 \\
& & & & CUF & 1.320 \\
\hline
\end{tabular}

Table 5-39. CUF results for safety injection nozzle using NUREG/CR-5999 interim fatigue curve and anticipated cycles.

\begin{tabular}{lccrrc}
\hline \multicolumn{1}{c}{ Load pair } & $\mathrm{S}_{\text {alt }}$ & $\mathrm{S}_{\text {alt }}($ adjusted) & $\mathrm{N}$ & $\mathrm{n}$ & $\mathrm{u}$ \\
\hline Cooldown A/null & 66.30 & 72.17 & 440 & 101 & 0.230 \\
Cooldown B/leak test & 50.01 & 54.53 & 1512 & 200 & 0.132 \\
Cooldown B/hydrotest & 48.08 & 52.33 & 1938 & 10 & 0.005 \\
Cooldown B/heatup & 39.72 & 43.23 & 6120 & 290 & 0.047 \\
Cooldown C/heatup & 19.88 & 21.64 & $>10^{6}$ & 210 & 0.000 \\
Cooldown C/steady state & 18.77 & 20.43 & $>10^{6}$ & 290 & 0.000 \\
& & & & CUF & 0.414 \\
\hline
\end{tabular}

Table 5-40. CUF results for the safety injection nozzle safe end using revised interim fatigue curves with conservative assumptions removed and anticipated cycles.

\begin{tabular}{lccrrr}
\hline \multicolumn{1}{c}{ Load pair } & $\mathrm{S}_{\text {alt }}$ & $\mathrm{S}_{\text {alt }}$ (adjusted) & \multicolumn{1}{c}{$\mathrm{N}$} & $\mathrm{n}$ & $\mathrm{u}$ \\
\hline Cooldown A/null & 66.30 & 72.17 & 557 & 101 & 0.181 \\
Cooldown B/leak test & 50.01 & 54.53 & 1933 & 200 & 0.103 \\
Cooldown B/hydrotest & 48.08 & 52.33 & 2433 & 10 & 0.004 \\
Cooldown B/heatup & 39.72 & 43.23 & 10036 & 290 & 0.029 \\
\cline { 5 - 6 } & & & & CUF & 0.317 \\
\hline
\end{tabular}

and numbers of cycles for the shutdown cooling system of the newer vintage Combustion Engineering plant in Section 5.1.

The portions of the shutdown cooling system that would be classified as Class 1 systems in newer vintage plants were analyzed for fatigue. CUF calculations were performed using the current (1992) edition of the ASME Code for both the letdown line of the shutdown cooling piping and the return line to the reactor coolant system. The highest CUF (0.014) was found to be on the return line, as shown in Figure 5-1. The CUF using the NUREG/CR-5999 interim fatigue curves is shown in Table 5-41. Application of the NUREG/CR-5999 interim fatigue curve increased the CUF by a factor of 9.93 over the design basis number. If the plant is operated for 60 years, the CUF is 0.209 . 


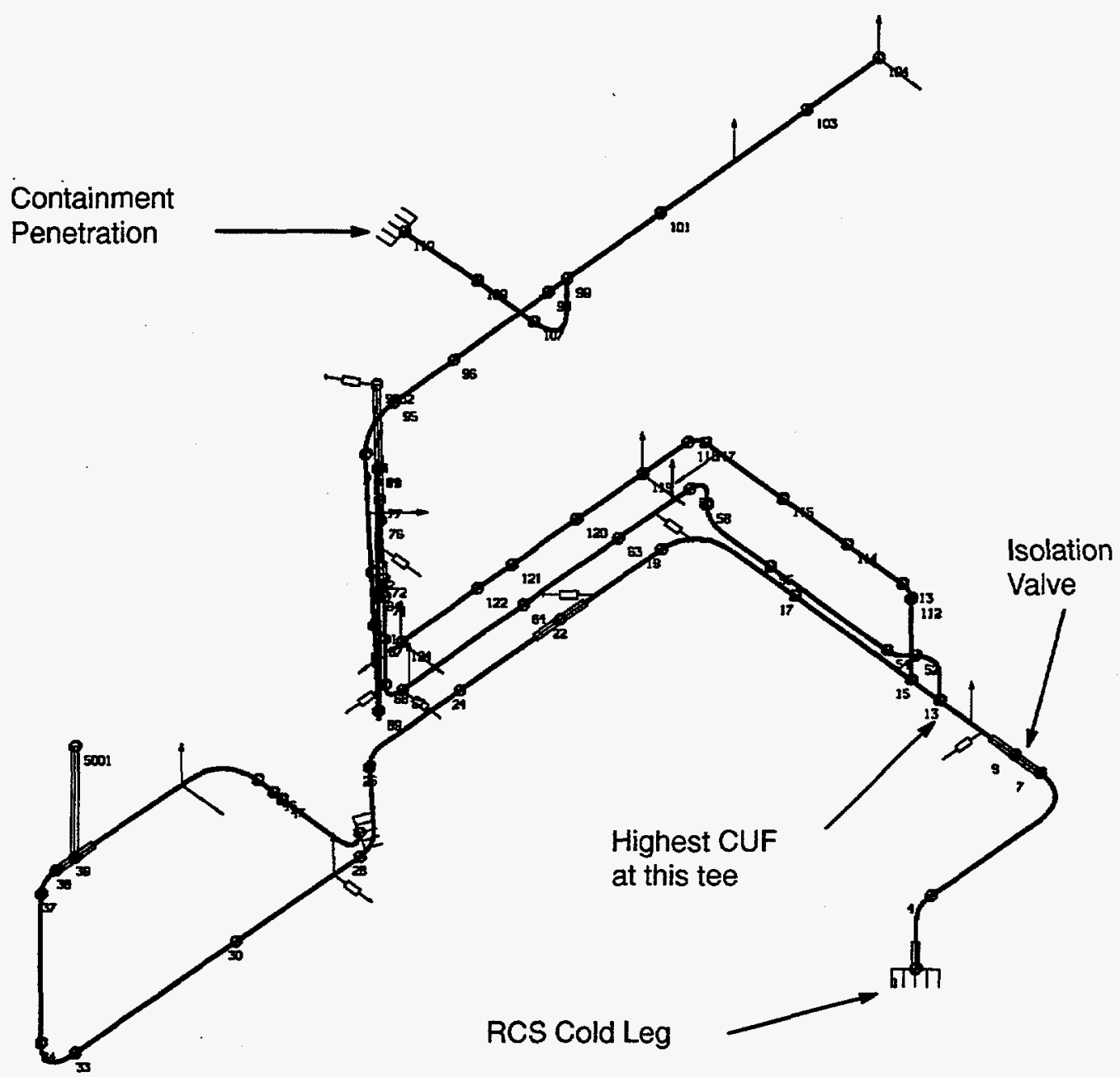

Figure 5-1. Shutdown cooling system model isometric view.

\subsubsection{NUREG/CR-5999 CUF with Con- servative Assumptions Removed. Since the CUF did not exceed 1.0 for 60 years, no further calculations were performed.}

\subsubsection{High Stresses in Connecting}

Piping. In performing fatigue calculations for the shutdown cooling system, we calculated CUFs only for locations on the shutdown cooling line itself; however, we modeled connecting piping in order to assure that branch line effects were properly considered. The computer code included stress calculations for these connecting lines, as well as the shutdown cooling line. At a 3-in. weldolet joining a 3 -in. line to a 12-in. line, the Class 1 stress limit (ASME Code NB-3600
Equation 12) was slightly exceeded (by about $.7 \%$ ), although the ASME Code Class 2 allowable value (ASME Code NC-3600 Equation 11) was not exceeded (the calculated stress was about $6 \%$ below its limit). The difference in the two calculations was that although the Class 1 allowable value is 1.5 times the Class 2 allowable value, the stress indices for the Class 1 analysis are greater than 1.5. Since these connecting lines were not included in the scope of work for this task, additional efforts to reduce analysis conservatisms (for example, an NB-3200 analysis) were not pursued. Changing one pipe support would probably reduce the high thermal expansion stresses below their Class 1 limit. 
Table 5-41. CUF results for the shutdown cooling system piping using NUREG/CR-5999 interim fatigue curve.

\begin{tabular}{lcccc}
\multicolumn{1}{c}{ Load pair } & $\mathrm{S}_{\text {alt }}$ & $\mathrm{N}$ & $\mathrm{n}$ & $\mathrm{u}$ \\
\hline $\begin{array}{l}\text { Shutdown cooling A/reactor trip } \\
\text { \& OBE }\end{array}$ & 47.60 & 3428 & 50 & 0.015 \\
Step increase/emergency & & & & \\
injection & 43.48 & 5911 & 70 & 0.012 \\
Shutdown cooling A/leak test & 43.10 & 6232 & 200 & 0.032 \\
Step increase/shutdown cooling A & 42.78 & 6517 & 250 & 0.038 \\
Shutdown cooling B/reactor trip & 35.26 & 20865 & 400 & 0.003 \\
Step increase/shutdown cooling B & 35.26 & 20865 & 100 & 0.005 \\
Step increase/leak test & 34.82 & 22503 & 200 & 0.009 \\
Step increase/null & 34.82 & 22503 & 500 & 0.022 \\
Step increase/cooldown & 25.38 & 150950 & 500 & 0.003 \\
& & & CUF & 0.139 \\
\hline
\end{tabular}

\subsubsection{CUF Based on Revised Interim} Fatigue Curves. Since the CUF extrapolated to 60 years was below 1.0 , the $0.001 \% / \mathrm{s}$ curve was used. The results are shown in Table 5-42. The extrapolated CUF for 60 years is 0.126 .

\subsubsection{Results and Conclusions. We} obtained the latest design basis fatigue calculations for five components on an older vintage Combustion Engineering plant, and calculated a representative design basis CUF for the sixth component. The CUF obtained from the design basis calculations for the location with the highest calculated fatigue usage on each component was recomputed using the NUREG/CR-5999 interim fatigue curves. The results are summarized in Table 5-43. The increases in the magnitudes of the design CUFs are as follows:

\section{Stainless Steel}

Surge line

11.45

Charging nozzle

Safety injection nozzle

Shutdown cooling piping

$\underline{9.93}$

12.78 average

\section{Carbon/Low-alloy Steel}

Reactor vessel shelly

lower head

Reactor vessel inlet nozzle

2.36

Reactor vessel outlet nozzle

1.95

\subsection{8 average}

Conservative assumptions were identified, and where justifiable, the design CUFs were recomputed with conservative assumptions removed. The 40-year CUFs were multiplied by 1.5 to determine a 60-year CUF, as shown in Table 5-43.

Using the NUREG/CR-5999 interim fatigue curves, the CUF remained below 1.0 for all components except the surge line, for which an NB-3600 piping analysis was used. Our judgment is that with more detailed analyses (that is, ASME Code NB-3200) or fatigue monitoring and cycle counting, the CUF could be reduced below 1.0 for the surge line. As listed in Table 5-33, a number of possibilities remain available to further reduce the CUF of the surge line. Using the revised interim fatigue curves, the CUF for 60 years was less than 1.0. 
Table 5-42. CUF results for the shutdown cooling system piping using revised interim fatigue curves.

\begin{tabular}{lcccc}
\hline \multicolumn{1}{c}{ Load pair } & $\mathrm{S}_{\text {alt }}$ & $\mathrm{N}$ & $\mathrm{n}$ & $\mathrm{u}$ \\
\hline $\begin{array}{l}\text { Shutdown cooling A/reactor trip } \\
\text { \& OBE }\end{array}$ & 47.60 & 4478 & 50 & 0.011 \\
$\begin{array}{l}\text { Step increase/emergency } \\
\text { injection }\end{array}$ & 43.48 & 9487 & 70 & 0.007 \\
Shutdown cooling A/leak test & 43.10 & 10342 & 200 & 0.019 \\
Step increase/shutdown cooling A & 42.78 & 11155 & 250 & 0.022 \\
Shutdown cooling B/reactor trip & 35.26 & 45784 & 400 & 0.009 \\
Step increase/shutdown cooling B & 35.26 & 45784 & 100 & 0.002 \\
Step increase/leak test & 34.82 & 49212 & 200 & 0.004 \\
Step increase/null & 34.82 & 49212 & 500 & 0.010 \\
Step increase/cooldown & 25.38 & $>10^{6}$ & 500 & 0.000 \\
& & & CUF & 0.084 \\
\hline
\end{tabular}

\subsection{B\&W Plant}

A comparison of the design CUFs from the licensee's design basis calculations and CUFs using the NUREG/CR-5999 interim fatigue curves was carried out for the locations of highest design CUF for the six components listed below:

1. Reactor vessel shell and lower head

2. Reactor vessel inlet and outlet nozzles

3. Surge line

4. Makeup/high pressure injection (HPI) nozzle

5. Reactor vessel core flood nozzle (decay heat removal system return)

6. Decay heat removal system Class 1 piping (a Class 1 fatigue analysis for the plant evaluated was never performed, so an analysis from another B\&W 177 fuel assembly plant was used).

As of early 1994, the plant has been operated approximately 23 of the 40 years currently approved in its operating license. Table 5-44 shows the design basis cycles for transients that are important from a fatigue standpoint for the six components that were evaluated. The numbers of transients to date have been extrapolated to 40 years by multiplying by $40 / 23$.

Fatigue monitoring of the surge line had been performed on this plant and the results were included in the licensee's calculations. The results were not used except to adjust the number of anticipated stratification cycles based on the expected number of heatups and cooldowns in Table 5-44.

The licensee and $B \& W$ have redefined the plant transients as part of their Allowable Operating Transient Cycles (AOTC) program. In this program, the heatup cycles have been divided into $35^{\circ} \mathrm{F} / \mathrm{h}$ ( $\left.30 \mathrm{cycles}\right), 60^{\circ} \mathrm{F} / \mathrm{h}$ ( 310 cycles) and $100^{\circ} \mathrm{F} / \mathrm{h}$ ( $\left.20 \mathrm{cycles}\right)$ transients. The cooldown cycles have been divided into $60^{\circ} \mathrm{F} / \mathrm{h}$ (170 cycles) and $100^{\circ} \mathrm{F} / \mathrm{h}$ (190 cycles) transients. The reactor trip has been divided into four types of trips and increased from 400 to 412 . The number of rapid depressurization cycles has been reduced from 80 to 40 . One purpose of this redefinition was to increase the number of allowable heatup/cooldown cycles. The heatup and cooldown cycles have been increased from 240 to 360 total cycles, but the numbers at $100^{\circ} \mathrm{F} / \mathrm{h}$ have been reduced from 240 to 20 . However, the numbers of cycles for several of the components [the reactor vessel (lower head, inlet and outlet nozzles, and core flood nozzle) and the makeup/HPI nozzle] were 
Table 5-43. Summary of older vintage Combustion Engineering plant CUFs.

\begin{tabular}{|c|c|c|c|c|c|c|c|c|c|}
\hline \multirow[b]{2}{*}{ Component } & \multirow[b]{2}{*}{ Location } & \multirow[b]{2}{*}{ Material } & \multirow[b]{2}{*}{$\begin{array}{l}\text { Design } \\
\text { CUF }\end{array}$} & \multicolumn{4}{|c|}{ NUREG/CR-5999 CUF } & \multicolumn{2}{|c|}{$\begin{array}{l}\text { Revised curves } \\
\text { (stainless steel) }\end{array}$} \\
\hline & & & & $\begin{array}{l}\text { Based on } \\
\text { design } \\
\text { stresses }\end{array}$ & $\begin{array}{l}\text { Conservative } \\
\text { assumptions } \\
\text { removed }\end{array}$ & $\begin{array}{l}\text { Based on } \\
\text { expected } \\
\text { cycles }\end{array}$ & $\begin{array}{l}\text { Extrapolated } \\
\text { to } 60 \text { years }\end{array}$ & 40 years & 60 years \\
\hline \multirow[t]{3}{*}{ Reactor vessel } & $\begin{array}{l}\text { At lower head } \\
\text { to shell juncture }\end{array}$ & $\begin{array}{l}\text { SA-533, Grade B, } \\
\text { Class } 1^{\text {a }}\end{array}$ & 0.008 & 0.013 & - & - & 0.020 & - & - \\
\hline & Inlet nozzle & SA-336 & 0.073 & 0.172 & - & - & 0.258 & - & - \\
\hline & Outlet nozzle & $\mathrm{SA}-336^{\mathrm{a}}$ & 0.284 & 0.554 & - & - & 0.831 & - & - \\
\hline Surge line & Elbow & SA-376, Type $316^{\mathrm{b}}$ & 0.705 & 8.070 & - & 1.345 & 2.018 & 0.661 & 0.992 \\
\hline Charging nozzle & Nozzle & SA-351, Type $316^{\mathrm{b}}$ & 0.266 & 3.918 & - & 0.666 & 0.999 & 0.562 & 0.843 \\
\hline $\begin{array}{l}\text { Safety injection } \\
\text { nozzle }\end{array}$ & Nozzle & SA-351, Type $316^{\mathrm{b}}$ & 0.088 & 1.320 & - & 0.414 & 0.621 & 0.317 & 0.476 \\
\hline $\begin{array}{l}\text { Shutdown cooling } \\
\text { line }\end{array}$ & Inlet transition & SA-376, Type $316^{\mathrm{b}}$ & $0.014^{c}$ & 0.139 & - & - & 0.209 & 0.084 & 0.126 \\
\hline
\end{tabular}


Table 5-44. Number of selected design basis cycles compared to anticipated number of cycles over 40-year license life.

\begin{tabular}{lcc}
\hline \multicolumn{1}{c}{ Transient } & $\begin{array}{c}\text { Design basis cycles: } \\
\text { original (AOTC) }\end{array}$ & $\begin{array}{c}\text { Anticipated cycles } \\
\text { for 40 years }\end{array}$ \\
\hline Heatup & $240(360)$ & 152 \\
Cooldown & $240(360)$ & 155 \\
Reactor trip & $400(412)$ & 214 \\
Rapid depressurization & $80(40)$ & 0 \\
Step load reduction & $160(310)$ & 47 \\
High pressure injection (HPI) & $70(70)$ & 33 \\
manual actuation & & 7 \\
HPI test & $40(40)$ & \\
\hline
\end{tabular}

analyzed for the original 240 cycles, and no updated analyses based on the AOTC revision were provided by the licensee. The surge line was analyzed using the AOTC transients, but since no details were provided of the surge line analysis, the only use we could make of the AOTC numbers was to ratio the numbers of the anticipated transients to the design basis transients. Since the decay heat removal system was from another $B \& W$ plant that does not incorporate AOTC transients, and since the CUF calculated using the NUREG/CR-5999 interim fatigue curve was less than 1.0 when extrapolated to 60 years, the AOTC numbers of cycles were not considered.

\subsubsection{Reactor Vessel Shell and Lower} Head. The highest CUFs on the shell and head are 0.360 for the support skirt, 0.120 for the lower lower head near the support skirt juncture, 0.158 for the instrumentation nozzles, and $0.564^{\mathrm{d}}$ for the weld where the instrumentation penetrations are joined to the lower head. Since the support skirt location is on the outer wall, it is not in contact with the primary coolant and thus is not subject to full environmental fatigue effects. The effect of the NUREG/CR-5999 interim fatigue curves is calculated for the low-alloy steel head

d. This value was calculated in the licensee's design analysis using the design fatigue curve for low-alloy steel instead of Alloy 600 . Using the Alloy 600 curve results in a CUF of 0.097 . and for the partial penetration weld joining the Alloy 600 instrumentation nozzles to the head. The SA-302 Grade B head is protected from the coolant by a layer of stainless steel cladding. No fatigue analysis was performed for the cladding. The Alloy 600 weld is in direct contact with the coolant.

\subsubsection{NUREG/CR-5999 CUF Based on Licensee's Design Calculation Stresses for Reactor Vessel Lower. Head. The effect} of the NUREG/CR-5999 interim fatigue curve is shown in Table 5-45. As previously discussed, the results shown in Table 5-45 assume that the coolant is in contact with the low-alloy steel base metal underneath the cladding. The licensee's CUF calculations used the ASME Code, Section III, 1965 edition, through Summer 1967 Addenda. The $S_{\text {alt }}$ value shown in Table 5-45 was adjusted for the effect of the modulus of elasticity in the licensee's design calculations. The value of the modulus of elasticity in the current (1992) ASME Code fatigue curve for carbon/low-alloy steel has not changed. The calculations lumped all load sets that were considered to affect the lower head into a single load pair.

Application of the NUREG/CR-5999 interim fatigue curve increased the CUF by a factor of 1.86 over the design basis number. If the plant is operated for 60 years, the CUF is 0.335 and would not exceed the ASME Code limit of 1.0. 
Table 5-45. CUF results for reactor vessel lower head using NUREG/CR-5999 interim fatigue curve.

\begin{tabular}{lccccc}
\hline & Load pair & $\mathrm{S}_{\text {alt }}$ & $\mathrm{N}$ & $\mathrm{n}$ & $\mathrm{u}$ \\
\hline All & 35.30 & 6449 & 1440 & 0.223 \\
\cline { 4 - 5 } & & & CUF & 0.223 \\
\hline
\end{tabular}

5.3.1.2 NUREG/CR-5999 CUF Based on Licensee's Design Calculation Stresses for Instrumentation Penetration Weld. The effect of the NUREG/CR-5999 interim fatigue curve is shown in Table 5-46. NUREG/CR-5999 does not include an interim fatigue curve for Alloy 600 , so the stainless steel curve was used. The licensee's CUF calculations used the ASME Code, Section III, 1965 edition, through Summer 1967 Addenda. B\&W informed us that the weld material is Alloy 600. Therefore the licensee's analysis used the incorrect fatigue curve from the ASME Code (the carbon /low-alloy steel curve was used instead of the stainless steel/Alloy 600 curve). We used the curve for Alloy 600 and calculated the CUF as 0.097 (instead of 0.564). We assumed that the correct material properties for the weld were used in the licensee's analysis to compute the stresses.

The $S_{\text {alt }}$ values shown in the first column of Table 5-46 were not adjusted for the effect of the modulus of elasticity in the licensee's design calculations. This adjustment was not required in the 1965 edition of the ASME Code. The average value of the modulus of elasticity that was used in the design calculation was $29.26 \times 10^{6} \mathrm{psi}$. Since NUREG/CR-5999 uses a modulus of elasticity of $28.3 \times 10^{6} \mathrm{psi}$, the $S_{\text {alt }}$ values were multiplied by $28.3 / 29.26$, and these adjusted $S_{\text {alt }}$ values (shown in the second column of Table 5-46) were used to calculate the CUF.

Application of the NUREG/CR-5999 interim fatigue curve increased the CUF by a factor of 15.11 over the (corrected, that is, 0.097) design basis number. The CUF exceeds the ASME Code limit of 1.0 .
5.3.1.3 NUREG/CR-5999 CUF with Conservative Assumptions Removed for Reactor Vessel Lower Head. Since the CUF did not exceed the ASME Code limit of 1.0 for 60 years, no further calculations were performed.

\subsubsection{NUREG/CR-5999 CUF with Con-} servative Assumptions Removed for Instrumentation Penetration Weld. The CUF was calculated conservatively in that the heatup and cooldown ( 240 cycles), reactor trip from full power ( 400 cycles), and rapid depressurization ( 80 cycles) transients have been lumped together into the first load pairing. A review of the calculations showed that a maximum cooldown rate of $300^{\circ} \mathrm{F} / \mathrm{h}$ for the rapid depressurization transient was used to envelope all three transients. The only other transient for which there were analysis results was for the end of the cooldown, where the cooldown rate was $35^{\circ} \mathrm{F} / \mathrm{h}$. However, the allowable number of cycles for this low cooldown rate was 594, which are not very much greater than the 491 cycles calculated for the $300^{\circ} \mathrm{F} / \mathrm{h}$ cooldown rate. Therefore, there does not appear to be a great deal of benefit to be gained by separating the first load pair. We do know that the AOTC program has broken the heatup/cooldown transient into separate rates, and the reactor trips have been broken into four types. However, we were not provided with stress/fatigue analyses that could be used to reduce the conservative assumptions in the design basis analyses.

A fatigue strength reduction factor (FSRF) of 4 was applied to the partial penetration weld in accordance with ASME Code NB-3352.4(d)(5). The Code does not differentiate between the crown and the root of the weld. The obvious location of the stress concentration is at the root of the weld, but there was no reason for the Code to consider the crown or root since environmental effects were not recognized. However, if 
Table 5-46. CUF results for instrumentation penetration weld using NUREG/CR-5999 interim fatigue curve.

\begin{tabular}{lccccc}
\hline \multicolumn{1}{c}{ Load pair } & $\mathrm{S}_{\text {alt }}$ & $\mathrm{S}_{\text {alt }}$ (adjusted) & $\mathrm{N}$ & $\mathrm{n}$ & $\mathrm{u}$ \\
\hline $\begin{array}{l}\text { Heatup/cooldown/reactor trip/rapid } \\
\text { depressurization }\end{array}$ & 71.30 & 68.96 & 491 & 720 & 1.466 \\
Step load reduction/turbine trip & 23.48 & 22.99 & $>10^{6}$ & 390 & 0.000 \\
& & & & $\mathrm{CUF}$ & 1.466 \\
\hline
\end{tabular}

environmental effects are considered, the weld crown (which would have less stress concentration) is in contact with the primary coolant, whereas the weld root is the location of the full stress concentration, but is not in contact with the primary coolant. Thus, this is a potential conservatism; however, according to current Code rules, the FSRF is appropriate for the weld. On the other hand, the weld root does experience the environmental effect of temperature.

The licensee provided us with the numbers of cycles for selected transients. These are shown in Table 5-44. Using 155 cycles for heatup/cooldown, 214 cycles for reactor trip, and 0 cycles of rapid depressurization, a revised CUF is shown in Table 5-47. The revised CUF is less than the ASME Code limit of 1.0. If the plant is operated for 60 years, the extrapolated CUF is 1.113 . A summary of the potential to eliminate conservative assumptions to reduce the CUF is shown in Table 5-48.

\subsubsection{NUREG/CR-5999 CUF Based on Revised Interim Curves for Instru- mentation Penetration Weld. Since the CUF extrapolated to 60 years was below 1.0 (using the revised interim fatigue curves), the $0.001 \% / \mathrm{s}$ curve was used. The results are shown in Table 5-49. The extrapolated CUF for 60 years is 0.819 .}

\subsubsection{Reactor Vessel Inlet and Outlet} Nozzles. No analysis was performed for the inlet nozzle since in the judgment of the licensee's analyst, the CUF would be less than the outlet nozzle. This has been true for the other inlet and outlet nozzle calculations that we have reviewed for reactor vessels in Westinghouse and Combustion Engineering plants. B\&W stated that they are currently performing fatigue analyses of the inlet nozzles for their 177 fuel assembly plants. The SA-508 Class 2 nozzle is protected from the coolant by a layer of stainless steel cladding. No fatigue analysis was performed for the cladding.

\subsubsection{NUREG/CR-5999 CUF Based on Licensee's Design Calculation Stresses.} The licensee's design calculations showed that the highest CUF for the reactor vessel outlet nozzle is 0.143 The stress calculations were performed using an interaction analysis that did not distinguish between the inside and outside surfaces of the nozzle. The licensee's design CUF calculations used the ASME Code, Section III, 1965 edition, through Summer 1967 addenda.

Upon examination of the licensee's fatigue analysis, it was apparent that an inappropriate fatigue curve had been used. The calculations were performed using the carbon/low-alloy steel curve for materials with an ultimate tensile strength of 115-130 ksi (which first appears in the 1971 edition of the Code), rather than the curve in the 1965 edition (which is appropriate for SA-508 Class 2 material). If the current ASME Code is used, and the modulus of elasticity is adjusted by multiplying by $30 / 27.5$ (the adjustment made for the reactor vessel lower head in Section 5.3.1.1), the CUF is 1.418. The 1965 edition of the ASME Code did not require an adjustment for the modulus of elasticity. With no such adjustment the CUF would be 1.021 using the current ASME Code equations. No equations for allowable cycles as a function of $S_{\text {alt }}$ were included in the 1965 edition of the ASME Code. Rather, minor grid marks 
Table 5-47. CUF results for instrumentation penetration weld using NUREG/CR-5999 interim fatigue curve and anticipated cycles.

\begin{tabular}{|c|c|c|c|c|c|}
\hline Load pair & $\mathrm{S}_{\mathrm{alt}}$ & $\mathrm{S}_{\text {alt }}$ (adjusted) & $\mathbf{N}$ & $\mathrm{n}$ & $\mathrm{u}$ \\
\hline $\begin{array}{l}\text { Heatup/cooldown/reactor } \\
\text { trip/rapid depressurization }\end{array}$ & 71.30 & 68.63 & 497 & 369 & 0.742 \\
\hline \multirow[t]{2}{*}{ Step load reduction/turbine trip } & 23.48 & 22.60 & $>10^{6}$ & 390 & 0.000 \\
\hline & & & & CUF & 0.742 \\
\hline
\end{tabular}

Table 5-48. Potential for elimination of conservative assumptions to reduce CUF for instrumentation penetration weld using NUREG/CR-5999 interim fatigue curve.

\begin{tabular}{|c|c|c|c|}
\hline $\begin{array}{l}\text { Assumption } \\
\text { (Section 4.3) }\end{array}$ & $\begin{array}{l}\text { Potential } \\
\text { for use }\end{array}$ & Used & Comments \\
\hline $\begin{array}{l}\text { Correct CUF } \\
\text { calculation }\end{array}$ & Yes & Yes & Analyst used wrong fatigue curve \\
\hline Detailed load pairs & Yes & No & Insufficient detail \\
\hline SCF/FSRF & Yes & No & ASME Code requires FSRF $=4$ \\
\hline$S_{\mathrm{m}}$ value & No & No & $\mathrm{K}_{\mathrm{e}}=1$ \\
\hline $\begin{array}{l}\text { Material property } \\
\text { changes }\end{array}$ & Yes & No & Slight changes in $\mathrm{E}, \alpha$; insufficient detail \\
\hline Fatigue curve $E$ value & Yes & Yes & Adjustment was made for modulus of elasticity \\
\hline Code analysis changes & No & No & No changes \\
\hline Actual cycles & Yes & Yes & Adjustment was made for projected cycles \\
\hline High temperature rates & Yes & No & Actual heatup/cooldown rates are less than design \\
\hline $\begin{array}{l}\text { Detailed stress } \\
\text { modeling }\end{array}$ & Yes & No & Detailed finite element model of weld not used \\
\hline $\begin{array}{l}\text { Conservative thermal } \\
\text { parameters }\end{array}$ & Yes & No & Steep cooldown rate assumed \\
\hline $\begin{array}{l}\text { Time phasing of } \\
\text { stresses }\end{array}$ & No & No & Time phasing not expected to reduce vessel CUF \\
\hline Number of OBEs & No & No & OBE did not contribute to CUF \\
\hline CC N-411 damping & No & No & Dynamic loads did not contribute to CUF \\
\hline Number of hydrotests & No & No & Hydrotests did not contribute to CUF \\
\hline Fatigue monitoring & Yes & No & Actual transients may be less severe than design \\
\hline Plastic analysis & Yes & No & Elastic-plastic finite element analysis could be used \\
\hline
\end{tabular}

Table 5-49. CUF results for instrumentation penetration weld using revised interim fatigue curves with conservative assumptions removed and anticipated cycles.

\begin{tabular}{|c|c|c|c|c|c|}
\hline Load pair & $S_{\text {alt }}$ & $S_{\text {alt }}($ adjusted $)$ & $\mathrm{N}$ & $\mathrm{n}$ & $\mathbf{u}$ \\
\hline \multirow{2}{*}{$\begin{array}{l}\text { Heatup/cooldown/reactor } \\
\text { trip/rapid depressurization }\end{array}$} & 71.30 & 68.63 & 676 & 369 & 0.546 \\
\hline & & & & CUF & 0.546 \\
\hline
\end{tabular}


were placed on the log-log graph, and the analyst had to visually determine the allowable cycles. The CUF is about 0.9 using the minor grid marks on the ASME Code 1965 edition fatigue curve.

The $S_{\text {ait }}$ values were not adjusted for the effect of the modulus of elasticity in the design calculations, so the same adjustment that was made for the reactor vessel lower head in Section 5.3.1.1 was used, that is, the $S_{\text {alt }}$ values were multiplied by $30 / 27.5$. The effect of the NUREG/CR-5999 interim fatigue curves is shown in Table 5-50.

The Table 5-50 results indicate that the CUF increased by a factor of 2.39 over the (corrected) design basis number of 0.900 . The CUF exceeds the ASME Code limit of 1.0.

\subsubsection{NUREG/CR-5999 CUF with Con-} servative Assumptions Removed. The CUF is conservative in that a stress concentration factor (SCF) of 1.89 was imposed on the stresses caused by the piping loads at each location. This SCF is applicable to the radius on the exterior of the nozzle, but at the interior surface, where the metal is in contact with the coolant, there is no reentrant corner that would cause a stress concentration. The SCF may have been applied to the stresses caused by thermal loads in the nozzle as well as the piping loads, but there was insufficient detail in the analyses to determine if this was the case. However, removing the SCF from the stresses caused by the piping loads reduces the CUF below 1.0, so no further removal of conservative assumptions was undertaken. Furthermore, most of the CUF results from the 48,000 cycles of plant loading/unloading. Although the licensee did not provide the number of these cycles to date, based on the comparable numbers from the other plants we reviewed in this study, the cycles for this transient are probably no more than several hundred, since it is a base-loaded plant.

The revised CUF is shown in Table 5-51 and is less than the ASME Code limit of 1.0. If the plant is operated for 60 years, the extrapolated CUF is 0.704 .

5.3.3 Surge Line. The highest CUFs for the surge line piping and nozzles are 0.592 for the SA-508 Class 1 carbon steel hot leg nozzle and 0.490 for one of the SA-403 Type 304 stainless steel piping elbows. The latest fatigue analyses were performed by $B \& W$ to assess thermal stratification conditions as required by NRC Bulletin 88-11.

Table 5-50. CUF results for reactor vessel outlet nozzle using NUREG/CR-5999 interim fatigue curve.

\begin{tabular}{lccrrr}
\hline \multicolumn{1}{c}{ Load pair } & $\mathrm{S}_{\text {alt }}$ & $\mathrm{S}_{\text {alt }}($ adjusted $)$ & \multicolumn{1}{c}{$\mathrm{N}$} & \multicolumn{1}{c}{$\mathrm{n}$} & $\mathrm{u}$ \\
\hline Heatup/cooldown & 41.3 & 45.05 & 2483 & 240 & 0.097 \\
Step load/reactor trip & 26.8 & 29.24 & 12429 & 480 & 0.039 \\
Plant loading/unloading & 22.3 & 24.33 & 28260 & 48000 & 1.699 \\
All other & 21.8 & 23.78 & 31458 & 9850 & 0.313 \\
\cline { 5 - 6 } & & & & CUF & 2.148 \\
\hline
\end{tabular}

Table 5-51. CUF results for reactor vessel outlet nozzle using NUREG/CR-5999 interim fatigue curve with conservative assumptions removed.

\begin{tabular}{lccrrr}
\hline \multicolumn{1}{c}{ Load pair } & $\mathrm{S}_{\text {alt }}$ & $\mathrm{S}_{\text {alt }}$ (adjusted) & \multicolumn{1}{c}{$\mathbf{N}$} & \multicolumn{1}{c}{ n } & \multicolumn{1}{c}{$\mathbf{u}$} \\
\hline Heatup/cooldown & 34.8 & 37.96 & 4853 & 240 & 0.049 \\
Step load/reactor trip & 20.3 & 22.15 & 43885 & 480 & 0.011 \\
Plant loading/unloading & 15.8 & 17.24 & 138590 & 48000 & 0.346 \\
All other & 15.3 & 16.69 & 155130 & 9850 & 0.063 \\
\cline { 4 - 6 } & & & & CUF & 0.469 \\
\hline
\end{tabular}


5.3.3.1 NUREG/CR-5999 CUF for Surge Line Hot Leg Nozzle Based on Licensee's Design Calculation Stresses. The licensee's design CUF calculations used the ASME Code, Section III, 1986 edition. The $S_{\text {alt }}$ values were adjusted for the effect of the modulus of elasticity. There were approximately 300 load pairs in the analysis, so the calculations using the NUREG/CR-5999 interim fatigue curve are not reported in detail. The CUF using the NUREG/CR-5999 interim fatigue curve is 1.092 , which increased the CUF by a factor of 1.84 over the licensee's design basis number. The CUF exceeds the ASME Code limit of 1.0.

\subsubsection{NUREG/CR-5999 CUF for Surge Line Piping Based on Licensee's Design Calculation Stresses. The licensee's design} CUF calculations used the ASME Code, Section III, 1986 edition. B\&W stated that the load pairs and details of the analysis were not printed from the computer program that was used for the calculations. Since no details were available for using the NUREG/CR-5999 interim fatigue curves, our estimate is based on the average of the increase in the CUF for the other four stainless steel PWR plant surge lines $(8.85,11.45$, $10.18,7.57$ ). The average is 9.5 . (The location for the highest CUF on some of the other plants was at an elbow, the same as for the B\&W location to which we are applying the factor, while for other plants it was at the hot leg nozzle safe end). Applying this factor to the $B \& W$ plant surge line, the CUF using the NUREG/CR-5999 interim fatigue curve is 4.656 . The CUF exceeds the ASME Code limit of 1.0.

\subsubsection{NUREG/CR-5999 CUF for Surge Line Hot Leg Nozzle with Conservative Assumptions Removed. The analysis conducted by $B \& W$ was very detailed, and no apparent conservative assumptions could readily be removed. If we assume that the analysis was based on 360 heatup/cooldown transients and adjust for the 155 cycles in Table 5-44, the CUF would be reduced to 0.470 . If the plant is operated for 60 years, the extrapolated CUF is 0.705 .}

\subsubsection{NUREG/CR-5999 CUF for Surge} Line Piping with Conservative Assumptions Removed. The analysis conducted by $B \& W$ was very detailed, including a full plastic analysis to ensure that shakedown to elastic action occurs. No apparent conservative assumptions could readily be eliminated. If we assume that the analysis was based on 360 heatup/ cooldown transients and adjust for the 155 cycles in Table 5-44, the CUF would be reduced to 2.005. If the plant is operated for 60 years, the extrapolated CUF is 3.008 . A summary of the potential for elimination of conservative assumptions to reduce the CUF is shown in Table 5-52.

\subsubsection{CUF Based on Revised Interim} Fatigue Curves. The estimated surge line CUF is based on the decrease in the surge line CUFs for the other four PWRs. The average of the CUFs using the revised interim fatigue curves was $66.7 \%$ of the CUFs using the NUREG/CR-5999 curve; therefore, the 40- and 60-year CUFs are 1.338 and 2.007 , respectively.

\subsubsection{Makeup/High Pressure Injection} Nozzle. The nozzle consists of a carbon steel forging and a SA-376 Type 316 stainless steel safe end. The highest CUF is 0.740 for the inside surface of the safe end. Since the effect of the NUREG/CR-5999 interim fatigue curves is greater for stainless steel than for carbon/low-alloy steel, and since the safe end metal is in direct contact with the primary system coolant, the CUF for the safe end was investigated.

\footnotetext{
5.3.4.1 NUREG/CR-5999 CUF Based on Licensee's Design Calculation Stresses. The licensee's CUF calculations used the draft USAS B31.7 1968 Code, through June 1968 errata. In the licensee's calculations, the $S_{\text {alt }}$ values were adjusted for the effect of the modulus of elasticity using a value of $26 \times 10^{6} \mathrm{psi}$ (the value in pre-1980 ASME Code editions). The NUREG/ CR-5999 curves are based on a modulus of elasticity of $28.3 \times 10^{6} \mathrm{psi}$, so the $S_{\text {alt }}$ values were multiplied by $28.3 / 26$. The CUF using the NUREG/CR-5999 interim fatigue curves is shown in Table 5-53.
} 
Table 5-52. Potential for elimination of conservative assumptions to reduce CUF for surge line using NUREG/CR-5999 interim fatigue curve.

\begin{tabular}{|c|c|c|c|}
\hline $\begin{array}{l}\text { Assumption } \\
\text { (Section 4.3) }\end{array}$ & $\begin{array}{l}\text { Potential } \\
\text { for use }\end{array}$ & Used & Comments \\
\hline $\begin{array}{l}\text { Correct CUF } \\
\text { calculation }\end{array}$ & No & No & Analysis appears to be correct \\
\hline Detailed load pairs & No & No & Detailed load pairs were used \\
\hline SCF/FSRF & Yes & No & Insufficient detail \\
\hline$S_{m}$ value & No & No & Average $S_{\mathrm{m}}$ at $\max$ and $\min$ temperatures used \\
\hline $\begin{array}{l}\text { Material property } \\
\text { changes }\end{array}$ & No & No & 1986 Code edition was used \\
\hline Fatigue curve $E$ value & No & No & 1986 Code edition was used \\
\hline Code analysis changes & No & No & 1986 Code edition was used \\
\hline Actual cycles & Yes & Yes & Adjustment was made for projected cycles \\
\hline High temperature rates & No & No & Transients based on measurements \\
\hline $\begin{array}{l}\text { Detailed stress } \\
\text { modeling }\end{array}$ & No & No & Detailed finite element model used \\
\hline $\begin{array}{l}\text { Conservative thermal } \\
\text { parameters }\end{array}$ & Yes & No & $\begin{array}{l}\text { Conservative heat transfer coefficients may have been } \\
\text { used }\end{array}$ \\
\hline $\begin{array}{l}\text { Time phasing of } \\
\text { stresses }\end{array}$ & No & No & Time phasing not expected to reduce nozzle CUF \\
\hline Number of OBEs & No & No & OBE did not contribute to CUF \\
\hline CC N-411 damping & No & No & Dynamic loads did not contribute to CUF \\
\hline Number of hydrotests & No & No & Hydrotests did not contribute to CUF \\
\hline Fatigue monitoring & Yes & No & Actual transients may be less severe than design \\
\hline Plastic analysis & No & No & Elastic plastic finite element analysis was used \\
\hline
\end{tabular}

Table 5-53. CUF results for makeup/HPI nozzle using NUREG/CR-5999 interim fatigue curve.

\begin{tabular}{lccrrc}
\hline \multicolumn{1}{c}{ Load pair } & $\mathrm{S}_{\text {alt }}$ & $\mathrm{S}_{\text {alt }}$ (adjusted) & $\mathrm{N}$ & $\mathrm{n}$ & $\mathrm{u}$ \\
\hline HPI actuation A/B \& OBE & 209.2 & 227.71 & 27 & 30 & 1.111 \\
HPI actuation A/B & 200.8 & 218.56 & 30 & 40 & 1.333 \\
Rapid depressurization A/B & 192.2 & 209.20 & 34 & 40 & 1.176 \\
Test/null & 117.3 & 127.68 & 112 & 40 & 0.357 \\
Heatup/cooldown & 11.01 & 11.98 & $>10^{6}$ & 200 & 0.000 \\
\cline { 4 - 6 } & & & & CUF & 3.977 \\
\hline
\end{tabular}


The Table 5-53 results indicate that the CUF increased by a factor of 5.37 over the design basis number. The CUF exceeds the ASME Code limit of 1.0 .

\subsubsection{NUREG/CR-5999 CUF with Con-} servative Assumptions Removed. The high CUF resulted from the manual HPI actuation with and without OBE (load pairs 1 and 2), rapid depressurization (load pair 3), and HPI test transients (load pair 4), all of which have in operation been rare events (see Table 5-44), but which have high postulated cooldown rates associated with them. An interaction model of the nozzle was used in the licensee's analysis, and the thermal analysis assumptions were probably overly severe. However, we have insufficient information to assess the degree of conservatism. When the anticipated numbers of cycles from Table 5-44 are used, the resulting CUF is shown in Table 5-54. If the plant is operated for 60 years, the extrapolated CUF is 1.761 .

The licensee's analysis used an interaction model to determine the thermal stresses, and applied the elastic-plastic penalty factors in B31.7. The method in B31.7 is different than in the present ASME Code edition. Two multipliers, $\mathrm{K}_{\mathrm{f}}$ and $\mathrm{K}_{\mathrm{e}}$, are used in B31.7. The product of these values ranged from 2.514 to 3.364 in the licensee's calculations. Using the current Code equations, $\mathrm{K}_{\mathrm{e}}$ is 3.333 and the CUF increases to 1.263 (Table 5-55). If the plant is operated for 60 years, the CUF is 1.895 . For the transient that is the major contributor to the CUF, it was assumed that while the nozzle is at $579^{\circ} \mathrm{F}, 60^{\circ} \mathrm{F}$ fluid is injected for a short time and then stopped so that the temperature of the nozzle returns to $579^{\circ} \mathrm{F}$. This assumption is very severe.

A summary of the potential to eliminate conservative assumptions to reduce the CUF is shown in Table 5-56. Probably the most promising reduction could be made by considering this nozzle to be a piping component and relying on the change to ASME Table 3217-2 in the classification of the linear radial thermal gradient. The stress caused by a linear radial thermal gradient was classified as a secondary stress In B31.7-1968, while it is classified as a peak stress

Table 5-54. CUF results for makeup/HPI nozzle using NUREG/CR-5999 interim fatigue curve and anticipated cycles.

\begin{tabular}{|c|c|c|c|c|c|}
\hline Load pair & $S_{\text {alt }}$ & $S_{\text {alt }}($ adjusted $)$ & $\mathrm{N}$ & $\mathrm{n}$ & $\mathbf{u}$ \\
\hline HPI actuation $\mathrm{A} / \mathrm{B} \& \mathrm{OBE}$ & 209.2 & 227.71 & 27 & 0 & 0.000 \\
\hline HPI actuation A/B & 200.8 & 218.56 & 30 & 33 & 1.111 \\
\hline Rapid depressurization A/B & 192.2 & 209.20 & 34 & 0 & 0.000 \\
\hline Test/null & 117.3 & 127.68 & 112 & 7 & 0.063 \\
\hline \multirow[t]{2}{*}{ Heatup/cooldown } & 11.01 & 11.98 & $>10^{6}$ & 200 & 0.000 \\
\hline & & & & CUF & 1.174 \\
\hline
\end{tabular}

Table 5-55. CUF results for makeup/HPI nozzle using NUREG/CR-5999 interim fatigue curve based on anticipated numbers of cycles and 1992 Code edition $\mathrm{K}_{\mathrm{e}}$.

\begin{tabular}{lccrrr}
\multicolumn{1}{c}{ Load pair } & \multicolumn{1}{c}{$\mathrm{S}_{\text {alt }}$} & $\mathrm{S}_{\text {alt }}$ (adjusted) & $\mathrm{N}$ & $\mathrm{n}$ & $\mathrm{u}$ \\
\hline HPI actuation A/B \& OBE & 207.28 & 225.62 & 27 & 0 & 0.000 \\
HPI actuation A/B & 203.26 & 221.24 & 29 & 33 & 1.138 \\
Rapid depressurization A/B & 195.65 & 212.96 & 32 & 0 & 0.000 \\
Test/null & 155.55 & 169.31 & 56 & 7 & 0.125 \\
Heatup/cooldown & 11.01 & 11.98 & $>10^{6}$ & 200 & 0.000 \\
\cline { 3 - 6 } & & & & $\mathrm{CUF}$ & 1.263 \\
\hline
\end{tabular}


Table 5-56. Potential for elimination of conservative assumptions to reduce CUF for makeup/high pressure injection nozzle using NUREG/CR-5999 interim fatigue curve.

\begin{tabular}{|c|c|c|c|}
\hline $\begin{array}{l}\text { Assumption } \\
\text { (Section 4.3) }\end{array}$ & $\begin{array}{l}\text { Potential } \\
\text { for use }\end{array}$ & Used & Comments \\
\hline $\begin{array}{l}\text { Correct CUF } \\
\text { calculation }\end{array}$ & No & No & Analysis appear to be correct \\
\hline Detailed load pairs & No & No & Detailed load pairs were used \\
\hline SCF/FSRF & Yes & No & Insufficient detail \\
\hline$S_{\mathrm{m}}$ value & Yes & No & Potential for use if $K_{e}$ could be reduced \\
\hline $\begin{array}{l}\text { Material property } \\
\text { changes }\end{array}$ & Yes & No & Insufficient detail \\
\hline Fatigue curve $\mathrm{E}$ value & Yes & Yes & Adjustment was made for modulus of elasticity \\
\hline Code analysis changes & Yes & No & $\begin{array}{l}\text { Table } 3217-2 \text { stress classification for linear radial } \\
\text { thermal gradient changed to peak stress }\end{array}$ \\
\hline Actual cycles & Yes & Yes & Adjustment was made for projected cycles \\
\hline High temperature rates & Yes & No & Actual $\Delta T$ probably less than design \\
\hline $\begin{array}{l}\text { Detailed stress } \\
\text { modeling }\end{array}$ & Yes & No & Interaction model used \\
\hline $\begin{array}{l}\text { Conservative thermal } \\
\text { parameters }\end{array}$ & Yes & No & $\begin{array}{l}\text { Conservative heat transfer coefficients may have been } \\
\text { used }\end{array}$ \\
\hline $\begin{array}{l}\text { Time phasing of } \\
\text { stresses }\end{array}$ & No & No & Time phasing not expected to reduce nozzle CUF \\
\hline Number of OBEs & Yes & Yes & OBE minimal contributor to CUF \\
\hline CC N-411 damping & No & No & Dynamic loads minimal contributor to CUF \\
\hline Number of hydrotests & No & No & Hydrotests did not contribute to CUF \\
\hline Fatigue monitoring & Yes & No & Actual transients probably less severe than design \\
\hline Plastic analysis & Yes & No & Elastic plastic finite element analysis could be used \\
\hline
\end{tabular}

in the current (1992) edition of the ASME Code. We did not have sufficient information from the licensee's analysis to separate the stresses caused by a radial thermal gradient from those caused by an axial thermal gradient. However, based on our analysis of the charging system nozzle for the older vintage Westinghouse plant (Section 5.5.4), most of the stresses in the nozzle-to-piping region during a thermal shock is caused by the radial thermal gradient. Reclassifying the stress caused by a radial thermal gradient as a peak stress could reduce the primary-plus-secondary stress intensity range below the $3 S_{m}$ limit, reducing the $K_{e}$ factor to 1 . This would lower $S_{\text {alt }}$ and no doubt reduce the CUF below 1.0.
5.3.4.3 CUF Based on Revised Interim Curves. The strain rates for the two contributing load pairs are 0.0261 and $0.0199 \% / \mathrm{s}$ respectively. Using these strain rates, the CUF results are shown in Table 5-57. The extrapolated CUF for 60 years is 1.577 .

5.3.5 Core Flood Nozzle. The nozzle consists of a SA-508 Class 2 low-alloy steel forging and a SA-336-F8m stainless steel safe end. The highest CUF reported by the licensee for the nozzle is 0.345, and the highest CUF for the safe end is essentially zero, so the estimate of the NUREG/CR-5999 interim fatigue curve effects will be made for the nozzle. No differentiation is 
Table 5-57. CUF results for makeup/HPI nozzle using NUREG/CR-5999 interim fatigue curve based on anticipated numbers of cycles and 1992 Code edition $\mathrm{K}_{\mathrm{e}}$.

\begin{tabular}{lccrrc}
\hline \multicolumn{1}{c}{ Load pair } & $\mathrm{S}_{\text {alt }}$ & $\mathrm{S}_{\text {alt }}$ (adjusted) & $\mathrm{N}$ & $\mathrm{n}$ & $\mathrm{u}$ \\
\hline HPI actuation A/B \& OBE & 207.28 & 225.62 & 34 & 0 & 0.000 \\
HPI actuation A/B & 203.26 & 221.24 & 35 & 33 & 0.943 \\
Rapid depressurization A/B & 195.65 & 212.96 & 38 & 0 & 0.000 \\
Test/null & 155.55 & 169.31 & 65 & 7 & 0.108 \\
Heatup/cooldown & 11.01 & 11.98 & $>10^{6}$ & 200 & 0.000 \\
\cline { 4 - 6 } & & & & CUF & 1.051 \\
\hline
\end{tabular}

made between the inside and outside surfaces of the nozzle. The low-alloy steel is clad with a layer of stainless steel and therefore is not in direct contact with the reactor coolant. No fatigue analysis is performed for the cladding.

\subsubsection{NUREG/CR-5999 CUF Based on Licensee's Design Calculation Stresses.} The licensee's design CUF calculations used the ASME Code, 1965 edition, through Summer 1967 addenda. The $S_{\text {alt }}$ values were not adjusted for the effect of the modulus of elasticity in the design calculations because the 1965 ASME Code procedure did not call for this adjustment. However, since we are using the NUREG/CR-5999 interim fatigue curve and the 1992 ASME Code, an adjustment was made by multiplying $S_{\text {alt }}$ by $30 / 27.5$, the factor that was used for the reactor vessel lower head. The CUF using the licensee's stress values and the NUREG/CR-5999 interim fatigue curve is shown in Table 5-58.

Application of the NUREG/CR-5999 interim fatigue curve increased the CUF by a factor of 1.83 over the design basis number. The CUF does not exceed the ASME Code limit of 1.0. If the plant is operated for 60 years, the extrapolated CUF would be 0.948 .

5.3.5.2 NUREG/CR-5999 CUF with Conservative Assumptions Removed. Since the CUF did not exceed the ASME Code limit of 1.0 for 60 years, no further calculations were performed.

\subsubsection{Decay Heat Removal System Class 1 Piping. Although we intended to}

review the decay heat removal system piping from the plant selected for review, we found that Class 1 fatigue analyses were never performed on this system. Subsequently, the licensee arranged for the review of fatigue calculations for this system from another B\&W 177 fuel assembly plant. The transients for both plants are essentially the same, so we considered that the alternate plant's fatigue analysis was representative of the plant being evaluated, and applied the projected number of cycles for the plant being evaluated.

The fatigue analysis for the decay heat removal system piping was performed in 1990. The highest CUF was for a SA-376 Type 316 stainless steel reducing tee (CUF $=3.310$ for the 480 design cycles), so operation was limited to a reduced number of startup/shutdown cycles.

\subsubsection{CUF Results for the Decay Heat Removal System Piping Using NUREG/CR-5999 and Licensee's Design Calculation Stresses. The CUF calculations used the B31.7 Code. The $S_{\text {alt }}$ values were not adjusted for the effect of the modulus of elasticity, since B31.7 does not call for an adjustment of the modulus of elasticity. The CUF using the NUREG/CR-5999 interim fatigue curves is shown in Table 5-59. Application of the NUREG/CR-5999 interim fatigue curve increased the CUF by a factor of 4.29 over the design basis number.}

\subsubsection{NUREG/CR-5999 CUF with Con-} servative Assumptions Removed. There are several conservative assumptions that can be removed. The B31.7 Code used in the analysis 
Table 5-58. CUF results for core flood nozzle using NUREG/CR-5999 interim fatigue curve.

\begin{tabular}{lccrrr}
\hline \multicolumn{1}{c}{ Load pair } & $\mathrm{S}_{\text {alt }}$ & $\mathrm{S}_{\text {alt }}$ (adjusted) & $\mathrm{N}$ & $\mathrm{n}$ & $\mathrm{u}$ \\
\hline Plant loading/unloading & 23 & 25.09 & 24465 & 240 & 0.010 \\
Heatup/cooldown & 18 & 19.64 & 77128 & 48000 & 0.622 \\
& & & & $\mathrm{CUF}$ & 0.632 \\
\hline
\end{tabular}

Table 5-59. CUF results for the decay heat removal system piping using NUREG/CR-5999 interim fatigue curve.

\begin{tabular}{lrrrc}
\hline \multicolumn{1}{c}{ Load pair } & $\mathrm{S}_{\mathrm{alt}}$ & $\mathrm{N}$ & $\mathrm{n}$ & $\mathrm{u}$ \\
\hline Cooldown/OBE- & 261.76 & 20 & 30 & 1.500 \\
Cooldown/OBEt & 261.76 & 20 & 30 & 1.500 \\
Cooldown/rod withdrawal & 218.69 & 30 & 40 & 1.333 \\
Cooldown/power reduction & 196.62 & 39 & 160 & 4.103 \\
Cooldown/unloading & 196.50 & 39 & 220 & 5.641 \\
Hydrotest A/hydrotest B & 57.11 & 1145 & 20 & 0.017 \\
Rapid depressurization/leakage & 45.95 & 4239 & 80 & 0.019 \\
backflow & & & & \\
Unloading/null & 44.35 & 5246 & 480 & 0.091 \\
Functional test/leakage backflow & 39.77 & 10111 & 40 & 0.004 \\
Unloading/functional test & 31.72 & 39443 & 40 & 0.001 \\
& & & CUF & 14.209 \\
\hline
\end{tabular}

included the $\Delta T_{1}$ term in the primary plus secondary stress intensity range used in the calculation for $\mathrm{K}_{e}$, so this was removed. The analysis used a coefficient of thermal expansion of $9.11 \times 10^{-6} \mathrm{in} / \mathrm{in} /{ }^{\circ} \mathrm{F}$, whereas the $1992 \mathrm{ASME}$ Code lists a value of $8.42 \times 10^{-6} \mathrm{in} / \mathrm{in} /{ }^{\circ} \mathrm{F}$. Finally, the $S_{m}$ value used in the calculation for $K_{e}$ was adjusted to the average value for the maximum and minimum temperatures of each of the first five transients (where $K_{e}>1$ ). The results of these three changes are shown in Table 5-60.

The licensee provided us with the numbers of cycles for selected transients. These are shown in Table 5-44. Using 155 cycles for cooldown (included in the first five load pairs) and 47 cycles for power reduction step load changes (load pair 4), a revised CUF is shown in Table 5-61. If the plant is operated for 60 years, the extrapolated
CUF is 0.915 . The first two load pairs include OBE cycles, none of which have occurred to date, so elimination of these cycles would further reduce the CUF.

\subsubsection{CUF Based on Revised Interim} Fatigue Curves. Since the CUF extrapolated to 60 years was below 1.0 , the $0.001 \% / \mathrm{s}$ curve was used. The results are shown in Table 5-62. The extrapolated CUF for 60 years is 0.795 .

5.3.7 Results and Conclusions. We obtained the latest design basis fatigue calculations for six components on a B\&W 177 fuel assembly plant. The design CUF obtained from the licensee's calculations for the location with the highest calculated fatigue usage on each component was recomputed using the NUREG/ CR-5999 interim fatigue curves. The results are summarized 
Table 5-60. CUF results for the decay heat removal system piping using NUREG/CR-5999 interim fatigue curve with conservative assumptions removed.

\begin{tabular}{lcccc}
\hline \multicolumn{1}{c}{ Load pair } & $\mathrm{S}_{\text {alt }}$ & $\mathrm{N}$ & $\mathrm{n}$ & $\mathrm{u}$ \\
\hline Cooldown/OBE- & 94.81 & 228 & 30 & 0.132 \\
Cooldown/OBE+ & 94.81 & 228 & 30 & 0.132 \\
Cooldown/rod withdrawal & 74.13 & 412 & 40 & 0.097 \\
Cooldown/power reduction & 70.12 & 471 & 160 & 0.340 \\
Cooldown/unloading & 69.87 & 475 & 220 & 0.463 \\
Hydrotest A/hydrotest B & 57.11 & 1145 & 20 & 0.017 \\
Rapid depressurization/leakage & 45.95 & 4239 & 80 & 0.019 \\
backflow & & & & \\
Unloading/null & 44.35 & 5246 & 480 & 0.091 \\
Functional test/leakage backflow & 39.77 & 10111 & 40 & 0.004 \\
Unloading/functional test & 31.72 & 39443 & 40 & 0.001 \\
& & & CUF & 1.296 \\
\hline
\end{tabular}

Table 5-61. CUF results for the decay heat removal system piping using NUREG/CR-5999 interim fatigue curve with conservative assumptions removed and anticipated cycles.

\begin{tabular}{lcccc}
\hline \multicolumn{1}{c}{ Load pair } & $\mathrm{S}_{\text {alt }}$ & $\mathrm{N}$ & $\mathrm{n}$ & $\mathrm{u}$ \\
\hline Cooldown/OBE- & 94.81 & 228 & 30 & 0.132 \\
Cooldown/OBE + & 94.81 & 228 & 30 & 0.132 \\
Cooldown/rod withdrawal & 74.13 & 412 & 40 & 0.097 \\
Cooldown/power reduction & 70.12 & 471 & 47 & 0.100 \\
Cooldown/unloading & 69.87 & 475 & 8 & 0.017 \\
Hydrotest A/hydrotest B & 57.11 & 1145 & 20 & 0.017 \\
Rapid depressurization/leakage & 45.95 & 4239 & 80 & 0.019 \\
backflow & & & & \\
Unloading/null & 44.35 & 5246 & 480 & 0.091 \\
Functional test/leakage backflow & 39.77 & 10111 & 40 & 0.004 \\
Unloading/functional test & 31.72 & 39443 & 40 & 0.001 \\
& & & CUF & 0.610 \\
\hline
\end{tabular}

in Table 5-63. The increases in the magnitudes of the design CUFs are as follows:

$$
\text { Stainless steel/Alloy } 600
$$

Instrument nozzle weld

Surge line piping

Makeup/HPI nozzle

Decay heat removal piping
15.11 insufficient detail

4.29 8.26 average
Carbon/Low-alloy Steel

Reactor vessel shell/lower head

Reactor vessel outlet nozzle

Surge line hot leg nozzle

Decay heat removal line 
Table 5-62. CUF results for the decay heat removal system piping using revised interim fatigue curve with conservative assumptions removed and anticipated cycles.

\begin{tabular}{lcccc}
\hline \multicolumn{1}{c}{ Load pair } & $\mathrm{S}_{\text {alt }}$ & $\mathrm{N}$ & $\mathrm{n}$ & $\mathrm{u}$ \\
\hline Cooldown/OBE- & 94.81 & 221 & 30 & 0.136 \\
Cooldown/OBE + & 94.81 & 221 & 30 & 0.136 \\
Cooldown/rod withdrawal & 74.13 & 504 & 40 & 0.079 \\
Cooldown/power reduction & 70.12 & 622 & 47 & 0.076 \\
Cooldown/unloading & 69.87 & 631 & 8 & 0.013 \\
Hydrotest A/hydrotest B & 57.11 & 1522 & 20 & 0.013 \\
Rapid depressurization/leakage & 45.95 & 5849 & 80 & 0.014 \\
backflow & & & & \\
Unloading/null & 44.35 & 7890 & 480 & 0.061 \\
Functional test/leakage backflow & 39.77 & 24682 & 40 & 0.002 \\
Unloading/functional test & 31.72 & 89843 & 40 & 0.000 \\
& & & CUF & 0.530 \\
\hline
\end{tabular}

Conservative assumptions were identified, and where justifiable, the design CUFs were recomputed with conservative assumptions removed. The 40 -year CUFs were multiplied by 1.5 to determine a 60 -year CUF, as shown in Table 5-63.

All components have 40-year CUFs less than 1.0 with the exception of the surge line and the makeup/HPI nozzle. Since an NB-3200 plastic analysis has already been used to lower the CUF, it appears that a better description of thermal stratification transients (which may be less conservative that that used in the licensee's analysis) would be required to reduce the CUF for the surge line below 1.0 . The $519^{\circ} \mathrm{F}$ step change in makeup/ HPI nozzle temperature is probably overly conservative and a more realistic transient would no doubt reduce the CUF to less than 1.0. Reclassifying the stress caused by the radial thermal gradient as a peak stress (a change from the B31.7 Code used in the analysis to the present ASME Code edition) could reduce the primary-plussecondary stress intensity range below the $3 \mathrm{~S}_{\mathrm{m}}$ limit, and no doubt reduce the CUF below 1.0. The CUF for the instrumentation nozzle weld in the lower head exceeds 1.0 for 60 years using the NUREG/CR-5999 interim fatigue curve, but is less than 1.0 using the revised interim curves.

\subsection{Newer Vintage Westinghouse Plant}

A comparison of the design CUFs from the licensee's design basis calculations and CUFs using the NUREG/CR-5999 interim fatigue curves was carried out for the locations of highest design CUF for the six components listed below:

1. Reactor vessel shell and lower head

2. Reactor vessel inlet and outlet nozzles

3. Surge line

4. Charging nozzle

5. Safety injection nozzle

6. Residual heat removal (RHR) system Class 1 piping.

As of early 1994 , the plant has been operated approximately 4 of the 40 years currently approved in its operating license. Table 5-64 shows the design basis cycles for transients that are important from a fatigue standpoint for the six components that were evaluated. The numbers of transients to date have been extrapolated to 40 years by multiplying by $40 / 4$. 
Table 5-63. Summary of B\&W 177 fuel assembly plant CUFs.

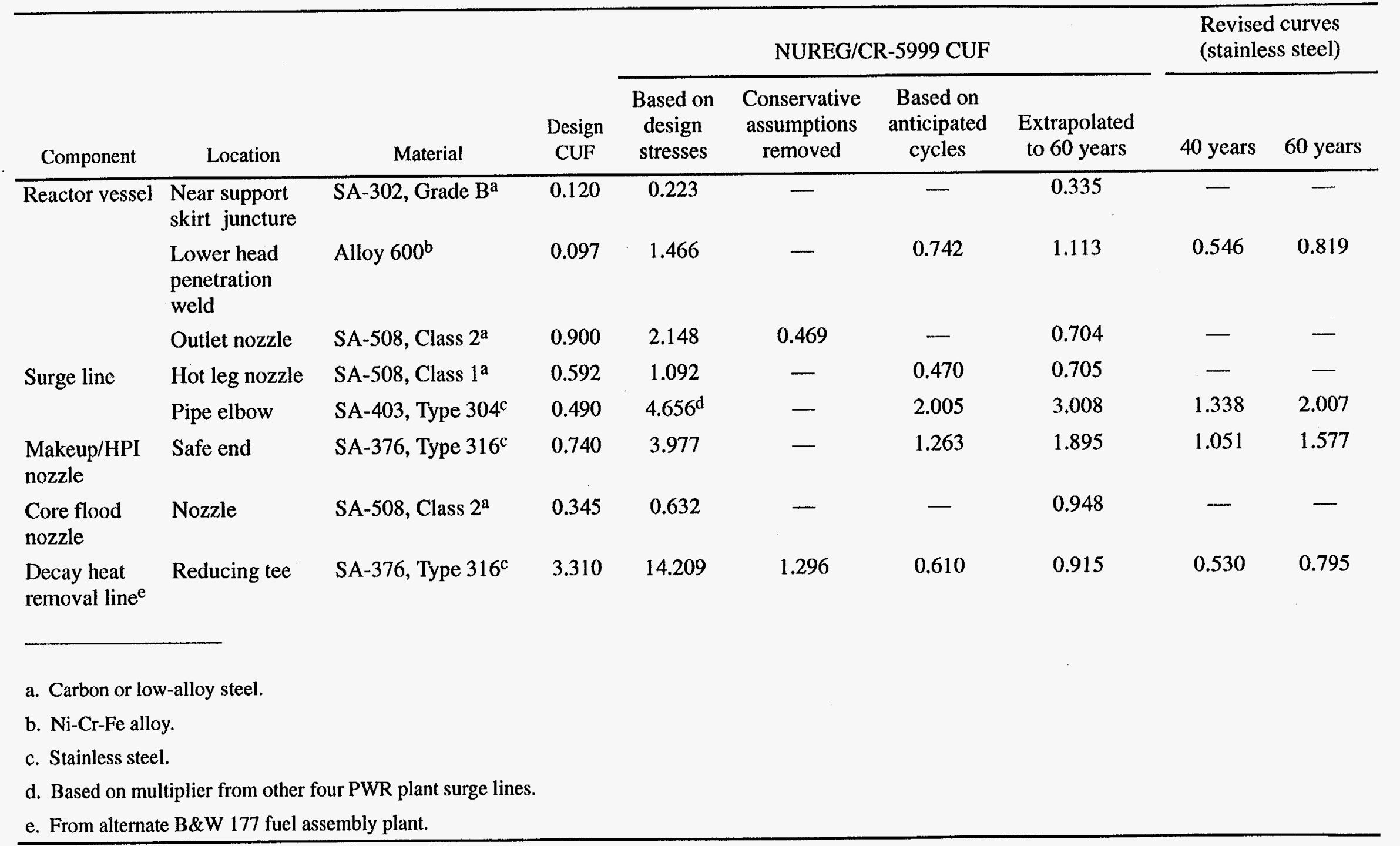


Table 5-64. Number of selected design basis cycles compared to anticipated number of cycles over the 40-year license life.

\begin{tabular}{lcc}
\hline \multicolumn{1}{c}{ Transient } & Design basis cycles & $\begin{array}{c}\text { Anticipated cycles } \\
\text { for 40 years }\end{array}$ \\
\hline Heatup & 200 & 65 \\
Cooldown & 200 & 55 \\
Reactor trip & 400 & 280 \\
Safety injection actuation & 60 & 30 \\
\hline
\end{tabular}

Fatigue monitoring results from a residual heat removal line were included in the licensee's calculations. In addition, the results of a generic Westinghouse plant study of thermal stratification in surge lines was included in the licensee's fatigue analysis of the surge line. There were no plant specific data to remove conservative assumptions for this particular plant. The results were not used except to adjust the number of anticipated stratification cycles based on the expected number of heatups and cooldowns in Table 5-64.

\subsubsection{Reactor Vessel Shell and Lower} Head. The highest CUF on the lower shell and head is 0.010 for the lower head at the shell-tohead transition. The SA-533 Grade B Class 1 head is protected from the coolant by a layer of stainless steel cladding. No fatigue analysis is performed for the cladding.

\subsubsection{NUREG/CR-5999 CUF Based on} Licensee's Design .Calculation Stresses. The licensee's CUF calculations used the ASME Code, Section III, 1971 edition, through Winter 1972 Addenda. No interpolation equations were available in this edition of the Code, so the analyst used the minor grid marks on the fatigue curve to determine the allowable numbers of cycles. Had the equations in the latest (1992) edition of the Code been used, the CUF would have been 0.012 .

The effect of the NUREG/CR-5999 interim fatigue curve is shown in Table 5-65. As previously discussed, the results shown in Table 5-65 assume that the coolant is in contact with the low-alloy steel base metal underneath the cladding. The $S_{\text {alt }}$ value was adjusted for the effect of the modulus of elasticity in the design calculations by multiplying by 1.111 . The value of the modulus of elasticity in the current (1992) ASME Code fatigue curve for carbon/low-alloy steel has not changed.

Application of the NUREG/CR-5999 interim fatigue curve increased the CUF by a factor of 1.50 over the (corrected) licensee's design basis number. If the plant is operated for 60 years, the CUF is 0.027 and would not exceed the ASME Code limit of 1.0.

\subsubsection{NUREG/CR-5999 CUF with Con- servative Assumptions Removed. Since} the CUF did not exceed the ASME Code limit of 1.0 for 60 years, no further calculations were performed.

\subsubsection{Reactor Vessel Inlet and Outlet} Nozzles. The CUFs for the inlet and outlet nozzles are 0.110 and 0.398 , respectively. Each of the SA-508 Class 2 nozzles is protected from the coolant by a layer of stainless steel cladding. No fatigue analysis is performed for the cladding.

\footnotetext{
5.4.2.1 NUREG/CR-5999 CUF Based on Licensee's Design Calculation Stresses for Inlet Nozzle. The licensee's design CUF calculations used the ASME Code, Section III, 1971 edition, through Winter 1972 addenda. The $S_{\text {alt }}$ values were adjusted for the effect of the modulus of elasticity in the design calculations by multiplying by 1.111 , so the same adjustment was made for the revised calculation. The effect of the NUREG/CR-5999 interim fatigue curve is shown in Table 5-66. The load pairs on the copy of the
} 
Table 5-65. CUF results for reactor vessel lower head using NUREG/CR-5999 interim fatigue curve.

\begin{tabular}{lccccc}
\hline \multicolumn{1}{c}{ Load pair } & $\mathrm{S}_{\mathrm{alt}}$ & $\mathrm{S}_{\text {alt }}$ (adjusted) & $\mathrm{N}$ & $\mathrm{n}$ & $\mathrm{u}$ \\
\hline Turbine roll/inadvertent & 22.29 & 25.21 & 23924 & 20 & 0.001 \\
depressurization & & & & & \\
Reactor trip/heatup & 22.03 & 24.48 & 27457 & 200 & 0.007 \\
Reactor trip/hydrotest & 21.92 & 24.35 & 28151 & 10 & 0.000 \\
Reactor trip/leak test & 21.92 & 24.35 & 28151 & 190 & 0.007 \\
Inadvertent loop & 18.96 & 21.06 & 55599 & 10 & 0.000 \\
startup/hydrotest & & & & & \\
Leak test A/leak test B & 18.77 & 20.85 & 58274 & 80 & 0.001 \\
Control rod drop/refueling & 15.31 & 17.01 & 145216 & 80 & 0.001 \\
Inadvertent safety & 13.30 & 14.78 & 237713 & 60 & 0.000 \\
injection/cooldown & & & & & \\
Feedwater cycling/cooldown & 13.14 & 14.60 & 248183 & 140 & 0.001 \\
& & & & $\mathrm{CUF}$ & 0.018 \\
\hline
\end{tabular}

Table 5-66. CUF results for reactor vessel inlet nozzle using NUREG/CR-5999 interim fatigue curve.

\begin{tabular}{ccrrc}
\hline $\mathrm{S}_{\text {alt }}$ & $\mathrm{S}_{\text {alt }}$ (adjusted) & N & n & u \\
\hline 50.17 & 55.74 & 1119 & 200 & 0.179 \\
44.94 & 49.73 & 1676 & 10 & 0.006 \\
42.40 & 47.11 & 2078 & 20 & 0.010 \\
39.42 & 43.80 & 2772 & 10 & 0.004 \\
38.94 & 43.26 & 2910 & 250 & 0.086 \\
26.81 & 27.79 & 15150 & 80 & 0.005 \\
23.95 & 26.61 & 18568 & 20 & 0.001 \\
17.14 & 19.04 & 89205 & 50 & 0.001 \\
15.49 & 17.21 & 139432 & 30 & 0.008 \\
28.67 & 9.63 & $3.2 \times 10^{6}$ & 30 & 0.000 \\
& & & CUF & 0.290 \\
\hline
\end{tabular}

licensee's analysis were smeared and very difficult to read. Since the CUF for 60 years was below 1.0 and the load pairs were not used to reduce conservative assumptions, the load pairs are not shown in Table 5-66.

The Table 5-66 results indicate that the CUF increased by a factor of 2.64 over the design basis number of 0.110 . The CUF does not exceed the ASME Code limit of 1.0. If the plant is operated for 60 years, the CUF is 0.435 .

\subsubsection{NUREG/CR-5999 CUF Based on} Licensee's Design Calculation Stresses for Outlet Nozzle. The licensee's design CUF calculations used the ASME Code, Section III, 1971 edition, through Winter 1972 addenda. The $S_{\text {alt }}$ values were adjusted for the effect of the modulus of elasticity in the design calculations by multiplying by 1.111 , so the same adjustment was made for the revised calculation. The effect of the NUREG/CR-5999 interim fatigue curve is shown in Table 5-67. The load pairs on the copy of the 
Table 5-67. CUF results for reactor vessel outlet nozzle using NUREG/CR-5999 interim fatigue curve.

\begin{tabular}{ccrrr}
\hline$S_{\text {alt }}$ & $\mathrm{S}_{\text {alt }}($ adjusted $)$ & $\mathrm{N}$ & $\mathrm{n}$ & $\mathrm{u}$ \\
\hline 43.82 & 48.68 & 1825 & 80 & 0.044 \\
40.86 & 45.40 & 2407 & 10 & 0.004 \\
39.91 & 44.34 & 2642 & 20 & 0.008 \\
35.95 & 39.94 & 3977 & 20 & 0.005 \\
30.95 & 34.39 & 7012 & 70 & 0.010 \\
26.38 & 29.31 & 12320 & 130 & 0.011 \\
25.47 & 28.30 & 14013 & 150 & 0.011 \\
24.38 & 27.09 & 17075 & 50 & 0.003 \\
24.29 & 26.99 & 17374 & 30 & 0.002 \\
19.56 & 21.37 & 51918 & 40 & 0.001 \\
18.18 & 20.20 & 67603 & 1930 & 0.029 \\
18.18 & 20.20 & 67603 & 2000 & 0.030 \\
18.12 & 20.13 & 68712 & 9270 & 0.135 \\
16.97 & 18.85 & 93499 & 60 & 0.001 \\
16.60 & 18.44 & 103654 & 230 & 0.002 \\
16.52 & 18.35 & 106059 & 10 & 0.000 \\
16.25 & 18.05 & 114581 & 80 & 0.001 \\
15.88 & 17.64 & 127614 & 160 & 0.001 \\
15.88 & 17.64 & 127614 & 26400 & 0.207 \\
15.35 & 17.05 & 144035 & 2000 & 0.014 \\
14.75 & 16.39 & 165234 & 400 & 0.002 \\
14.39 & 15.99 & 180237 & 13200 & 0.073 \\
13.83 & 15.37 & 207136 & 13200 & 0.064 \\
13.41 & 14.90 & 231047 & 80 & 0.000 \\
13.36 & 14.84 & 234349 & 80 & 0.000 \\
13.23 & 14.70 & 242295 & 0.000 \\
\hline & & & 0.658 \\
\hline
\end{tabular}

licensee's analysis were smeared and very difficult to read. Since the CUF for 60 years was below 1.0 and the load pairs were not used to reduce conservative assumptions, the load pairs are not shown in Table 5-67.

The Table 5-67 results indicate that the CUF increased by a factor of 1.65 over the design basis number of 0.398 . The CUF does not exceed the ASME Code limit of 1.0. If the plant is operated for 60 years, the CUF is 0.987 .
5.4.2.3 NUREG/CR-5999 CUF with Conservative Assumptions Removed. Since the CUF did not exceed the ASME Code limit of 1.0 for' 60 years, no further calculations were performed.

5.4.3 Surge Line. The highest CUF for the surge line piping and nozzles was 0.743 for the SA-182 F316N stainless steel hot leg nozzle near the safe-end-to-piping transition. The latest fatigue analyses were performed by Westinghouse 
to assess thermal stratification conditions as required by NRC Bulletin 88-11.

\subsubsection{NUREG/CR-5999 CUF Based on Licensee's Design Calculation Stresses.} The licensee's design CUF calculations used the ASME Code, Section III, 1986 edition. The $S_{\text {alt }}$ values were adjusted for the effect of the modulus of elasticity. There are a large number of load pairs in the analysis, so the calculations using the NUREG/CR-5999 interim fatigue curve are not reported in detail. The CUF using the NUREG/CR-5999 interim fatigue curve is 7.562, which increased the CUF by a factor of 10.18 over the licensee's design basis number. The CUF exceeds the ASME Code limit of 1.0.

\subsubsection{NUREG/CR-5999 CUF with Con-} servative Assumptions Removed. Two areas in the first group of potential conservative assumptions that possibly could be applied to the surge line are (1) conservative stress indices and (2) conservative numbers of estimated cycles. While the stress indices used appear reasonable, they are not the same that would be obtained from Table NB-3681(a)-1 of the ASME Code. The CUF results almost entirely from the heatup transients. From Table 5-64, the number of anticipated heatup cycles for 40 years is 65 , whereas 200 design cycles were used in the licensee's design CUF calculation. Furthermore, 20 OBE events were used in the licensee's design CUF calculation, but none have occurred to date. The CUF after 40 years can be estimated by multiplying 7.562 by $65 / 200$, resulting in a 2.458 CUF. If the plant is operated for 60 years, the CUF would be 3.687 .

There are a number of other potential conservative assumptions that could be removed, as shown in Table 5-68. [The stress indices are included under the stress concentration factor (SCF) and fatigue strength reduction factor (FSRF) category in Table 5-68.] For example, performing a detailed finite element analysis using NB-3200 methods may reduce the CUF calculated using NB-3600 piping rules. The stratification temperature differences assumed in the analysis are probably conservative, and the CUF computed from thermal striping exceeds that computed by other vendors considerably. Other potential conservative assumptions such as the use of ASME Code Case N-411 (CC N-411) damping values had already been taken advantage of in the licensee's design basis calculations. If removing the conservative assumptions did not reduce the CUF below 1.0 , then fatigue monitoring or plastic analyses could be used.

\subsubsection{CUF Based on Revised Interim} Fatigue Curves. From a review of the licensee's stress analysis, it appears that the strain rates from all transients were low; consequently, the $0.001 \% / \mathrm{s}$ curve was used for all load pairs. The CUF is 5.335. The number of anticipated heatup cycles for 40 years is 65 , whereas 200 design cycles were used in the licensee's design CUF calculation. The CUF after 40 years can be estimated by multiplying 5.335 by $65 / 200$, resulting in a 1.734 CUF. If the plant is operated for 60 years, the CUF would be 2.601 .

5.4.4 Charging Nozzle. The highest CUF for the SA-182 F316N stainless steel nozzle is 0.829 near the knuckle region.

\subsubsection{NUREG/CR-5999 CUF Based on Licensee's Design Calculation Stresses.} The licensee's design CUF calculations used the ASME Code, Section III, 1977 edition, through Summer 1979 addenda. The $S_{\text {alt }}$ values were adjusted for the effect of the modulus of elasticity. The CUF using the NUREG/CR-5999 interim fatigue curves is shown in Table 5-69. Seven loads pairs made significant contributions to the CUF. Application of the NUREG/CR-5999 interim fatigue curve increased the CUF by a factor of 6.26 over the licensee's design basis number. 
Table 5-68. Potential for elimination of conservative assumptions to reduce CUF for surge line hot leg nozzle using NUREG/CR-5999 interim fatigue curve.

\begin{tabular}{lccl}
\hline \multicolumn{1}{c}{$\begin{array}{c}\text { Assumption } \\
\text { (Section 4.3) }\end{array}$} & $\begin{array}{c}\text { Potential } \\
\text { for use }\end{array}$ & Used & \multicolumn{1}{c}{ Comments } \\
\hline Correct CUF calculation & No & No & Analysis appear to be correct \\
Detailed load pairs & No & No & Detailed load pairs were used \\
SCF/FSRF & Yes & No & Insufficient information \\
$S_{\mathrm{m}}$ value & No & No & Average $S_{\mathrm{m}}$ values used \\
Material property & No & No & No changes, 1986 Code edition used \\
changes & & & \\
Fatigue curve E value & No & No & Proper adjustment was made \\
Code analysis changes & No & No & No changes, 1986 Code edition used \\
Actual cycles & Yes & Yes & Adjustment was made for projected cycles \\
High temperature rates & Yes & No & Actual cooldown rates probably less than design \\
Detailed stress modeling & Yes & No & NB-3600 analysis used \\
Conservative thermal & Yes & No & CUF from thermal striping may be conservative \\
parameters & & & \\
Time phasing of stresses & Yes & No & Highest moment and thermal stresses may not occur \\
& & & simultaneously \\
Number of OBEs & No & No Only 20 OBE cycles were assumed \\
CC N-411 damping & No & No CC N-411 damping used \\
Number of hydrotests & No & No Hydrotests did not contribute to CUF \\
Fatigue monitoring & Yes & No Actual transients probably less severe than design \\
Plastic analysis & Yes & No Elastic plastic finite element analysis could be used \\
\hline
\end{tabular}

Table 5-69. CUF results for charging nozzle using NUREG/CR-5999 interim fatigue curve.

\begin{tabular}{lrrrr}
\hline \multicolumn{1}{c}{ Load pair } & \multicolumn{1}{c}{$\mathrm{S}_{\mathrm{alt}}$} & $\mathrm{N}$ & $\mathrm{n}$ & $\mathrm{u}$ \\
\hline Loss of charging-prompt return/null & 146.24 & 80 & 120 & 1.500 \\
Loss of charging-delayed return/null & 145.52 & 81 & 12 & 0.148 \\
Normal charging and letdown shutdown/null & 101.06 & 196 & 60 & 0.306 \\
Loss of letdown-delayed return/null & 56.05 & 1282 & 8 & 0.006 \\
Reactor trip/OBE & 54.23 & 1563 & 20 & 0.013 \\
Loss of letdown-delayed return/flow increase & 47.47 & 3484 & 4 & 0.001 \\
Loss of charging-prompt return/flow increase & 46.47 & 3961 & 120 & 0.030 \\
Step increase in charging/flow increase & 41.74 & 7558 & 14276 & 1.887 \\
Step increase in charging/flow decrease & 40.87 & 8580 & 124 & 0.014 \\
Letdown increase/flow decrease & 38.49 & 12311 & 1076 & 0.087 \\
Letdown increase/reactor trip & 37.35 & 14754 & 30 & 0.002 \\
Letdown increase/flow increase & 36.74 & 16291 & 13294 & 0.816 \\
Cooldown/flow increase & 35.48 & 20098 & 5 & 0.000 \\
Flow decrease/flow increase & 34.88 & 22271 & 1101 & 0.049 \\
Flow decrease/reactor trip & 34.13 & 25384 & 10 & 0.000 \\
Letdown increase/letdown decrease & 32.33 & 35171 & 89 & 0.003 \\
Letdown increase/flow decrease & 31.17 & 43822 & 14311 & 0.326 \\
Reactor trip/flow decrease & 30.33 & 51654 & 5 & 0.000 \\
\hline
\end{tabular}




\subsubsection{NUREG/CR-5999 CUF with Con- servative Assumptions Removed. The} fatigue analysis was performed recently (1989) using a fairly recent (Summer 1979 addenda) ASME Code edition. While the stress indices used appear reasonable, they are not the same that would be obtained from Table NB-3681(a)-1 of the ASME Code. As with the BIT nozzle in Section 5.4.5, the nozzle is made of SA-182 $316 \mathrm{~F}$ material, but the fatigue analysis was conducted using $S_{m}$ values for CF8A (cast Type 304 stainless steel) in the generic Westinghouse fatigue calculation computer program. These $S_{m}$ values are lower (more conservative) than for SA-182 F316N stainless steel. The results of applying this conservative assumption reduction are shown in Table 5-70. As with other PWRs, the licensee does not count the numbers of transients that are the significant contributors to the CUF, for example, changes in letdown and charging system flow. Therefore, we do not have sufficient information to estimate the anticipated cycles. The high fatigue usage is a result of a large num- ber of cycles of various loss of letdown and loss of charging system flow. Other PWRs have reported that the actual cycles of these types of transients are less than the numbers assumed in the design calculations. If the plant is operated for 60 years, the CUF is 7.288 .

There are a number of other potential conservatisms that could be eliminated, such as using a NB-3200 finite element analysis. The list of potential conservative assumptions that could be removed is shown in Table 5-71. If removing these conservative assumptions did not reduce the CUF below 1.0, then fatigue monitoring or plastic analyses could be used.

\subsubsection{CUF Based on Revised Interim} Fatigue Curves. The licensee's calculations did not contain sufficient information to determine the strain rates, so the $0.001 \% / \mathrm{s}$ curve was used. The CUF results are shown in Table 5-72. The extrapolated CUF for 60 years is 5.877. From the licensee's transient plots it appears that the

Table 5-70. CUF results for charging nozzle using NUREG/CR-5999 interim fatigue curve with conservative assumptions removed.

\begin{tabular}{lrrrc}
\hline \multicolumn{1}{c}{ Load pair } & \multicolumn{1}{c}{$\mathrm{S}_{\mathrm{alt}}$} & $\mathrm{N}$ & $\mathrm{n}$ & $\mathrm{u}$ \\
\hline Loss of charging-prompt return/null & 133.44 & 100 & 120 & 1.200 \\
Loss of charging-delayed return/null & 132.78 & 101 & 12 & 0.119 \\
Normal charging and letdown shutdown/null & 101.06 & 196 & 60 & 0.306 \\
Loss of letdown-delayed return/null & 56.05 & 1281 & 8 & 0.006 \\
Reactor trip/OBE & 54.23 & 1564 & 20 & 0.013 \\
Loss of letdown-delayed return/flow increase & 47.47 & 3483 & 4 & 0.001 \\
Loss of charging-prompt return/flow increase & 46.47 & 3960 & 120 & 0.030 \\
Step increase in charging/flow increase & 41.74 & 7564 & 14276 & 1.887 \\
Step increase in charging/flow decrease & 40.87 & 8580 & 124 & 0.014 \\
Letdown increase/flow decrease & 38.49 & 12304 & 1076 & 0.087 \\
Letdown increase/reactor trip & 37.35 & 14746 & 30 & 0.002 \\
Letdown increase/flow increase & 36.74 & 16288 & 13294 & 0.816 \\
Cooldown/flow increase & 35.48 & 20115 & 5 & 0.000 \\
Flow decrease/flow increase & 34.88 & 22290 & 1101 & 0.049 \\
Flow decrease/reactor trip & 34.13 & 25379 & 10 & 0.000 \\
Letdown increase/letdown decrease & 32.33 & 35171 & 89 & 0.003 \\
Letdown increase/flow decrease & 31.17 & 43839 & 14311 & 0.326 \\
Reactor trip/flow decrease & 30.33 & 51644 & 5 & 0.000 \\
& & & $\mathrm{CUF}$ & 4.859 \\
\hline
\end{tabular}


Table 5-71. Potential for elimination of conservative assumptions to reduce CUF for charging nozzle using NUREG/CR-5999 interim fatigue curve.

\begin{tabular}{lccl}
\hline \multicolumn{1}{c}{$\begin{array}{c}\text { Assumption } \\
\text { (Section 4.3) }\end{array}$} & $\begin{array}{c}\text { Potential } \\
\text { for use }\end{array}$ & Used & \multicolumn{1}{c}{ Comments } \\
\hline Correct CUF calculation & No & No & Analysis appear to be correct \\
Detailed load pairs & No & No & Detailed load pairs were used \\
SCF/FSRF & Yes & No & Insufficient information \\
$S_{\mathrm{m}}$ value & Yes & Yes & Conservative $S_{\mathrm{m}}$ used \\
Material property changes & No & No & No changes, Summer 1979 addenda used \\
Fatigue curve E value & No & No & Proper adjustment was made \\
Code analysis changes & No & No & No changes, Summer 1979 addenda used \\
Actual cycles & Yes & No & No data for numbers of actual cycles \\
High temperature rates & Yes & No & Actual rates probably less than design \\
Detailed stress modeling & Yes & No & NB-3600 analysis used \\
Conservative thermal & Yes & No & Conservative heat transfer coefficients may have \\
parameters & & & been used \\
Time phasing of stresses & Yes & No & Maximums of $\Delta \mathrm{T}_{1}, \Delta \mathrm{T}_{2}$, and $\mathrm{T}_{\mathrm{a}}-\mathrm{T}_{\mathrm{b}}$ terms may \\
& & & have been used \\
Number of OBEs & No & No & Only 20 OBE cycles were assumed \\
CC N-411 damping & No & No & CC N-411 damping used \\
Number of hydrotests & No & No & Hydrotests did not contribute to CUF \\
Fatigue monitoring & Yes & No & Actual transients probably less severe than design \\
Plastic analysis & Yes & No & Elastic plastic finite element analysis could be used \\
\hline
\end{tabular}

Table 5-72. CUF results for charging nozzle using revised interim fatigue curves with conservative assumptions removed.

\begin{tabular}{lrrrc}
\hline \multicolumn{1}{c}{ Load pair } & \multicolumn{1}{c}{$\mathrm{S}_{\text {alt }}$} & $\mathrm{N}$ & $\mathrm{n}$ & $\mathrm{u}$ \\
\hline Loss of charging-prompt return/null & 133.44 & 66 & 120 & 1.818 \\
Loss of charging-delayed return/null & 132.78 & 66 & 12 & 0.182 \\
Normal charging and letdown shutdown/null & 101.06 & 182 & 60 & 0.330 \\
Loss of letdown-delayed return/null & 56.05 & 1673 & 8 & 0.005 \\
Reactor trip/OBE & 54.23 & 1993 & 20 & 0.010 \\
Loss of letdown-delayed return/flow increase & 47.47 & 4565 & 4 & 0.001 \\
Loss of charging-prompt return/flow increase & 46.47 & 5355 & 120 & 0.022 \\
Step increase in charging/flow increase & 41.74 & 14611 & 14276 & 0.977 \\
Step increase in charging/flow decrease & 40.87 & 18864 & 124 & 0.007 \\
Letdown increase/flow decrease & 38.49 & 28848 & 1076 & 0.037 \\
Letdown increase/reactor trip & 37.35 & 33544 & 30 & 0.001 \\
Letdown increase/flow increase & 36.74 & 36555 & 13294 & 0.364 \\
Cooldown/flow increase & 35.48 & 44239 & 5 & 0.000 \\
Flow decrease/flow increase & 34.88 & 48763 & 1101 & 0.023 \\
Flow decrease/reactor trip & 34.13 & 55414 & 10 & 0.000 \\
Letdown increase/letdown decrease & 32.33 & 78577 & 89 & 0.001 \\
Letdown increase/flow decrease & 31.17 & 102284 & 14311 & 0.140 \\
Reactor trip/flow decrease & 30.33 & 126777 & 5 & 0.000 \\
\hline
\end{tabular}


transients for the first two load pairs last about 90 seconds, and the third load pair can be assumed to last about 30 seconds. Using the corresponding strain rates, the CUFs for 40 and 60 years are 3.373 and 5.060 .

5.4.5 Safety Injection Nozzle. In Westinghouse 4-loop plants, there are a number of nozzles through which safety injection water can enter the reactor coolant system. The highest CUF $(0.966)$ location on these nozzles is for the SA-182 F316N stainless steel boron injection tank (BIT) nozzle near the knuckle region. Therefore, this location was evaluated.

The BIT nozzle connects the $11 / 2$-in. boron injection line to the reactor coolant system at the cold leg. Flow through this line occurs whenever the high head portion of the safety injection system is activated.

\subsubsection{NUREG/CR-5999 CUF Based on Licensee's Design Calculation Stresses.}

The licensee's design CUF calculations used the ASME Code, Section III, 1977 edition, through Summer 1979 addenda. The $S_{\text {alt }}$ values were computed using the modulus of elasticity at room temperature, and NB-3600 requires no adjustment. The CUF using the NUREG/CR-5999 interim fatigue curve is shown in Table 5-73. The $A$ and $B$ on the transient designations refer to whether the safety injection water temperature was 32 or $60^{\circ} \mathrm{F}$. The heatup group represents a combination of several transients. Only the first 15 transients with high $S_{\text {alt }}$ values that are the major contributors to the CUF are included. Application of the NUREG/CR-5999 interim fatigue curve increased the CUF by a factor of 5.05 over the design basis number.

\subsubsection{NUREG/CR-5999 CUF with Con-} servative Assumptions Removed. The fatigue analysis was performed only a few years ago (1989) using a fairly recent (Summer 1979 addenda) ASME Code edition. While the stress indices used appear reasonable, they are not the

Table 5-73. CUF results for safety injection (BIT) nozzle using NUREG/CR-5999 interim fatigue curve.

\begin{tabular}{lrrrc}
\hline \multicolumn{1}{c}{ Load pair } & \multicolumn{1}{c}{$\mathrm{S}_{\text {alt }}$} & $\mathrm{N}$ & $\mathrm{n}$ & $\mathrm{u}$ \\
\hline Small LOCA B/OBE & 287.60 & 15 & 2 & 0.133 \\
Depressurization B/OBE & 272.67 & 18 & 10 & 0.556 \\
Reactor trip with cooldown B/heatup group & 267.56 & 18 & 5 & 0.278 \\
Contingency B/heatup group & 267.56 & 18 & 4 & 0.222 \\
Inadvertent SI B/heatup group & 266.95 & 19 & 30 & 1.579 \\
Large steamline break/heatup group & 254.24 & 21 & 1 & 0.048 \\
Small LOCA A/heatup group & 240.24 & 24 & 3 & 0.125 \\
Depressurization A/OBE & 238.67 & 24 & 5 & 0.208 \\
Reactor trip with cooldown A/heatup group & 238.67 & 24 & 5 & 0.208 \\
Contingency A/heatup group & 238.08 & 25 & 4 & 0.160 \\
Inadvertent SI A/heatup group & 238.01 & 25 & 30 & 1.200 \\
Depressurization A/loss of load & 174.48 & 52 & 5 & 0.096 \\
Small steamline break B/heatup group & 119.68 & 130 & 2 & 0.015 \\
Small steamline break A/heatup group & 99.29 & 204 & 3 & 0.015 \\
Large LOCA/loss of load & 68.45 & 500 & 10 & 0.020 \\
& 38.12 & 13069 & 74 & 0.006 \\
& 38.12 & 13069 & 42 & 0.003 \\
& 31.12 & 44248 & 20 & 0.000 \\
& 28.62 & 73247 & 148 & 0.002 \\
& 28.42 & 76405 & 7 & 0.000 \\
\hline
\end{tabular}


same that would be obtained from Table NB-3681(a)-1 of the ASME Code. There are two conservative assumptions that can readily be removed. The first is that while the nozzle is made of SA-182 F316N material, the fatigue analysis was conducted using $S_{m}$ values for CF8A (cast Type 304 stainless steel) in the generic Westinghouse computer program for fatigue calculations. These $S_{m}$ values are lower (more conservative) than for SA-182 F316N stainless steel. The second conservative assumption is that the CUF primarily results from low probability events, for example, small break loss-of-coolant accident (LOCA), small and large steamline breaks, and rapid depressurization. Eliminating these three types of transients, and using the anticipated cycles from Table 5-64 (the safety injection cycles are reduced to 30 ), the CUF can be significantly lowered. The results of applying these conservative assumption reductions are shown in Tables 5-74 and 5-75. If the plant is operated for 60 years, the CUF is 2.267 .

Table 5-74. CUF results for safety injection (BIT) nozzle using NUREG/CR-5999 interim fatigue curve with conservative assumptions removed.

\begin{tabular}{lrrrr}
\hline \multicolumn{1}{c}{ Load pair } & \multicolumn{1}{c}{$\mathrm{S}_{\text {alt }}$} & $\mathrm{N}$ & $\mathrm{n}$ & $\mathrm{u}$ \\
\hline Small LOCA B/OBE & 226.91 & 28 & 2 & 0.071 \\
Depressurization B/OBE & 214.50 & 32 & 10 & 0.313 \\
Reactor trip with cooldown B/heatup group & 260.12 & 20 & 5 & 0.250 \\
Contingency B/heatup group & 260.12 & 20 & 4 & 0.200 \\
Inadvertent SI B/heatup group & 259.53 & 20 & 30 & 1.500 \\
Large steamline break/heatup group & 252.80 & 21 & 1 & 0.048 \\
Small LOCA A & 198.35 & 38 & 3 & 0.079 \\
Depressurization A/OBE & 186.80 & 44 & 5 & 0.114 \\
Reactor trip with cooldown A/heatup group & 230.70 & 27 & 5 & 0.185 \\
Contingency A/heatup group & 230.70 & 27 & 4 & 0.148 \\
Inadvertent SI A/heatup group & 230.11 & 27 & 30 & 1.111 \\
Depressurization A/loss of load & 153.21 & 72 & 5 & 0.069 \\
Small steamline break B/heatup group & 115.09 & 143 & 2 & 0.014 \\
Small steamline break A/heatup group & 94.55 & 233 & 3 & 0.013 \\
Large LOCA/loss of load & 66.45 & 537 & 10 & 0.019 \\
& 38.12 & 13069 & 74 & 0.006 \\
& 38.12 & 13069 & 42 & 0.003 \\
& 31.12 & 44248 & 20 & 0.000 \\
& 28.62 & 73247 & 148 & 0.002 \\
& 28.42 & 76405 & 7 & 0.000 \\
\hline
\end{tabular}

The CUF is about a factor of 3 greater than the CUF for the safety injection nozzles for the newer and older vintage Combustion Engineering plants (Sections 5.1.5 and 5.2.5). However, the analyses for these plants used ASME Code NB-3200 methods rather than NB-3600 methods. The CUF for the newer vintage Westinghouse plant (computed using NB-3600 methods) is comparable to the CUF for the older vintage Westinghouse plant that we computed using NB-3600 methods (Section 5.5.5). Using NB-3200 methods for the same transients on the older vintage Westinghouse plant, we were able to reduce the CUF well below 1.0. Therefore, the CUF for this nozzle could also probably be reduced below 1.0 by using NB- 3200 methods.

The list of potential conservative assumptions that could be removed is shown in Table 5-76. If removing these conservative assumptions did not reduce the CUF below 1.0 , then fatigue monitoring or plastic analyses could be used. 
Table 5-75. CUF results for safety injection (BIT) nozzle using NUREG/CR-5999 interim fatigue curve with conservative assumptions removed and anticipated cycles.

\begin{tabular}{lrrrr}
\hline \multicolumn{1}{c}{ Load pair } & \multicolumn{1}{c}{$\mathrm{S}_{\text {alt }}$} & $\mathrm{N}$ & $\mathrm{n}$ & $\mathrm{u}$ \\
\hline Small LOCA B/OBE & 226.91 & 28 & 0 & 0.000 \\
Depressurization B/OBE & 214.50 & 32 & 0 & 0.000 \\
Reactor trip with cooldown B/heatup group & 260.12 & 20 & 5 & 0.250 \\
Contingency B/heatup group & 260.12 & 20 & 0 & 0.000 \\
Inadvertent SI B/heatup group & 259.53 & 20 & 25 & 1.250 \\
Large steamline break/heatup group & 252.80 & 21 & 0 & 0.000 \\
Small LOCA A & 198.35 & 38 & 0 & 0.000 \\
Depressurization A/OBE & 186.80 & 44 & 0 & 0.000 \\
Reactor trip with cooldown A/heatup group & 230.70 & 27 & 0 & 0.000 \\
Contingency A/heatup group & 230.70 & 27 & 0 & 0.000 \\
Inadvertent SI A/heatup group & 230.11 & 27 & 0 & 0.000 \\
Depressurization A/loss of load & 153.21 & 72 & 0 & 0.000 \\
Small steamline break B/heatup group & 115.09 & 143 & 0 & 0.000 \\
Small steamline break A/heatup group & 94.55 & 233 & 0 & 0.000 \\
Large LOCA/loss of load & 66.45 & 537 & 0 & 0.000 \\
& 38.12 & 13069 & 74 & 0.006 \\
& 38.12 & 13069 & 42 & 0.003 \\
& 31.12 & 44248 & 20 & 0.000 \\
& 28.62 & 73247 & 148 & 0.002 \\
& 28.42 & 76405 & 7 & 0.000 \\
\hline
\end{tabular}

5.4.5.3 CUF Based on Revised Interim Fatigue Curves. The licensee's calculations did not contain sufficient information to determine the strain rates, so the $0.001 \% / \mathrm{s}$ curve was used. The CUF results are shown in Table 5-77. The extrapolated CUF for 60 years is 3.006 . If we assume that the maximum stresses occur at 30 seconds, the CUFs for 40 and 60 years are 1.460 and 2.190 , respectively.

\subsubsection{Residual Heat Removal System} Class 1 Piping. The fatigue analysis for the residual heat removal system piping was performed by Westinghouse in 1991, and includes the effects of thermal stratification in the line. The highest CUF (0.896) was for a SA-376 Type 316 stainless steel inlet piping transition.

5.4.6.1 CUF Results for the Residual Heat Removal System Piping Using NUREG/CR-5999 and Licensee's Design Calculation Stresses. The CUF calculations used the ASME Code, 1986 edition. The $S_{\text {alt }}$ values were not adjusted for the effect of the modulus of elasticity, since NB-3600 does not call for an adjustment of the modulus of elasticity. The CUF using the NUREG/CR-5999 interim fatigue curves is shown in Table 5-78. Application of the NUREG/CR-5999 interim fatigue curve increased the CUF by a factor of 6.39 over the design basis number. The first seven load pairs, where the $S_{\text {alt }}$ values are high and which contribute the majority of the CUF, are listed. Various types of stratification conditions were assumed in the licensee's calculations, and are identified in Table 5-78 by sequential numbers, of which $16,18,25$, and 27 are the major contributors to the CUF.

5.4.6.2 NUREG/CR-5999 CUF with Conservative Assumptions Removed. The CUF results almost entirely from the heatup/cooldown (including thermal stratification) transients. From Table 5-64, the number of anticipated heatup cycles for 40 years is 65 , whereas 200 design cycles were used in the licensee's 
Table 5-76. Potential for elimination of conservative assumptions to reduce CUF for safety injection (BIT) nozzle using NUREG/CR-5999 interim fatigue curve.

\begin{tabular}{lccl}
\hline \multicolumn{1}{c}{$\begin{array}{c}\text { Assumption } \\
\text { (Section 4.3) }\end{array}$} & $\begin{array}{c}\text { Potential } \\
\text { for use }\end{array}$ & Used & Comments \\
\hline Correct CUF calculation & No & No & Analysis appear to be correct \\
Detailed load pairs & No & No & Detailed load pairs were used \\
SCF/FSRF & Yes & No & Insufficient information \\
$\mathrm{S}_{\mathrm{m}}$ value & Yes & Yes & Conservative $\mathrm{S}_{\mathrm{m}}$ used \\
Material property changes & No & No No changes, Summer 1979 addenda used \\
Fatigue curve E value & No & No Proper adjustment was made \\
Code analysis changes & No & No No changes, Summer 1979 addenda used \\
Actual cycles & Yes & Yes Adjustment was made for projected cycles \\
High temperature rates & Yes & No Actual cooldown rates probably less than design \\
Detailed stress modeling & Yes & No NB-3600 analysis used \\
Conservative thermal & Yes & No Conservative heat transfer coefficients may have been used \\
parameters & & & \\
Time phasing of stresses & Yes & No Maximums of $\Delta \mathrm{T}_{1}, \Delta \mathrm{T}_{2}$, and $\mathrm{T}_{\mathrm{a}}-\mathrm{T}_{\mathrm{b}}$ terms may have been used \\
Number of OBEs & No & No Only 20 OBE cycles were assumed \\
CC N-411 damping & No & No CC N-411 damping used \\
Number of hydrotests & No & No Hydrotests did not contribute to CUF \\
Fatigue monitoring & Yes & No Actual transients probably less severe than design \\
Plastic analysis & Yes & No Elastic plastic finite element analysis could be used \\
\hline
\end{tabular}

Table 5-77. CUF results for safety injection (BIT) nozzle using revised interim fatigue curves with conservative assumptions removed and anticipated cycles.

\begin{tabular}{lrrrr}
\hline \multicolumn{1}{c}{ Load pair } & \multicolumn{1}{c}{$\mathrm{S}_{\text {alt }}$} & $\mathrm{N}$ & $\mathrm{n}$ & $\mathrm{u}$ \\
\hline Small LOCA B/OBE & 226.91 & 13 & 0 & 0.000 \\
Depressurization B/OBE & 214.50 & 14 & 0 & 0.000 \\
Reactor trip with cooldown B/heatup group & 260.12 & 15 & 5 & 0.333 \\
Contingency B/heatup group & 260.12 & 15 & 0 & 0.000 \\
Inadvertent SI B/heatup group & 259.53 & 15 & 25 & 1.667 \\
Large steamline break/heatup group & 252.80 & 17 & 0 & 0.000 \\
Small LOCA A & 198.35 & 19 & 0 & 0.000 \\
Depressurization A/OBE & 186.80 & 20 & 0 & 0.000 \\
Reactor trip with cooldown A/heatup group & 230.70 & 20 & 0 & 0.000 \\
Contingency A/heatup group & 230.70 & 20 & 0 & 0.000 \\
Inadvertent SI A/heatup group & 230.11 & 20 & 0 & 0.000 \\
Depressurization A/loss of load & 153.21 & 42 & 0 & 0.000 \\
Small steamline break B/heatup group & 115.09 & 112 & 0 & 0.000 \\
Small steamline break A/heatup group & 94.55 & 192 & 0 & 0.000 \\
Large LOCA/loss of load & 66.45 & 683 & 0 & 0.000 \\
& 38.12 & 30271 & 74 & 0.002 \\
& 38.12 & 30271 & 42 & 0.001 \\
& 31.12 & 103487 & 20 & 0.000 \\
& 28.62 & 215250 & 148 & 0.001 \\
& 28.42 & 231407 & 7 & 0.000 \\
\hline
\end{tabular}


Table 5-78. CUF results for the residual heat removal system piping using NUREG/CR-5999 interim fatigue curve.

\begin{tabular}{lrrrr}
\hline \multicolumn{1}{c}{ Load pair } & \multicolumn{1}{c}{$\mathrm{S}_{\text {alt }}$} & $\mathrm{N}$ & $\mathrm{n}$ & $\mathrm{u}$ \\
\hline Rapid depressurization/stratification 16 & 194.13 & 40 & 20 & 0.500 \\
Heatup/stratification 16 & 166.02 & 59 & 200 & 3.390 \\
OBE/stratification 18 & 146.32 & 80 & 20 & 0.250 \\
Stratification 16/stratification 25 & 143.39 & 84 & 20 & 0.238 \\
Stratification 18/stratification 25 & 110.77 & 157 & 140 & 0.892 \\
Stratification 18/stratification 27 & 110.77 & 157 & 10 & 0.064 \\
Reactor trip/stratification 18 & 106.52 & 173 & 30 & 0.173 \\
& 40.22 & 9449 & 196 & 0.021 \\
& 39.03 & 11321 & 140 & 0.012 \\
& 35.78 & 19105 & 230 & 0.012 \\
& 31.93 & 37908 & 6004 & 0.158 \\
& 31.03 & 45026 & 80 & 0.002 \\
& 29.42 & 62048 & 10 & 0.000 \\
& 29.28 & 63855 & 160 & 0.003 \\
& 29.12 & 65996 & 230 & 0.003 \\
& 28.30 & 78376 & 90 & 0.001 \\
& 25.06 & $1.5 \times 10^{6}$ & 6866 & 0.005 \\
& 24.61 & $2.3 \times 10^{6}$ & 6534 & 0.003 \\
\hline
\end{tabular}

design CUF calculation. The CUF was recalculated by assuming no rapid depressurization transients, and multiplying transients that included thermal stratification by $65 / 200$. There were 240 cycles of stratification transient 16 , which were reduced to 78 . There were 200 cycles of stratification transient 18 , which were reduced to 65 . There were 160 cycles of stratification transient 25 , which were reduced to 52 . The results are shown in Table 5-79. If the plant is operated for 60 years, the CUF is 3.557 .

There are a number of other potential conservative assumptions that could be removed, as shown in Table 5-80. For example, performing a detailed finite element analysis using NB-3200 methods may reduce the CUF calculated using NB-3600 piping rules. The stratification temperature differences assumed in the analysis are probably conservative. In fact, most PWR plants have not shown that thermal stratification is a contributor to the CUF for their residual heat removal lines. Not considering thermal stratification, the licensee's design basis CUF for the same location is 0.243 , about a factor of 4 less than the CUF calculated including thermal stratification. If removing these conservative assumptions did not reduce the CUF below 1.0 , then additional fatigue monitoring or plastic analyses could be used. Because of thermal stratification, this line falls into the same category as the PWR surge lines with respect to reducing the CUF below 1.0. Based on the experience with surge lines, it may be difficult to reduce the CUF below 1.0 using NUREG/CR-5999 fatigue curves without more stratification data.

\subsubsection{CUF Based on Revised Interim} Curves. The licensee's calculations did not contain sufficient information to determine the strain rates, so the $0.001 \% / \mathrm{s}$ curve was used. The stratification transients are not necessarily thermal shocks, so the low strain rate may be reasonable. The CUF results are shown in Table 5-81. The extrapolated CUF for 60 years is 4.100 .

5.4.7 Results and Conclusions. We obtained the latest design basis fatigue calculations for six components on a newer vintage Westinghouse plant. The design CUF obtained from the licensee's calculations for the location 
Table 5-79. CUF results for the residual heat removal system piping using NUREG/CR-5999 interim fatigue curve and anticipated cycles.

\begin{tabular}{lrrrr}
\hline \multicolumn{1}{c}{ Load pair } & \multicolumn{1}{c}{$\mathrm{S}_{\text {alt }}$} & $\mathrm{N}$ & $\mathrm{n}$ & $\mathrm{u}$ \\
\hline Rapid depressurization/stratification 16 & 194.13 & 40 & 0 & 0.000 \\
Heatup/stratification 16 & 166.02 & 59 & 65 & 1.102 \\
OBE/stratification 18 & 146.32 & 80 & 20 & 0.250 \\
Stratification 16/stratification 25 & 143.39 & 84 & 45 & 0.536 \\
Stratification 18/stratification 25 & 110.77 & 157 & 7 & 0.045 \\
Stratification 18/stratification 27 & 110.77 & 157 & 7 & 0.045 \\
Combination/stratification 18 & 106.52 & 173 & 30 & 0.173 \\
& 40.22 & 9449 & 196 & 0.021 \\
& 39.03 & 11321 & 140 & 0.012 \\
& 35.78 & 19105 & 230 & 0.012 \\
& 31.93 & 37908 & 6004 & 0.158 \\
& 31.03 & 45026 & 80 & 0.002 \\
& 29.42 & 62048 & 10 & 0.000 \\
& 29.28 & 63855 & 160 & 0.003 \\
& 29.12 & 65996 & 230 & 0.003 \\
& 28.30 & 78376 & 90 & 0.001 \\
& 25.06 & $1.5 \times 10^{6}$ & 6866 & 0.005 \\
& 24.61 & $2.3 \times 10^{6}$ & 6534 & 0.003 \\
\cline { 2 - 5 } & & & $\mathrm{CUF}$ & 2.371 \\
\hline
\end{tabular}

Table 5-80. Potential for elimination of conservative assumptions to reduce CUF for residual heat removal system using NUREG/CR-5999 interim fatigue curve.

\begin{tabular}{|c|c|c|c|}
\hline $\begin{array}{l}\text { Assumption } \\
\text { (Section 4.3) }\end{array}$ & $\begin{array}{l}\text { Potential } \\
\text { for use }\end{array}$ & Used & Comments \\
\hline Correct CUF calculation & No & No & Analysis appear to be correct \\
\hline Detailed load pairs & No & No & Detailed load pairs were used \\
\hline SCF/FSRF & No & No & Stress indices appear correct \\
\hline$S_{\mathrm{m}}$ value & No & No & Average $S_{\mathrm{m}}$ values used \\
\hline $\begin{array}{l}\text { Material property } \\
\text { changes }\end{array}$ & No & No & No changes, 1986 Code edition used \\
\hline Fatigue curve E value & No & No & Proper adjustment was made \\
\hline Code analysis changes & No & No & No changes, 1986 Code edition used \\
\hline Actual cycles & Yes & Yes & Adjustment was made for projected cycles \\
\hline High temperature rates & Yes & No & Actual cooldown rates probably less than design \\
\hline Detailed stress modeling & Yes & No & NB-3600 analysis used \\
\hline $\begin{array}{l}\text { Conservative thermal } \\
\text { parameters }\end{array}$ & Yes & No & $\begin{array}{l}\text { Conservative heat transfer coefficients may have been } \\
\text { used }\end{array}$ \\
\hline Time phasing of stresses & Yes & No & $\begin{array}{l}\text { Highest moment and thermal stresses may not occur } \\
\text { simultaneously }\end{array}$ \\
\hline Number of OBEs & No & No & Only 20 OBE cycles were assumed \\
\hline CC N-411 damping & No & No & CC N-411 damping used \\
\hline Number of hydrotests & No & No & Hydrotests did not contribute to CUF \\
\hline Fatigue monitoring & Yes & No & Actual transients probably less severe than design \\
\hline Plastic analysis & Yes & No & Elastic plastic finite element analysis could be used \\
\hline
\end{tabular}


Table 5-81. CUF results for the residual heat removal system piping using revised interim fatigue curve and anticipated cycles.

\begin{tabular}{lrrrr}
\hline \multicolumn{1}{c}{ Load pair } & \multicolumn{1}{c}{$\mathrm{S}_{\text {alt }}$} & \multicolumn{1}{c}{$\mathrm{N}$} & $\mathrm{n}$ & $\mathrm{u}$ \\
\hline Rapid depressurization/stratification 16 & 194.13 & 32 & 0 & 0.000 \\
Heatup/stratification 16 & 166.02 & 47 & 65 & 1.383 \\
OBE/stratification 18 & 146.32 & 65 & 20 & 0.308 \\
Stratification 16/stratification 25 & 143.39 & 69 & 45 & 0.652 \\
Stratification 18/stratification 25 & 110.77 & 139 & 7 & 0.050 \\
Stratification 18/stratification 27 & 110.77 & 139 & 7 & 0.050 \\
Combination/stratification 18 & 106.52 & 156 & 30 & 0.192 \\
& 40.22 & 23428 & 196 & 0.008 \\
& 39.03 & 26977 & 140 & 0.005 \\
& 35.78 & 42179 & 230 & 0.006 \\
& 31.93 & 85703 & 6004 & 0.070 \\
& 31.03 & 105802 & 80 & 0.001 \\
& 29.42 & 165077 & 10 & 0.000 \\
& 29.28 & 172489 & 160 & 0.001 \\
& 29.12 & 181593 & 230 & 0.001 \\
& 28.30 & 241997 & 90 & 0.000 \\
& 25.06 & $1.6 \times 10^{6}$ & 6866 & 0.004 \\
& 24.61 & $2.8 \times 10^{6}$ & 6534 & 0.002 \\
\hline
\end{tabular}

with the highest calculated fatigue usage on each component was recomputed using the NUREG/CR-5999 interim fatigue curves. The results are summarized in Table 5-82. The increases in the magnitudes of the design CUFs are as follows:

Stainless Steel

$\begin{array}{ll}\text { Surge line } & 10.18 \\ \text { Charging nozzle } & 6.26 \\ \text { Safety injection nozzle } & 5.05 \\ \text { Residual heat removal piping } & \frac{6.39}{6.97} \text { average }\end{array}$

Carbon/Low-alloy Steel

Reactor vessel shell/lower

$\begin{array}{ll}\text { head } & 1.50 \\ \text { Reactor vessel inlet nozzle } & 2.64 \\ \text { Reactor vessel outlet nozzle } & \frac{1.65}{1.93} \text { average }\end{array}$

Conservative assumptions were identified, and where justifiable, the design CUFs were recomputed with conservative assumptions removed. The 40-year CUFs were multiplied by 1.5 to determine a 60-year CUF, as shown in Table 5-82.

Using the NUREG/CR-5999 interim fatigue curves, the CUF remained below 1.0 for the reactor vessel lower shell/head and inlet/outlet nozzles, but was above 1.0 for the reactor coolant system branch nozzles and the residual heat removal line. NB-3600 piping analyses were used for the four components for which the CUF was above 1.0. It appears that with more detailed analyses (that is, using ASME Code NB-3200 methods) and cycle counting of the actual numbers of transients, the CUF could rather easily be reduced below 1.0 for the charging and safety injection nozzles. More effort, including possibly additional monitoring and plastic analysis might be required for the surge and residual heat removal lines since the major load pairs involve thermal stratification cycles. 
Table 5-82. Summary of newer vintage Westinghouse plant CUFs.

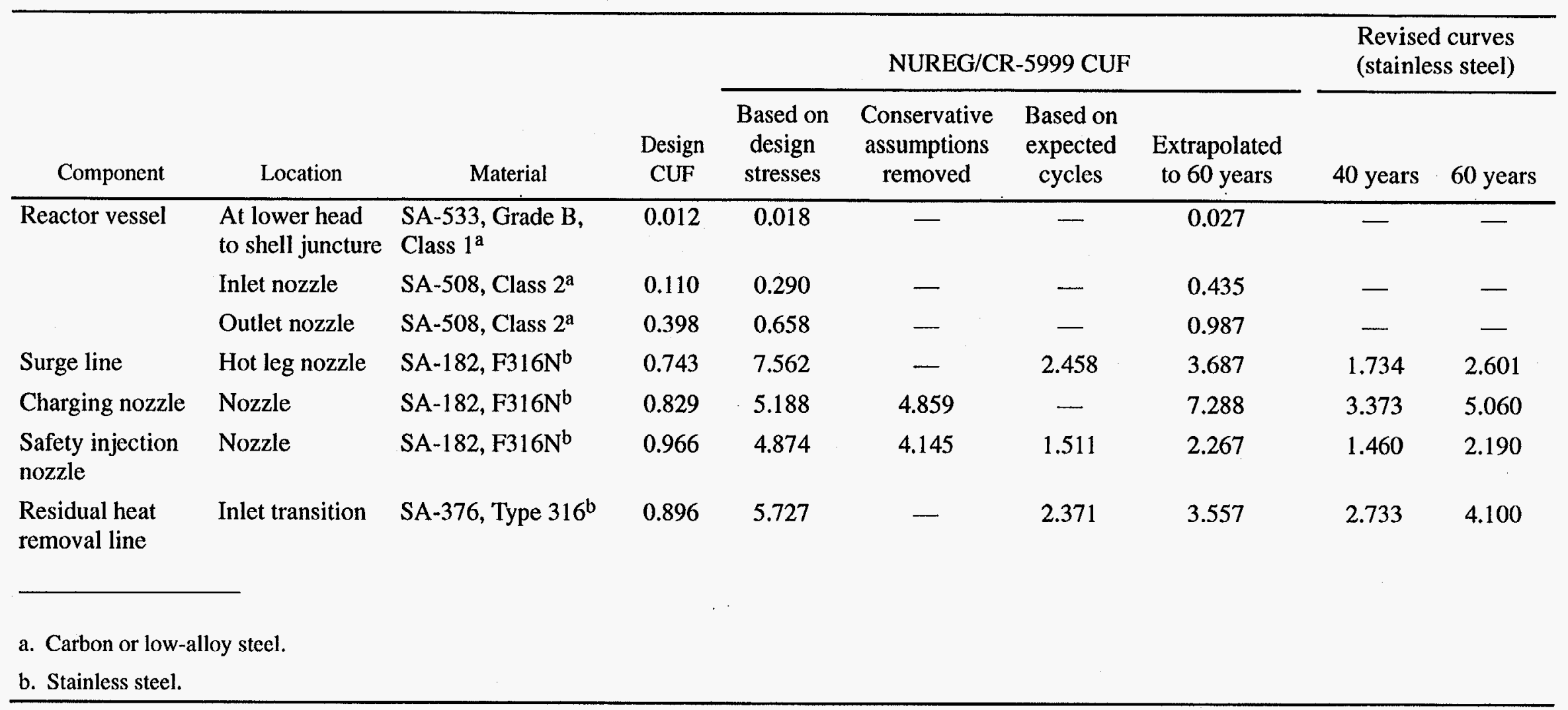




\subsection{Older Vintage Westinghouse Plant}

A comparison of the design CUFs from the licensee's design basis calculations and CUFs using the NUREG/CR-5999 interim fatigue curves was carried out for the locations of highest design CUF for the six components listed below:

1. Reactor vessel shell and lower head

2. Reactor vessel inlet and outlet nozzles

3. Pressurizer surge line (including hot leg and pressurizer nozzles)

4. Reactor coolant piping charging system nozzle (representative design basis fatigue calculation performed by INEL)

5. Reactor coolant piping safety injection nozzle (representative design basis fatigue calculation performed by INEL)

6. Residual Heat Removal system Class 1 piping (representative design basis fatigue calculation performed by INEL).

As of late 1993, the plant has been operated approximately 20 of the 40 years currently approved in its operating license. Table 5-83 shows the design basis cycles for transients that are important from a fatigue standpoint for the six components that were evaluated. The numbers of transients to date have been extrapolated to 40 years by multiplying by $40 / 20$.
The results of a generic Westinghouse plant study of thermal stratification in surge lines was included in the licensee's fatigue analysis of the surge line. There were no plant specific data to remove conservatism assumptions for this particular plant.

\subsubsection{Reactor Vessel Shell and Lower} Head. The highest CUF on the lower shell and head is 0.290 for the inside surface of the lower head near the shell-to-head transition, where core support guides are welded to the interior of the shell. The SA-302 Grade B head is protected from the coolant by a layer of stainless steel and Alloy 600 cladding. No fatigue analysis is performed for the cladding.

\subsubsection{NUREG/CR-5999 CUF Based on Licensee's Design Calculation Stresses.} The licensee's CUF calculations used the ASME Code, Section III, 1965 edition, through Summer 1966 addenda.

The effect of the NUREG/CR-5999 interim fatigue curve is shown in Table 5-84. As previously discussed, the results shown in Table 5-84 assume that the coolant is in contact with the lowalloy steel base metal underneath the cladding. The $S_{\text {alt }}$ values were adjusted for the effect of the modulus of elasticity by multiplying by $30 / 27$, the ratio of the modulus of elasticity on the fatigue curve in the current edition of the Code to the value at $500^{\circ} \mathrm{F}$ for SA-302 Grade B low-alloy steel. The 1965 Code edition did not require an adjustment for the effect of the modulus of elasticity.

Table 5-83. Number of selected design basis cycles compared to anticipated number of cycles over 40-year license life.

\begin{tabular}{lcc}
\hline \multicolumn{1}{c}{ Transient } & Design basis cycles & $\begin{array}{c}\text { Anticipated cycles } \\
\text { for 40 years }\end{array}$ \\
\hline Heatup/cooldown & 200 & 172 \\
Reactor trip & 400 & 426 \\
Hydrotest & 5 & 2 \\
$5 \%$ power change & 14500 & 512 \\
$10 \%$ power change (up/down) & $2000 / 7000$ & $42 / 86$ \\
$50 \%$ power change & 200 & 136 \\
\hline
\end{tabular}


Table 5-84. CUF results for reactor vessel lower head and shell using NUREG/CR-5999 interim fatigue curve.

\begin{tabular}{lccrrc}
\hline \multicolumn{1}{c}{ Load pair } & $\mathrm{S}_{\text {alt }}$ & $\mathrm{S}_{\text {alt }}$ (adjusted) & $\mathrm{N}$ & $\mathrm{n}$ & $\mathrm{u}$ \\
\hline OBE A/OBE B & 19.86 & 22.07 & 44636 & 400 & 0.009 \\
Frictional forces/vibration & 13.48 & 14.98 & 226736 & 200000 & 0.882 \\
\cline { 4 - 6 } & & & & $\mathrm{CUF}$ & 0.891 \\
\hline
\end{tabular}

Application of the NUREG/CR-5999 interim fatigue curve increased the CUF by a factor of 3.07 over the licensee's design basis number. If the plant is operated for 60 years, the CUF is 1.337 which exceeds the ASME Code limit of 1.0.

\subsubsection{NUREG/CR-5999 CUF with Con- servative Assumptions Removed. As can} be seen from Table 5-84, almost all of the CUF comes from a single transient. The stresses were calculated from equations for the shear, moment, and torsion. No computer model was used. The assumed loads are 200,000 cycles of an alternating $50,000 \mathrm{lb}$. load in both the vertical and horizontal directions caused by frictional forces retarding growth. The only variables or assumptions are the number of cycles, the magnitude of the load, and the stress concentration factor. The stress concentration factor of 2.15 appears reasonable, but might be reduced if a finite element model were used. Thus there is no readily available way to reduce the CUF. Options to reduce the CUF are outlined in Table 5-85.

\subsubsection{Reactor Vessel Inlet and Outlet Nozzles. The maximum CUFs for the inlet and outlet nozzles are 0.208 and 0.431 , respectively. The inside surface of each of the SA-302 Grade B low-alloy steel nozzles is protected from the cool- ant by a layer of stainless steel cladding. No fatigue analysis is performed for the cladding.}

\footnotetext{
5.5.2.1 NUREG/CR-5999 CUF Based on Licensee's Design Calculation Stresses for Inlet Nozzle. The licensee's design CUF calculations used the ASME Code, Section III, 1965 edition, through Summer 1966 addenda. The licensee's analysis report showed the fatigue analysis calculations for both the interior and exterior surfaces of the nozzle (the CUFs are 0.135 and 0.208 , respectively), and both locations were used
}

to assess the effect of the NUREG/CR-5999 fatigue curves. The $S_{\text {alt }}$ values were adjusted for the effect of the modulus of elasticity by multiplying by $30 / 27$, the ratio of the modulus of elasticity in the current edition of the Code to the value commonly used in analyses in the 1965-1970 time period (the actual value used in the analysis was not reported). The effect of the NUREG/CR-5999 interim fatigue curve is shown in Table 5-86.

The Table 5-86 results indicate that the CUF is increased by factors of 2.24 (inside surface) and 2.38 (outside surface) over the licensee's design basis number. The CUF does not exceed the ASME Code limit of 1.0. If the plant is operated for 60 years, the CUFs are 0.453 (inside surface) and 0.744 (outside surface).

\subsubsection{NUREG/CR-5999 CUF Based on} Licensee's Design Calculation Stresses for Outlet Nozzle. The licensee's design CUF calculations used the ASME Code, Section III, 1965 edition, through Summer 1966 addenda. The licensee's analysis report showed the fatigue analysis calculations for both the interior and exterior surfaces of the nozzle (the CUFs are 0.193 and 0.431 , respectively), and both locations were used to assess the effect of the NUREG/CR-5999 fatigue curves. The $S_{\text {alt }}$ values were adjusted for the effect of the modulus of elasticity by multiplying by $30 / 27$, the ratio of the modulus of elasticity in the current edition of the Code to the value commonly used in analyses in the 1965-1970 time period (the actual value used in the analysis was not reported). The effect of the NUREG/CR-5999 interim fatigue curve is shown in Table 5-87.

The Table 5-87 results indicate that the CUF is increased by factors of 2.59 (inside surface) and 2.69 (outside surface) over the licensee's design 
Table 5-85. Potential for elimination of conservative assumptions to reduce CUF for reactor vessel lower head/shell using NUREG/CR-5999 interim fatigue curve.

\begin{tabular}{lccl}
\hline \multicolumn{1}{c}{$\begin{array}{c}\text { Assumption } \\
\text { (Section) }\end{array}$} & $\begin{array}{c}\text { Potential } \\
\text { for use }\end{array}$ & Used & \multicolumn{1}{c}{ Comments } \\
\hline Correct CUF calculation & No & No & Analysis appears to be correct \\
Detailed load pairs & No & No & Detailed load pairs were used \\
SCF/FSRF & Yes & No & Finite element model might lower SCF \\
S $_{\mathrm{m}}$ value & No & No & $\mathrm{K}_{\mathrm{e}}=1$ for all load pairs \\
Material property & No & No & No relevant changes \\
changes & & & \\
Fatigue curve E value & Yes & Yes & Adjustment was made \\
Code analysis changes & No & No & No relevant changes \\
Actual cycles & Yes & No & Revised estimate of cycles is possible \\
High temperature rates & No & No & Rates not relevant \\
Detailed stress modeling & Yes & No & Finite element model might lower SCF \\
Conservative thermal & No & No & Parameters irrelevant \\
parameters & & & \\
Time phasing of stresses & No & No & Ke 1 for all load pairs \\
Number of OBEs & No & No & OBE cycles not significant contributor to CUF \\
CC N-411 damping & No & No & Dynamic loads not significant contributor to CUF \\
Number of hydrotests & No & No Hydrotests did not contribute to CUF \\
Fatigue monitoring & Yes & No Actual transients might be less severe than design \\
Plastic analysis & No & No & Stresses are elastic \\
\hline
\end{tabular}

Table 5-86. CUF results for reactor vessel inlet nozzle using NUREG/CR-5999 interim fatigue curve.

\begin{tabular}{lccccc}
\hline \multicolumn{1}{c}{$\mathrm{S}_{\text {alt }}$} & $\mathrm{S}_{\text {alt }}$ & $\mathrm{S}_{\text {alt }}$ (adjusted) & $\mathrm{N}$ & $\mathrm{n}$ & $\mathrm{u}$ \\
\hline Heatup/cooldown & 13.5 & 15.00 & 225674 & 350 & 0.000 \\
Plant load/unload & 17.5 & 19.44 & 80920 & 14500 & 0.179 \\
Combination & 23.0 & 25.56 & 22426 & 2760 & 0.123 \\
$\quad$ Inside Surface & & & & $\mathrm{CUF}$ & 0.302 \\
Heatup/cooldown & 37.0 & 41.11 & 3552 & 350 & 0.099 \\
Plant load/unload & 19.5 & 21.26 & 53189 & 14500 & 0.273 \\
Combination & 23.0 & 25.56 & 22426 & 2760 & 0.123 \\
$\quad$ Outside Surface & & & & CUF & 0.496 \\
\hline
\end{tabular}

basis number. The CUF for the outside surface exceeds the ASME Code limit of 1.0; however, if the number of power changes is reduced down to several hundred cycles consistent with the experience of base-loaded plants and Table 5-83, the CUF for 60 years would be well below 1.0. If the plant is operated for 60 years, the CUF for the inside surface is 0.749 .
5.5.2.3 NUREG/CR-5999 CUF with Conservative Assumptions Removed. Since the CUFs for the inlet nozzle did not exceed the ASME Code limit of 1.0 for 60 years, no further calculations were performed. For the outlet nozzle outside surface, the 14100 design cycles in load pair 2 are part of the 14500 cycles shown in Table 5-83 for $5 \%$ step power reductions. From 
Table 5-87. CUF results for reactor vessel outlet nozzle using NUREG/CR-5999 interim fatigue curve.

\begin{tabular}{llcrrr}
\hline \multicolumn{1}{c}{$\mathrm{S}_{\text {alt }}$} & $\mathrm{S}_{\mathrm{alt}}$ & $\mathrm{S}_{\text {alt }}$ (adjusted) & $\mathrm{N}$ & \multicolumn{1}{c}{$\mathrm{n}$} & $\mathrm{u}$ \\
\hline Heatup/cooldown & 15.5 & 17.22 & 139150 & 350 & 0.003 \\
Plant loading/unloading & 17.0 & 18.89 & 92575 & 14100 & 0.152 \\
OBE A/OBE B & 18.85 & 20.94 & 57109 & 400 & 0.007 \\
Combination & 29.5 & 32.78 & 8179 & 2760 & 0.337 \\
$\quad$ Inside Surface & & & & $\mathrm{CUF}$ & 0.499 \\
Heatup/cooldown & 25.0 & 27.78 & 15176 & 350 & 0.023 \\
Plant loading/unloading & 24.5 & 27.22 & 16696 & 14100 & 0.845 \\
OBE A/OBE B & 26.35 & 29.28 & 12367 & 400 & 0.032 \\
Combination & 27.5 & 30.56 & 10569 & 2760 & 0.261 \\
$\quad$ Outside Surface & & & & CUF & 1.161 \\
\hline
\end{tabular}

Table 5-83, the number of these cycles is projected to be only 512 . Using this reduced number of cycles for load pair 2 lowers the CUF to 0.347 . If the plant is operated for 60 years, the CUF for the outside surface is 0.520 .

5.5.3 Surge Line. The highest CUF for the surge line piping and nozzles was 0.900 at the SA-376 Type 316 stainless steel 12 -inch Schedule 140 hot leg nozzle safe end. The latest fatigue analyses were performed by Westinghouse to assess thermal stratification conditions as required by NRC Bulletin 88-11.

\subsubsection{NUREG/CR-5999 CUF Based on} Licensee's Design Calculation Stresses. The licensee's design CUF calculations used the ASME Code, Section III, 1986 edition. The $S_{\text {alt }}$ values in the licensee's calculations were assumed to be corrected for the effect of the modulus of elasticity. The CUF calculations involved a large number of load pairs, so a table of the pairings is not included in this report. The CUF calculated using the NUREG/CR-5999 interim fatigue curve is 6.814 , including the effects of thermal striping. The CUF increased by a factor of 7.57 over the licensee's design basis number.

\subsubsection{NUREG/CR-5999 CUF with Con-} servative Assumptions Removed. Since the analysis was performed relatively recently, few of the areas in the first group of potential conservative assumptions that possibly could be removed are applicable to the surge line. Although a finite element model of the nozzle was used for the stress analysis, stress indices from NB-3600 of the ASME Code were used. A more detailed finite element model could be used to obtain a better estimate of the stress concentration factor for the particular geometry. The CUF is almost entirely a result of the heatup and cooldown (including thermal stratification) transients. From Table 5-83, the number of anticipated heatup cycles for 40 years is 172 , whereas 200 design cycles were used in the licensee's design CUF calculation. Multiplying the 40-year CUF by $172 / 200$, the CUF after 40 years is 5.860 . If the plant is operated for 60 years, the CUF is 8.790 .

Other changes that could be used to reduce the CUF are listed in Table 5-88. Since the Westinghouse staff had reduced the CUF about as low as possible for the set of assumed transients using NB-3600 methods, a NB-3200 finite element analysis, including possibly additional monitoring and plastic analysis, would be required to reduce the CUF below 1.0.

\subsubsection{CUF Based on Revised Interim} Curves. Using the $0.001 \% / \mathrm{s}$ curve for all load pairs, the CUF is 6.973 . The number of anticipated heatup cycles for 40 years is 172 , whereas 200 design cycles were used in the licensee's design CUF calculation. The CUF after 40 years can be estimated by multiplying 6.973 by $172 / 200$, resulting in a 5.997 CUF. If the plant is operated for 60 years, the CUF would be 8.995 . 
Table 5-88. Potential for elimination of conservative assumptions to reduce CUF for surge line elbow using NUREG/CR-5999 interim fatigue curve.

\begin{tabular}{lccl}
\multicolumn{1}{c}{$\begin{array}{c}\text { Assumption } \\
\text { (Section 4.3) }\end{array}$} & $\begin{array}{c}\text { Potential } \\
\text { for use }\end{array}$ & Used & \multicolumn{1}{c}{ Comments } \\
\hline Correct CUF calculation & No & No & Analysis appears to be correct \\
Detailed load pairs & No & No & Detailed load pairs were used \\
SCF/FSRF & Yes & No & SCFs may be reduced \\
$S_{\mathrm{m}}$ value & No & No & Average $\mathrm{S}_{\mathrm{m}}$ value was used \\
Material property & No & No & No changes, 1986 Code edition used \\
changes & No & No & Proper adjustment was made \\
Fatigue curve E value & No & No & No changes, 1986 Code edition used \\
Code analysis changes & Yes & Yes & Adjustment was made for projected cycles \\
Actual cycles & Yes & No & Actual rates may be lower, but fatigue monitoring \\
High temperature rates & & & results were considered \\
& Yes & No & SCFs may be reduced \\
Detailed stress modeling & Yes & No & Insufficient information \\
Conservative thermal & & & \\
parameters & Yes & No & Highest moment and thermal stresses may not occur \\
Time phasing of stresses & & & simultaneously \\
& No & No & OBE cycles not significant contributor to CUF \\
Number of OBEs & No & No & Dynamic loads not significant contributor to CUF \\
CC N-411 damping & No & No & Hydrotests did not contribute to CUF \\
Number of hydrotests & Yes & No & Actual transients probably less severe than design \\
Fatigue monitoring & Yes & No & Elastic plastic finite element analysis could be used \\
Plastic analysis & & &
\end{tabular}

If we assume that the maximum stresses occur after 30 seconds, the CUF is 4.940 . Multiplying by $172 / 200$ to adjust for anticipated cycles, the CUF is 4.248 . If the plant is operated for 60 years, the CUF would be 6.372 . However, all stratification transient may not result in thermal shocks.

5.5.4 Charging Nozzle. Since the piping was designed to the rules of the B31.1 piping code, no fatigue analyses had been conducted. Consequently, the INEL staff performed a fatigue analysis using representative transients based on the charging nozzle analyses from the other PWR plants reviewed in this study, and the methods of the current (1992) edition of the ASME Code. Both ASME Code NB-3600 (piping) and NB-3200 (design by analysis) methods were used, and typical analytical models comparable with those in the licensees' analyses were developed. For the transients that were the major contributors to the CUF, representative design basis cycles were assumed as shown in Table 5-89. In all, 24 different load sets were considered.

The knuckle region of the nozzle is protected by a thermal sleeve, which mitigates the thermal shocks to this region during severe transients. The thermal sleeve is welded to the nozzle.

\subsubsection{CUF Based on ASME Code} Fatigue Curve. Calculations for the charging system nozzle were completed using the methods of NB-3600 of the ASME Code and the NUPIPE-II computer code. Three areas of the nozzle were considered: the nozzle-to-pipe weld, the area at the thermal sleeve junction, and the nozzle body where the nozzle is connected to the main coolant piping, which was considered to be a branch connection. Moments applied to the nozzle by the connecting charging system piping for various transients were supplied by the licensee, so these moments were used in the analysis 
Table 5-89. Major charging system transients assumed in the analysis.

\begin{tabular}{clr}
\hline Set number & \multicolumn{1}{c}{ Load set } & Cycles \\
\hline 1 & Charging and letdown shutoff & 1460 \\
2 & Delayed return to service after transient 1 & 100 \\
3 & Letdown shutoff with prompt restart & 200 \\
4 & Letdown shutoff with delayed restart & 20 \\
5 & Charging shutoff with prompt restart & 20 \\
6 & Charging shutoff with delayed restart & 20 \\
\hline
\end{tabular}

and the full charging system was not modeled. The CUF was 0.460 for the branch connection to the main coolant piping, but low $(0.022)$ for the weld to the charging system piping and $(0.008)$ at the thermal sleeve. The major contributor to the CUF was the letdown shutoff with delayed restart transient. The axial thermal gradient (the $\alpha_{a} T_{a}$ $\alpha_{b} T_{b}$ term) produced most of the stress intensity at the branch connection, whereas the $\Delta \mathrm{T}_{1}$ and $\Delta T_{2}$ terms produced most of the stress intensity in the charging system piping region of the nozzle.

An NB-3200 finite element analysis was also performed for the nozzle using the same pressures, thermal transients, moments, and numbers of cycles as were used in the NB-3600 analysis. A small axisymmetric finite element model was used to model the nozzle in the region of the connection to the charging system piping where the geometry is truly axisymmetric. A larger 3-dimensional model (with a larger mesh size) was used to model the knuckle region where the geometry is not axisymmetric. The three-dimensional model is shown in Figure 5-2 and the axisymmetric model is shown in Figure 5-3. Both models were developed using the I-DEAS (version 6.1) solid modeling software. Heat transfer and stress calculations were subsequently made for both models using the ABAQUS (version 5.2) finite element analysis software. The thermal sleeve was represented by the use of different heat transfer coefficients for the nozzle areas, depending on their relation to the thermal sleeve. A table of temperature-dependent moduli of elasticity were used in the finite element model instead of a single temperature, so the alternating stress intensity ranges were adjusted by multiplying by the ratio of the modulus of elasticity on the fatigue curve to the modulus of elasticity at the average temperature during the transients that made up the load pairs $\left(300^{\circ} \mathrm{F}\right)$.

The interior surface of the nozzle contains no reentrant corners, so no areas of stress concentration needed to be considered. The weld between the nozzle and the main coolant piping is made in the shop and no fatigue strength reduction factors are typically applied to this type weld. For example, the charging nozzle analyses for the newer vintage Combustion Engineering plant and the $\mathrm{B} \& \mathrm{~W}$ plant used no fatigue strength reductions for this weld. The thermal sleeve is welded to the interior of the nozzle but no stress concentration factor or fatigue strength reduction factor is typically applied to account for this weld. The geometry of the weld is not shown on the fabrication drawing. (No stress indices were applied for this weld in the NB-3600 analysis either. The ASME Code does not list stress indices for this case.) The nozzle-to-piping weld is a field weld. It is not typically included in nozzle analyses, but is included in NB-3600 analyses of the adjoining piping as the terminal end. In one analysis of a surge nozzle that we reviewed, for which an NB-3200 analysis was performed on the surge line and nozzle, the appropriate NB-3600 stress indices for a girth butt weld were applied to the stresses at the field-welded safe-end-to-piping weld.

NB-3200 provides different classifications for the linear portions of the stresses due to radial thermal gradients in Tables NB-3217.1 and NB-3217.2. For vessels, Table NB-3217.1 classifies these stresses as secondary stresses whereas for piping, Table NB-3217.2 classifies them as peak stresses. The piping definition in Table NB-3217.2 was used in the calculations to compute the primary plus secondary stress 
Component Evaluations

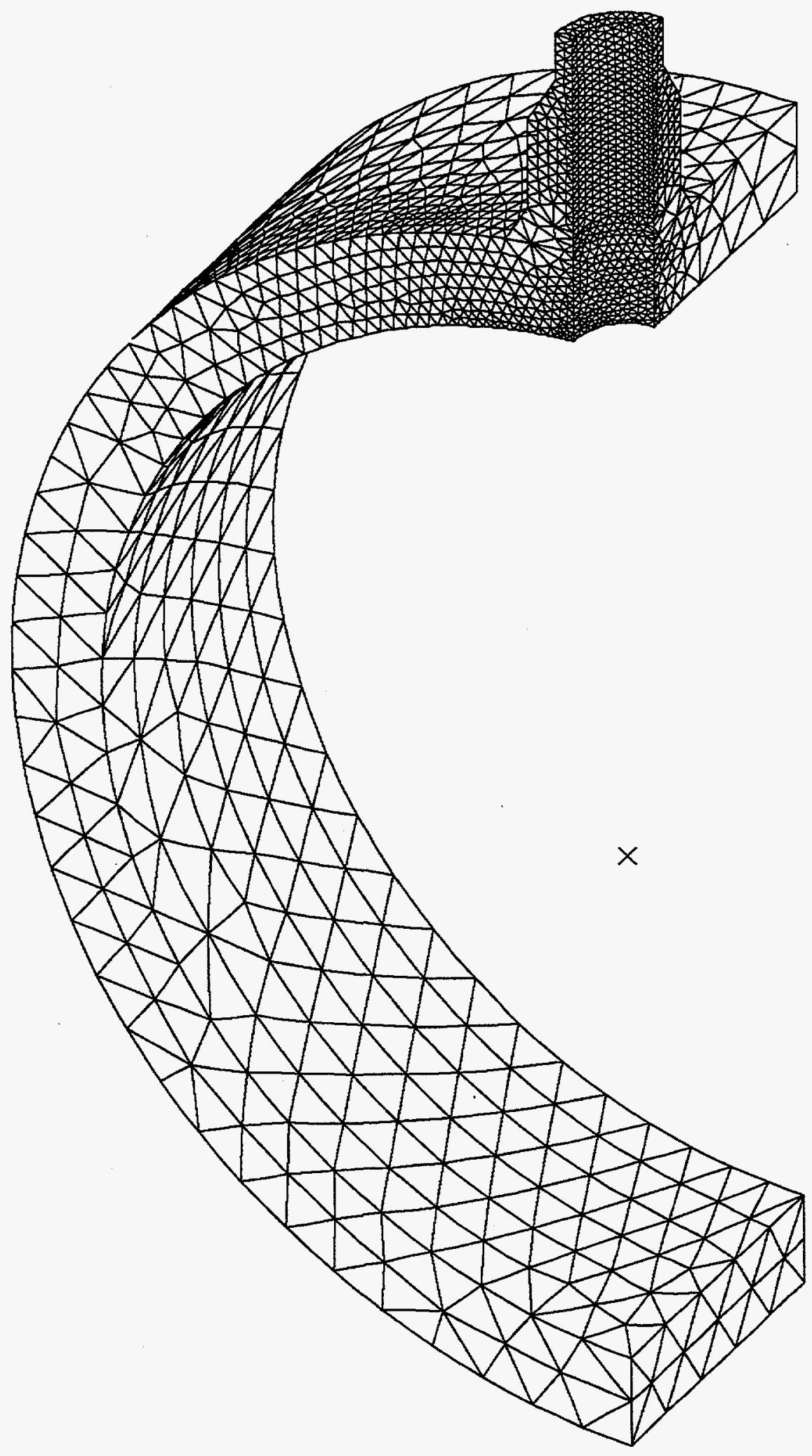

Figure 5-2. Charging system nozzle finite element model. 


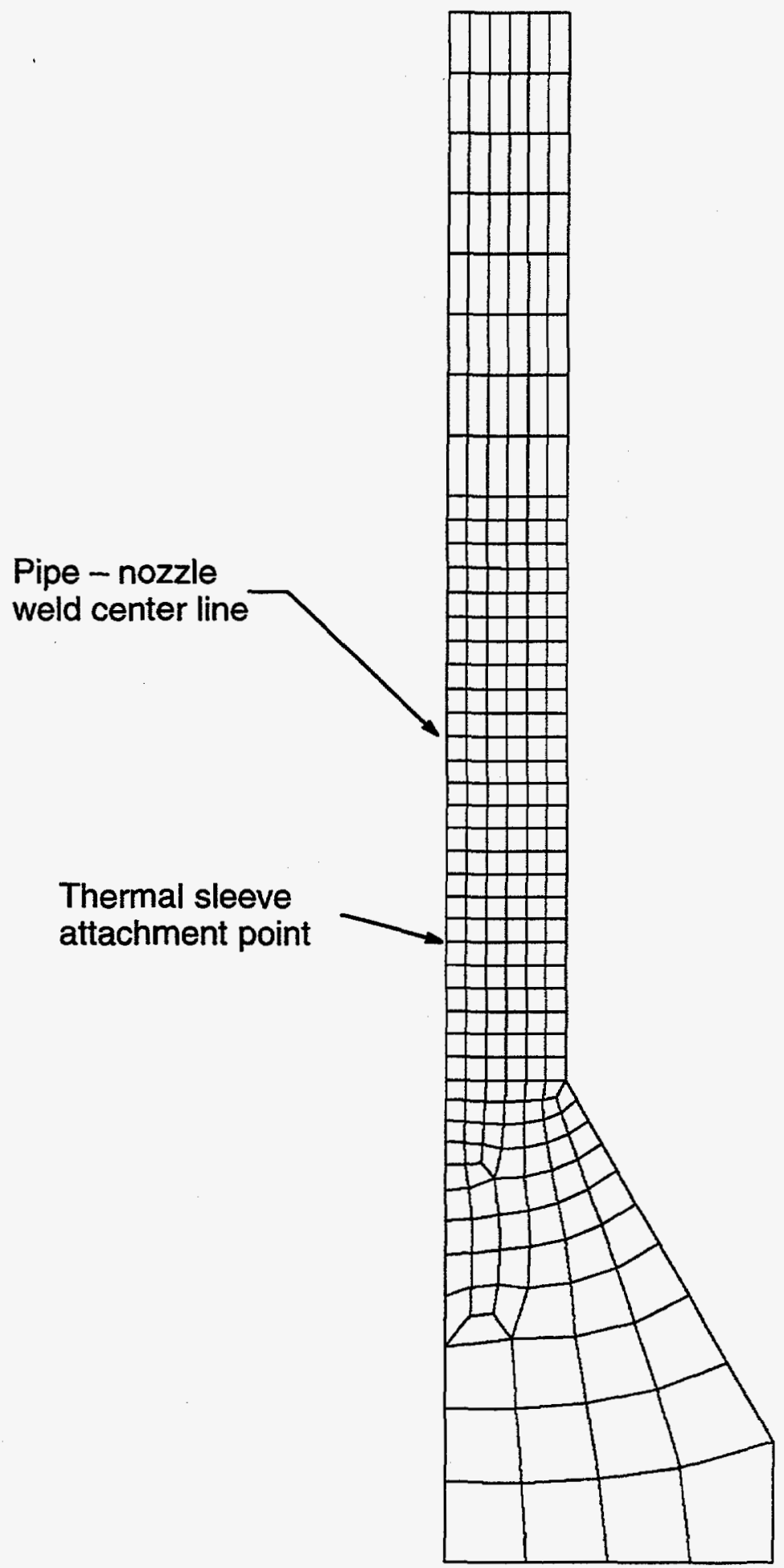

Figure 5-3. Charging nozzle axisymmetric finite element model. 
intensity range. The text in NB-3213.9 (secondary stress definition) and NB-3213.13 (definition of thermal stress) makes no differentiation between vessels and piping, and the wording is consistent with Table NB-3217.1. It appears that Table NB-3217.2 is consistent with the deletion of the $\Delta T_{1}$ term from Equation 10 of NB-3650 for piping components, and since we consider the charging nozzle to be a piping component, the stress caused by the radial thermal gradient was considered to be a peak stress. In the region of the nozzle-to-charging system piping junction, we could clearly differentiate between the stresses caused by radial and axial gradients, because the axial gradients were negligible. However, in the knuckle region, the stresses resulted from a combination of axial and radial gradients, so the linear portions were considered to be secondary stresses.

For most of the transients, the individual usages were negligible, as we found with the NB-3600 analysis. The major contributing transients were various combinations of charging and letdown shutoff, and recovery from those transients. The maximum CUF was 0.030 in the region above the thermal sleeve, and 0.020 for the nozzle body region. The maximum stress intensity from initiation of cold charging water into the hot nozzle (such as from the letdown shutoff event) occurred part-way into the transient for the nozzle-tocharging system piping region where the radial thermal gradient caused most of the stresses. How- ever, for the nozzle body region, the maximum stress intensity occurred after the steady-state condition had been reached when the charging system piping region was at the cold injection water temperature (assumed to be $32^{\circ} \mathrm{F}$ ), the main coolant piping was hot $\left(560^{\circ} \mathrm{F}\right)$, and an axial thermal gradient existed in the knuckle region. A comparison of the three highest $S_{\text {alt }}$ values (which contributed nearly all of the CUF) and the fatigue usage for each load pair are shown in Table 5-90. The load pairs were all various combinations of the load sets listed in Table 5-89.

The difference in the NB-3200 results upstream of the thermal sleeve and at the piping weld is that stress indices were applied to the NB-3600 stresses to represent the field weld. If NB-3600 stress indices were applied to the NB-3200 stresses to represent the field weld, the CUF for the field weld would be higher for the NB-3200 results than for the NB-3600 results. The axisymmetric model shown in Figure 5-3 was used for the analysis. Although the element meshing is comparable to the meshing used in the licensees' analyses that we reviewed in this project, extrapolation of the stress gradient to the surface may require a finer mesh size.

Whereas the NB-3200 and NB-3600 results were comparable for the $S_{\text {alt }}$ computed for the nozzle-to-charging system junction region, the $S_{\text {alt }}$ was reduced by more than a factor of four in the nozzle body (considered to be a branch connection in the NB-3600 analysis) region using the

Table 5-90. Results for charging nozzle using NB-3200 and NB-3600 methods and ASME Code fatigue curve.

\begin{tabular}{lcrccc}
\hline \multirow{2}{*}{ Location } & Load pair & \multicolumn{2}{c}{ NB-3600 } & \multicolumn{2}{c}{ NB-3200 } \\
\cline { 3 - 5 } & & \multicolumn{1}{c}{$\mathrm{S}_{\text {alt }}$} & usage & S $_{\text {alt }}$ & usage \\
\hline Branch connection/ & 1 & 363.53 & 0.452 & 87.69 & 0.007 \\
nozzle body & 2 & 46.00 & 0.004 & 80.94 & 0.020 \\
Nozzle-to-pipe weld & 3 & 46.00 & 0.004 & 29.47 & 0.000 \\
\cline { 2 - 6 } & 1 & 84.62 & 0.006 & - & - \\
Nozzle region upstream of & 2 & 70.04 & 0.012 & - & - \\
thermal sleeve & 3 & 52.11 & 0.004 & - & - \\
& 1 & - & - & 84.79 & 0.006 \\
& 2 & - & - & 82.86 & 0.022 \\
& 3 & - & - & 46.15 & 0.002 \\
\hline
\end{tabular}


NB-3200 finite element analysis. Most of the NB-3600 CUF resulted from a single load pair. The reduction in CUF can be attributed to the $\mathrm{C}_{3} \mathrm{~K}_{3}$ stress indices of $1.8 \times 1.7=3.06$ applied to the $\alpha_{a} T_{a}-\alpha_{b} T_{b}$ term in the NB-3600 analysis, the resulting $3.333 \mathrm{~K}_{\mathrm{e}}$ penalty factor, and smoothing of the axial temperature gradient in the NB-3200 analysis. Whereas the NB-3200 and -3600 results for the $S_{\text {alt }}$ values computed for the nozzle-tocharging system piping region are comparable, the highest $S_{\text {alt }}$ was reduced significantly in the nozzle body region using the finite element model.

When the alternating stress intensity results mainly from a through-wall (radial) thermal gradient, as in the case of the area of the nozzle-to-charging system piping junction (the top portion of the model in Figure 5-3), the alternating stress intensities computed using NB-3200 and NB-3600 methods were comparable. This is because NB-3600 uses the result of an equation developed from an analysis of a radial temperature gradient in a thin cylinder for the $\Delta T_{1}$ and $\Delta T_{2}$ terms. However, when the alternating stress intensity is mainly the result of an axial gradient in the nozzle, as is the case in the nozzle body region where the $\alpha_{a} T_{a}-\alpha_{b} T_{b}$ term is the major contributor, then using an NB-3200 finite element model can reduce the CUF considerably.

In our modeling of the thermal sleeve, we considered the coolant in the annulus between the nozzle and the thermal sleeve to be stagnant. This is consistent with the modeling used in all of the licensees' analyses. However, there may be conditions where there is varying turbulent penetration from the coolant in the main loop into the annulus region during periods of thermal transients. Such a phenomenon may alternately heat and cool the annular region, and has not been addressed in any analyses. There is no physical evidence that such a phenomenon occurs. The sleeves in branch lines of several plants have become separated over the years, but the root cause has generally been attributed to flow induced vibrations rather than thermal fatigue.
5.5.4.2 CUF Based on NUREG/CR-5999 Interim Fatigue Curves. The CUF calculated using the NUREG/CR-5999 interim fatigue curve is shown in Table 5-91. The location is at the nozzle region above the thermal sleeve, where the NB-3200 analysis resulted in the highest CUF ( 0.030 using ASME Code fatigue curves). The CUF for the nozzle-to-piping field weld $(0.022$ using ASME Code fatigue curves), typically computed using NB-3600 analysis methods, was lower. The CUF for the nozzle region above the thermal sleeve is based on the results of the NB-3200 analysis of the nozzle, since these are the stresses that would typically be used at this location.

The CUF increased by a factor of 11.63 over the CUF calculated using the ASME Code fatigue curves. The CUF does not exceed the ASME Code limit of 1.0. If the plant is operated for 60 years, the CUF is 0.524 .

\subsubsection{NUREG/CR-5999 CUF with Con-} servative Assumptions Removed. Since the CUF is below 1.0, no further calculations were performed.

\subsubsection{CUF Based on Revised Interim} Curves. Since the CUF was below 1.0, the $0.001 \% / \mathrm{s}$ curve was used. The CUF results are shown in Table 5-92. The extrapolated CUF for 60 years is 0.479 .

5.5.5 Safety Injection Nozzle. Since the piping was designed to the rules of the B31.1 piping code, no fatigue analyses had been conducted. Consequently, the INEL staff performed a fatigue analysis using representative transients based on the safety injection nozzle analyses from the other PWR plants reviewed in this study, and the methods of the current (1992) edition of the ASME Code. Both ASME Code NB-3600 (piping) and NB-3200 (design by analysis) methods were used, and typical analytical models comparable with those in the licensees' analyses were developed. For the two transients that were the major contributors to the CUF, representative design basis cycles of 70 for emergency injection (design basis numbers range from 60 to 260 and expected 
Table 5-91. CUF results for charging nozzle using NUREG/CR-5999 interim fatigue curve.

\begin{tabular}{cccrrr}
\hline Load pair (Table 5-89) & $\mathbf{S}_{\text {alt }}$ & $\mathrm{S}_{\text {alt }}$ (adjusted) & \multicolumn{1}{c}{$\mathbf{N}$} & \multicolumn{1}{c}{$\mathbf{n}$} & $\mathbf{u}$ \\
\hline 2A/4B & 80.89 & 84.79 & 299 & 20 & 0.067 \\
2A/3B & 79.05 & 82.86 & 316 & 80 & 0.253 \\
4A/3B & 44.03 & 46.15 & 4129 & 20 & 0.005 \\
3A/3B & 43.95 & 46.06 & 4178 & 100 & 0.024 \\
\cline { 5 - 6 } & & & & CUF & 0.349 \\
\hline
\end{tabular}

Table 5-92. CUF results for charging nozzle using revised interim fatigue curve.

\begin{tabular}{cccrrr}
\hline Load pair (Table 5-89) & $\mathrm{S}_{\text {alt }}$ & $\mathrm{S}_{\text {alt }}$ (adjusted) & \multicolumn{1}{c}{$\mathrm{N}$} & $\mathrm{n}$ & $\mathrm{u}$ \\
\hline 2A/4B & 80.89 & 84.79 & 316 & 20 & 0.063 \\
2A/3B & 79.05 & 82.86 & 341 & 80 & 0.235 \\
4A/3B & 44.03 & 46.15 & 5652 & 20 & 0.004 \\
3A/3B & 43.95 & 46.06 & 5739 & 100 & 0.0217 \\
\cline { 4 - 6 } & & & & CUF & 0.319 \\
\hline
\end{tabular}

numbers range from 30 to 100 for the other PWRs), and 200 for initiation of RHR during cooldowns (from Table 5-83), were assumed. The knuckle region of the nozzle is protected by a thermal sleeve, which mitigates the thermal shocks to this region during severe transients. The thermal sleeve is welded to the nozzle.

\subsubsection{CUF Based on ASME Code} Fatigue Curve. Calculations for the safety injection nozzle were completed using the methods of NB-3600 of the ASME Code and the NUPIPEII computer code. Three areas of the nozzle were considered: the nozzle-to-pipe weld, the area at the thermal sleeve junction, and the nozzle body where the nozzle is connected to the main coolant piping, which was considered to be a branch connection. The model used to analyze the RHR piping in Section 5.5.6 was also used to analyze the safety injection nozzle. The CUF was high (1.993) for the branch connection to the main coolant piping, but low (0.046) for the weld to the safety injection system piping and (0.010) at the thermal sleeve. The major contributor to the CUF was the emergency injection transient/plant trip load pair, with the former transient providing almost all of the stress range. This is consistent with the results for the newer vintage Westinghouse plant in Table 5-77 after transients such as LOCAs, steamline breaks, and rapid depressurizations had been eliminated. The axial thermal gradient (the $\alpha_{a} T_{a}-\alpha_{b} T_{b}$ term) produced most of the stress intensity at the branch connection, whereas the $\Delta T_{1}$ and $\Delta T_{2}$ terms produced most of the stress intensity at the weld to the safety injection system piping and the thermal sleeve region of the nozzle.

An NB-3200 finite element analysis was also performed for the nozzle using the same pressures, thermal transients, moments, and numbers of cycles as were used in the NB-3600 analysis. A small axisymmetric finite element model was used to model the nozzle in the region of the connection to the safety injection system piping where the geometry is truly axisymmetric, and a larger 3-dimensional model (with a larger mesh size) was used to model the knuckle region where the geometry is not axisymmetric. The threedimensional model is shown in Figure 5-4 and the axisymmetric model is shown in Figure 5-5. Both models were developed using the I-DEAS (version 6.1) solid modeling software. Heat transfer and stress calculations were subsequently made for both models using the ABAQUS (version 5.2) finite element analysis software. The thermal sleeve was represented by the use of different heat transfer coefficients for the nozzle areas, depending on their relation to the thermal sleeve. A table of temperature- dependent moduli of elasticity were used in the finite element model instead of a 
Component Evaluations

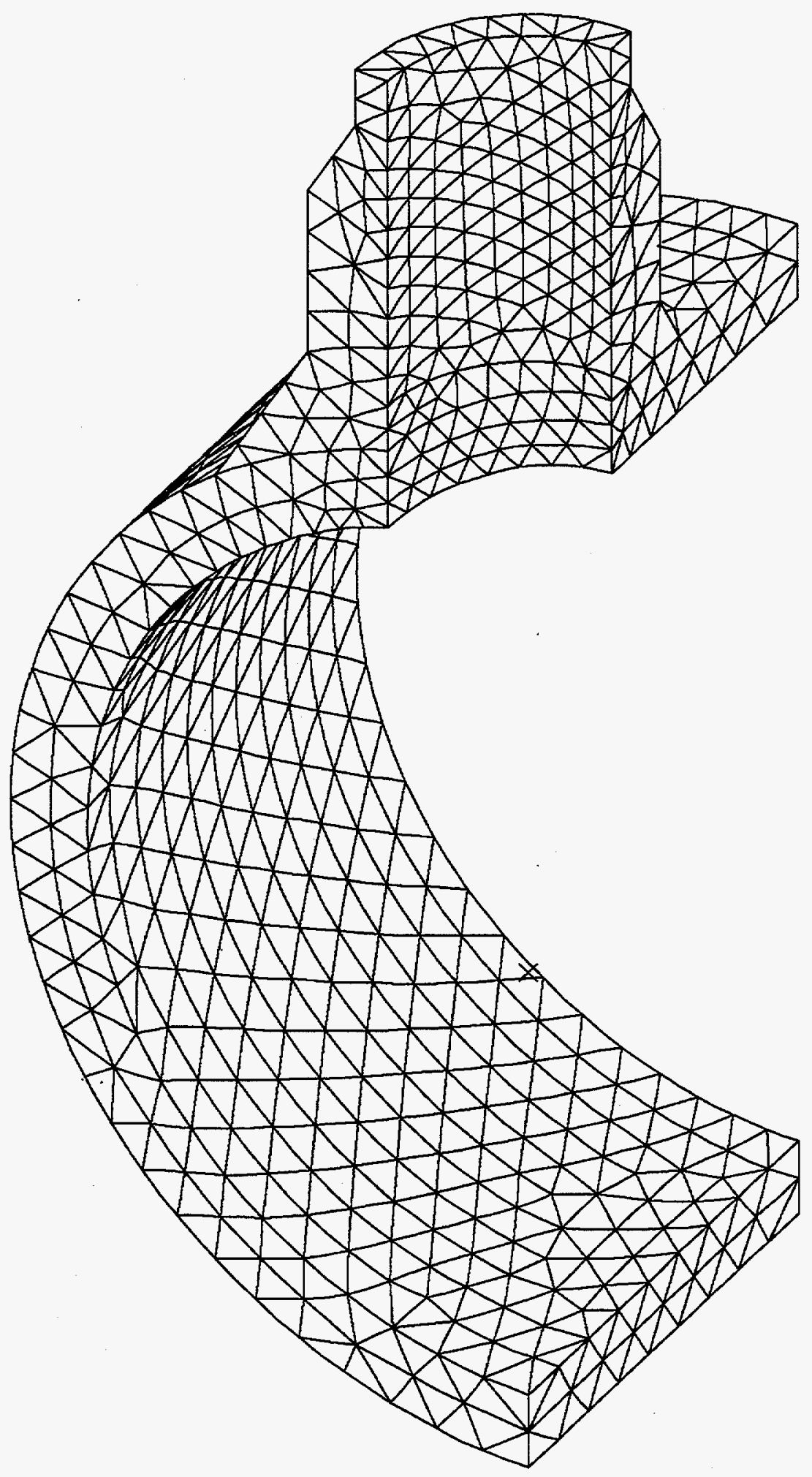

Figure 5-4. Safety injection nozzle finite element model. 


\section{Component Evaluations}

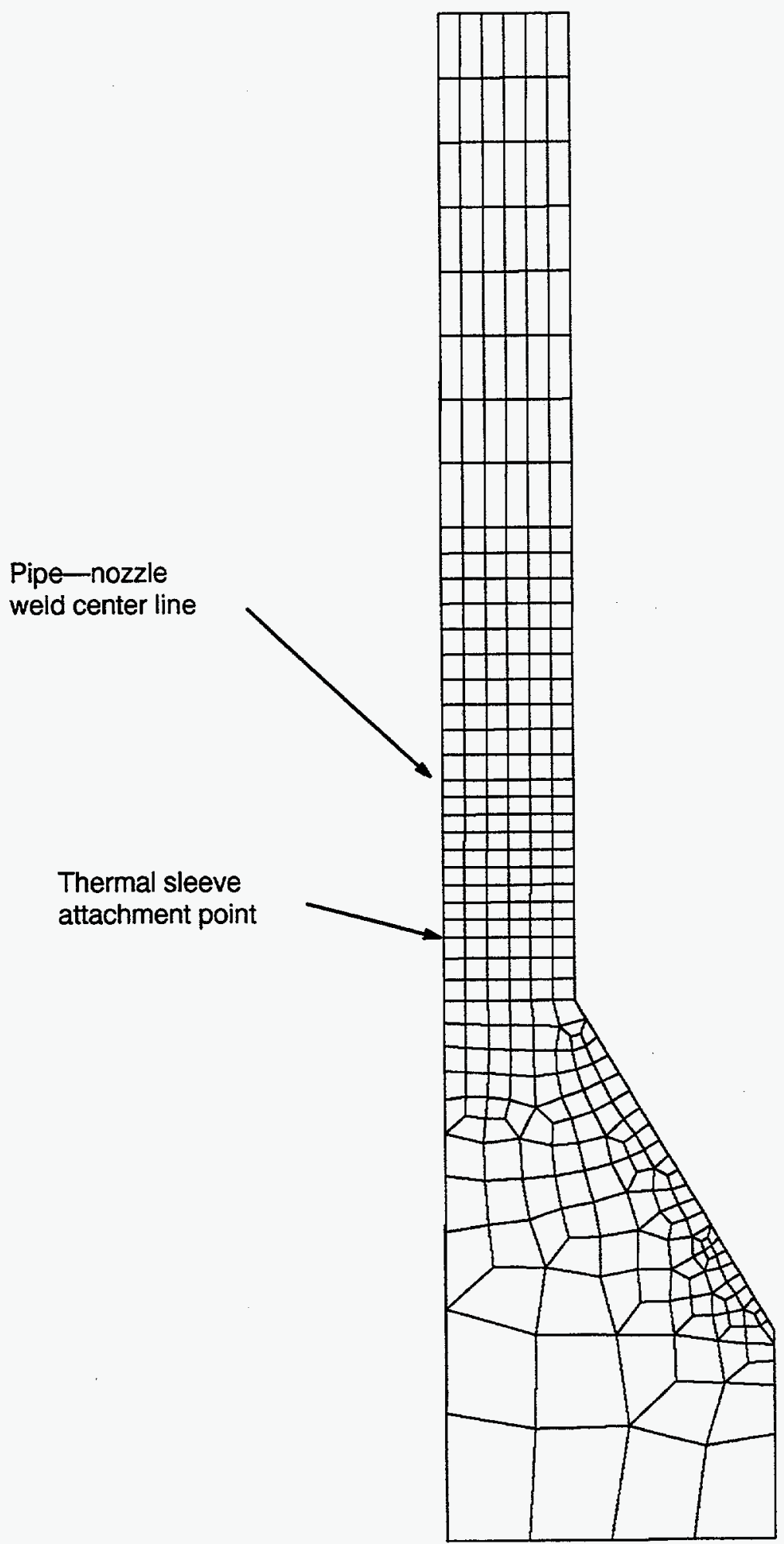

Figure 5-5. Safety injection nozzle axisymmetric finite element model. 
single temperature, so the alternating stress intensities were adjusted by multiplying by the ratio of the modulus of elasticity on the fatigue curve to the modulus of elasticity at the average temperature during the transients that made up the load pairs $\left(300^{\circ} \mathrm{F}\right)$.

The interior surface of the nozzle contains no reentrant comers, so no areas of stress concentration needed to be considered. The weld between the nozzle and the main coolant piping is made in the shop and no fatigue strength reduction factors are typically applied to this type weld. For example, the charging nozzle analyses for the newer vintage Combustion Engineering plant and the $\mathrm{B} \& W$ plant included no fatigue strength reduction factors for this weld. The thermal sleeve is welded to the interior of the nozzle but no stress concentration factor or fatigue strength reduction factor is typically applied to account for this weld. The geometry of the weld is not shown on the fabrication drawing. (No stress indices were applied for this weld in the NB-3600 analysis either. The ASME Code does not list stress indices for this case.) The nozzle-to-piping weld is a field weld. It is not typically included in nozzle analyses, but is the terminal end of NB-3600 analyses models of the adjoining piping. In one analysis of a surge nozzle that we reviewed, for which an NB-3200 analysis was performed on the surge line and nozzle, the appropriate NB-3600 stress indices for a girth butt weld were applied to the stresses at the field-welded safe-end-to-piping weld.

NB-3200 provides different classifications for the linear portions of the stresses due to radial thermal gradients in Tables NB-3217.1 and NB-3217.2. For vessels, Table NB-3217.1 classifies these stresses as secondary stresses whereas for piping, Table NB-3217.2 classifies them as peak stresses. The piping definition in Table NB-3217.2 was used in the calculations to compute the primary plus secondary stress intensity range. The text in NB-3213.9 (secondary stress definition) and NB-3213.13 (definition of thermal stress) makes no differentiation between vessels and piping, and the wording is consistent with Table NB-3217.1. It appears that Table NB-3217.2 is consistent with the deletion of the $\Delta T_{1}$ term from Equation 10 of NB-3650 for piping components, and since we consider the safety injection nozzle to be a piping component, the stress caused by the radial thermal gradient was considered to be a peak stress. In the region of the nozzle-to-safety injection system piping junction, we could clearly differentiate between the stresses caused by radial and axial gradients because the axial gradients were negligible. However, in the main body region of the nozzle the stresses resulted from a combination of axial and radial gradients, so the linear portions were considered to be secondary stresses.

For most of the transients, the individual usages were negligible, as we found with the NB-3600 analysis. The maximum stress intensity from initiation of cold safety injection water into the hot nozzle occurred part-way into the transient for the nozzle-to-safety injection system piping junction region where the radial thermal gradient caused most of the stresses. However, for the nozzle body region, the maximum stress intensity occurred at the end of the transient. A comparison of the highest $S_{\text {alt }}$ (which contributed nearly all of the CUF) and the CUFs (summed from the individual usages of all load pairs) are shown in Table 5-93.

The difference in the NB-3200 results upstream of the thermal sleeve and at the piping weld is that NB-3600 stress indices were applied to the NB-3200 stresses to represent the field weld. Whereas there was not much difference between NB-3200 and NB-3600 results for the $S_{\text {alt }}$ computed for the nozzle-to-safety injection piping system region, the $S_{\text {alt }}$ was reduced by more than a factor of 10 in the nozzle body (considered to be a branch connection in the NB-3600 analysis) region using the NB-3200 finite element analysis. The reduction in CUF can be attributed to the $\mathrm{C}_{3} \mathrm{~K}_{3}$ stress indices of $1.8 \times 1.7=3.06$ applied to the $\alpha_{a} T_{a}-\alpha_{b} T_{b}$ term in the NB-3600 analysis, the resulting $3.333 \mathrm{~K}_{\mathrm{e}}$ penalty factor, and smoothing of the axial temperature gradient in the NB-3200 analysis. The NB-3200 $S_{\text {alt }}$ and CUF at the nozzle-to-pipe weld (which incorporated NB-3600 stress indices) are higher than the NB-3600 results. The axisymmetric model shown in Figure 5-5 was used for the analysis. Although 
Table 5-93. Results for safety injection nozzle using NB-3200 and NB-3600 methods and ASME Code fatigue curve (safety injection/reactor trip).

\begin{tabular}{lcccc}
\hline \multirow{2}{*}{ Location } & \multicolumn{2}{c}{ NB-3600 } & \multicolumn{2}{c}{ NB-3200 } \\
\cline { 2 - 5 } & $\mathrm{S}_{\text {alt }}$ & CUF & \multicolumn{1}{c}{$\mathrm{S}_{\text {alt }}$} & CUF \\
\hline Branch connection/nozzle body & 400.22 & 1.976 & 32.88 & 0.002 \\
Upstream of thermal sleeve & - & - & 92.48 & 0.031 \\
Nozzle-to-pipe weld & 102.57 & 0.046 & 125.14 & 0.095 \\
\hline
\end{tabular}

the element meshing is comparable to the meshing used in the licensees' analyses that we reviewed in this project, extrapolation of the stress gradient to the surface may require a finer mesh size.

When the alternating stress intensity results mainly from a through-wall (radial) thermal gradient, as in the case of the area of the nozzleto-safety injection system piping connection (the top portion of the model in Figure 5-5), the alternating stress intensities computed using NB-3200 and NB-3600 methods were similar. This is because NB-3600 uses the result of an equation developed from an analysis of a radial temperature gradient in a thin cylinder for the $\Delta \mathrm{T}_{1}$ and $\Delta T_{2}$ terms. However, when the alternating stress intensity is mainly the result of an axial gradient in the nozzle, as is the case in the nozzle body region downstream of the thermal sleeve where the $\alpha_{a} T_{a}-\alpha_{b} T_{b}$ term is the major contributor, then using an NB-3200 finite element model can reduce the CUF considerably.

In our modeling of the thermal sleeve, we considered the coolant in the annulus between the nozzle and the thermal sleeve to be stagnant. This is consistent with the modeling used in all of the licensees' analyses. However, there may be conditions where there is varying turbulent penetration from the coolant in the main loop into the annulus region during period of emergency injection. Such a phenomenon may alternately heat and cool the annular region, and has not been addressed in any analyses. There is no physical evidence that such a phenomenon occurs. The sleeves in branch lines of several plants have become separated over the years, but the root cause has generally been attributed to flow induced vibrations rather than thermal fatigue.

\subsubsection{CUF Based on NUREG/CR-5999} Interim Fatigue Curves. The CUF calculated using the NUREG/CR-5999 interim fatigue curves is shown in Table 5-94. The location is at the nozzle-to-safety injection piping weld, since the NB-3200 analysis demonstrated that this region had the highest CUF. The CUF is based on the results of the NB-3600 analysis of the nozzle, since these are the stresses that would typically be used at this location.

The CUF increased by a factor of 9.04 over the CUF calculated using the ASME Code fatigue curves. The CUF does not exceed the ASME Code limit of 1.0.

\subsubsection{NUREG/CR-5999 CUF with Con- servative Assumptions Removed. Based} on 172 heatup/cooldowns from Table 5-83 the CUF is reduced to 0.410 . If the plant is operated for 60 years, the CUF is 0.615 .

\subsubsection{CUF Based on Revised Interim}

Curves. The strain rate for the first load pair was based on a 30-second rise time to the maximum stress, while $0.001 \% / \mathrm{s}$ was used for the other two load sets. The CUF results are shown in Table 5-95. The extrapolated CUF for 60 years is 0.491 .

\subsubsection{Residual Heat Removal System Class 1 Piping. No CUF analyses have been performed by the licensee for the SA-376 Type 316 residual heat removal system. Conse- quently, system drawings were supplied by the licensee and a representative fatigue analysis was performed by the INEL staff.}


Table 5-94. CUF results for safety injection nozzle using NUREG/CR-5999 interim fatigue curve.

\begin{tabular}{lrrrr}
\hline \multicolumn{1}{c}{ Load pair } & $\mathrm{S}_{\text {alt }}$ & $\mathrm{N}$ & $\mathrm{n}$ & $\mathbf{u}$ \\
\hline Safety injection/reactor trip & 102.57 & 189 & 70 & 0.370 \\
Initiation of RHR/OBE & 46.79 & 3802 & 50 & 0.013 \\
Initiation of RHR/leak test & 45.49 & 4503 & 150 & 0.033 \\
& & & $\mathrm{CUF}$ & 0.416 \\
\hline
\end{tabular}

Table 5-95. CUF results for safety injection nozzle using revised interim fatigue curves.

\begin{tabular}{lrrrr}
\hline \multicolumn{1}{c}{ Load pair } & $\mathrm{S}_{\text {alt }}$ & $\mathrm{N}$ & $\mathrm{n}$ & $\mathrm{u}$ \\
\hline Safety injection/reactor trip & 102.57 & 235 & 70 & 0.298 \\
Initiation of RHR/OBE & 46.79 & 5085 & 50 & 0.010 \\
Initiation of RHR/leak test & 45.49 & 6346 & 122 & 0.019 \\
& & & $\mathrm{CUF}$ & 0.327 \\
\hline
\end{tabular}

5.5.6.1 CUF Based on ASME Code Fatigue Curve. Before a fatigue analysis could be conducted, a set of representative transients for the plant had to be defined. The postulated set of transients used in the analysis was based on the plant operation and numbers of cycles defined by the licensee for other components, and the definition of transients and numbers of cycles for the RHR and shutdown cooling systems of the newer vintage Westinghouse and Combustion Engineering plants, respectively. No thermal stratification transients were included since this condition has not been identified in this plant's residual heat removal system (although thermal stratification has been identified in similar systems in other PWRs).

The portions of the residual heat removal system that would be classified as Class 1 systems in newer vintage plants were analyzed for fatigue. CUF calculations were performed using the current (1992) edition of the ASME Code. The highest CUF (0.022) was found to be on an $8 \times 8 \times 8$ in. tee, as shown Figure 5-6.

5.5.6.2 CUF Based on NUREG/CR-5999 Interim Fatigue Curve. The CUF using the
NUREG/CR-5999 interim fatigue curve is shown in Table 5-96. Application of the NUREG/ CR-5999 interim fatigue curve increased the CUF by a factor of 13.00 over the design basis number. If the plant is operated for 60 years, the CUF is 0.429 .

5.5.6.3 NUREG/CR-5999 CUF with Conservative Assumptions Removed. Since the CUF is below 1.0, no further calculations were performed.

\subsubsection{CUF Based on Revised Interim} Curves. Since the CUF was below 1.0, the $0.001 \% / \mathrm{s}$ curve was used. The CUF results are shown in Table 5-97. The extrapolated CUF for 60 years is 0.308 .

5.5.7 Results and Conclusions. We obtained the latest design basis fatigue calculations for three components on an older vintage Westinghouse plant, and calculated a representative design basis CUF for the other three components. The CUF obtained from the design basis calculations for the location with the highest calculated fatigue usage on each component was recomputed using the NUREG/CR-5999 interim fatigue curves. The results are summarized in 


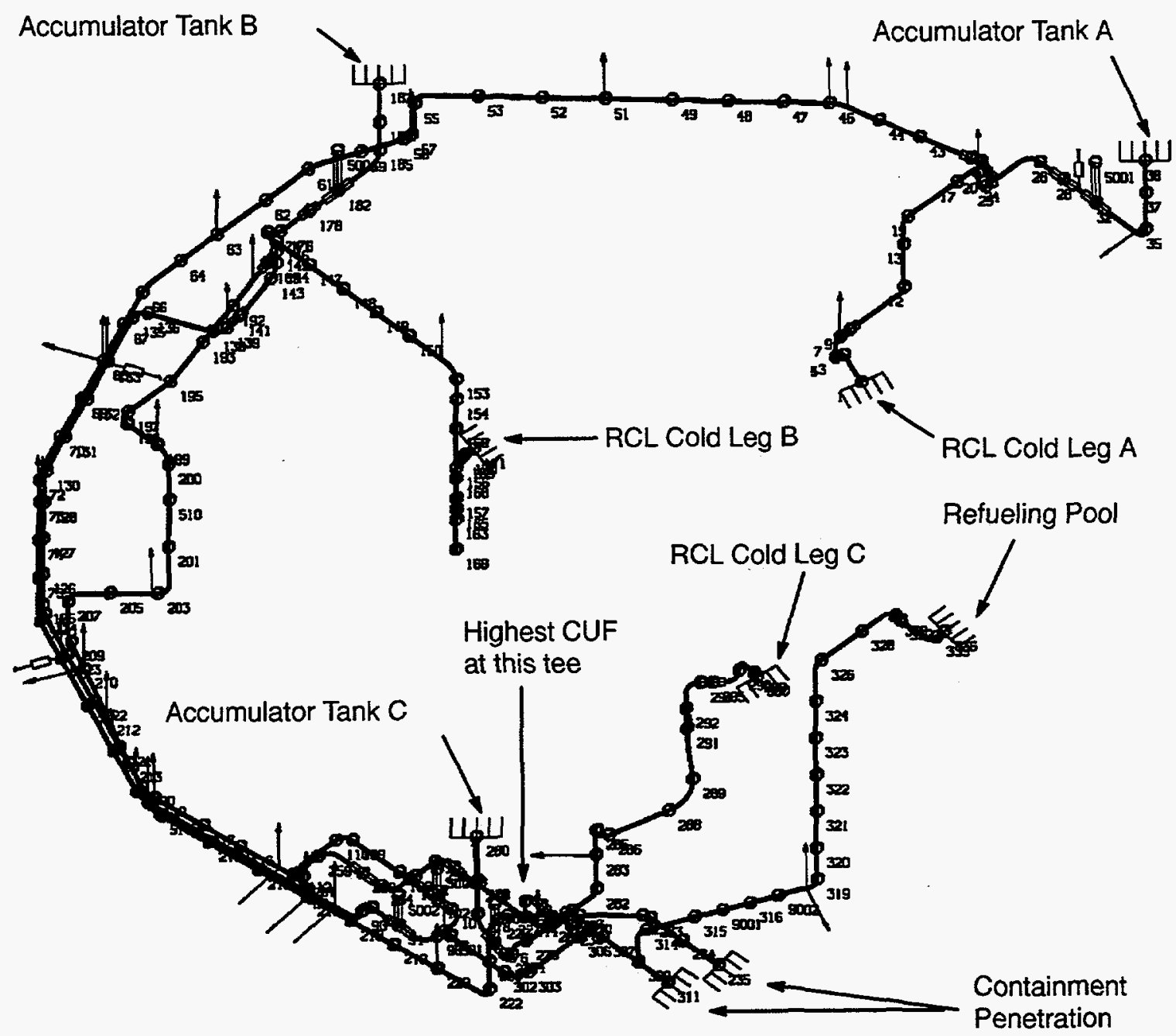

Figure 5-6. Residual heat removal system model isometric view.

Table 5-96. CUF results for the residual heat removal system piping using NUREG/CR-5999 interim fatigue curve.

\begin{tabular}{|c|c|c|c|c|}
\hline Load pair & $S_{\text {alt }}$ & $\mathrm{N}$ & $\mathrm{n}$ & $\mathbf{u}$ \\
\hline Shutdown cooling $A / O B E$ & 56.91 & 1169 & 50 & 0.043 \\
\hline Shutdown cooling A/leak test $A$ & 51.60 & 2109 & 150 & 0.071 \\
\hline Reactor trip/emergency injection & 50.61 & 2370 & 70 & 0.030 \\
\hline Step power increase/shutdown cooling B & 46.44 & 3976 & 200 & 0.050 \\
\hline Leak test $\mathrm{B} /$ reactor trip & 46.28 & 4060 & 150 & 0.037 \\
\hline Step power increase/null & 46.26 & 4070 & 200 & 0.049 \\
\hline Cooldown/reactor trip & 32.36 & 34975 & 180 & 0.005 \\
\hline \multirow[t]{2}{*}{ Step power increase/cooldown } & 32.36 & 34975 & 20 & 0.001 \\
\hline & & & CUF & 0.286 \\
\hline
\end{tabular}


Table 5-97. CUF results for the residual heat removal system piping using revised interim fatigue curve.

\begin{tabular}{lcrrc}
\hline \multicolumn{1}{c}{ Load pair } & $\mathrm{S}_{\mathrm{alt}}$ & $\mathrm{N}$ & $\mathrm{n}$ & $\mathrm{u}$ \\
\hline Shutdown cooling A/OBE & 56.91 & 1549 & 50 & 0.032 \\
Shutdown cooling A/leak test A & 51.60 & 2642 & 150 & 0.057 \\
Reactor trip/emergency injection & 50.61 & 2973 & 70 & 0.024 \\
Step power increase/shutdown cooling B & 46.44 & 5382 & 200 & 0.037 \\
Leak test B/reactor trip & 46.28 & 5528 & 150 & 0.027 \\
Step power increase/null & 46.26 & 5547 & 200 & 0.026 \\
Cooldown/reactor trip & 32.36 & 78079 & 180 & 0.002 \\
Step power increase/cooldown & 32.36 & 78079 & 20 & 0.000 \\
& & & CUF & 0.205 \\
\hline
\end{tabular}

Table 5-98. The increases in the magnitudes of the design CUFs are as follows:

\section{Stainless Steel}

Surge line

Charging nozzle

Safety injection nozzle

Residual heat removal piping

13.00

10.31 average

Carbon/Low-alloy Steel

Reactor vessel shell/lower

head

Reactor vessel inlet nozzle

Reactor vessel outlet nozzle

\subsection{1 average}

Conservative assumptions were identified, and where justifiable, the design CUFs were recomputed with conservative assumptions removed. The 40-year CUFs were multiplied by 1.5 to determine a 60-year CUF, as shown in Table 5-98.

Using the NUREG/CR-5999 interim fatigue curves, the CUF remained below 1.0 for the inlet and outlet nozzles, safety injection and charging nozzles, and the residual heat removal line. The CUF for the reactor vessel lower head was less than 1.0 for 40 years, but exceeded 1.0 for 60 years. Most of the CUF was due to the assumptions for frictional forces and vibration between the core blocks and the lower head. These assumptions may be conservative, and the the excess conservatism may be sufficiently removed to reduce the CUF below 1.0. However, for the surge line piping, our judgment is that a more detailed (that is, ASME Code NB-3200) stress analysis or fatigue monitoring and cycle counting would have to be used to reduce the CUF below 1.0. As listed in Table 5-88, there remain a number of options available to further reduce the CUF.

\subsection{Newer Vintage General Electric Plant}

A comparison of the design CUFs from the licensee's design basis calculations and CUFs using the NUREG/CR-5999 interim fatigue curves was carried out for the locations of highest design CUF for the six components listed below:

1. Reactor vessel shell and lower head

2. Reactor vessel feedwater nozzle

3. Reactor recirculation piping (including inlet and outlet nozzles)

4. Core spray line reactor vessel nozzle and associated Class 1 piping

5. Residual heat removal nozzles and associated Class 1 piping

6. Feedwater line Class 1 piping. 
Table 5-98. Summary of older vintage Westinghouse plant CUFs.

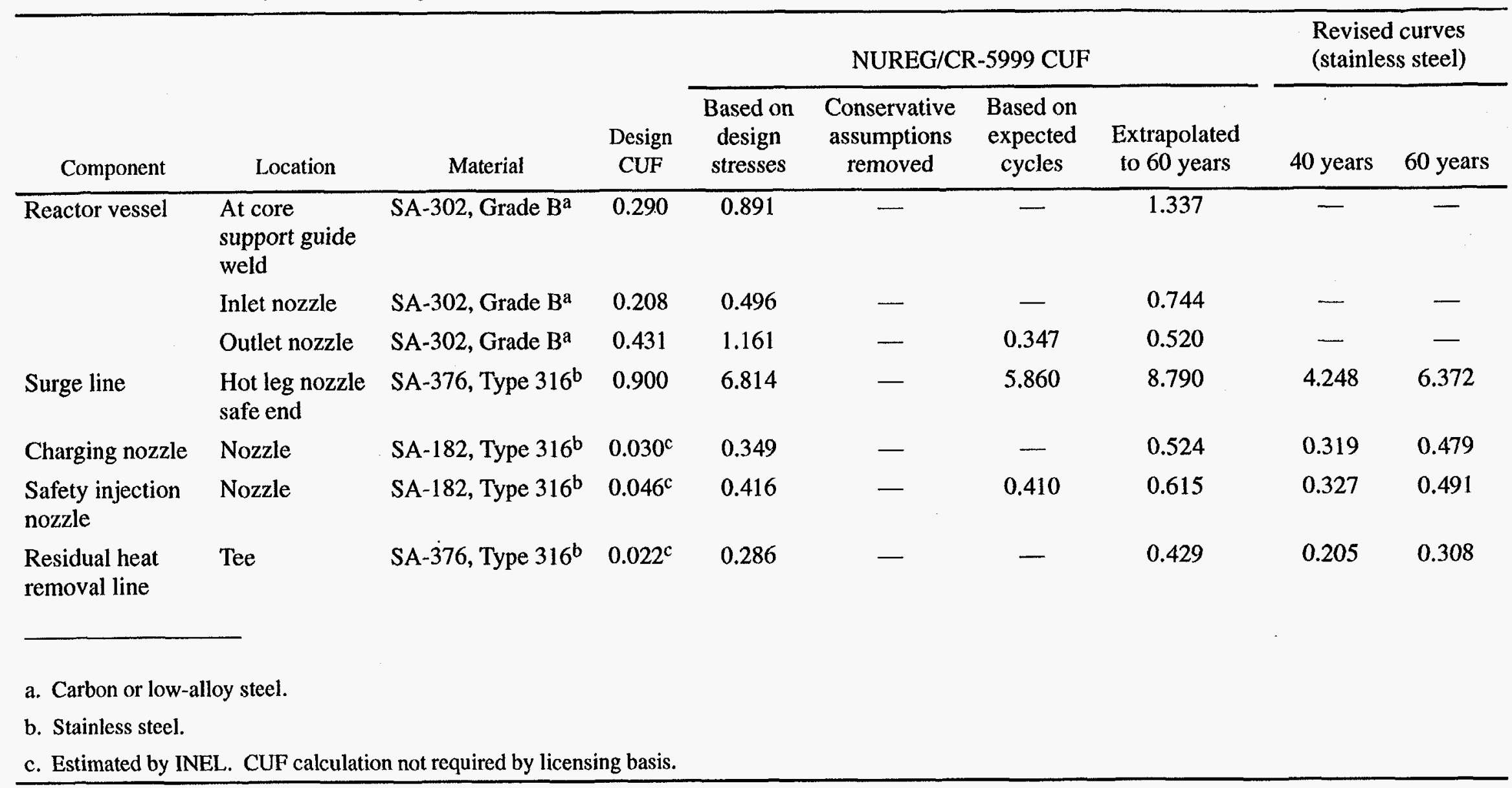


As of early 1994, the BWR/6 plant has been operated approximately 7 of the 40 years currently approved in its operating license. Table 5-99 shows the design basis cycles for transients that are important from a fatigue standpoint for the six components that were evaluated. The anticipated transients are based on preliminary data for the plant for cycles through February 1994 , and have been extrapolated to 40 years by multiplying by $40 / 7$. No fatigue monitoring has been performed on this plant.

The cycles-to-date extrapolated to 40 years are greater than the design basis cycles for several transients. However, there have been no occurrences of several transients that are major contributors to the design basis CUF for some components. Therefore, we cannot state on a general basis whether components are experiencing more of less fatigue usage than would be predicted by the design basis transients.

\subsubsection{Reactor Vessel Shell and Lower}

Head. The highest CUFs on the interior surfaces of the lower shell and head are in the vicinity of the lower head control rod drive mechanism (CRDM) penetrations The location with the highest CUF is in the weld region between the lowalloy steel shell and the Alloy 600 CRDM penetration. The CUF is 0.200 for the head and 0.407 for the CRDM penetration weld material. The SA-508 Class 2 head is protected from the coolant by a layer of cladding. No fatigue analysis is performed for the cladding. The original analysis was performed in 1976.

\subsubsection{NUREG/CR-5999 CUF Based on Licensee's Design Calculation Stresses for Low-Alloy Steel Material. The effect of the NUREG/CR-5999 interim fatigue curve is shown in Table 5-100. As previously discussed, the results shown in Table 5-100 assume that the coolant was in contact with the low-alloy steel base metal underneath the cladding. The licens- ee's CUF calculations used the ASME Code, Section III, 1971 edition, through Winter 1972}

Table 5-99. Number of selected design basis cycles compared to anticipated number of cycles over 40-year license life.

\begin{tabular}{lcc}
\hline \multicolumn{1}{c}{ Transient } & Design basis cycles & Anticipated cycles \\
\hline Hydro/leak test & 40 & 40 \\
Startup & 120 & 280 \\
Loss of feedwater pumps & 30 & 0 \\
Turbine trip (full loss of & 10 & 34 \\
feedwater heaters) & & \\
Partial feedwater heater bypass & 70 & 85 \\
Turbine trip (scram) & 40 & 0 \\
Other scrams & 140 & 223 \\
Refueling scrams & 300 & 0 \\
Reduction to 0\% power, hot & 111 & 263 \\
standby, and shutdown & & 309 \\
Partial transients through 50\% & 113 & \\
power level & & \\
\hline
\end{tabular}

Table 5-100. CUF results for reactor vessel lower head near CRDM penetration weld using NUREG/CR-5999 interim fatigue curve.

\begin{tabular}{|c|c|c|c|c|c|}
\hline Load pair & $S_{\mathrm{alt}}(\mathrm{ksi})$ & $\mathrm{S}_{\mathrm{alt}}$ (adjusted) & $\mathrm{N}$ & $\mathrm{n}$ & $\mathbf{u}$ \\
\hline \multirow[t]{2}{*}{ All } & 46.34 & 47.97 & 94 & 1100 & 11.702 \\
\hline & & & & CUF & 11.702 \\
\hline
\end{tabular}


Addenda. The modulus of elasticity used in the analysis was for $300^{\circ} \mathrm{F}$, so a multiplication factor of 30/29 (the ratio of the modulus of elasticity on the fatigue curve to the modulus of elasticity at $300^{\circ} \mathrm{F}$ in the 1971 edition of the ASME Code) was included. The analysis lumps all cycles together with the highest $S_{\text {alt }}$, so the highest temperature of $288^{\circ} \mathrm{C}$ and a saturated $(0.001 \% / \mathrm{s})$ strain rate is assumed.

Application of the NUREG/CR-5999 interim fatigue curve increased the CUF by a factor of 58.51 over the design basis number. The CUF exceeds the ASME Code limit of 1.0.

\subsubsection{NUREG/CR-5999 CUF Based on Licensee's Design Calculation Stresses for Weld Metal Material. The effect of the} NUREG/CR-5999 interim fatigue curve is shown in Table 5-101. NUREG/CR-5999 does not include a fatigue curve for Alloy 600 , so the stainless steel curve was used. The licensee's CUF calculations used the ASME Code, Section III, 1971 edition, through Winter 1972 Addenda. The modulus of elasticity used in the analysis was for $300^{\circ} \mathrm{F}$, so a multiplication factor of $28.3 / 30.5$ (the ratio of the modulus of elasticity for the NUREG/CR-5999 fatigue curve to the modulus of elasticity at $300^{\circ} \mathrm{F}$ in the 1971 edition of the ASME Code) was included.

Application of the NUREG/CR-5999 interim fatigue curve increased the CUF by a factor of
6.67 over the design basis number. The CUF exceeds the ASME Code limit of 1.0.

\subsubsection{NUREG/CR-5999 CUF with Con- servative Assumptions Removed for Low-Alloy Steel Material. The CUF is calcu-} lated conservatively in that the total cycles (n) for all load pairs have been included in the CUF calculation for the load pair with the highest $S_{\text {alt }}$, and the numbers for all cycles have been considered individually, rather than paired. The cycles can be broken into two combined load pairs (a) hydrotest (40 cycles), OBE (10 cycles), and loss-offeedwater-pumps ( 30 cycles), and (b) all remaining transients (1020 cycles). The first load pair corresponds to the highest $S_{\text {alt }}$, and results from a combination of the hydrotest and loss-of-feedwater-pumps transients. The number of combinations for this load pair is 40 cycles (allowing an extra ten cycles for the loss of feedwater pumps transient). Since $S_{\text {alt }}$ for the OBE/loss-of-feedwater-pumps load combination is less than $46.34 \mathrm{ksi}$, the ten OBE cycles can be conservatively included with the hydrotest/loss-of-feedwaterpumps load pair for a total of 50 cycles. The number of allowable cycles is shown in Table 5-102.

The maximum alternating stress for the remaining loads pairs was calculated using the licensee's stress results. The analysis used a multiplication factor of 1.4 to account for plasticity in regions of local thermal stress. (The ASME Code requires that a Poisson's ratio of 0.5 be used in

Table 5-101. CUF results for CRDM penetration weld using NUREG/CR-5999 interim fatigue curve.

\begin{tabular}{|c|c|c|c|c|c|}
\hline Load pair & $S_{\text {alt }}(\mathrm{ksi})$ & $S_{\text {alt }}($ adjusted $)$ & $\mathrm{N}$ & $\mathbf{n}$ & $\mathfrak{u}$ \\
\hline \multirow[t]{2}{*}{ All } & 80.50 & 74.68 & 405 & 1100 & 2.716 \\
\hline & & & & CUF & 2.716 \\
\hline
\end{tabular}

Table 5-102. CUF results for reactor vessel lower head near CRDM penetration weld using NUREG/CR-5999 interim fatigue curve with conservative assumptions removed.

\begin{tabular}{|c|c|c|c|c|c|}
\hline Load pair & $\mathrm{S}_{\text {alt }}(\mathrm{ksi})$ & $S_{\text {alt }}$ (adjusted) & $\mathrm{N}$ & $\mathbf{n}$ & $\mathrm{u}$ \\
\hline $\begin{array}{l}\text { Hydro/OBE/loss of feedwater } \\
\text { pumps }\end{array}$ & 46.34 & 47.97 & 94 & 50 & 0.532 \\
\hline \multirow[t]{2}{*}{ All other } & 15.16 & 15.16 & 10579 & 1020 & 0.096 \\
\hline & & & & CUF & 0.628 \\
\hline
\end{tabular}


regions of local thermal stress, rather than the value of 0.3 that was used in the analysis. The ratio of 1 minus Poisson's ratio for values of 0.3 and 0.5 is $0.7 / 0.5=1.4$ ). Adjusting the alternating stress intensity for the second load pair in the licensee's calculations by $30 / 29 \times 1.4$ results in an $S_{\text {alt }}$ of $15.16 \mathrm{ksi}$. The remaining 1020 cycles still have not been paired, but since the 80 cycles of hydrotest/OBE/loss-of-feedwater have been paired, the total number of cycles used in the fatigue calculation has been reduced from 1100 to 1020 .

The revised CUF is shown in Table 5-102. It is less than the ASME Code limit of 1.0. If the plant is operated for 60 years, the extrapolated CUF is 0.942 .

The anticipated numbers of cycles for the startups and other scrams are 243 greater than the numbers of design basis transients, but these are more than compensated for by the reduction in the loss-of-feedwater-pumps and refueling scram transients, for which the anticipated number is 330 less than the design basis cycles.

5.6.1.4 NUREG/CR-5999 CUF with Conservative Assumptions Removed for Weld Metal Material. The CUF is calculated conservatively in that the total cycles for all load pairs have been included in the CUF calculation for the load pair with the highest $S_{\text {alt }}$, and the numbers for all cycles have been considered individually, rather than paired. The cycles can be broken into three combined load pairs (a) hydrotest ( 40 cycles), OBE (10 cycles), and loss-of-feedwater-pumps (30 cycles); (b) control rod drive isolation ( 50 cycles) and single control rod scram (10 cycles); and (c) all remaining transients ( 960 cycles). The first load pair corresponds to the highest $S_{\text {alt }}$ and results from a combination of the hydrotest and loss-of-feedwater-pumps transients. The number of combinations for this load pair is 40 cycles (allowing an extra ten cycles for the loss-of-feedwater-pumps transient). Since $S_{\text {alt }}$ for the OBE/loss-of-feedwater-pumps load combination is less than $80.50 \mathrm{ksi}$, the ten OBE cycles can be conservatively included with the hydrotest/loss-of-feedwaterpumps load pairing for a total of 50 cycles.

The maximum alternating stress for the remaining load pairs was calculated using the licensee's stress results. The modulus of elasticity used in the analysis was $300^{\circ} \mathrm{F}$, so a multiplication factor of $28.3 / 30.5$ (the ratio of the modulus of elasticity for the NUREG/CR-5999 fatigue curve to the modulus of elasticity at $300^{\circ} \mathrm{F}$ in the 1971 edition of the ASME Code) was included for the second and third load pair cases. In addition, the stress intensities were multiplied by a factor of 1.4 to account for local plasticity as described in Section 5.6.1.3.

The revised CUF is shown in Table 5-103. It is less than the ASME Code limit of 1.0. If the plant is operated for 60 years, the extrapolated CUF is 0.711 .

Table 5-103. CUF results for CRDM penetration weld using NUREG/CR-5999 interim fatigue curve with conservative assumptions removed.

\begin{tabular}{lccccc}
\hline \multicolumn{1}{c}{ Load pair } & $\mathrm{S}_{\text {alt }}(\mathrm{ksi})$ & $\mathrm{S}_{\text {alt }}$ (adjusted) & $\mathrm{N}$ & $\mathrm{n}$ & $\mathrm{u}$ \\
\hline $\begin{array}{l}\text { Hydro/OBE/loss of feedwater } \\
\text { pumps }\end{array}$ & 80.50 & 74.69 & 405 & 50 & 0.124 \\
$\begin{array}{l}\text { CRD isolation/single control } \\
\text { rod scram }\end{array}$ & - & 62.19 & 685 & 60 & 0.088 \\
$\begin{array}{l}\text { All other } \\
\text { n }\end{array}$ & - & 47.08 & 3662 & 960 & 0.262 \\
& & & & $\mathrm{CUF}$ & 0.474 \\
\hline
\end{tabular}


The anticipated numbers of cycles for the startups and other scrams are 243 greater than the numbers of design basis transients, but these are more than compensated for by the reduction in the loss-of-feedwater-pump transients and refueling scrams, for which the anticipated number of cycles is $\mathbf{3 3 0}$ less than the number of design basis cycles.

\subsubsection{CUF for Weld Metal Material Based on Revised Interim Fatigue Curves. Since the CUF was below 1.0, the $0.001 \% / \mathrm{s}$ curve was used. The CUF results are shown in Table 5-104. The extrapolated CUF for 60 years is 0.539 .}

\subsubsection{Reactor Vessel Feedwater Nozzle.} The highest CUFs for the feedwater nozzle are 0.795 for the nozzle thermal sleeve, and 0.301 for the nozzle safe end. The effect of the NUREG/CR-5999 interim fatigue curves were assessed for both the thermal sleeve and the safe 'end, since the thermal sleeve is not a pressure boundary.

\subsubsection{NUREG/CR-5999 CUF Based on Licensee's Design Calculation Stresses} for Thermal Sleeve. The licensee's design calculations show that the highest CUF for the reactor vessel feedwater nozzle is located on the thermal sleeve near its weld to the nozzle. The licensee's design CUF calculations used the ASME Code, Section III, 1971 edition, through Summer 1973 addenda. NUREG/CR-5999 does not include an interim fatigue curve for Alloy 600 , so the stainless steel curves were used. The $S_{\text {alt }}$ values in the design calculations were the stress values used to determine the allowable cycles. No further adjustment for the effect of modulus of elasticity was made, so it was assumed that the proper adjustment had already been incorporated. Since the 1971 edition of the Code used an modulus of elasticity of $26.0 \times 10^{6}$ psi (ASME Code Figure I-9.2), the $S_{\text {alt }}$ values were multiplied by $28.3 / 26$ because the NUREG/CR-5999 interim fatigue curve was developed using a modulus of elasticity of $28.3 \times 10^{6} \mathrm{psi}$. The effect of the NUREG/ CR-5999 interim fatigue curve is shown in Table 5-105.

Table 5-104. CUF results for CRDM penetration weld using revised interim fatigue curve with conservative assumptions removed.

\begin{tabular}{lccccc}
\hline \multicolumn{1}{c}{ Load pair } & $\mathrm{S}_{\text {alt }}(\mathrm{ksi})$ & $\mathrm{S}_{\mathrm{alt}}$ (adjusted) & $\mathrm{N}$ & $\mathrm{n}$ & $\mathrm{u}$ \\
\hline $\begin{array}{l}\text { Hydro/OBE/loss of feedwater } \\
\text { pumps }\end{array}$ & 80.50 & 74.69 & 490 & 50 & 0.102 \\
$\begin{array}{l}\text { CRD isolation/single control } \\
\text { rod scram }\end{array}$ & - & 62.19 & 1021 & 60 & 0.059 \\
All other & - & 47.08 & 4853 & 960 & 0.198 \\
& & & & $\mathrm{CUF}$ & 0.359 \\
\hline
\end{tabular}

Table 5-105. CUF results for reactor vessel feedwater nozzle thermal sleeve using NUREG/CR-5999 interim fatigue curve.

\begin{tabular}{lccrrc}
\hline \multicolumn{1}{c}{ Load pair } & $\mathrm{S}_{\text {alt }}(\mathrm{ksi})$ & $\mathrm{S}_{\text {alt }}$ (adjusted) & $\mathrm{N}$ & $\mathrm{n}$ & $\mathrm{u}$ \\
\hline Turbine roll A/turbine trip B & 204.29 & 222.36 & 29 & 10 & 0.345 \\
Turbine roll A/turbine roll B & 160.97 & 175.21 & 52 & 110 & 2.115 \\
Hot standby/turbine roll B & 135.79 & 147.80 & 78 & 20 & 0.256 \\
Hot standby A/TG trip & 122.89 & 133.76 & 100 & 210 & 2.100 \\
Hot standby A/hot standby B & 87.85 & 95.62 & 224 & 2 & 0.009 \\
Hot standby B/shutdown A & 50.99 & 55.50 & 1360 & 220 & 0.162 \\
Shutdown A/shutdown B & 47.09 & 51.26 & 2194 & 335 & 0.153 \\
Turbine trip A/shutdown B & 37.62 & 40.95 & 8479 & 10 & 0.001 \\
TG trip/shutdown B & 19.89 & 21.65 & $6.6 \times 10^{7}$ & 15117 & 0.000 \\
& & & & CUF & 5.141 \\
\hline
\end{tabular}


The results indicate that the CUF increased by a factor of 6.47 over the design basis number. The CUF exceeds the ASME Code limit of 1.0. If the plant is operated for 60 years, the extrapolated CUF is 7.712 .

\subsubsection{NUREG/CR-5999 CUF Based on} Licensee's Design Calculation Stresses For Safe End. The licensee's design calculations show that the highest CUF for a carbon/ low-alloy steel component on the reactor vessel feedwater nozzle is located on the inside surface of the safe end near the feedwater piping. This location is in direct contact with the reactor coolant. The metal is SA-508 Class 1 carbon steel (in the 1971 Code it was called Grade 1). The licensee's design CUF calculations used the ASME Code, Section III, 1971 edition, through Summer 1973 addenda. The $S_{\text {alt }}$ values in the design calculations were the stress values used to determine the allowable cycles. Since no further adjustment for the effect of modulus of elasticity was made, it was assumed that the proper adjustment had already been incorporated. No changes have been made to the modulus of elasticity for the ASME Code carbon/low-alloy steel fatigue curves since 1971 . The high-oxygen carbon/low- alloy steel interim fatigue curves in NUREG/ CR-5999 are temperature dependent. Temperatures at the location of the highest CUF at the times of maximum and minimum $S_{\text {alt }}$ were obtained from the design analysis, and the maximum of the two temperatures was used. If we only consider the increasing portion of the tensile stress of the load pair, where it is expected that metal cracking is occurring, average strain rates can be estimated from the stress calculations. The resulting CUF is shown Table 5-106.

The results indicate that the CUF increased by a factor of 5.75 over the design basis number. The CUF exceeds the ASME Code limit of 1.0.

\subsubsection{NUREG/CR-5999 CUF with Con- servative Assumptions Removed for} Thermal Sleeve. With the given information, there are no readily apparent conservative assumptions that can be removed for the thermal sleeve. The transients have not been lumped together but are separated into quite a few load pairs. Although some $K_{e}$ values are greater than $1.0, \mathrm{~S}_{\mathrm{m}}$ does not change with temperature, so no conservative assumption reductions for the $\mathrm{K}_{e}$ calculations can be made.

Table 5-106. CUF results for reactor vessel feedwater nozzle safe end using NUREG/CR-5999 interim fatigue curve.

\begin{tabular}{|c|c|c|c|c|c|c|}
\hline Load pair & $S_{\text {alt }}$ & $\begin{array}{c}\text { Temperature } \\
\left({ }^{\circ} \mathrm{C}\right)\end{array}$ & $\begin{array}{l}\text { Strain rate } \\
(\% / s)\end{array}$ & $\mathrm{N}$ & $\mathbf{n}$ & $\mathrm{u}$ \\
\hline Turbine roll $\mathrm{A} / \mathrm{TG}$ trip $\mathrm{A}$ & 82.27 & 200 & 0.028 & 226 & 120 & 0.531 \\
\hline Turbine roll $\mathrm{A} /$ hot standby $\mathrm{A}$ & 72.60 & 200 & 0.026 & 297 & 90 & 0.303 \\
\hline Hot standby A/null & 64.41 & 200 & 0.026 & 402 & 142 & 0.353 \\
\hline Shutdown A/null & 38.98 & 200 & 0.002 & 1113 & 555 & 0.499 \\
\hline Turbine roll $\mathrm{A} /$ turbine trip $\mathrm{A}$ & 29.28 & 200 & 0.001 & 2557 & 10 & 0.004 \\
\hline Turbine roll B/TG trip B & 20.85 & 200 & 0.001 & 11484 & 120 & 0.010 \\
\hline TG trip $B /$ null & 19.21 & 200 & 0.001 & 17260 & 98 & 0.006 \\
\hline Turbine trip $\mathrm{B} /$ null & 17.56 & 288 & 0.001 & 6326 & 10 & 0.002 \\
\hline OBE/null & 17.44 & 288 & 0.001 & 6479 & 10 & 0.002 \\
\hline Hot standby $B /$ null & 13.85 & 288 & 0.001 & 19967 & 222 & 0.011 \\
\hline Shutdown B/null & 13.43 & 200 & 0.001 & 147221 & 666 & 0.005 \\
\hline Startup/null & 13.33 & 288 & 0.001 & 70527 & 120 & 0.002 \\
\hline \multirow[t]{2}{*}{ Reverse OBE/null } & 8.52 & 288 & 0.001 & $5.9 \times 10^{6}$ & 12625 & 0.002 \\
\hline & & & & & CUF & 1.730 \\
\hline
\end{tabular}


Using the anticipated numbers of cycles for 40 years from Table 5-99, the cycles in Table 5-105 were adjusted as shown in Table 5-107. Since the actual number of turbine generator (TG) trips was not reported, the 210 cycles in the design basis were used. There are five temperature cycles assumed in the analysis for each shutdown, so the 263 anticipated shutdown cycles are multiplied by 5 , resulting in 1315 temperature cycles. If the plant is operated for 60 years, the extrapolated CUF is 12.483 . There are a number of potential conservative assumptions that could be removed to reduce the CUF. These are listed in Table 5-108.

\subsubsection{NUREG/CR-5999 CUF with Con- servative Assumptions Removed for Safe} End. The primary plus secondary stress intensity ranges for the first 4 load pairs exceeded the $3 S_{m}$ limit, so a simplified elastic-plastic analysis adjustment factor $\left(K_{e}\right)$ was applied to the $S_{a l t}$ value. However, the licensee's calculation conservatively assumed the highest temperature value to determine the $3 S_{m}$ value used in the calculation for $K_{e}$. The definition for $S_{m}$ to be used for $3 S_{m}$ from ASME Code Figure NB-3222-1, Note 3, is the average at the high and low temperatures during the transient, if no mechanical loads contribute to the secondary stress. Although we did not have sufficient information to determine the magnitudes of secondary stresses due to mechanical Ioads, we assume that the contributions to secondary stresses from mechanical loads are negligible since the stresses are mainly caused by thermal transients. Based on the temperatures in the design calculations, the average temperatures for the two transients were used to calculate $\mathrm{K}_{\mathrm{e}}$. This reduces the $\mathrm{K}_{e}$ factors for the first four load pairs.

The adjusted CUF resulting from the application of this conservative assumption reduction is included in Table 5-109. If the plant is operated for 60 years, the extrapolated CUF is 1.628 .

Based our estimate of the numbers of transients for the first seven load pairs in Table 5-106 (which contribute the majority of the CUF), the CUF based on anticipated cycles is shown in Table 5-110. Since the actual number of turbine generator (TG) trips was not reported, the 210 cycles in the design basis was used. There are five temperature cycles assumed in the analysis for each shutdown, so the 263 anticipated shutdown cycles are multiplied by 5 , resulting in 1315 temperature cycles.

Table 5-107. CUF results for reactor vessel feedwater nozzle thermal sleeve using NUREG/CR-5999 interim fatigue curve and anticipated numbers of cycles.

\begin{tabular}{lccrrr}
\hline \multicolumn{1}{c}{ Load pair } & $\mathrm{S}_{\text {alt }}(\mathrm{ksi})$ & $\mathrm{S}_{\text {alt}}$ (adjusted) & $\mathrm{N}$ & $\mathrm{n}$ & $\mathrm{u}$ \\
\hline Turbine roll A/turbine trip B & 204.29 & 222.36 & 29 & 0 & 0.000 \\
Turbine roll A/turbine roll B & 160.97 & 175.21 & 52 & 280 & 5.385 \\
Hot standby/turbine roll B & 135.79 & 147.80 & 78 & 0 & 0.000 \\
Hot standby A/TG trip & 122.89 & 133.76 & 100 & 210 & 2.100 \\
Hot standby A/hot standby B & 87.85 & 95.62 & 224 & 53 & 0.237 \\
Hot standby B/shutdown A & 50.99 & 55.50 & 1360 & 0 & 0.000 \\
Shutdown A/shutdown B & 47.09 & 51.26 & 2194 & 1315 & 0.600 \\
Turbine trip A/shutdown B & 37.62 & 40.95 & 8479 & 0 & 0.000 \\
TG trip/shutdown B & 19.89 & 21.65 & $6.6 \times 10^{7}$ & 0 & 0.000 \\
\hline
\end{tabular}


Table 5-108. Potential for elimination of conservative assumptions to reduce CUF for feedwater nozzle thermal sleeve using NUREG/CR-5999 interim fatigue curve.

\begin{tabular}{lccl}
\multicolumn{1}{c}{$\begin{array}{c}\text { Assumption } \\
\text { (Section 4.3) }\end{array}$} & $\begin{array}{c}\text { Potential } \\
\text { for use }\end{array}$ & Used & \multicolumn{1}{c}{ Comments } \\
\hline $\begin{array}{l}\text { Correct CUF } \\
\text { calculation }\end{array}$ & No & No & Analysis appear to be correct \\
$\begin{array}{l}\text { Detailed load pairs } \\
\text { SCF/FSRF }\end{array}$ & No & No & Detailed load pairs were used \\
$\mathrm{S}_{\mathrm{m}}$ value & Yes & No & Finite element analysis may reduce SCF \\
Material property & No & No & S $_{\mathrm{m}}$ constant with temperature \\
changes & No & No & No significant changes \\
Fatigue curve E value & Yes & Yes & Adjustment was made for modulus of elasticity \\
Code analysis changes & No & No & No significant changes \\
Actual cycles & Yes & No & Insufficient information \\
High temperature rates & Yes & No & Actual $\Delta T$ probably less than design \\
Detailed stress & Yes & No & More detailed model could be used \\
modeling & & & \\
Conservative thermal & Yes & No & Conservative heat transfer coefficients may have been \\
parameters & & & used \\
Time phasing of & No & No & Time phasing not expected to reduce nozzle CUF \\
stresses & & & \\
Number of OBEs & No & No & OBE did contribute to CUF \\
CC N-411 damping & No & No & Dynamic loads did contribute to CUF \\
Number of hydrotests & No & No & Hydrotests did not contribute to CUF \\
Fatigue monitoring & Yes & No & Actual transients probably less severe than design \\
Plastic analysis & Yes & No & Elastic plastic finite element analysis could be used \\
\hline
\end{tabular}

Table 5-109. CUF results for reactor vessel feedwater nozzle safe end using NUREG/CR-5999 interim fatigue curve with conservative assumptions removed.

\begin{tabular}{lccrrrr}
\hline \multicolumn{1}{c}{ Load pair } & $\mathrm{S}_{\text {alt }}$ & $\begin{array}{c}\text { Temperature } \\
\left({ }^{\circ} \mathrm{C}\right)\end{array}$ & $\begin{array}{c}\text { Strain rate } \\
(\% / \mathrm{s})\end{array}$ & $\mathrm{N}$ & $\mathrm{n}$ & $\mathrm{u}$ \\
\hline Turbine roll A/TG trip A & 67.27 & 200 & 0.028 & 366 & 120 & 0.328 \\
Turbine roll A/hot standby A & 61.13 & 200 & 0.026 & 463 & 90 & 0.194 \\
Hot standby A/null & 51.65 & 200 & 0.026 & 792 & 142 & 0.179 \\
Shutdown A/null & 35.34 & 200 & 0.002 & 1634 & 555 & 0.340 \\
Turbine roll A/turbine trip A & 29.28 & 200 & 0.001 & 2557 & 10 & 0.004 \\
Turbine roll B/TG trip B & 20.85 & 200 & 0.001 & 11484 & 120 & 0.010 \\
TG trip B/null & 19.21 & 200 & 0.001 & 17260 & 98 & 0.006 \\
Turbine trip B/null & 17.56 & 288 & 0.001 & 6326 & 10 & 0.002 \\
OBE/null & 17.44 & 288 & 0.001 & 6479 & 10 & 0.002 \\
Hot standby B/null & 13.85 & 288 & 0.001 & 19967 & 222 & 0.011 \\
Shutdown B/null & 13.43 & 200 & 0.001 & 147221 & 666 & 0.005 \\
Startup/null & 13.33 & 288 & 0.001 & 70527 & 120 & 0.002 \\
Reverse OBE/null & 8.52 & 288 & 0.001 & $5.9 \times 10^{6}$ & 12625 & 0.002 \\
\hline & & & & & CUF & 1.085 \\
\hline
\end{tabular}


Table 5-110. CUF results for reactor vessel feedwater nozzle safe end using NUREG/CR-5999 interim fatigue curves with conservative assumptions removed and anticipated cycles.

\begin{tabular}{|c|c|c|c|c|c|c|}
\hline Load pair & $\mathrm{S}_{\mathrm{alt}}$ & $\begin{array}{c}\text { Temperature } \\
\left({ }^{\circ} \mathrm{C}\right)\end{array}$ & $\begin{array}{c}\text { Strain rate } \\
(\% / \mathrm{s})\end{array}$ & $\mathrm{N}$ & $\mathrm{n}$ & $\mathrm{u}$ \\
\hline Turbine roll A/TG trip A & 67.27 & 200 & 0.028 & 366 & 210 & 0.574 \\
\hline Turbine roll $\mathrm{A} /$ hot standby $\mathrm{A}$ & 61.13 & 200 & 0.026 & 463 & 0 & 0.000 \\
\hline Turbine roll $\mathrm{A} /$ null & 57.79 & 200 & 0.026 & 548 & 70 & 0.128 \\
\hline Hot standby A/null & 51.65 & 200 & 0.026 & 792 & 263 & 0.332 \\
\hline Shutdown A/null & 35.34 & 200 & 0.002 & 1634 & 1315 & 0.805 \\
\hline Turbine roll $\mathrm{A} /$ turbine trip $\mathrm{A}$ & 29.28 & 200 & 0.001 & 2557 & 0 & 0.000 \\
\hline Turbine roll B/TG trip B & 20.85 & 200 & 0.001 & 11484 & 210 & 0.018 \\
\hline TG trip B/null & 19.21 & 200 & 0.001 & 17260 & 0 & 0.000 \\
\hline Turbine trip $\mathrm{B} /$ null & 17.56 & 288 & 0.001 & 6326 & 10 & 0.002 \\
\hline OBE/null & 17.44 & 288 & 0.001 & 6479 & 10 & 0.002 \\
\hline Hot standby $\mathrm{B} /$ null & 13.85 & 288 & 0.001 & 19967 & 222 & 0.011 \\
\hline Shutdown B/null & 13.43 & 200 & 0.001 & 147221 & 666 & 0.005 \\
\hline Startup/null & 13.33 & 288 & 0.001 & 70527 & 120 & 0.002 \\
\hline \multirow[t]{2}{*}{ Reverse OBE/null } & 8.52 & 288 & 0.001 & $5.9 \times 10^{6}$ & 12625 & 0.002 \\
\hline & & & & & CUF & 1.881 \\
\hline
\end{tabular}

If the plant is operated for 60 years, the CUF is 2.822. Potential conservative assumptions that might be removed to reduce the CUF are listed in Table 5-111. Based on fatigue monitoring by GE of a Japanese BWR for two fuel cycles, the 40 -year CUF for the feedwater nozzle has been estimated at only 0.0074 versus a design basis CUF of 0.387 (Sakai et al., 1993), a reduction of about a factor of 50. Deardorff and Smith (1994) report than based on monitoring of 12 startups and 11 shutdowns at a domestic BWR, the design basis CUF for the feedwater nozzle during the monitoring period was about 30 times that computed from fatigue monitoring of actual transients.

\subsubsection{CUF Based on Revised Interim} Fatigue Curves for Thermal Sleeve. From the licensee's calculations, the increasing portion of the tensile stress occurred after 15.6 seconds and accounted for about two-thirds of the strain range. Using the corresponding strain rates, the CUF results are shown in Table 5-112. The extrapolated CUF for 60 years is 9.707 .

5.6.3 Reactor Recirculation Piping. The highest CUFs for the recirculation system are
0.002 for the SA-508 Class 2 low-alloy steel nozzles (portion in contact with the reactor coolant), and 0.298 for the SA-358 Type 304 stainless steel piping at a tee on the suction piping. Since the nozzle has a factor of about 500 before the ASME Code fatigue allowable value of 1.0 is reached, only the piping was considered.

\subsubsection{NUREG/CR-5999 CUF Based on Licensee's Design Calculation Stresses.} The licensee's design CUF calculations used the ASME Code, Section III, 1983 edition, through Winter 1984 addenda. This analysis was performed to support a snubber reduction program. The $S_{\text {alt }}$ values were not adjusted for the effect of modulus of elasticity; NB-3600 does not specify any modulus of elasticity adjustment. The value of the modulus of elasticity on the fatigue curve has not changed since 1983. However, from a review of the licensee's calculations, it appears the number of cycles were obtained from a fatigue curve using a modulus of elasticity of $26 \times 10^{6} \mathrm{psi}$, the value before the modulus of elasticity was changed to $28.3 \times 10^{6} \mathrm{psi}$. Therefore, the $S_{\text {alt }}$ values were multiplied by $28.3 / 26$ to 
Table 5-111. Potential for elimination of conservative assumptions to reduce CUF for feedwater nozzle safe end using NUREG/CR-5999 interim fatigue curve.

\begin{tabular}{lccl}
\hline \multicolumn{1}{c}{$\begin{array}{c}\text { Assumption } \\
\text { (Section 4.3) }\end{array}$} & $\begin{array}{c}\text { Potential } \\
\text { for use }\end{array}$ & Used & \\
\hline $\begin{array}{l}\text { Correct CUF } \\
\text { calculation }\end{array}$ & No & No & Analysis appear to be correct \\
$\begin{array}{l}\text { Detailed load pairs } \\
\text { SCF/FSRF }\end{array}$ & No & No & Detailed load pairs were used \\
S & Yes value & No & Insufficient detail \\
Material property & Yes & No & Potential for use if $K_{e}$ could be reduced \\
changes & Yes & No & Insufficient detail \\
Fatigue curve E value & Yes & Yes & Adjustment was made for modulus of elasticity \\
Code analysis changes & No & No & Thermal stresses calculated using NB-3200 method \\
Actual cycles & Yes & Yes & Adjustment was made for projected cycles \\
High temperature rates & Yes & No & Actual $\Delta T$ probably less than design \\
Detailed stress & Yes & No & Interaction model used \\
modeling & Yes & & \\
Conservative thermal & No & Conservative heat transfer coefficients may have been \\
parameters & & & used \\
Time phasing of & No & No & Time phasing not expected to reduce nozzle CUF \\
stresses & & & \\
Number of OBEs & Yes & Yes & OBE minimal contributor to CUF \\
CC N-411 damping & No & No & Dynamic loads minimal contributor to CUF \\
Number of hydrotests & No & No & Hydrotests did not contribute to CUF \\
Fatigue monitoring & Yes & No & Actual transients probably less severe than design \\
Plastic analysis & Yes & No & Elastic plastic finite element analysis could be used \\
\hline & & &
\end{tabular}

Table 5-112. CUF results for reactor vessel feedwater nozzle thermal sleeve using revised interim fatigue curves.

\begin{tabular}{|c|c|c|c|c|c|}
\hline Load pair & $\mathrm{S}_{\mathrm{alt}}(\mathrm{ksi})$ & $S_{\text {alt }}($ adjusted $)$ & $\mathbf{N}$ & $\mathrm{n}$ & $\mathrm{u}$ \\
\hline Turbine roll A/turbine trip $\mathrm{B}$ & 204.29 & 222.36 & 39 & 0 & 0.000 \\
\hline Turbine roll A/turbine roll B & 160.97 & 175.21 & 68 & 280 & 4.118 \\
\hline Hot standby/turbine roll B & 135.79 & 147.80 & 101 & 0 & 0.000 \\
\hline Hot standby A/TG trip & 122.89 & 133.76 & 129 & 210 & 1.628 \\
\hline Hot standby A/hot standby B & 87.85 & 95.62 & 215 & 53 & 0.247 \\
\hline Hot standby B/shutdown A & 50.99 & 55.50 & 1761 & 0 & 0.125 \\
\hline Shutdown A/shutdown B & 47.09 & 51.26 & 2751 & 1316 & 0.478 \\
\hline \multirow[t]{2}{*}{ Turbine trip A/shutdown B } & 37.62 & 40.95 & 18409 & 0 & 0.000 \\
\hline & & & & CUF & 6.471 \\
\hline
\end{tabular}


use the NUREG/CR-5999 curve. The CUF results using the NUREG/CR-5999 interim fatigue curve are included in Table 5-113.

Application of the NUREG/CR-5999 interim fatigue curve increased the CUF by a factor of 7.23 over the licensee's design basis number. The CUF exceeds the ASME Code limit of 1.0.

5.6.3.2 NUREG/CR-5999 CUF with Conservative Assumptions Removed. The primary plus secondary stress intensity ranges for the first 12 load pairings exceeded the $3 \mathrm{~S}_{\mathrm{m}}$ limit, so a simplified elastic-plastic analysis adjustment factor $\left(K_{e}\right)$ was applied to the $S_{\text {alt }}$ value. How- ever, the licensee's calculation conservatively assumed the highest temperature value to determine the $3 \mathrm{~S}_{\mathrm{m}}$ value used in the calculation for $\mathrm{K}_{\mathrm{e}}$. The definition for $S_{m}$ to be used for $3 S_{m}$ from ASME Code Figure NB-3222-1, Note 3, is the average at the high and low temperatures during the transient, if no mechanical loads contribute to the secondary stress. Although we did not have sufficient information to determine the magnitudes of secondary stresses due to mechanical loads, we assume that the contributions to secondary stresses from mechanical loads are negligible since the stresses are mainly caused by thermal transients. The average temperatures for

Table 5-113. CUF results for the recirculation system piping using NUREG/CR-5999 interim fatigue curve.

\begin{tabular}{lccrrr}
\hline \multicolumn{1}{c}{ Load pair } & $\mathrm{S}_{\text {alt }}$ & $\mathrm{S}_{\text {alt }}($ adjusted $)$ & \multicolumn{1}{c}{$\mathrm{N}$} & \multicolumn{1}{c}{$\mathrm{n}$} & $\mathbf{u}$ \\
\hline Composite loss/null & 139.05 & 151.35 & 74 & 10 & 0.135 \\
Composite loss/null & 136.86 & 148.97 & 77 & 10 & 0.130 \\
Turbine generator trip/null & 130.44 & 141.98 & 86 & 5 & 0.058 \\
Turbine generator trip/null & 130.44 & 141.98 & 86 & 5 & 0.058 \\
Composite loss/null & 125.89 & 137.03 & 94 & 10 & 0.106 \\
Relief valve event/unbolt & 117.91 & 128.34 & 110 & 30 & 0.273 \\
Relief valve event/unbolt & 117.91 & 128.34 & 110 & 93 & 0.845 \\
Hydro/relief valve event & 111.10 & 120.93 & 127 & 40 & 0.315 \\
& 110.74 & 120.53 & 128 & 7 & 0.055 \\
& 108.17 & 117.93 & 135 & 1 & 0.007 \\
& 79.51 & 86.54 & 284 & 9 & 0.032 \\
& 69.92 & 76.11 & 387 & 10 & 0.026 \\
& 50.31 & 54.76 & 1474 & 10 & 0.007 \\
& 47.12 & 51.28 & 2189 & 20 & 0.009 \\
& 46.39 & 50.49 & 2404 & 111 & 0.046 \\
& 45.99 & 50.06 & 2531 & 50 & 0.020 \\
& 44.60 & 48.54 & 3047 & 40 & 0.013 \\
& 44.21 & 48.12 & 3211 & 10 & 0.003 \\
& 44.16 & 48.06 & 3235 & 10 & 0.003 \\
& 44.06 & 47.96 & 3276 & 42 & 0.001 \\
& 36.47 & 39.70 & 10219 & 10 & 0.001 \\
& 33.25 & 36.19 & 17839 & 130 & 0.007 \\
& 31.15 & 33.90 & 26438 & 111 & 0.004 \\
& 19.75 & 21.49 & $>10^{7}$ & 660 & 0.000 \\
& 18.10 & 19.70 & $>10^{6}$ & 10 & 0.000 \\
& 17.47 & 19.01 & $>10^{6}$ & 8 & 0.000 \\
& 17.13 & 18.64 & $>10^{6}$ & 10 & 0.000 \\
& 11.77 & 12.81 & $>10^{7}$ & 4800 & 0.000 \\
\hline & & & & $\mathrm{CUF}$ & 2.154 \\
\hline
\end{tabular}


the two transients (based on the temperatures in the design calculations) were used to calculate the $\mathrm{K}_{\mathrm{e}}$ factors. This reduces the $\mathrm{K}_{\mathrm{e}}$ factors for the first twelve load pairs.

The adjusted CUF resulting from the application of this conservative assumption reduction is included in Table 5-114. If the plant is operated for 60 years, the extrapolated CUF is 1.245 .

The number of anticipated cycles are difficult to determine because the cycles in the design basis report do not have a one-for-one correspondence with the transients in Table 5-99. It appears that because the numbers of anticipated startups exceed the design basis number of startups, the anticipated CUF would be greater than that shown in Table 5-114. However, startups are not part of the first eight transients, which produce the majority of the CUF, so the effect would be minor. There are a number of potential conservative assumptions that could be removed to reduce the CUF. These are listed in Table 5-115.

Table 5-114. CUF results for the recirculation system piping using NUREG/CR-5999 interim fatigue curves.

\begin{tabular}{|c|c|c|c|c|c|}
\hline Load pair & $S_{\mathrm{alt}}$ & $S_{\text {alt }}$ (adjusted) & $\mathrm{N}$ & $\mathrm{n}$ & $\mathrm{u}$ \\
\hline Composite loss/null & 90.24 & 98.22 & 210 & 10 & 0.048 \\
\hline Composite loss/null & 92.27 & 100.43 & 199 & 10 & 0.050 \\
\hline Turbine generator trip/null & 84.40 & 91.87 & 246 & 5 & 0.020 \\
\hline Turbine generator trip/null & 84.40 & 91.87 & 246 & 5 & 0.020 \\
\hline Composite loss/null & 83.78 & 91.19 & 251 & 10 & 0.040 \\
\hline Relief valve event/unbolt & 74.71 & 81.32 & 330 & 30 & 0.091 \\
\hline Relief valve event/unbolt & 74.71 & 81.32 & 330 & 93 & 0.282 \\
\hline \multirow[t]{22}{*}{ Hydro/relief valve event } & 71.13 & 77.42 & 372 & 40 & 0.108 \\
\hline & 68.94 & 75.04 & 401 & 7 & 0.017 \\
\hline & 74.06 & 80.61 & 337 & 1 & 0.003 \\
\hline & 57.87 & 62.77 & 648 & 9 & 0.014 \\
\hline & 54.54 & 59.36 & 907 & 10 & 0.011 \\
\hline & 50.31 & 54.76 & 1474 & 10 & 0.007 \\
\hline & 47.12 & 51.28 & 2189 & 20 & 0.009 \\
\hline & 46.39 & 50.49 & 2404 & 111 & 0.046 \\
\hline & 45.99 & 50.06 & 2531 & 50 & 0.020 \\
\hline & 44.60 & 48.54 & 3047 & 40 & 0.013 \\
\hline & 44.21 & 48.12 & 3211 & 10 & 0.003 \\
\hline & 44.16 & 48.06 & 3235 & 10 & 0.003 \\
\hline & 44.06 & 47.96 & 3276 & 42 & 0.013 \\
\hline & 36.47 & 39.70 & 10219 & 10 & 0.001 \\
\hline & 33.25 & 36.19 & 17839 & 130 & 0.007 \\
\hline & 31.15 & 33.90 & 26438 & 111 & 0.004 \\
\hline & 19.75 & 21.49 & $>10^{7}$ & 660 & 0.000 \\
\hline & 18.10 & 19.70 & $>10^{6}$ & 10 & 0.000 \\
\hline & 17.47 & 19.01 & $>10^{6}$ & 8 & 0.000 \\
\hline & 17.13 & 18.64 & $>10^{6}$ & 10 & 0.000 \\
\hline & 11.77 & 12.81 & $>10^{7}$ & 4800 & 0.000 \\
\hline & & & & CUF & 0.830 \\
\hline
\end{tabular}


Table 5-115. Potential for elimination of conservative assumptions to reduce CUF for recirculation system using NUREG/CR-5999 interim fatigue curve.

\begin{tabular}{lccl}
\multicolumn{1}{c}{$\begin{array}{c}\text { Assumption } \\
\text { Section 4.3) }\end{array}$} & $\begin{array}{c}\text { Potential } \\
\text { for use }\end{array}$ & Used & \multicolumn{1}{c}{ Comments } \\
\hline Correct CUF & No & No & Analysis appear to be correct \\
calculation & & & \\
Detailed load pairs & No & No & Detailed load pairs were used \\
SCF/FSRF & No & No & Stress indices appear correct \\
$\mathrm{S}_{\mathrm{m}}$ value & Yes & Yes & Average $\mathrm{S}_{\mathrm{m}}$ used \\
Material property & No & No & No significant changes \\
changes & & & \\
Fatigue curve E value & Yes & Yes & Adjustment was made for modulus of elasticity \\
Code analysis changes & No & No & No significant changes \\
Actual cycles & Yes & No & Insufficient information \\
High temperature rates & Yes & No & Actual $\Delta T$ probably less than design \\
Detailed stress & Yes & No & More detailed model could be used \\
modeling & & & \\
Conservative thermal & Yes & No & Conservative heat transfer coefficients may have been \\
parameters & & & used \\
Time phasing of & Yes & No & Time phasing may reduce CUF \\
stresses & & & \\
Number of OBEs & No & No & OBE did contribute to CUF \\
CC N-411 damping & No & No & Dynamic loads did contribute to CUF \\
Number of hydrotests & No & No & Hydrotests did not contribute to CUF \\
Fatigue monitoring & Yes & No & Actual transients probably less severe than design \\
Plastic analysis & Yes & No & Elastic plastic finite element analysis could be used \\
\hline
\end{tabular}

\subsubsection{CUF Based on Revised Interim} Fatigue Curves. The licensee's calculations did not contain sufficient information to determine the strain rates, so the $0.001 \% / \mathrm{s}$ curve was used. The CUF results are shown in Table 5-116. The extrapolated CUF for 60 years is 1.119 .

\subsubsection{Core Spray Line Reactor Vessel Nozzle and Associated Class 1 Piping.} The highest CUFs for the core spray line are 0.165 for the nozzle thermal sleeve, 0.050 for the nozzle safe-end extension, and 0.031 for the piping. Since the thermal sleeve is not a pressure boundary, the effect of the NUREG/CR-5999 interim fatigue curves on both the thermal sleeve and the nozzle safe-end extension, which is a part of the pressure boundary and has the next highest design CUF, will be assessed.
5.6.4.1 NUREG/CR-5999 CUF Based on Licensee's Design Calculation Stresses for Thermal Sleeve. The licensee's design CUF calculations used the ASME Code, 1971 edition, through Summer 1973 addenda. NUREG/CR-5999 does not include an interim fatigue curve for Alloy 600 , so the stainless steel curves were used. The $S_{\text {alt }}$ values in the design calculations were used to determine the allowable cycles. No further adjustment for the effect of modulus of elasticity was made; therefore, it was assumed that the proper adjustment had already been incorporated. Since the 1971 edition of the Code used a modulus of elasticity of $26.0 \times 10^{6}$ psi (Figure I-9.2), the $S_{\text {alt }}$ values were multiplied by $28.3 / 26$ because the NUREG/CR-5999 interim fatigue curve as developed using a modulus of 
Table 5-116. CUF results for the recirculation system piping using revised interim fatigue curves.

\begin{tabular}{|c|c|c|c|c|c|}
\hline Load pair & $S_{\text {alt }}$ & $\mathrm{S}_{\mathrm{alt}}$ (adjusted) & $\mathrm{N}$ & $\mathrm{n}$ & $\mathbf{u}$ \\
\hline Composite loss/null & 90.24 & 98.22 & 198 & 10 & 0.048 \\
\hline Composite loss/null & 92.27 & 100.43 & 185 & 10 & 0.050 \\
\hline Turbine generator trip/null & 84.40 & 91.87 & 244 & 5 & 0.020 \\
\hline Turbine generator trip/null & 84.40 & 91.87 & 244 & 5 & 0.020 \\
\hline Composite loss/null & 83.78 & 91.19 & 249 & 10 & 0.040 \\
\hline Relief valve event/unbolt & 74.71 & 81.32 & 363 & 30 & 0.091 \\
\hline Relief valve event/unbolt & 74.71 & 81.32 & 363 & 93 & 0.282 \\
\hline \multirow[t]{17}{*}{ Hydro/relief valve event } & 71.13 & 77.42 & 431 & 40 & 0.108 \\
\hline & 68.94 & 75.04 & 482 & 7 & 0.017 \\
\hline & 74.06 & 80.61 & 374 & 1 & 0.003 \\
\hline & 57.87 & 62.77 & 980 & 9 & 0.014 \\
\hline & 54.54 & 59.36 & 1263 & 10 & 0.011 \\
\hline & 50.31 & 54.76 & 1890 & 10 & 0.007 \\
\hline & 47.12 & 51.28 & 2743 & 20 & 0.009 \\
\hline & 46.39 & 50.49 & 3018 & 111 & 0.046 \\
\hline & 45.99 & .50 .06 & 3185 & 50 & 0.020 \\
\hline & 44.60 & 48.54 & 3903 & 40 & 0.013 \\
\hline & 44.21 & 48.12 & 4146 & 10 & 0.003 \\
\hline & 44.16 & 48.06 & 4180 & 10 & 0.003 \\
\hline & 44.06 & 47.96 & 4245 & 42 & 0.013 \\
\hline & 36.47 & 39.70 & 24885 & 10 & 0.001 \\
\hline & 33.25 & 36.19 & 39628 & 130 & 0.007 \\
\hline & 31.15 & 33.90 & 57713 & 111 & 0.004 \\
\hline & & & & CUF & 0.746 \\
\hline
\end{tabular}

elasticity of $28.3 \times 10^{6} \mathrm{psi}$. The CUF using the licensee's stress values and the NUREG/CR-5999 interim fatigue curve is included in Table 5-117. Some warmups and cooldowns have loss-of-feedpumps (LOFP) events.

Application of the NUREG/CR-5999 interim fatigue curve increased the CUF by a factor of 5.72 over the design basis number. The CUF does not exceed the ASME Code limit of 1.0. If the plant is operated for 60 years, the extrapolated CUF would be 1.415 .

\footnotetext{
5.6.4.2 NUREG/CR-5999 CUF Based on Licensee's Design Calculation Stresses for Safe-End Extension. The licensee's design CUF calculations used the ASME Code, 1971 edition, through Summer 1973 addenda. The
}

calculations show that the highest CUF for a carbon/low-alloy steel component nozzle is located on the inside surface of the safe-end extension near the core spray piping. This location is in direct contact with the reactor coolant. The metal is SA-508 Class 1 carbon steel. The $S_{\text {alt }}$ values in the design calculations were the stress values used to determine the allowable cycles. Since no further adjustment for the effect of modulus of elasticity was made, it was assumed that the proper adjustment had already been incorporated. The highoxygen carbon/low-alloy steel interim fatigue curves in NUREG/CR-5999 are temperature dependent. Temperatures at the location of the highest CUF for the times of maximum and minimum peak stress intensity were obtained from the licensee's detailed calculations, and the maximum 
Component Evaluations

Table 5-117. CUF results for core spray nozzle thermal sleeve using NUREG/CR-5999 interim fatigue curve.

\begin{tabular}{lrrrrr}
\hline \multicolumn{1}{c}{ Load pair } & $\mathrm{S}_{\text {alt }}$ & $\mathrm{S}_{\text {alt }}$ (adjusted) & \multicolumn{1}{c}{$\mathbf{N}$} & \multicolumn{1}{c}{$\mathbf{n}$} & $\mathbf{u}$ \\
\hline Warmup/cooldown(LOFP) & 201.02 & 218.80 & 30 & 10 & 0.333 \\
Warmup(LOFP)/cooldown(LOFP) & 167.53 & 182.35 & 47 & 20 & 0.426 \\
Cooldown/warmup(LOFP) & 151.00 & 164.36 & 61 & 10 & 0.164 \\
Cooldown/null & 68.68 & 74.76 & 404 & 8 & 0.020 \\
OBE/null & 6.98 & 7.60 & $>10^{7}$ & 2524 & 0.000 \\
\cline { 5 - 7 } & & & & CUF & 0.943 \\
\hline
\end{tabular}

of these two temperatures was used. Since there was insufficient information available to determine the strain rates, the saturated curves are used. The effect of the NUREG/CR-5999 interim fatigue curves is shown in Table 5-118.

Application of the NUREG/CR-5999 interim fatigue curve increased the CUF by a factor of 13.50 over the design basis number. If the plant is operated for 60 years, the extrapolated CUF is 1.012 .

\subsubsection{NUREG/CR-5999 CUF with Con-} servative Assumptions Removed for Thermal Sleeve. The four load pairs that are the major contributors to the CUF are not conservatively lumped together. There are only 8 to 20 cycles per pair. The $K_{e}$ factors are greater than 1.0 , but since the $S_{m}$ values for Alloy 600 are constant from 70 to $700^{\circ} \mathrm{F}$, no adjustment based on temperature can be made. The second load pair is based entirely on the loss-of-feedwater-pumps transient. The licensee informed us that there have been no loss-of-feedwater-pumps cycles (Table 5-99). Making this adjustment, the CUF is shown in Table 5-119. The additional startup/ shutdown transients are included in load pair 5 , and would not affect the CUF. If the plant is operated for 60 years, the CUF is 0.776 .

\subsubsection{NUREG/CR-5999 CUF with Con- servative Assumptions Removed for Safe-End Extension. The primary plus sec- ondary stress intensity ranges for the first two load pairs exceeded the $3 S_{\mathrm{m}}$ limit, so a simplified elastic-plastic analysis adjustment factor, $\mathrm{K}_{\mathrm{e}}$, was applied to the $S_{\text {alt }}$ value. However, the licensee's}

calculation conservatively assumed the highest temperature value to determine the $3 S_{\mathrm{m}}$ value used in the calculation for $\mathrm{K}_{\mathrm{e}}$. The definition for $S_{\mathrm{m}}$ to be used for $3 S_{\mathrm{m}}$ from ASME Code Figure NB-3222-1, Note 3 , is the average at the high and low temperatures during the transient. Based on the temperatures in the design calculations, the average $S_{m}$ for the two transients in the first load pair was used to calculate $K_{e}$, again assuming that contributions to the secondary stresses from mechanical loads were negligible. This increases $3 \mathrm{~S}_{\mathrm{m}}$ from 53.1 to $63.9 \mathrm{ksi}$, and reduces the $\mathrm{K}_{\mathrm{e}}$ factor from 2.287 to 1.152 . The resulting CUF is shown in Table 5-120. If the plant is operated for 60 years, the extrapolated CUF is 0.654 . The second load pair is based entirely on the loss-offeedwater-pumps transient. The licensee informed us that there have been no loss-of-feedwater-pumps cycles (Table 5-99). Consequently, even adding additional startup/ shutdown cycles from Table 5-99, the CUF based on anticipated transients would be less than shown in Table 5-120.

\subsubsection{CUF for Thermal Sleeve Based} on Revised Interim Fatigue Curves. Since the CUF was below 1.0 , the $0.001 \% / \mathrm{s}$ curve was used. The CUF results are shown in Table 5-121. The extrapolated CUF for 60 years is 0.956 .

5.6.5 Feedwater Line Class 1 Piping. The fatigue analysis for the feedwater line piping was performed by an architect engineering firm. The highest design CUF is 0.435 at a 12 -in. longradius elbow made of SA-333 Grade 6 low-alloy steel. The material is in direct contact with the reactor coolant. 
Table 5-118. CUF results for core spray nozzle safe-end extension using NUREG/CR-5999 interim fatigue curve.

\begin{tabular}{lccrrc}
\hline \multicolumn{1}{c}{ Load pair } & $\mathrm{S}_{\text {alt }}$ & Temperature & \multicolumn{1}{c}{$\mathrm{N}$} & $\mathrm{n}$ & $\mathrm{u}$ \\
\hline Cooldown/null & 91.33 & 200 & 65 & 18 & 0.277 \\
Cooldown(LOFP)/null & 80.85 & 200 & 86 & 30 & 0.349 \\
OBE/null & 22.38 & 288 & 2477 & 10 & 0.004 \\
Warmup/null & 21.95 & 200 & 8892 & 10 & 0.001 \\
Warmup(LOFP)/null & 20.44 & 200 & 12676 & 30 & 0.002 \\
Warmup/null & 16.73 & 288 & 7486 & 310 & 0.041 \\
OBE/null & 10.69 & 288 & $1.9 \times 10^{6}$ & 1804 & 0.001 \\
& & & & CUF & 0.675 \\
\hline
\end{tabular}

Table 5-119. CUF results for core spray nozzle thermal sleeve using NUREG/CR-5999 interim fatigue curve.

\begin{tabular}{lrrrrc}
\hline \multicolumn{1}{c}{ Load pair } & \multicolumn{1}{c}{$\mathrm{S}_{\text {alt }}$} & $\mathrm{S}_{\text {alt }}$ (adjusted) & $\mathrm{N}$ & $\mathrm{n}$ & $\mathrm{u}$ \\
\hline Warmup/cooldown(LOFP) & 201.02 & 218.80 & 30 & 10 & 0.333 \\
Warmup(LOFP)/cooldown(LOFP) & 167.53 & 182.35 & 47 & 0 & 0.000 \\
Cooldown/warmup(LOFP) & 151.00 & 164.36 & 61 & 10 & 0.164 \\
Cooldown/null & 68.68 & 74.76 & 404 & 8 & 0.020 \\
OBE/null & 6.98 & 7.60 & $>10^{7}$ & 2524 & 0.000 \\
\cline { 5 - 6 } & & & & CUF & 0.517 \\
\hline
\end{tabular}

Table 5-120. CUF results for core spray nozzle safe-end extension using NUREG/CR-5999 interim fatigue curve with conservative assumptions removed.

\begin{tabular}{lccrrr}
\hline \multicolumn{1}{c}{ Load pair } & $\mathrm{S}_{\text {alt }}$ & $\begin{array}{c}\text { Temperature } \\
\left({ }^{\circ} \mathrm{C}\right)\end{array}$ & $\mathrm{N}$ & $\mathrm{n}$ & $\mathrm{u}$ \\
\hline Cooldown/null & 46.00 & 200 & 473 & 18 & 0.038 \\
Cooldown(LOFP)/null & 80.85 & 200 & 86 & 30 & 0.349 \\
OBE/null & 22.38 & 288 & 2477 & 10 & 0.004 \\
Warmup/null & 21.95 & 200 & 8892 & 10 & 0.001 \\
Warmup(LOFP)/null & 20.44 & 200 & 12676 & 30 & 0.002 \\
Warmup/null & 16.73 & 288 & 7486 & 310 & 0.041 \\
OBE/null & 10.69 & 288 & $1.9 \times 10^{6}$ & 1804 & 0.001 \\
& & & & CUF & 0.436 \\
\hline
\end{tabular}

Table 5-121. CUF results for core spray nozzle thermal sleeve using revised interim fatigue curves and anticipated cycles.

\begin{tabular}{lrrrrr}
\hline \multicolumn{1}{c}{ Load pair } & $\mathrm{S}_{\text {alt }}$ & $\mathrm{S}_{\text {alt }}$ (adjusted) & $\mathrm{N}$ & \multicolumn{1}{c}{$\mathrm{n}$} & $\mathrm{u}$ \\
\hline Warmup/cooldown(LOFP) & 201.02 & 218.80 & 24 & 10 & 0.417 \\
Warmup(LOFP)/cooldown(LOFP) & 167.53 & 182.35 & 38 & 0 & 0.000 \\
Cooldown/warmup(LOFP) & 151.00 & 164.36 & 49 & 10 & 0.204 \\
Cooldown/null & 68.68 & 74.76 & 489 & 8 & 0.016 \\
\cline { 5 - 6 } & & & & CUF & 0.637 \\
\hline
\end{tabular}




\subsubsection{NUREG/CR-5999 CUF Based on Licensee's Design Calculation Stresses.}

The CUF calculations used the ASME Code, 1977 edition, through Winter 1979 addenda. The $S_{\text {alt }}$ values were not adjusted for the effect of modulus of elasticity, since NB-3653.4 of the ASME Code does not call for an adjustment of the modulus of elasticity. No change has been made to the ASME Code fatigue design curve modulus of elasticity since 1979 . The highoxygen carbon/low-alloy steel interim fatigue curves in NUREG/CR-5999 are temperature dependent. Temperatures at the location of the highest CUF at the times of maximum and mini- mum peak stress intensity were obtained from the design stress analysis computer output, and the maximum of the two temperatures was used. Cycles were interpolated between temperatures and strain rates as described in Chapter 3. The CUF using the NUREG/CR-5999 interim fatigue curves is shown in Table 5-122. Accounting for temperature but not for strain rate, the CUF would have been 5.520 .

Application of the NUREG/CR-5999 interim fatigue curve increased the CUF by a factor of 8.61 over the licensee's design basis number. The CUF exceeds the ASME Code limit of 1.0.

Table 5-122. CUF results for feedwater line piping using NUREG/CR-5999 interim fatigue curve.

\begin{tabular}{|c|c|c|c|c|c|c|}
\hline Load pair & $S_{\text {alt }}$ & $\begin{array}{c}\text { Temperature } \\
\left({ }^{\circ} \mathrm{C}\right) \\
\end{array}$ & $\begin{array}{c}\text { Strain rate } \\
(\% / \mathrm{s})\end{array}$ & $\mathrm{N}$ & $\mathbf{n}$ & $\mathbf{u}$ \\
\hline High 18/Low 21 & 110.07 & 200 & 0.117 & 183 & 5 & 0.027 \\
\hline High 18/Low 21 & 107.97 & 200 & 0.114 & 189 & 5 & 0.027 \\
\hline High $18 /$ Low 21 & 106.51 & 200 & 0.113 & 195 & 5 & 0.026 \\
\hline Low 14/Low 17 & 94.88 & 200 & 0.001 & 60 & 8 & 0.133 \\
\hline High 8/Low 17 & 89.40 & 200 & 0.095 & 271 & 10 & 0.037 \\
\hline High 3/Low 16 & 88.27 & 200 & 0.094 & 278 & 5 & 0.018 \\
\hline High $8 /$ High 7 & 86.77 & 200 & 0.041 & 225 & 126 & 0.560 \\
\hline High $7 /$ High 8 & 81.43 & 215 & 0.086 & 300 & 10 & 0.033 \\
\hline High 7/Low 13 & 67.93 & 200 & 0.001 & 131 & 97 & 0.740 \\
\hline High 7/Low 13 & 66.71 & 200 & 0.001 & 138 & 14 & 0.101 \\
\hline High $7 /$ Low 15 & 61.29 & 200 & 0.001 & 173 & 6 & 0.035 \\
\hline High $7 /$ Low 15 & 61.16 & 212 & 0.001 & 142 & 64 & 0.451 \\
\hline High 8/Low 12 & 55.50 & 200 & 0.001 & 235 & 92 & 0.391 \\
\hline High $3 /$ Low 12 & 46.63 & 215 & 0.001 & 346 & 88 & 0.254 \\
\hline High $7 /$ Low 22 & 42.88 & 212 & 0.001 & 511 & 15 & 0.029 \\
\hline High 3/High 7 & 39.44 & 215 & 0.001 & 674 & 212 & 0.315 \\
\hline High $3 /$ High 7 & 38.13 & 224 & 0.001 & 663 & 69 & 0.104 \\
\hline High 3/Low 20 & 36.80 & 224 & 0.001 & 762 & 11 & 0.014 \\
\hline High $4 /$ Low 20 & 34.32 & 215 & 0.001 & 1139 & 60 & 0.053 \\
\hline Low $11 /$ Low 20 & 32.95 & 200 & 0.001 & 1663 & 203 & 0.122 \\
\hline High 7 Low 11 & 32.53 & 200 & 0.001 & 1777 & 360 & 0.203 \\
\hline High 6/Low 11 & 29.77 & 200 & 0.025 & 6332 & 222 & 0.035 \\
\hline High 2/High 19 & 26.09 & 212 & 0.028 & 9321 & 30 & 0.003 \\
\hline High 5/High 19 & 26.04 & 200 & 0.028 & 10981 & 81 & 0.007 \\
\hline High 5/High 9 & 21.64 & 212 & 0.001 & 7894 & 96 & 0.012 \\
\hline High 1/High11 & 20.56 & 200 & 0.001 & 12312 & 40 & 0.003 \\
\hline Low 10/Low 11 & 14.18 & 200 & 0.001 & 56880 & 30 & 0.001 \\
\hline \multirow[t]{2}{*}{ High 5/Low 11} & 11.22 & 200 & 0.001 & $1.5 \times 10^{6}$ & 11545 & 0.008 \\
\hline & & & & & CUF & 3.746 \\
\hline
\end{tabular}


5.6.5.2 NUREG/CR-5999 CUF with Conservative Assumptions Removed. The primary plus secondary stress intensity ranges for the first through the fourth and the seventh load pairs exceeded the $3 \mathrm{~S}_{\mathrm{m}}$ limit, so a simplified elastic-plastic analysis adjustment factor $\left(\mathrm{K}_{\mathrm{e}}\right)$ was applied to the $S_{\text {alt }}$ value. However, the licensee's calculation conservatively assumed the highest temperature value to determine the $3 S_{m}$ value used in the calculation for $\mathrm{K}_{\mathrm{e}}$. The definition for $S_{\mathrm{m}}$ to be used for $3 S_{\mathrm{m}}$ from ASME Code Figure NB-3222-1, Note 3, is the average at the high and low temperatures during the transient. Based on the temperatures in the design calculations, the average temperature for the two transients in the first load pair was used to calculate $\mathrm{K}_{\mathrm{e}}$, again assuming that the contribution to secondary stresses from mechanical loads is negligible. The resulting CUF is shown in Table 5-123. The high and low load sets were enveloped sets of load pairs depending on whether the temperature was increasing (high) or decreasing (low). If the plant is operated for 60 years, the extrapolated CUF is 5.532 .

Table 5-123. CUF results for feedwater line piping using NUREG/CR-5999 interim fatigue curve and removing conservative assumptions.

\begin{tabular}{lrrrrrr}
\hline \multicolumn{1}{c}{ Load pair } & S alt & $\begin{array}{c}\text { Temperature } \\
\left({ }^{\circ} \mathrm{C}\right)\end{array}$ & $\begin{array}{c}\text { Strain rate } \\
(\% / s)\end{array}$ & $\mathrm{N}$ & $\mathrm{n}$ & \multicolumn{1}{c}{$\mathrm{u}$} \\
\hline High 18/Low 21 & 106.04 & 200 & 0.117 & 199 & 5 & 0.025 \\
High 18/Low 21 & 103.96 & 200 & 0.114 & 206 & 5 & 0.024 \\
High 18/Low 21 & 102.61 & 200 & 0.113 & 211 & 5 & 0.024 \\
Low 14/Low 17 & 91.59 & 200 & 0.001 & 65 & 8 & 0.123 \\
High 8/Low 17 & 89.40 & 200 & 0.095 & 271 & 10 & 0.037 \\
High 3/Low 16 & 88.27 & 200 & 0.094 & 278 & 5 & 0.018 \\
High 8/High 7 & 83.76 & 200 & 0.041 & 243 & 126 & 0.519 \\
High 7/High 8 & 81.43 & 215 & 0.086 & 300 & 10 & 0.033 \\
High 7/Low 13 & 67.93 & 200 & 0.001 & 131 & 97 & 0.740 \\
High 7/Low 13 & 66.71 & 200 & 0.001 & 138 & 14 & 0.101 \\
High 7/Low 15 & 61.29 & 200 & 0.001 & 173 & 6 & 0.035 \\
High 7/Low 15 & 61.16 & 212 & 0.001 & 142 & 64 & 0.451 \\
High 8/Low 12 & 55.50 & 200 & 0.001 & 235 & 92 & 0.391 \\
High 3/Low 12 & 46.63 & 215 & 0.001 & 346 & 88 & 0.254 \\
High 7/Low 22 & 42.88 & 212 & 0.001 & 511 & 15 & 0.029 \\
High 3/High 7 & 39.44 & 215 & 0.001 & 674 & 212 & 0.315 \\
High 3/High 7 & 38.13 & 224 & 0.001 & 663 & 69 & 0.104 \\
High 3/Low 20 & 36.80 & 224 & 0.001 & 762 & 11 & 0.014 \\
High 4/Low 20 & 34.32 & 215 & 0.001 & 1139 & 60 & 0.053 \\
Low 11/Low 20 & 32.95 & 200 & 0.001 & 1663 & 203 & 0.122 \\
High 7/Low 11 & 32.53 & 200 & 0.001 & 1777 & 360 & 0.203 \\
High 6/Low 11 & 29.77 & 200 & 0.025 & 6332 & 222 & 0.035 \\
High 2/High 19 & 26.09 & 212 & 0.028 & 9321 & 30 & 0.003 \\
High 5/High 19 & 26.04 & 200 & 0.028 & 10981 & 81 & 0.007 \\
High 5/High 9 & 21.64 & 212 & 0.001 & 7894 & 96 & 0.012 \\
High 1/High11 & 20.56 & 200 & 0.001 & 12312 & 40 & 0.003 \\
Low 10/Low 11 & 14.18 & 200 & 0.001 & 56880 & 30 & 0.001 \\
High 5/Low 11 & 11.22 & 200 & 0.001 & $1.5 \times 106$ & 11545 & 0.008 \\
\hline & & & & $\mathrm{CUF}$ & 3.688 \\
\hline & & & & &
\end{tabular}


The number of anticipated cycles are difficult to determine because the cycles in the design basis report do not have a one-for-one correspondence with the transients in Table 5-99. There are a number of potential conservative assumptions that could be removed to reduce the CUF. These are listed in Table 5-124.

\subsubsection{Residual Heat Removal (RHR) Nozzles and Associated Class 1 Piping.} The RHR suction line was evaluated. BWR/6 plants do not have RHR injected into the recirculation line, as do earlier BWR designs. The coolant retum from the RHR system during normal system operation enters the feedwater line upstream of the Class 1 piping and therefore no fatigue evaluation is required.

The fatigue analysis for the RHR suction line piping was performed in 1993 to reflect new conditions due to snubber removal, single loop operation, and thermal stratification in response to NRC Bulletin 88-08. The highest design CUFs are 0.407 for the carbon steel portion and 0.189 for the stainless steel portion. Since the CUF is higher for the carbon steel portion and the effect of the NUREG/CR-5999 curves is more pronounced for carbon than for stainless steel, only the carbon steel portion was evaluated. The location of highest CUF occurs in a straight run of SA-333 Grade 6 carbon steel pipe that is in direct contact with the reactor coolant.

\subsubsection{NUREG/CR-5999 CUF Based on Licensee's Design Calculation Stresses.} The CUF calculations used the ASME Code, 1977 edition, through Winter 1979 addenda. The $S_{\text {alt }}$ values were not adjusted for the effect of modulus of elasticity, since NB-3653.4 of the

Table 5-124. Potential for elimination of conservative assumptions to reduce CUF for feedwater line piping using NUREG/CR-5999 interim fatigue curve.

\begin{tabular}{lccl}
\multicolumn{1}{c}{$\begin{array}{c}\text { Assumption } \\
\text { Section 4.3) }\end{array}$} & $\begin{array}{c}\text { Potential } \\
\text { for use }\end{array}$ & Used & \multicolumn{1}{c}{ Comments } \\
\hline $\begin{array}{l}\text { Correct CUF } \\
\text { calculation }\end{array}$ & No & No & Analysis appear to be correct \\
$\begin{array}{l}\text { Detailed load pairs } \\
\text { SCF/FSRF }\end{array}$ & No & No & Detailed load pairs were used \\
S $\mathrm{m}$ value & No & No & Stress indices appear correct \\
Material property & Yes & Yes & Average $S_{\mathrm{m}}$ used \\
changes & No & No & No significant changes \\
Fatigue curve E value & Yes & Yes & Adjustment was made for modulus of elasticity \\
Code analysis changes & No & No & No significant changes \\
Actual cycles & Yes & No & Insufficient information \\
High temperature rates & Yes & No & Actual $\Delta T$ probably less than design \\
Detailed stress & Yes & No & More detailed model could be used \\
modeling & & & \\
Conservative thermal & Yes & No & Conservative heat transfer coefficients may have been \\
parameters & & & used \\
Time phasing of & Yes & No & Time phasing may reduce CUF \\
stresses & & & \\
Number of OBEs & No & No & OBE did contribute to CUF \\
CC N-411 damping & No & No & Dynamic loads did contribute to CUF \\
Number of hydrotests & No & No & Hydrotests did not contribute to CUF \\
Fatigue monitoring & Yes & No & Actual transients probably less severe than design \\
Plastic analysis & Yes & No & Elastic plastic finite element analysis could be used \\
\hline
\end{tabular}


ASME Code does not call for an adjustment of the modulus of elasticity. There has been no change in the modulus of elasticity used on the ASME Code carbon/low-alloy steel fatigue curves since 1979. The high-oxygen carbon/ low-alloy steel interim fatigue curves in NUREG/CR-5999 are temperature dependent. Temperatures at the location of the highest CUF were obtained from the design calculation computer output. The highest temperature for each load pair was approximately $288^{\circ} \mathrm{C}$, so the fatigue curve at this temperature was used. There was insufficient detail in the licensee's calculations to determine the strain rates, so the saturated curve was used. The CUF using the NUREG/CR-5999 interim fatigue curves is shown in Table 5-125. The high and low load sets were enveloped sets of load pairs depending on whether the temperature was increasing (high) or decreasing (low). The stratification transients were divided into a steady state (10) and transient (11) groupings.

Application of the NUREG/CR-5999 interim fatigue curve increased the CUF by a factor of 27.67 over the licensee's design basis number. The CUF exceeds the ASME Code limit of 1.0. If the plant is operated for 60 years, the extrapolated CUF is 16.89 .

5.6.6.2 NUREG/CR-5999 CUF with Conservative Assumptions Removed. With the given information, there are no readily apparent conservative assumptions that can be removed. The transients have not been lumped together but are separated into quite a few load pairs, and all $\mathrm{K}_{e}$ values are 1.0. All of the load pairs have large numbers of cycles that are associated with thermal stratification, for which we had no detailed information to assess potential conservative assumptions. Actions that might be taken to reduce the CUF are listed in Table 5-126.

5.6.7 Results and Conclusions. We obtained the latest design basis fatigue calculations for six components from a newer vintage (BWR/6) General Electric plant. The design CUF obtained from the licensee's calculations for the location with the highest calculated fatigue usage on each component was recomputed using the
NUREG/CR-5999 interim fatigue curves. The results are summarized in Table 5-127. The increases in the magnitudes of the design CUFs using the interim fatigue curves (expressed as multiplication factors) are as follows:

$$
\text { Stainless steel/Alloy } 600
$$

$$
\text { CRDM penetration }
$$

Feedwater nozzle thermal sleeve

Recirculation piping

Core spray nozzle thermal sleeve

\subsection{2}

6.52 average

Carbon/Low-alloy Steel

Reactor vessel shell/lower head $58.51^{\mathrm{e}}$

Feedwater nozzle safe end

Core spray nozzle safe end

Feedwater piping

RHR line

$$
\underline{27.67^{\mathrm{f}}}
$$

22.81 average

Conservative assumptions were identified, and where justifiable, the design CUFs were recomputed with certain conservative assumptions removed. Additionally, the 40-year CUFs were multiplied by 1.5 to determine a 60 -year CUF. These CUFs are also shown in Table 5-127.

CUFs for the carbon/low-alloy steel portions of the feedwater nozzles and piping were computed based on the strain rate during the increasing portion of the tensile stress cycle. For these two components, the average increase in CUF was 7.18 , which is in the same range as for stainless steel. Even using the saturated strain rate curves,

e. Not considering strain rate. CUF less than 1.0.

f. Not considering strain rate. Insufficient information. 
Table 5-125. CUF results for the residual heat removal suction line piping using NUREG/CR-5999 interim fatigue curve.

\begin{tabular}{llrrr}
\hline \multicolumn{1}{c}{ Load pair } & \multicolumn{1}{c}{$\mathrm{S}_{\text {alt }}$} & $\mathrm{N}$ & $\mathrm{n}$ & $\mathrm{u}$ \\
\hline High 4/stratification 10 & 46.93 & 102 & 5 & 0.049 \\
High 4/stratification 10 & 46.84 & 103 & 114 & 1.107 \\
Low 7/stratification 10 & 24.73 & 1430 & 152 & 0.106 \\
Low 7/stratification 10 & 23.78 & 1780 & 11976 & 6.728 \\
High 1/stratification 10 & 23.24 & 2025 & 523 & 0.258 \\
High 3/stratification 10 & 23.14 & 2074 & 610 & 0.294 \\
High 2/stratification 10 & 22.97 & 2161 & 1620 & 0.750 \\
High 2/stratification 11 & 16.68 & 7565 & 10480 & 1.385 \\
Low 8/stratification 11 & 16.21 & 8359 & 242 & 0.029 \\
Low 9/stratification 11 & 15.81 & 9127 & 360 & 0.039 \\
Low 6/stratification 11 & 15.74 & 9271 & 300 & 0.032 \\
Low 5/stratification 11 & 15.37 & 10080 & 619 & 0.061 \\
High 1/high 2 & 8.21 & $7.1 \times 10^{6}$ & $3.0 \times 10^{6}$ & 0.422 \\
& & & $\mathrm{CUF}$ & 11.260 \\
\hline
\end{tabular}

Table 5-126. Potential for elimination of conservative assumptions to reduce CUF for RHR piping using NUREG/CR-5999 interim fatigue curve.

\begin{tabular}{|c|c|c|c|}
\hline $\begin{array}{l}\text { Assumption } \\
\text { (Section 4.3) }\end{array}$ & $\begin{array}{l}\text { Potential } \\
\text { for use }\end{array}$ & Used & Comments \\
\hline $\begin{array}{l}\text { Correct CUF } \\
\text { calculation }\end{array}$ & No & No & Analysis appear to be correct \\
\hline Detailed load pairs & No & No & Detailed load pairs were used \\
\hline SCF/FSRF & No & No & Stress indices appear correct \\
\hline$S_{\mathrm{m}}$ value & No & No & $\mathrm{K}_{\mathrm{e}}$ is 1 for all load pairs \\
\hline $\begin{array}{l}\text { Material property } \\
\text { changes }\end{array}$ & No & No & No significant changes \\
\hline Fatigue curve $E$ value & No & No & NB-3200 requires no adjustment \\
\hline Code analysis changes & No & No & No significant changes \\
\hline Actual cycles & Yes & No & Insufficient information \\
\hline High temperature rates & Yes & No & Actual $\Delta T$ probably less than design \\
\hline $\begin{array}{l}\text { Detailed stress } \\
\text { modeling }\end{array}$ & Yes & No & More detailed model could be used \\
\hline $\begin{array}{l}\text { Conservative thermal } \\
\text { parameters }\end{array}$ & Yes & No & $\begin{array}{l}\text { Conservative heat transfer coefficients may have been } \\
\text { used }\end{array}$ \\
\hline $\begin{array}{l}\text { Time phasing of } \\
\text { stresses }\end{array}$ & Yes & No & Time phasing may reduce CUF \\
\hline Number of OBEs & No & No & OBE did contribute to CUF \\
\hline CC N-411 damping & No & No & Dynamic loads did contribute to CUF \\
\hline Number of hydrotests & No & No & Hydrotests did not contribute to CUF \\
\hline Fatigue monitoring & Yes & No & Actual transients probably less severe than design \\
\hline Plastic analysis & Yes & No & Elastic plastic finite element analysis could be used \\
\hline
\end{tabular}


Table 5-127. Summary of newer vintage GE plant CUFs.

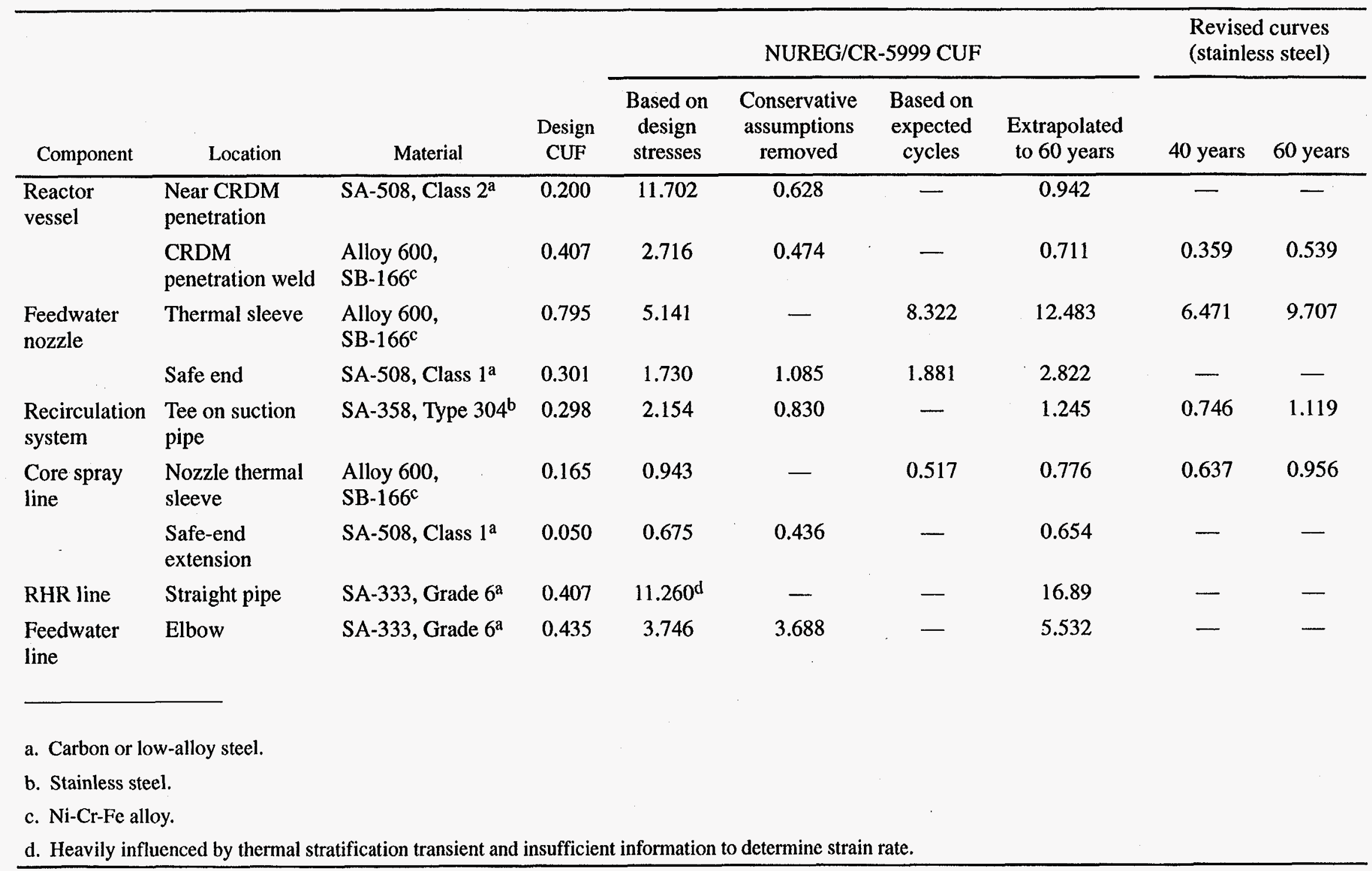


the CUFs for the reactor vessel shell/lower head and the core spray nozzle safe end were less than 1.0. Since the strain rates were unknown for the RHR piping analysis, the most conservative NUREG/CR-5999 curve was used for carbon/ low-alloy steel materials. One could speculate that the 7.18 factor of increase for the feedwater nozzle and piping may be representative for the RHR line also.

Adjustments for the anticipated cycles to end of life proved difficult, especially for RHR and feedwater system operations. The CUFs calculated using the NUREG/CR-5999 interim fatigue curves exceeded 1.0 for 40 years for three components. It appears that it will be difficult to reduce the CUF below 1.0 for several of the components without better definition of transients and more detailed thermal and stress models. Based on the experience with fatigue monitoring of BWR feedwater nozzles by two different organizations which showed that the design basis CUF could be reduced by a factor of 30 to 50 , we conclude that by fatigue monitoring, the CUF could be reduced below 1.0 using the NUREG/CR-5999 interim fatigue curves.

\subsection{Older Vintage General Electric Plant}

A comparison of the CUFs from the licensee's design calculations, or from representative CUFs calculated by the INEL for components for which no design fatigue analysis was required, and CUFs using the NUREG/CR-5999 interim fatigue curves was carried out for the locations of highest design CUF for the six components listed below:

\section{Reactor vessel shell and lower head}

\section{Reactor vessel feedwater nozzle}

3. Reactor recirculation piping (including inlet and outlet nozzles) (representative design basis fatigue calculation performed by INEL)
4. Core spray line reactor vessel nozzle and associated Class 1 piping

5. Residual heat removal (RHR) return line Class 1 piping (representative design basis fatigue calculation performed by INEL)

6. Feedwater line Class 1 piping (representative design basis fatigue calculation performed by INEL).

As of early 1994 , the BWR/4 has been operated approximately 10 of the 40 years currently approved in its operating license. Table 5-128 shows the design basis cycles for transients that are important from a fatigue standpoint, and for which the licensee provided the current cycle count. The current numbers of transients have been extrapolated to 40 years by multiplying by $40 / 10$, with the exception of the heatup and cooldown transients. Although 95 cooldowns occurred during the first ten years, the frequency for the past few years has been about 2.5 events year. Therefore, the extrapolation to 40 years was based on 95 events for the first ten years and 75 for the next 30 years. (The estimates are based on "major" heatups and cooldowns, which were assumed to be comparable to the transients used in the design basis stress/fatigue analysis. The projections for "minor" heatups and cooldowns are 228 and 244, respectively. The licensee's analyses do not differentiate between major and minor heatups and cooldowns, minor being $50^{\circ} \mathrm{F}$ or less.) No fatigue monitoring has been performed on this plant.

\subsubsection{Reactor Vessel Shell and Lower} Head. The highest CUF on the lower shell and head is 0.032 for the inside surface near the shellto-head transition. The SA-302 head is protected from the coolant by a layer of Alloy 600 cladding. No fatigue analysis is performed for the cladding.

\subsubsection{NUREG/CR-5999 CUF Based on} Licensee's Design Calculation Stresses. The licensee's CUF calculations used the ASME Code, Section III, 1965 edition. No interpolation equations were available in this edition of the 
Table 5-128. Number of selected design basis cycles compared to anticipated number of cycles over 40-year license life.

\begin{tabular}{lcc}
\hline \multicolumn{1}{c}{ Transient } & Design basis cycles & $\begin{array}{c}\text { Anticipated cycles } \\
\text { for 40 years }\end{array}$ \\
\hline Heatup & 120 & 172 \\
Cooldown & 120 & 170 \\
Hydrotest & 130 & 68 \\
25\% power change & 12000 & 828 \\
Feedwater heater bypass & 80 & 352 \\
Scram & 190 & 284 \\
\hline
\end{tabular}

Code, so the analyst used the minor grid marks on the fatigue curve to determine the allowable numbers of cycles.

The effect of the NUREG/CR-5999 interim fatigue curve is shown in Table 5-129. The NUREG/CR-5999 curve for $288^{\circ} \mathrm{C}$ and saturated conditions was used because the thermal transients occurred at relatively slow rates at operating temperatures. The results assume that the coolant is in contact with the low-alloy steel base metal underneath the cladding. The $S_{\text {alt }}$ values were adjusted for the effect of the modulus of elasticity by multiplying by $30 / 27$, the ratio of the modulus of elasticity in the current edition of the Code to the value commonly used in analyses in the 1965-1970 time period (the actual value used in the analysis was not reported). The 1965 Code edition did not require an adjustment for the effect of the modulus of elasticity.

Application of the NUREG/CR-5999 interim fatigue curve increased the CUF by a factor of 64.47 over the licensee's design basis number. The CUF exceeds the ASME Code limit of 1.0.

\subsubsection{NUREG/CR-5999 CUF with Con-} servative Assumptions Removed. As can be seen from Table 5-129, all transients were lumped together into a single load pair. The transients can be separated into two load pairs as shown in Table 5-130. The first pair represents 10 cycles of the loss of feedwater pump transients, and the second combines heatups/ cooldowns, blowdowns, and hydrotests. When the expected numbers of heatup/cooldowns and hydrotests in Table 5-128 are used for the second load pair in Table 5-130, the usage for all other transients remains 0.000 . If the plant is operated for 60 years, the CUF is 0.119 .

5.7.2 Feedwater Nozzle. The highest CUF for the feedwater nozzle is 0.758 at the blend radius on the interior of the nozzle. Each of the SA-508 low-alloy steel nozzles was originally protected from the coolant by a layer of cladding. No fatigue analysis is performed for the cladding. The cladding was removed because of fatigue cracking caused by thermal cycling of cold feedwater (leaking past the thermal sleeve) and hot coolant within the reactor vessel. The feedwater cracking in older BWRs was addressed in NUREG-0619 (Snaider, 1980). The CUF is based on an estimated leakage around the thermal sleeve and replacement of seals on a periodic basis. Most of the CUF is a result of high-cycle thermal mixing. The CUF for the nozzle bore upstream of the blend radius is 0.700 . The effect of the NUREG/CR-5999 curves was estimated for the nozzle bore because more detailed calculations were provided for this location and because the CUF is not based on an assumed schedule of seal maintenance.

\subsubsection{NUREG/CR-5999 CUF Based on Licensee's Design Calculation Stresses.} The licensee's design CUF calculations used the ASME Code, Section III, 1965 edition. The $S_{\text {alt }}$ values were adjusted for the effect of the modulus of elasticity by multiplying by $30 / 27$, the ratio of the modulus of elasticity in the current edition of the Code to the value commonly used in analyses in the 1965-1970 time period (the actual value used in the analysis was not reported). 
Table 5-129. CUF results for reactor vessel shell and lower head using NUREG/CR-5999 interim fatigue curve.

\begin{tabular}{lcccccc}
\hline & Load pair & $\mathrm{S}_{\text {alt }}$ & $\mathrm{S}_{\text {alt }}$ (adjusted) & $\mathrm{N}$ & $\mathrm{n}$ & $\mathrm{u}$ \\
\hline All & 40.00 & 44.44 & 127 & & 262 & 2.063 \\
\cline { 4 - 6 } & & & & & CUF & 2.063 \\
\hline
\end{tabular}

Table 5-130. CUF results for reactor vessel shell and lower head using NUREG/CR-5999 interim fatigue curve with conservative assumptions removed and based on anticipated cycles.

\begin{tabular}{lccccc}
\hline \multicolumn{1}{c}{ Load pair } & $\mathrm{S}_{\text {alt }}$ & $\mathrm{S}_{\text {alt }}$ (adjusted) & $\mathrm{N}$ & $\mathrm{n}$ & $\mathrm{u}$ \\
\hline Loss of feedwater pumps & 40.00 & 44.44 & 127 & 10 & 0.079 \\
All other & 7.00 & 7.78 & $>10^{6}$ & 252 & 0.000 \\
& & & & $\mathrm{CUF}$ & 0.079 \\
\hline
\end{tabular}

The NUREG/CR-5999 fatigue curve to be used for each load pair was based on the maximum temperature that was reported for the nozzle bore for each load pair. The strain rate was based on the average strain (assumed to be the alternating stress intensity divided by the modulus of elasticity, and multiplied by 100 to convert to percent) rate that occurred during the increasing tensile portion of the stress cycle. The effect of the NUREG/CR-5999 interim fatigue curves is shown in Table 5-131.

The Table 5-131 results indicate that the CUF increased by a factor of 14.08 over the licensee's design basis number. The CUF exceeds the ASME Code limit of 1.0.

\subsubsection{NUREG/CR-5999 CUF with Con-} servative Assumptions Removed. The only easily available change to the CUF was to use the anticipated cycles instead of the design basis cycles shown in the seventh column of Table 5-131. The first load pair was based on heatups and cooldowns, for which the anticipated cycles are greater than the design basis cycles $(120$ was increased to 170). The second load pair includes heatups/cooldowns (120), scrams (190), and several other events totaling 20 cycles. The total anticipated number of heatups/cooldowns (170), scrams (284), and the 20 other cycles also is greater than the design basis number. These cycles increase from 330 to 474 . However, the third and fifth load pairs included daily and weekly power changes. Since the plant is base loaded, the anticipated numbers of cycles are less than the number of design basis cycles. The third load pair includes 2000 cycles of $50 \%$ power reduction, 70 cycles of feedwater heater bypass, and 400 other cycles. Increasing the feedwater heater bypass cycles to 352 , but reducing the 2000 design basis weekly $50 \%$ reductions in power by the ratio of the actual-to-design-basis $25 \%$ power reductions $(2000 \times 828 / 12000=138)$ and including the 400 other cycles, the anticipated number is reduced from 2470 to to 890 . For the fifth load pair, 10,000 cycles were assumed for the $25 \%$ power reduction load pair, whereas only 828 are anticipated. The revised CUF is shown in Table 5-132. If the plant is operated for 60 years, the CUF is 4.752 .

NUREG/CR-0619 (Snaider, 1980) states that the CUF in the nozzle region "... could be reduced from 0.77 to 0.46 by adopting GE's proposed alternative operating procedures." These include directing RWCU flow to all feedwater nozzles at the maximum flow rate during all low flow conditions prior to turbine loading, loading the turbine at $600 \mathrm{psi}$ instead of $1000 \mathrm{psi}$, placing turbine extraction heaters on line at the time of turbine loading, and precluding on-off feedwater operating and greater than $25^{\circ} \mathrm{F}$ peak-to-peak mixture temperatures during steady state operation. The GE study was performed on a welded single sleeve sparger and not the design of the BWR/4 that we evaluated. There are different sparger designs and generic conclusions are difficult to make on older 
Table 5-131. CUF results for reactor vessel feedwater nozzle using NUREG/CR-5999 interim fatigue curves.

\begin{tabular}{|c|c|c|c|c|c|c|c|}
\hline Load pair & $S_{\text {alt }}$ & $\begin{array}{c}\mathrm{S}_{\text {alt }} \\
\text { (adjusted) }\end{array}$ & $\begin{array}{c}\text { Temperature } \\
\left({ }^{\circ} \mathrm{C}\right)\end{array}$ & $\begin{array}{c}\text { Strain } \\
\text { rate } \\
(\% / s)\end{array}$ & $\mathrm{N}$ & $\mathbf{n}$ & $\mathbf{u}$ \\
\hline Heatup/cooldown & 40.50 & 45.00 & 288 & 0.001 & 121 & 120 & 0.992 \\
\hline Scram and others & 45.50 & 50.56 & 200 & 0.100 & 1292 & 330 & 0.255 \\
\hline $\begin{array}{l}\text { Weekly power reduction } \\
\text { and others }\end{array}$ & 34.50 & 38.33 & 200 & 0.0014 & 1057 & 2470 & 2.337 \\
\hline Loss of feedwater pumps & 39.00 & 43.33 & 250 & 0.0016 & 273 & 10 & 0.037 \\
\hline \multirow[t]{2}{*}{ Daily power reduction } & 30.00 & 33.33 & 200 & 0.001 & 1603 & 10000 & 6.238 \\
\hline & & & & & & CUF & 9.859 \\
\hline
\end{tabular}

Table 5-132. CUF results for reactor vessel feedwater nozzle using NUREG/CR-5999 interim fatigue curves and anticipated cycles.

\begin{tabular}{|c|c|c|c|c|c|c|c|}
\hline Load pair & $S_{\text {alt }}$ & $\begin{array}{c}\mathrm{S}_{\text {alt }} \\
\text { (adjusted) }\end{array}$ & $\begin{array}{c}\text { Temperature } \\
\left({ }^{\circ} \mathrm{C}\right)\end{array}$ & $\begin{array}{c}\text { Strain } \\
\text { rate } \\
(\% / s)\end{array}$ & $\mathrm{N}$ & $\mathbf{n}$ & $\mathbf{u}$ \\
\hline Heatup/cooldown & 40.50 & 45.00 & 288 & 0.001 & 121 & 170 & 1.405 \\
\hline Scram and others & 45.50 & 50.56 & 200 & 0.100 & 1292 & 474 & 0.367 \\
\hline $\begin{array}{l}\text { Weekly power reduction } \\
\text { and others }\end{array}$ & 34.50 & 38.33 & 200 & 0.0014 & 1057 & 890 & 0.842 \\
\hline Loss of feedwater pumps & 39.00 & 43.33 & 250 & 0.0016 & 273 & 10 & 0.037 \\
\hline \multirow[t]{2}{*}{ Daily power reduction } & 30.00 & 33.33 & 200 & 0.001 & 1603 & 828 & 0.517 \\
\hline & & & & & & CUF & 3.168 \\
\hline
\end{tabular}

BWRs. If the licensee undertakes the recommended measures for the remainder of life, and if the GE calculated reduction in CUF of $40 \%$ is applicable to this plant, then the CUF would be 1.901. If the plant is operated for 60 years, the CUF is 2.851 .

The changes that would probably reduce the CUF the most are a more detailed analysis using a finite element model rather than an interaction model and better definition of the transients. Other potential changes that could be used to reduce the CUF are shown in Table 5-133. Based on fatigue monitoring by GE of a Japanese BWR for two fuel cycles, the 40-year CUF for the feedwater nozzle has been estimated at only 0.0074 versus a design basis CUF of 0.387 (Sakai et al., 1993), a reduction of about a factor of 50. Deardorff and Smith (1994) report than based on monitoring of 12 startups and 11 shutdowns at one
BWR, the design basis CUF for the feedwater nozzle during the monitoring period was about 30 times that computed from fatigue monitoring of actual transients.

5.7.3 Reactor Recirculation Piping. The recirculation piping system was initially designed and analyzed per the criteria of USAS B31.1-1967, rather than ASME Code Class 1 criteria. The nozzle CUF was 0.310 . Since the piping system did not have any specific fatigue analyses performed, the INEL performed analyses to predict a design CUF using transient data developed for a more recent (BWR/6) plant having a Class 1 analysis basis. However, once the actual details of the piping of the two plants were compared, it was recognized that the older and newer vintage BWR plant piping systems were not as similar as initially believed. The BWR/6 plant that we evaluated in Section 5.6 has only a 
Table 5-133. Potential for elimination of conservative assumptions to reduce CUF for feedwater nozzle using NUREG/CR-5999 interim fatigue curve.

\begin{tabular}{lccl}
\multicolumn{1}{c}{$\begin{array}{c}\text { Assumption } \\
\text { (Section 4.3) }\end{array}$} & $\begin{array}{c}\text { Potential } \\
\text { for use }\end{array}$ & Used & \multicolumn{1}{c}{ Comments } \\
\hline Correct CUF calculation & No & No & Analysis appears to be correct \\
Detailed load pairs & Yes & No & Some transients were lumped together \\
SCF/FSRF & Yes & No & Insufficient information \\
$S_{\mathrm{m}}$ value & No & No & $\mathrm{K}_{\mathrm{e}}=1$ for all load pairs \\
Material property & Yes & Yes & A few 1965 to 1992 edition changes \\
changes & & & \\
Fatigue curve E value & Yes & Yes & Adjustment was made when using NUREG/CR-5999 \\
& & & curves \\
Code analysis changes & Yes & Yes & A few 1965 to 1992 edition changes \\
Actual cycles & Yes & Yes & Adjustment was made for projected cycles \\
High temperature rates & Yes & No & Actual cooldown rates probably less than design \\
Detailed stress modeling & Yes & No & Interaction analysis used \\
Conservative thermal & Yes & No & Insufficient information \\
parameters & & & \\
Time phasing of stresses & No & No & Probably little benefit for nozzle \\
Number of OBEs & No & No & OBE cycles not significant contributor to CUF \\
CC N-411 damping & No & No & Dynamic loads not significant contributor to CUF \\
Number of hydrotests & No & No & Hydrotests did not contribute to CUF \\
Fatigue monitoring & Yes & No & Actual transients probably less severe than design \\
Plastic analysis & Yes & No & Elastic plastic finite element analysis could be used \\
\hline
\end{tabular}

residual heat removal (RHR) outlet line attached to the recirculation piping. The recirculation piping in the BWR/4 plant evaluated in this section contains one RHR outlet line and two RHR return lines. The geometry of the BWR $/ 4$ recirculation and RHR analysis model is shown in Figure 5-7.

\subsubsection{Calculation of Representative} Design CUF. Considerable efforts were made in order to acquire additional information so that accurate loadings could be applied to the piping model. Since the existing analysis used B31.1 criteria, detailed transient information was not available for all loadings. Therefore, design information was obtained from another BWR/4 plant that reanalyzed its recirculation piping to Class 1 criteria, as well as the BWR/6 plant discussed in Section 5.6. Comparing these transient data for the Class 1 analyses, we confirmed that the overall operating parameters and tran- sients for the plants were similar. The numbers of cycles used to compute the design CUF, the pressure levels, and the operating temperatures all appeared to be typical BWR values. Little variation existed between the BWR/4 and the BWR/6 defined transients.

Therefore, we used the existing BWR/ 6 transient data as much as possible, including the thermal gradients, in the NB-3600 analysis. Where the BWR/4 piping had a larger OD and a thicker wall than the BWR/6 plant (for example, a 28 -inch line versus a 20 -inch line), we performed thermal analyses for the same transient on both pipes sizes, divided each of the $\Delta T$ results of the larger pipe by the corresponding $\Delta T$ on the smaller pipe, and multiplied the BWR/6 $\Delta T$ s by the appropriate ratio to determine the $B W R / 4$ $\Delta$ Ts. 


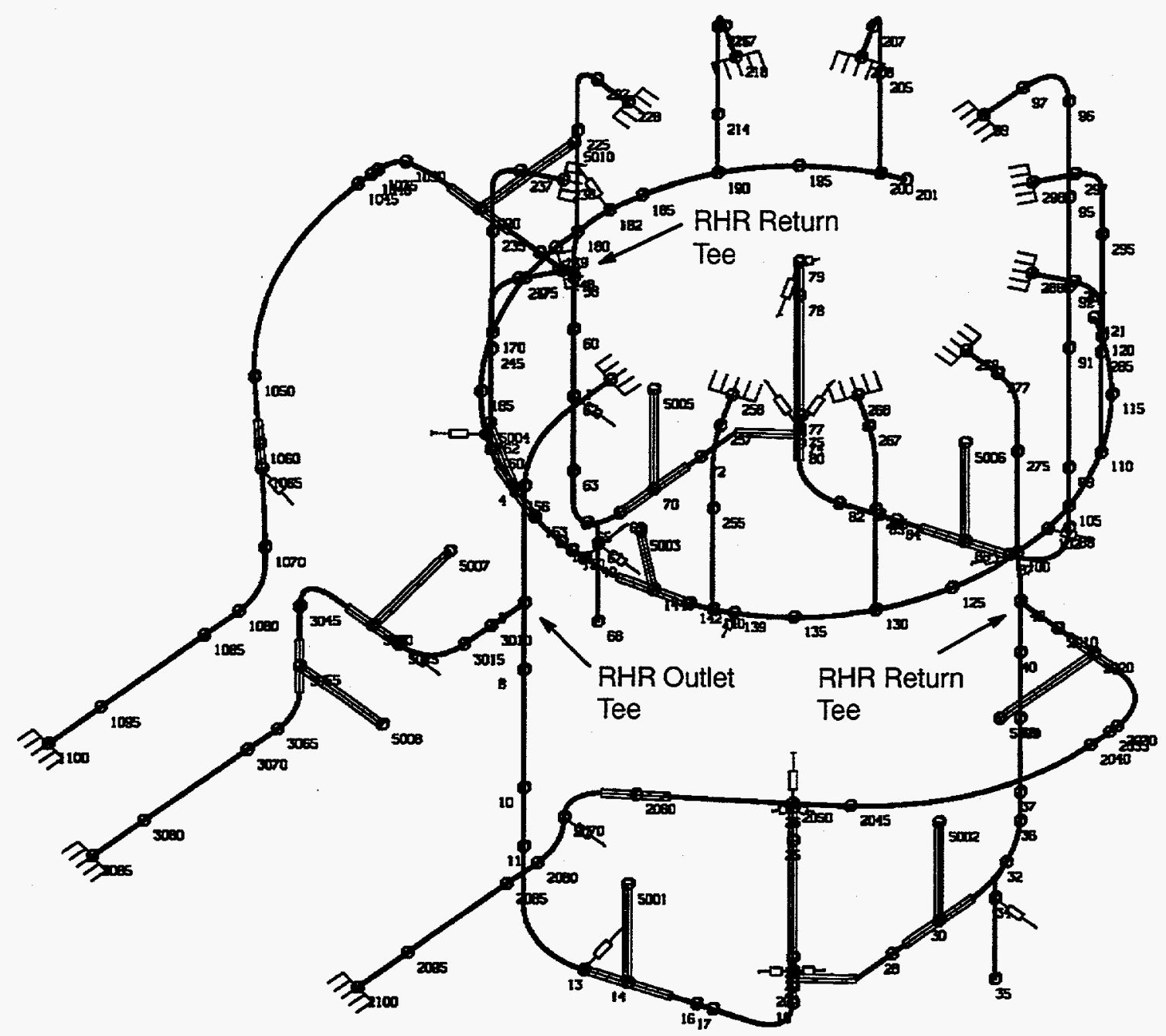

Figure 5-7. BWR/4 recirculation piping system isometric view.

The design differences between the BWR/6 and $\mathrm{BWR} / 4$ plants alter not only the geometry, but also the operational transients for some portions of the piping. Therefore, additional thermal transient data were developed to evaluate the effects of injecting RHR water into the recirculation piping during the RHR shutdown cooling transient. Initially, a definition of the RHR shutdown cooling transient provided by the licensee was utilized and a CUF value of 0.731 was calculated. However, this transient definition was extremely severe. General Electric (GE) provided two recommended transients. The RHR shutdown cooling transient definition used herein was defined by GE as transient number 2 . Figure 5-8 illustrates the differences between the transient provided by the licensee and the two transients defined by GE. A 10 minute time span (as specified in the licensee's transient definition) between the cooldown and heatup portions of the RHR shutdown cooling transient was utilized.

An ASME Code NB-3600 analysis was performed using the 1992 edition, through 1992 addenda. The results indicated that one of the RHR return tees was the component with the highest CUF (0.397). Time phasing of the thermal gradient stress terms was used for the fatigue analysis. However, the stress results exceeded 
Component Evaluations

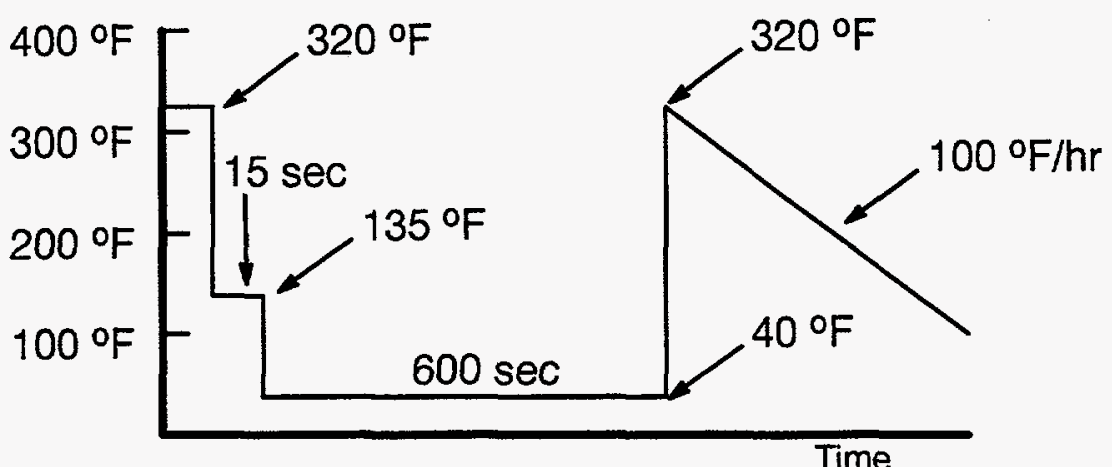

(a) Licensee-defined transient

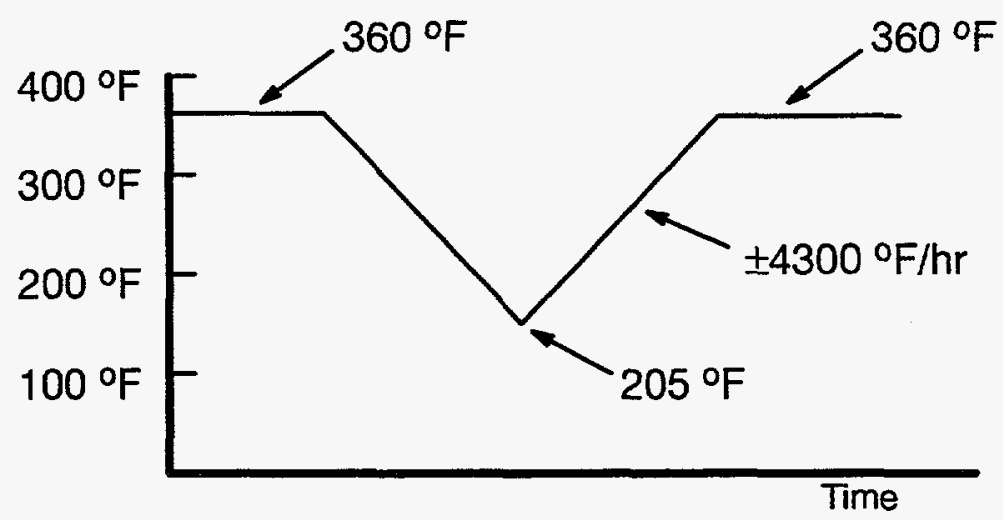

(b) GE transient no. 1

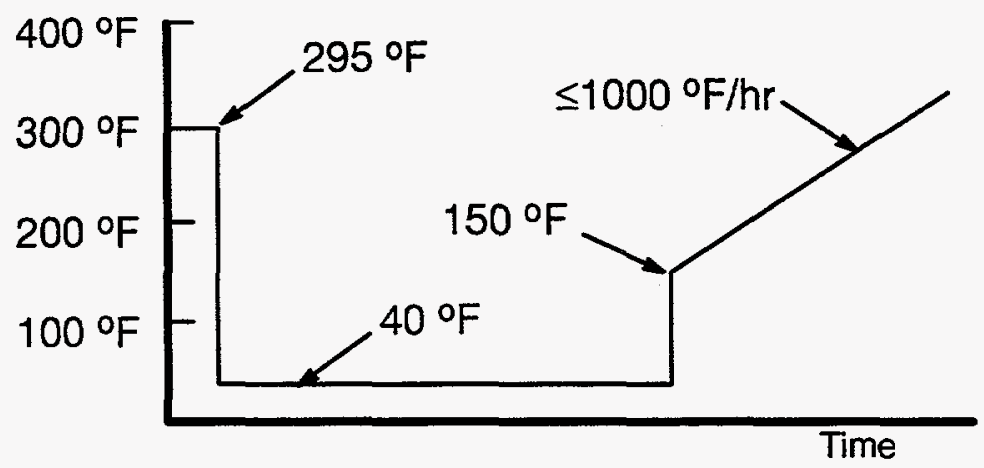

(c) GE transient no. 2

Figure 5-8. Comparison of RHR shutdown cooling transients. 
current ASME Code criteria. At the RHR retum line tee location, the calculated stress range from ASME Code NB-3650 Equation 12 slightly exceeded (by less than $3 \%$ ) the $3 \mathrm{~S}_{\mathrm{m}}$ stress limit for four load pairs. ASME Code NB-3650 Equation 13 stress levels were generally high but still below $3 \mathrm{~S}_{\mathrm{m}}$ levels. In addition, the thermal stress ratchet check per NB-3653.7 was exceeded for 8 load pairs. An NB-3200 analysis of the tee could be used to demonstrate compliance with the Equation 12 and thermal stress ratchet criteria.

All of the load pairs that exceed Code criteria include the RHR shutdown cooling transient loading. The other loadings making up the load pairs exceeding the stress ratchet criteria involved transients with pressures at or above normal operating pressure. Seven of the load pairs exceeded the thermal stress ratchet criteria by about 5 to $24 \%$ over the allowable values. Based on our experience with the older vintage Westinghouse plant NB-3200 versus NB-3600 results for two nozzles (Section 5.5), the stress ratchet criterion for the 7 load pairs and the Equation 12 criterion for the 4 load pairs could be satisfied using an NB-3200 analysis. The eighth load pair involves the RHR shutdown cooling transient paired with a scram at full power consisting of a composite loss of feedwater pumps, loss of auxiliary power, and turbine generator trip without bypass. The stress ratchet criteria was exceeded by almost $115 \%$ for this load pair. However, for the latter transient, the pressure increases to the relief valve setpoint for a very short time, during which the $\Delta T_{1}$ term is negligible. The reason the stress ratchet criteria was exceeded by so large a margin is that the pressure increase significantly reduces the allowable $\Delta T_{1}$ range. The $\Delta T_{1}$ range comes solely from the former transient, when the pressure is much lower. Therefore, the $\Delta T_{1}$ range and the high pressure are not coincident loadings. NB-3200 analysis procedures are more precise than the NB-3600 analysis rules. An NB-3200 analysis requires that thermal stress ratchet (NB-3222.5) be evaluated by calculating the maximum cyclic thermal stress in a shell loaded by a steady state internal pressure. The NB-3200 evaluation clearly implies a pressure loading coincident with the thermal stress. Therefore, an NB-3200 analysis technique would demonstrate ASME Code compliance for this load pair exceeding the NB-3600 thermal stress ratchet check.

A calculation was also performed using the expected numbers of cycles in Table 5-128. The numbers of heatups, cooldowns, and scrams increased, whereas the numbers of hydrotests and power reductions decreased from the design basis numbers. The resulting CUF is 0.526 . The transient that is the major contributor to the CUF is the RFR shutdown cooling transient.

We contacted GE regarding this CUF value. They confirmed that the RHR shutdown cooling transient is indeed severe. They also emphasized that it was important to know how the plant is actually operated in order to more precisely assess the impact of this transient.

In a related effort, an EPRI report (Deardorff and Rosario, 1993) also reanalyzed an older vintage BWR recirculation piping system using a similar upgraded Class 1 analysis effort. The pipe sizes and geometries of the RHR lines are different between the two plants. The EPRI-sponsored analysis reported a CUF of 0.35 at the RHR return tee location. It is important to note that the EPRI report definition of the RHR shutdown cooling transient was similar to transient number 2 as illustrated in Figure 5-8, but with only a 15 second interval between the cooldown and heatup portion. The shorter time span more closely matches that defined by GE in transient number 1 . The EPRI report transient definition is not as severe as that used for the analysis performed herein. However, the EPRI-sponsored analysis used 318 cycles for the RHR shutdown cooling transient, whereas the INEL analysis included 172 heatup/cooldown cycles (Table 5-128).

\subsubsection{CUF Results Using NUREG/} CR-5999 Interim Fatigue Curve. The CUF using the NUREG/CR-5999 interim fatigue curve is shown in Table 5-134. Application of the NUREG/CR-5999 interim fatigue curve increased the CUF by a factor of 7.31 over the design basis number. The load pairs which contribute most of the CUF are identified. The composite loss transients envelop several load sets. The CUF exceeds the ASME Code limit of 1.0. 
Table 5-134. CUF results for recirculation piping system using NUREG/CR-5999 interim fatigue curve.

\begin{tabular}{lrrrc}
\hline \multicolumn{1}{c}{ Load pair } & $\mathrm{S}_{\text {alt }}$ & $\mathrm{N}$ & $\mathrm{n}$ & $\mathrm{u}$ \\
\hline Composite loss E/OBE & 182.76 & 47 & 10 & 0.213 \\
Composite loss A/RHR B & 161.69 & 63 & 10 & 0.159 \\
Turbine roll A/RHR B & 144.89 & 82 & 109 & 1.329 \\
RHR A/OBE & 133.56 & 100 & 40 & 0.400 \\
RHR A/turbine roll A & 116.13 & 140 & 11 & 0.079 \\
RHR A/composite loss C & 107.48 & 169 & 10 & 0.059 \\
RHR A/composite loss D & 100.12 & 200 & 10 & 0.050 \\
RHR A/composite loss G & 99.65 & 203 & 10 & 0.049 \\
RHR A/turbine trip-scrams B & 94.26 & 232 & 38 & 0.164 \\
Turbine trip B/shutdown & 63.86 & 590 & 10 & 0.017 \\
Turbine trip A/cooldown & 62.33 & 676 & 10 & 0.015 \\
Turbine trip-scrams B/shutdown & 59.20 & 922 & 109 & 0.118 \\
Turbine trip-scrams B/cooldown & 57.14 & 1141 & 33 & 0.029 \\
Turbine roll B/null & 56.85 & 1177 & 120 & 0.102 \\
Warmup/composite loss F & 55.42 & 1372 & 10 & 0.007 \\
Hydrotest down/startup & 50.64 & 2361 & 40 & 0.017 \\
Reduction to power/cooldown & 50.56 & 2384 & 80 & 0.034 \\
Reduction to power/warmup & 50.43 & 2421 & 31 & 0.013 \\
Warmup/startup & 50.42 & 2423 & 80 & 0.033 \\
& 46.76 & 3815 & 25 & 0.007 \\
& 42.83 & 6475 & 10 & 0.002 \\
& 42.74 & 6551 & 30 & 0.005 \\
& 41.82 & 7477 & 2 & 0.000 \\
\hline
\end{tabular}

\subsubsection{NUREG/CR-5999 CUF Based on} Anticipated Cycles. The adjusted CUF resulting from the anticipated cycles from Table 5-128 is shown in Table 5-135. If the plant is operated for 60 years, the extrapolated CUF is 5.847. Other potential changes that could be used to reduce the CUF are shown in Table 5-136.

\subsubsection{CUF Based on Revised Interim} Fatigue Curves. The adjusted CUF resulting from the application of the revised interim curves is shown in Table 5-137. All transients had low strain rates with the exception of transients where a thermal shock was applied. The appropriate strain rate was applied to the first 9 load pairs by dividing the alternating stress intensity by the modulus of elasticity, multiplying by 100 to convert to percent, and dividing by the time to maximum stress (about $30 \mathrm{~s}$ ). The $0.001 \% / \mathrm{s}$ curve was used for all other load pairs. If the plant is operated for 60 years, the extrapolated CUF is 4.884.

5.7.4 Core Spray Line. The highest CUF for the SA-302 Grade B carbon steel core spray nozzle is 0.023 , while a CUF of 0.182 was calculated for the SA-376 Type 316 stainless steel safe end. Based on a review of the thermal transients in the line and the results from the (BWR/6) core spray line analysis (Section 5.6.4), it was judged that the highest CUF would occur at the nozzle location. Because of the differences in the effect of the NUREG/CR-5999 interim fatigue curves, an evaluation was made for each of the two materials. 
Table 5-135. CUF results for recirculation piping system using NUREG/CR-5999 interim fatigue curve and anticipated cycles.

\begin{tabular}{lrrrr}
\hline \multicolumn{1}{c}{ Load pair } & $\mathrm{S}_{\text {alt }}$ & $\mathrm{N}$ & $\mathrm{n}$ & $\mathrm{u}$ \\
\hline Composite loss E/OBE & 182.76 & 47 & 10 & 0.213 \\
Composite loss A/RHR B & 161.69 & 63 & 10 & 0.159 \\
Turbine roll A/RHR B & 144.89 & 82 & 160 & 1.951 \\
RHR A/OBE & 133.56 & 100 & 40 & 0.400 \\
RHR A/turbine roll A & 116.13 & 140 & 12 & 0.086 \\
RHR A/composite loss C & 107.48 & 169 & 10 & 0.059 \\
RHR A/composite loss D & 100.12 & 200 & 10 & 0.050 \\
RHR A/composite loss G & 99.65 & 203 & 10 & 0.049 \\
RHR A/turbine trip-scrams B & 94.26 & 232 & 88 & 0.379 \\
Turbine trip B/shutdown & 63.86 & 590 & 10 & 0.017 \\
Turbine trip A/null \& cooldown & 62.87 & 642 & 10 & 0.016 \\
Turbine trip-scrams B/shutdown & 59.20 & 922 & 160 & 0.174 \\
Turbine trip-scrams B/cooldown & 57.14 & 1141 & 36 & 0.032 \\
Turbine roll B/null & 56.85 & 1177 & 172 & 0.146 \\
Warmup/composite loss F & 55.42 & 1372 & 10 & 0.007 \\
Hydrotest down/startup & 50.64 & 2361 & 68 & 0.029 \\
Reduction to power/cooldown & 50.56 & 2384 & 139 & 0.058 \\
Reduction to power/warmup & 50.43 & 2421 & 26 & 0.011 \\
Warmup/startup & 50.42 & 2423 & 104 & 0.043 \\
& 46.76 & 3815 & 25 & 0.007 \\
& 42.83 & 6475 & 10 & 0.002 \\
& 42.74 & 6551 & 58 & 0.009 \\
& 41.82 & 7477 & 10 & 0.001 \\
\hline
\end{tabular}

\subsubsection{NUREG/CR-5999 CUF for the} Nozzle Based on Licensee's Design Calculation Stresses. The licensee's design CUF calculations used the ASME Code, Section III, 1965 edition, through Winter 1967 addenda. The results shown assume that the coolant is in contact with the low-alloy steel base metal underneath the cladding. The $S_{\text {alt }}$ values were adjusted for the effect of the modulus of elasticity by multiplying by $30 / 27$, the ratio of the modulus of elasticity in the current edition of the Code to the value commonly used in analyses in the 1965-1970 time period (the actual value used in the analysis was not reported). The 1965 Code edition did not require an adjustment for the effect of the modulus of elasticity. The temperature for the transient evaluated was approximately $288^{\circ} \mathrm{C}$, but since a step change in temperature was assumed in the analysis, a strain rate of $0.0078 \% / \mathrm{s}$ was used based on a 30 s time to reach the maximum tensile stress. The CUF using the NUREG/CR-5999 interim fatigue curve is shown in Table 5-138.

Application of the NUREG/CR-5999 interim fatigue curve increased the CUF by a factor of 19.17 over the design basis number.

5.7.4.2 NUREG/CR-5999 CUF for the Safe End Based on Licensee's Design Calculation Stresses. The licensee's design CUF calculations used the ASME Code, Section III, 1965 edition, through Winter 1967 addenda. The $S_{\text {ait }}$ values were adjusted for the effect of the modulus of elasticity by multiplying by $28.3 / 26$, the ratio of the modulus of elasticity in the current edition of the Code to the value commonly used in analyses in the 1965-1970 time period (the actual value used in the analysis was not reported). The 1965 Code edition did not 
Table 5-136. Potential for elimination of conservative assumptions to reduce design CUF for recirculation piping system.

\begin{tabular}{|c|c|c|c|}
\hline $\begin{array}{l}\text { Assumption } \\
\text { (Section 4.3) }\end{array}$ & $\begin{array}{l}\text { Potential } \\
\text { for use }\end{array}$ & Used & Comments \\
\hline $\begin{array}{l}\text { Correct CUF } \\
\text { calculation }\end{array}$ & NA & NA & Analysis appears to be correct \\
\hline Detailed load pairs & NA & NA & Detailed load pairs were used \\
\hline SCF/FSRF & NA & NA & Stress indices based on information received \\
\hline$S_{\mathrm{m}}$ value & NA & NA & 1992 Code used \\
\hline $\begin{array}{l}\text { Material property } \\
\text { changes }\end{array}$ & NA & NA & 1992 Code used \\
\hline $\begin{array}{l}\text { Fatigue curve } \mathrm{E} \\
\text { value }\end{array}$ & NA & NA & 1992 Code used \\
\hline $\begin{array}{l}\text { Code analysis } \\
\text { changes }\end{array}$ & NA & NA & 1992 Code used \\
\hline Actual cycles & Yes & Yes & Verification of transient data and cycles must be made \\
\hline $\begin{array}{l}\text { High temperature } \\
\text { rates }\end{array}$ & Yes & No & Verification of transient data and cycles must be made \\
\hline $\begin{array}{l}\text { Detailed stress } \\
\text { modeling }\end{array}$ & Yes & No & $\begin{array}{l}\text { NB-3200 analysis techniques could be used to further reduce } \\
\text { conservatisms }\end{array}$ \\
\hline $\begin{array}{l}\text { Conservative } \\
\text { thermal parameters }\end{array}$ & Yes & No & Used grouped design parameters from BWR/6 analysis \\
\hline $\begin{array}{l}\text { Time phasing of } \\
\text { stresses }\end{array}$ & Yes & Yes & $\begin{array}{l}\text { Highest moment and thermal stresses did not occur } \\
\text { simultaneously }\end{array}$ \\
\hline Number of OBEs & No & No & Number of OBE cycles consistent with SRP \\
\hline CC N-411 damping & Yes & $\mathrm{No}^{\mathrm{a}}$ & Dynamic loads are a contributor to CUF \\
\hline $\begin{array}{l}\text { Number of } \\
\text { hydrotests }\end{array}$ & No & No & Hydrotests did not contribute to CUF \\
\hline Fatigue monitoring & Yes & No & Actual transients probably less severe than design \\
\hline Plastic analysis & Yes & No & Elastic plastic finite element analysis could be used \\
\hline
\end{tabular}

a. A Housner spectrum was used in the licensee's analysis. A reanalysis of the building using a site-specific spectrum is needed for CC N-411 application.

require an adjustment for the effect of the modulus of elasticity. The CUF using the NUREG/CR-5999 interim fatigue curve is shown in Table 5-139.

Application of the NUREG/CR-5999 interim fatigue curve increased the CUF by a factor of 9.77 over the design basis number.

5.7.4.3 NUREG/CR-5999 CUF for Core Spray Nozzle Based on Anticipated Cycles. Even though the CUF is below 1.0, the anticipated cycles from Table 5-128 are greater than 455 . The anticipated heatups/cooldowns are 170 rather than 120 , the anticipated scrams are 284 rather than 190 , and the number of anticipated hydrotests is 68 rather than 130. Combined with 15 cycles of several other transients, an estimated 537 cycles for the transients used in the analysis are anticipated for 40 years. This number of cycles was estimated using the transients listed in Table 5-128, combined with several transients not in Table 5-128 for which no current numbers 
Table 5-137. CUF results for recirculation piping system using revised interim fatigue curves.

\begin{tabular}{|c|c|c|c|c|c|}
\hline Load pair & $\mathrm{S}_{\mathrm{alt}}$ & $\begin{array}{c}\text { Strain rate } \\
(\% / \mathrm{s})\end{array}$ & $\mathrm{N}$ & $\mathrm{n}$ & $\mathrm{u}$ \\
\hline Composite loss E/OBE & 182.76 & 0.022 & 54 & 10 & 0.185 \\
\hline Composite loss A/RHR B & 161.69 & 0.019 & 72 & 10 & 0.139 \\
\hline Turbine roll A/RHR B & 144.89 & 0.017 & 95 & 160 & 1.684 \\
\hline RHR A/OBE & 133.56 & 0.016 & 116 & 40 & 0.345 \\
\hline RHR A/turbine roll A & 116.13 & 0.014 & 167 & 12 & 0.072 \\
\hline RHR A/composite loss C & 107.48 & 0.013 & 206 & 10 & 0.049 \\
\hline RHR A/composite loss D & 100.12 & 0.012 & 252 & 10 & 0.040 \\
\hline RHR A/composite loss $G$ & 99.65 & 0.012 & 255 & 10 & 0.039 \\
\hline RHR A/turbine trip-scrams B & 94.26 & 0.011 & 300 & 88 & 0.293 \\
\hline Turbine trip B/shutdown & 63.86 & 0.001 & 910 & 10 & 0.011 \\
\hline Turbine trip A/null \& cooldown & 62.87 & 0.001 & 973 & 10 & 0.010 \\
\hline Turbine trip-scrams B/shutdown & 59.20 & 0.001 & 1279 & 160 & 0.125 \\
\hline Turbine trip-scrams B/cooldown & 57.14 & 0.001 & 1518 & 36 & 0.024 \\
\hline Turbine roll B/null & 56.85 & 0.001 & 1557 & 172 & 0.110 \\
\hline Warmup/composite loss F & 55.42 & 0.001 & 1774 & 10 & 0.006 \\
\hline Hydrotest down/startup & 50.64 & 0.001 & 2962 & 68 & 0.023 \\
\hline Reduction to power/cooldown & 50.56 & 0.001 & 2992 & 139 & 0.046 \\
\hline Reduction to power/warmup & 50.43 & 0.001 & 3040 & 26 & 0.009 \\
\hline \multirow[t]{6}{*}{ Warmup/startup } & 50.42 & 0.001 & 3044 & 104 & 0.034 \\
\hline & 46.76 & 0.001 & 5107 & 25 & 0.005 \\
\hline & 42.83 & 0.001 & 11022 & 10 & 0.001 \\
\hline & 42.74 & 0.001 & 11263 & 58 & 0.005 \\
\hline & 41.82 & 0.001 & 14273 & 10 & 0.001 \\
\hline & & & & CUF & 3.256 \\
\hline
\end{tabular}

Table 5-138. CUF results for core spray nozzle using NUREG/CR-5999 interim fatigue curve.

\begin{tabular}{|c|c|c|c|c|c|}
\hline Load pair & $S_{\text {alt }}$ & $S_{\text {alt }}$ (adjusted) & $\mathrm{N}$ & $\mathbf{n}$ & $\mathbf{u}$ \\
\hline \multirow[t]{2}{*}{ All } & 30.00 & 33.33 & 1032 & 455 & 0.441 \\
\hline & & & & CUF & 0.441 \\
\hline
\end{tabular}

Table 5-139. CUF results for core spray nozzle safe end using NUREG/CR-5999 interim fatigue curve.

\begin{tabular}{|c|c|c|c|c|c|}
\hline Load pair & $S_{\text {alt }}$ & $S_{\text {alt }}($ adjusted) & $N$ & $\mathbf{n}$ & $\mathrm{u}$ \\
\hline \multirow[t]{2}{*}{ All } & 83.00 & 90.34 & 256 & 455 & 1.778 \\
\hline & & & & CUF & 1.778 \\
\hline
\end{tabular}


of cycles were provided by the licensee, so design basis cycles were used. Using these numbers of cycles, the CUF is 0.520 . If the plant is operated for 60 years, the CUF is 0.780 .

\subsubsection{NUREG/CR-5999 CUF for Core} Spray Nozzle Safe End with Conservative Assumptions Removed. As with many of the older analyses, the details needed to assess conservative assumptions were unavailable. The most obvious conservative assumption is to break the single load pair into additional pairs. Unfortunately, there were no calculations for the other load pairs in the analysis. Since $K_{e}$ was greater than 1.0 , the average of the $S_{m}$ values at the high and low temperatures could be used. On the other hand, the analyst used $n=0.5$ as opposed to $n=0.3$ in the current ASME Code ( $\mathrm{n}$ is a material parameter defined in Section 3). The net result was to increase $\mathrm{K}_{\mathrm{e}}$ from 1.25 to 1.30 . This causes an increase in stress and a lower value of N. For 455 cycles, the CUF is 1.953 . For the expected 537 cycles, the CUF is 2.305 (Table 5-140). If the plant is operated for 60 years, the CUF is 3.458. Potential actions for reducing the CUF are listed in Table 5-141.

Table 5-140. CUF results for core spray nozzle safe end using NUREG/CR-5999 interim fatigue curve and anticipated cycles.

\begin{tabular}{lccccc}
\hline Load pair & $\mathrm{S}_{\text {alt }}$ & $\mathrm{S}_{\text {alt }}$ (adjusted) & $\mathrm{N}$ & $\mathrm{n}$ & $\mathrm{u}$ \\
\hline All & 86.32 & 93.95 & 233 & 537 & 2.305 \\
\cline { 4 - 5 } & & & & CUF & 2.305 \\
\hline
\end{tabular}

Table 5-141. Potential for elimination of conservative assumptions to reduce CUF for core spray nozzle safe end using NUREG/CR-5999 interim fatigue curve.

\begin{tabular}{|c|c|c|c|}
\hline $\begin{array}{l}\text { Assumption } \\
\text { (Section 4.3) }\end{array}$ & $\begin{array}{l}\text { Potential } \\
\text { for use }\end{array}$ & Used & Comments \\
\hline Correct CUF calculation & No & No & Analysis appears to be correct \\
\hline Detailed load pairs & Yes & No & $\begin{array}{l}\text { Insufficient information to break out individual load } \\
\text { pairs }\end{array}$ \\
\hline SCF/FSRF & No & No & SCF not used \\
\hline$S_{m}$ value & Yes & Yes & Average $S_{m}$ used \\
\hline $\begin{array}{l}\text { Material property } \\
\text { changes }\end{array}$ & Yes & Yes & 1965 edition used \\
\hline Fatigue curve $E$ value & Yes & Yes & $\begin{array}{l}\text { Adjustment was made when using NUREG/CR-5999 } \\
\text { curves }\end{array}$ \\
\hline Code analysis changes & Yes & Yes & 1965 edition used \\
\hline Actual cycles & Yes & Yes & Adjustment was made for projected cycles \\
\hline High temperature rates & Yes & No & Actual cooldown rates probably less than design \\
\hline Detailed stress modeling & Yes & No & Interaction analysis used \\
\hline $\begin{array}{l}\text { Conservative thermal } \\
\text { parameters }\end{array}$ & Yes & No & Insufficient information \\
\hline Time phasing of stresses & No & No & Probably little benefit for nozzle \\
\hline Number of OBEs & No & No & OBE cycles not significant contributor to CUF \\
\hline CC N-411 damping & No & No & Dynamic loads not significant contributor to CUF \\
\hline Number of hydrotests & No & No & Hydrotests did not contribute to CUF \\
\hline Fatigue monitoring & Yes & No & Actual transients probably less severe than design \\
\hline Plastic analysis & Yes & No & Elastic plastic finite element analysis could be used \\
\hline
\end{tabular}




\subsubsection{CUF Based on Revised Interim} Fatigue Curves. The licensee's calculations did not contain sufficient information to determine the strain rates, but the single transient considered was a thermal shock, so a 30 s time to maximum stress was assumed. The strain rate was $0.010 \% / \mathrm{s}$. The CUF results are shown in Table 5-142. The extrapolated CUF for 60 years is 2.658 .

5.7.5 RHR Return Line Piping. The residual heat removal (RHR) piping system was initially designed and analyzed per the criteria of USAS B31.1-1967, rather than ASME Code Class 1 criteria. Since the piping system did not have any specific fatigue analyses performed, the INEL performed a Class 1 analyses using the 1992 Code edition through 1992 addenda. The equivalent Class 1 portion of the RHR return line piping branches into the reactor recirculation piping at the RHR return tee. This tee was considered part of the reactor recirculation piping as discussed in Section 5.7.3. However, the RHR piping was incorporated into the same analysis model generated to analyze the reactor recirculation piping. The highest CUF value calculated on the RHR return line piping (other than the tee) was at a tapered transition to a valve.

\subsubsection{Calculation of Representative} Design CUF. As previously discussed in Section 5.7.3, efforts were made to determine representative loadings. For the RHR return line analysis, the component with the highest CUF was the butt weld attaching the RHR piping to the first isolation valve. Rather than assuming a large step change in wall thicknesses between the piping and the valve body, drawings of the specific isolation valves in the system were obtained from the licensee. This permitted a more accurate determination of the $T_{a}-T_{b}$ effects at this tapered transition location. However, the stress results exceeded current ASME Code criteria. The CUF was determined to be 0.032 based on representative design basis cycles. Time phasing of the thermal gradient stress terms was used for the fatigue analysis.

The NB-3653.7 thermal stress ratchet check was exceeded for six load pairs. All of the load pairs that exceed the thermal stress ratchet criteria include the RHR shutdown cooling transient. The other loadings making up the load pairs involved transients with pressures at or above normal operating pressure. Five of the load pairs exceeded the thermal stress ratchet criteria by about 3 to $14 \%$ over the allowable values. The stress ratchet criterion for the five load pairs could probably be satisfied using an NB-3200 analysis. The sixth load pair involves the RHR shutdown cooling transient paired with a scram at full power consisting of a composite loss of feedwater pumps, loss of auxiliary power, and turbine generator trip without bypass. The stress ratchet criterion was exceeded by almost $58 \%$ for this load pair. However, for the latter transient, the pressure increases to the relief valve setpoint for a very short time, during which the $\Delta T_{1}$ term is negligible. The reason the stress ratchet criterion was exceeded by so large a margin was that the pressure increase significantly reduces the allowable $\Delta T_{1}$ range. The $\Delta T_{1}$ range comes solely from the former transient, when the pressure is much lower. Therefore, the $\Delta T_{1}$ range and the high pressure are not coincident loadings. NB-3200 analysis procedures are more precise than the NB-3600 analysis rules. An NB-3200 analysis requires that thermal stress ratchet (NB-3222.5) be evaluated by calculating the maximum cyclic thermal stress in a shell loaded by a steady state internal pressure. The NB-3200 evaluation clearly implies a pressure loading coincident with the thermal stress. Therefore, an NB-3200 analysis technique would demonstrate ASME Code compliance for this load pair exceeding the NB-3600 thermal stress ratchet check.

Table 5-142. CUF results for core spray nozzle safe end using revised interim fatigue curve and anticipated cycles.

\begin{tabular}{|c|c|c|c|c|c|c|}
\hline Load pair & Load pair & $S_{\text {alt }}$ & $\mathrm{S}_{\text {alt }}$ (adjusted) & $\mathrm{N}$ & $\mathbf{n}$ & $\mathbf{u}$ \\
\hline \multirow[t]{2}{*}{ All } & 86.32 & 86.32 & 93.95 & 303 & 537 & 1.772 \\
\hline & & & & & CUF & 1.772 \\
\hline
\end{tabular}


An EPRI study (Deardorff and Rosario, 1993) reported a high CUF at the valve-to-pipe weld on the RHR return line for another older vintage BWR. A design CUF of 1.56 was calculated at this tapered transition (assumed to be an ASME Code NB-4250 transition by both EPRI and the INEL), but stated that a later analysis showed a CUF less than 1.0. The INEL CUF was 0.032 with time phasing of the stresses and 0.220 without time phasing. The thermal gradients used in the two analyses are similar. One major difference was that EPRI used 318 shutdown cooling cycles for the BWR plant studied, whereas we used 120 cycles for the design basis. Another difference, other than the system geometry, was that the EPRI return line piping was 16-in. Schedule 80 , whereas the INEL analysis incorporated 24-in. Schedule 80 pipe.

A calculation was also performed using the expected numbers of cycles in Table 5-128. The numbers of heatups, cooldowns, and scrams increased, whereas the numbers of hydrotests and power reductions decreased from the design basis numbers. The resulting CUF is 0.045 . The transient that was the major contributor to the CUF is the RHR shutdown cooling transient, for which the anticipated cycles are greater than the design basis number.

\subsubsection{CUF Results Using NUREG/} CR-5999 Interim Fatigue Curve. The CUF using the NUREG/CR-5999 interim fatigue curve is shown in Table 5-143. The first load pair, initiation of RHR shutdown cooling, contributes most of the CUF. Application of the NUREG/CR-5999 interim fatigue curve increased the CUF by a factor of 11.44 over the design basis number.

\subsubsection{NUREG/CR-5999 CUF Based on} Anticipated Cycles. The anticipated startup/ shutdown transients are 170 , so the CUF increases to 0.523 . If the plant is operated for 60 years, the CUF is 0.785 .

\subsubsection{CUF Based on Revised Interim}

Fatigue Curves. The licensee's calculations did not contain sufficient information to determine the strain rates, but since the CUF is low, the worst-case strain rate $(0.001 \% / \mathrm{s})$ can be used. The CUF results using anticipated cycles are shown in Table 5-144. If the plant is operated for 60 years, the CUF is 0.717 .

5.7.6 Feedwater Piping. The feedwater piping system was initially designed and analyzed to the criteria of USAS B31.1-1967, rather than ASME Code Class 1 criteria. Since the piping system did not have any specific fatigue analyses performed, the INEL performed analyses to predict a design CUF using transient data developed for a more recent (BWR/6) plant having a Class 1 analysis basis. However, once the actual details of the BWR/4 piping were obtained, we recognized that the older and newer vintage BWR plant piping system was not as similar as initially believed. In the BWR/6 feedwater line (Loop B),

Table 5-143. CUF results for RHR piping system using NUREG/CR-5999 interim fatigue curve.

\begin{tabular}{ccrrr}
\hline \multicolumn{1}{c}{ Load pair } & $\mathrm{S}_{\text {alt }}$ & $\mathrm{N}$ & $\mathrm{n}$ & $\mathrm{u}$ \\
\hline RHR shutdown cooling A/B & 81.78 & 326 & 119 & 0.365 \\
Composite loss G/blowdown & 37.70 & 13941 & 8 & 0.001 \\
\cline { 3 - 5 } & & & $\mathrm{CUF}$ & 0.366 \\
\hline
\end{tabular}

Table 5-144. CUF results for RHR piping system using revised interim fatigue curves.

\begin{tabular}{lcrrr}
\hline \multicolumn{1}{c}{ Load pair } & $\mathrm{S}_{\text {alt }}$ & $\mathrm{N}$ & $\mathrm{n}$ & $\mathrm{u}$ \\
\hline RHR shutdown cooling A/B & 81.78 & 356 & 170 & 0.478 \\
Composite loss G/blowdown & 37.70 & 76379 & 8 & 0.000 \\
& & & $\mathrm{CUF}$ & 0.478 \\
\hline
\end{tabular}


the reactor core isolation cooling (RCIC) line attaches to the feedwater piping in the Class 2 portion of the piping (upstream of the second isolation valve), whereas in the BWR/4 feedwater line, the RCIC piping attaches downstream of the second isolation valve in what would now be classified as Class 1 piping. This difference alters not only the geometry, but also the operational transients which the Class 1 portion of the piping system experiences. The BWR/4 computer model generated for the feedwater system is shown in Figure 5-9.

\subsubsection{Calculation of Representative} Design CUF. Considerable efforts were made in order to acquire additional information so that accurate loadings could be applied to the piping model. Since the existing analysis used B31.1 criteria, detailed transient information was not available for all loadings. Therefore, design information was obtained from another BWR/4 plant that analyzed its feedwater piping to Class 1 criteria, as well as the BWR/6 plant discussed in Section 5.6. Comparing these transient data for the Class 1 analyses, we confirmed that the overall operating parameters and transients for the plants were similar. The numbers of cycles used to compute the design CUF and the pressure levels appeared to be typical BWR values. Operating temperatures were adjusted to more closely match the BWR/4. Little variation existed between the BWR/4 and the BWR/6 transients.

Therefore, we used the existing BWR/6 transient data as much as possible, including the thermal gradients, in the NB-3600 analysis. When the BWR/4 piping had the same size piping as the $\mathrm{BWR} / 6$, the BWR/ $6 \Delta \mathrm{Ts}$ were utilized. When the BWR/4 piping had a larger OD and a different wall thickness than the BWR/6 plant, the ratio of the squares of the wall thicknesses were multiplied by the BWR/ $6 \Delta$ Ts to determine the BWR/4 $\Delta$ Ts.

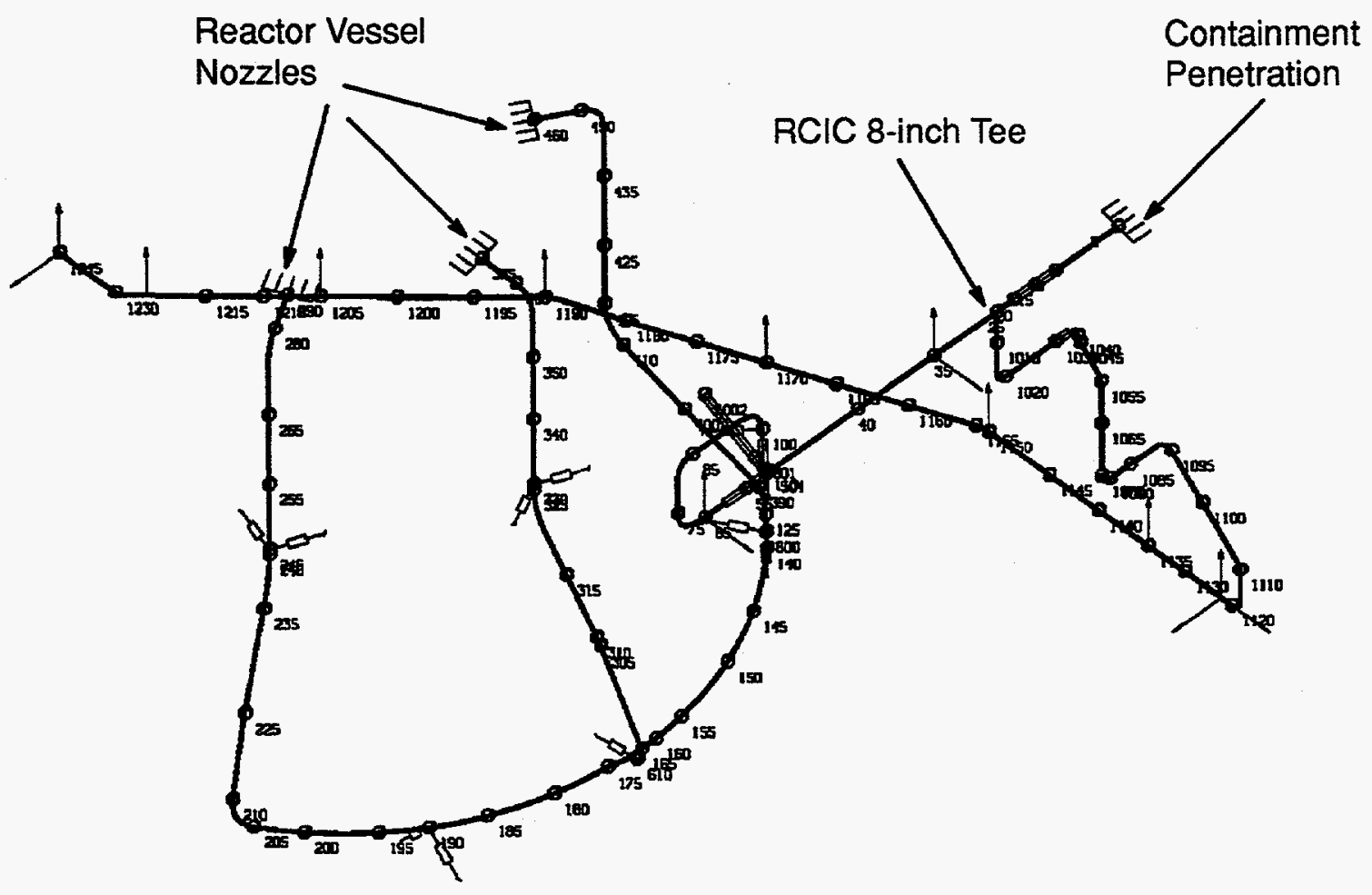

Figure 5-9. BWR/4 feedwater line with RCIC connection. 
Due to the BWR/6 versus BWR/4 piping changes, additional thermal transient data were developed to evaluate the effects of injecting RCIC/RWCU water into the feedwater piping. The RWCU line attaches to the RCIC line in close proximity to the eight-inch RCIC connection at the bottom of the feedwater line.

An ASME Code NB-3600 analysis was performed using the 1992 edition through 1992 addenda. The results indicated that the tee connecting the RCIC/RWCU line to the feedwater piping had the highest predicted CUF (0.427). This is a $20 \times 20 \times 8$ inch tee with a thermal sleeve. However, the predicted stress results exceeded current ASME Code criteria. At the RCIC/ RWCU tee, the calculated stress range from ASME Code NB-3650 Equation 13 slightly exceeded (by no more than $3.5 \%$ ) the $3 \mathrm{~S}_{\mathrm{m}}$ stress limit for three load pairs. The high stresses were due to large $T_{a}-T_{b}$ stress ranges involving RCIC and RWCU initiation. Based on our experience with the nozzles in the older vintage Westinghouse plant (Section 5.5), we believe that a more detailed NB-3200 analysis effort could demonstrate that this tee satisfies ASME Code criteria.

A calculation was also performed using the expected numbers of cycles in Table 5-128. The numbers of heatups, cooldowns, and scrams increased, whereas the numbers of hydrotests and power reductions decreased from the design basis numbers. The resulting CUF is 0.584 . The increase in the CUF from the greater numbers of heatups and cooldowns was offset in part by the decrease in the CUF from the reduced number of power reduction cycles.

\footnotetext{
5.7.6.2 NUREG/CR-5999 CUF Based on Design Calculation Stresses. The NUREG/ CR-5999 fatigue curve used for each load pair was based on the maximum temperature that was reported for each load pair. The temperature for all transients was $200^{\circ} \mathrm{C}$. The strain rate was calcu-
}

lated by dividing the alternating stress by the modulus of elasticity, multiplying by 100 to convert to percent, and dividing by the time to develop the maximum stress. Since the $\alpha_{a} T_{a}-\alpha_{b} T_{b}$ term was the major contributor to the alternating stress intensity range, the maximum stress took several minutes to develop; consequently, the saturated strain rate condition was appropriate for all load pairs. The effect of the NUREG/CR-5999 interim fatigue curves is shown in Table 5-145. The contributing cycles involve on-off feedwater, $\mathrm{RCIC}$, and RWCU operation. The high (increasing temperature) and low (decreasing temperature) load sets refer to various on-off feedwater transients that were enveloped in the licensee's analysis. No differentiation was made in the table between the various load sets. Only the first 14 transients, which contributed most of the CUF, are listed.

The results indicate that the CUF increased by a factor of 11.75 over the design basis number. The CUF exceeds the ASME Code limit of 1.0.

\subsubsection{NUREG/CR-5999 CUF with Con-} servative Assumptions Removed. The change to the CUF using the anticipated cycles is shown in Table 5-146. If the plant is operated for 60 years, the CUF is 10.470 . The changes that would probably reduce the CUF most significantly would be using a detailed finite element model, an NB-3200 analysis, and better definition of the transients. Other potential changes that could be used to reduce the CUF are shown in Table 5-147.

5.7.7 Results and Conclusions. We obtained the latest design basis fatigue calculations for three components on an older vintage General Electric plant, and calculated a design basis CUF for three other components. The design CUF obtained from the licensee's calculations for the location with the highest calculated CUF on each component was recomputed using the NUREG/CR-5999 interim fatigue curves. The results are summarized in Table 5-148. The 
Table 5-145. CUF results for feedwater piping using NUREG/CR-5999 interim fatigue curves.

\begin{tabular}{lcrrr}
\hline \multicolumn{1}{c}{ Load pair } & $\mathrm{S}_{\mathrm{alt}}(\mathrm{ksi})$ & $\mathrm{N}$ & $\mathrm{n}$ & $\mathrm{u}$ \\
\hline Low load set/RCIC initiation & 121.95 & 35 & 10 & 0.286 \\
Low load set/RCIC \& RWCU initiation & 73.10 & 109 & 8 & 0.073 \\
Low load set/RCIC \& RWCU initiation & 70.78 & 119 & 289 & 2.429 \\
Low load set/OBE & 54.46 & 249 & 50 & 0.201 \\
High load set/RCIC \& RWCU initiation & 51.82 & 294 & 203 & 0.690 \\
Low load set/null & 51.04 & 313 & 10 & 0.032 \\
High load set/null & 46.88 & 438 & 25 & 0.057 \\
High load set/null & 46.88 & 438 & 10 & 0.023 \\
Low load set/null & 46.56 & 450 & 70 & 0.156 \\
High load set A/high load set B & 46.12 & 468 & 19 & 0.041 \\
High load set/null & 45.98 & 473 & 5 & 0.011 \\
High load set/low load set & 45.82 & 480 & 11 & 0.023 \\
High load set/high load set & 45.31 & 502 & 10 & 0.020 \\
High load set/high load set & 42.25 & 660 & 180 & 0.273 \\
& 42.05 & 672 & 15 & 0.022 \\
& 41.87 & 684 & 4 & 0.006 \\
& 41.08 & 737 & 38 & 0.052 \\
& 41.08 & 737 & 32 & 0.043 \\
& 40.28 & 796 & 36 & 0.045 \\
& 39.82 & 832 & 15 & 0.018 \\
& 39.81 & 833 & 50 & 0.060 \\
& 38.06 & 993 & 15 & 0.015 \\
& 37.92 & 1007 & 111 & 0.110 \\
& 35.50 & 1304 & 233 & 0.179 \\
& 35.19 & 1347 & 94 & 0.070 \\
& 32.87 & 1677 & 15 & 0.009 \\
& 30.90 & 2099 & 111 & 0.053 \\
& 24.32 & 5355 & 15 & 0.003 \\
& 22.00 & 8784 & 111 & 0.013 \\
& 21.88 & 9039 & 30 & 0.003 \\
\hline & & & $\mathrm{CUF}$ & 5.016 \\
& & & &
\end{tabular}

increases in the magnitudes of the design CUFs are as follows:

Stainless Steel

$\begin{array}{lr}\text { Recirculation tee } & 7.31 \\ \text { Core spray nozzle safe end } & 9.77 \\ \text { RHR piping } & \underline{11.44} \\ & 9.51 \text { average }\end{array}$

Carbon/Low-alloy Steel

Reactor vessel shell/

lower head

64.47

Feedwater nozzle

14.08

Core spray nozzle

19.17

Feedwater piping

11.75

27.37 average 
Table 5-146. CUF results for feedwater piping using NUREG/CR-5999 interim fatigue curves based on anticipated cycles.

\begin{tabular}{lrrrc}
\hline \multicolumn{1}{c}{ Load pair } & $\mathrm{S}_{\text {alt }}(\mathrm{ksi})$ & \multicolumn{1}{c}{$\mathrm{N}$} & $\mathrm{n}$ & $\mathrm{u}$ \\
\hline Low load set/RCIC initiation & 121.95 & 35 & 10 & 0.286 \\
Low load set/RCIC \& RWCU initiation & 73.10 & 109 & 12 & 0.110 \\
Low load set/RCIC \& RWCU initiation & 70.78 & 119 & 423 & 3.555 \\
Low load set/OBE & 54.46 & 249 & 50 & 0.201 \\
High load set/RCIC \& RWCU initiation & 51.82 & 294 & 65 & 0.221 \\
Low load set/null & 51.04 & 313 & 10 & 0.032 \\
High load set/null & 46.88 & 438 & 32 & 0.073 \\
High load set/null & 46.88 & 438 & 10 & 0.023 \\
Low load set/null & 46.56 & 450 & 120 & 0.267 \\
High load set A/high load set B & 46.12 & 468 & 30 & 0.064 \\
High load set/low load set & 45.89 & 477 & 232 & 0.486 \\
High load set/high load set & 45.31 & 502 & 22 & 0.044 \\
High load set/high load set & 43.60 & 583 & 68 & 0.117 \\
High load set/RCIC initiation & 42.58 & 640 & 50 & 0.078 \\
High load set/high load set & 42.25 & 660 & 284 & 0.430 \\
& 42.05 & 672 & 22 & 0.033 \\
& 41.08 & 737 & 352 & 0.478 \\
& 39.82 & 832 & 22 & 0.026 \\
& 38.53 & 947 & 105 & 0.111 \\
& 38.06 & 993 & 19 & 0.019 \\
& 37.69 & 1032 & 22 & 0.021 \\
& 35.19 & 1347 & 284 & 0.211 \\
& 32.87 & 1677 & 22 & 0.013 \\
& 31.13 & 2042 & 3 & 0.001 \\
& 30.99 & 2076 & 155 & 0.075 \\
& 24.88 & 4859 & 3 & 0.001 \\
& 24.32 & 5327 & 22 & 0.004 \\
\hline & & & $\mathrm{CUF}$ & 6.980 \\
\hline
\end{tabular}

Conservative assumptions were identified, and where justifiable, the design CUFs were recomputed with conservative assumptions removed. The 40-year CUFs were multiplied by 1.5 to determine a 60-year CUF, as shown in Table 5-148.

CUFs for the carbon/low-alloy steel portions of the feedwater nozzle and piping and the core spray nozzle were computed using the strain rate during the increasing portion of the tensile stress cycle. For these three components, the average increase in CUF was 15.00, whereas the average for stainless steel was 9.51 .

We were not able to show ASME Code design stress limits (for example, thermal stress ratchet or thermal expansion) were met using NB-3600 analysis techniques for the three components analyzed by the INEL staff (the RHR return line tapered transition weld and the RHR/recirculation line and feedwater/RCIC line tees). However, it is believed that ASME Code compliance could be demonstrated using NB-3200 techniques. The CUFs for these three components were less than 1.0 using representative design basis transients and the ASME Code fatigue curves.

The CUFs calculated using the NUREG/ CR-5999 interim fatigue curves exceeded 1.0 for 40 years for four components. It would be difficult to reduce the CUF calculated using the interim fatigue curves below 1.0 for these components without better definition of transients and more detailed thermal and stress models. 
Table 5-147. Potential for elimination of conservative assumptions to reduce design CUF for feedwater piping.

\begin{tabular}{|c|c|c|c|}
\hline $\begin{array}{l}\text { Assumption } \\
\text { (Section 4.3) }\end{array}$ & $\begin{array}{l}\text { Potential } \\
\text { for use }\end{array}$ & Used & Comments \\
\hline Correct CUF calculation & NA & NA & Analysis appears to be correct \\
\hline Detailed load pairs & NA & NA & Detailed load pairs were used \\
\hline SCF/FSRF & NA & NA & Stress indices based on information received \\
\hline$S_{\mathrm{m}}$ value & NA & NA & 1992 Code used \\
\hline $\begin{array}{l}\text { Material property } \\
\text { changes }\end{array}$ & NA & NA & 1992 Code used \\
\hline Fatigue curve $\mathrm{E}$ value & NA & NA & 1992 Code used \\
\hline Code analysis changes & NA & NA & 1992 Code used \\
\hline Actual cycles & Yes & Yes & Verification of transient data and cycles must be made \\
\hline High temperature rates & Yes & No & Verification of transient data and cycles must be made \\
\hline Detailed stress modeling & Yes & No & $\begin{array}{l}\text { NB- } 3200 \text { analysis techniques could be used to further } \\
\text { reduce conservatisms }\end{array}$ \\
\hline $\begin{array}{l}\text { Conservative thermal } \\
\text { parameters }\end{array}$ & Yes & No & Used grouped design parameters from BWR/6 analysis \\
\hline Time phasing of stresses & Yes & Yes & $\begin{array}{l}\text { Highest moment and thermal stresses did not occur } \\
\text { simultaneously }\end{array}$ \\
\hline $\begin{array}{l}\text { Number of OBEs and } \\
\text { other dynamic events }\end{array}$ & Yes & No & Seismic events are not a significant contributor to CUF \\
\hline CC N-411 damping & Yes & $\mathrm{No}^{\mathrm{a}}$ & Dynamic loads are not a significant contributor to CUF \\
\hline Number of hydrotests & No & No & Hydrotests did not contribute to CUF \\
\hline Fatigue monitoring & Yes & No & Actual transients probably less severe than design \\
\hline Plastic analysis & Yes & No & Elastic plastic finite element analysis could be used \\
\hline
\end{tabular}

a. A Housner spectrum was used in the licensee's analysis. A reanalysis of the building using a site-specific spectrum is needed for CC N-411 application. 
Table 5-148. Summary of older vintage General Electric plant CUFs.

\begin{tabular}{|c|c|c|c|c|c|c|c|c|c|}
\hline \multirow[b]{2}{*}{ Component } & \multirow[b]{2}{*}{ Location } & \multirow[b]{2}{*}{ Material } & \multirow[b]{2}{*}{$\begin{array}{l}\text { Design } \\
\text { CUF }\end{array}$} & \multicolumn{4}{|c|}{ NUREG/CR-5999 CUF } & \multicolumn{2}{|c|}{$\begin{array}{l}\text { Revised curve } \\
\text { (stainless steel) }\end{array}$} \\
\hline & & & & $\begin{array}{c}\text { Based on } \\
\text { design } \\
\text { stresses }\end{array}$ & $\begin{array}{l}\text { Conservative } \\
\text { assumptions } \\
\text { removed }\end{array}$ & $\begin{array}{l}\text { Based on } \\
\text { expected } \\
\text { cycles }\end{array}$ & $\begin{array}{c}\text { Extrapolated } \\
\text { to } 60 \text { years }\end{array}$ & 40 years & 60 years \\
\hline Reactor vessel & $\begin{array}{l}\text { At lower head to } \\
\text { shell transition }\end{array}$ & $\mathrm{SA}-302^{\mathrm{a}}$ & 0.032 & 2.063 & 0.079 & - & 0.119 & - & - \\
\hline $\begin{array}{l}\text { Feedwater } \\
\text { nozzle }\end{array}$ & Bore & $\mathrm{SA}-508^{\mathrm{a}}$ & 0.700 & 9.859 & - & 3.168 & 4.752 & 一 & - \\
\hline $\begin{array}{l}\text { Recirculation } \\
\text { system }^{c}\end{array}$ & $\begin{array}{l}\text { RHR return line } \\
\text { tee }\end{array}$ & $\begin{array}{l}\text { SA-358, Type } 304 \\
\text { Class } 1^{\text {b }}\end{array}$ & $\begin{array}{l}0.397 \\
0.526^{d}\end{array}$ & 2.901 & - & 3.898 & 5.847 & 3.256 & 4.884 \\
\hline \multirow{2}{*}{$\begin{array}{l}\text { Core spray } \\
\text { system }\end{array}$} & Nozzle & SA-302, Grade Ba & 0.023 & 0.441 & - & 0.520 & 0.780 & - & - \\
\hline & Safe end & SA-376, Type $316^{b}$ & 0.182 & 1.778 & - & 2.305 & 3.458 & 1.772 & 2.658 \\
\hline $\begin{array}{l}\text { Residual heat } \\
\text { removal line }\end{array}$ & $\begin{array}{l}\text { Tapered } \\
\text { transition }\end{array}$ & $\begin{array}{l}\text { SA-358, Type } 304 \\
\text { Class } 1^{\text {b }}\end{array}$ & $\begin{array}{l}0.032 \\
0.045^{d}\end{array}$ & 0.366 & - & 0.523 & 0.785 & 0.478 & 0.717 \\
\hline Feedwater line ${ }^{c}$ & RCIC tee & SA-106 Grade Ba & $\begin{array}{l}0.427 \\
0.584^{d}\end{array}$ & 5.016 & - & 6.980 & 10.470 & - & - \\
\hline
\end{tabular}

a. Carbon or low-alloy steel.

b. Stainless steel.

c. Estimated by INEL using ASME Code NB-3600 techniques. CUF calculation not required by licensing basis.

d. CUFs based on representative design basis and anticipated numbers of cycles, respectively. 


\section{CONCLUSIONS}

The 40-year CUFs calculated using the NUREG/CR-5999 interim fatigue curves for the seven plants evaluated in this study are summarized in Table 6-1. The numbers are after conservative assumtions have been removed and are based on anticipated cycles. Commentary to the tables are presented in Sections 6.1 through 6.3. The conclusions from the study are divided into several parts: applications to PWR plants, applications to BWR plants, comparison of the CUFs of plants designed to B31.1 to plants designed to the ASME Code, the revised interim fatigue curves for stainless steel, and the overall conclusion.

\subsection{Applications to PWR Plants}

1. The anticipated number of cycles are less than the design basis number of cycles for all key transients, notably heatup and cooldown transients and power changes. (For example, the design analyses accounted for load following whereas the plants are being operated as base-loaded.)

2. After removing conservative assumptions and using anticipated numbers of cycles, the CUFs for all the reactor vessel components (shell and lower head, inlet and outlet nozzles) were less than 1.0 for a 40 -year life. In two cases, an Alloy 600 instrumentation nozzle and a lower head core support block, the CUFs (1.113 and 1.337, respectively) were slightly above 1.0 for 60 years.

3. The CUFs for the stainless steel surge lines of all five plants exceeded 1.0 for 40 years. The most significant transient for surge lines is thermal stratification which was not accounted for in the original design basis. The surge lines were reanalyzed for fatigue in response to NRC Bulletin 88-11. Fatigue monitoring was used to determine temperature differences and numbers of cycles during times of thermal stratification. More refined analyses to later (circa 1986) edi- tions of the ASME Code, including removal of conservative assumptions, were used by the licensees to reduce the CUF below 1.0 using ASME Code fatigue curves. However, there remain conservative assumptions that could be used to further reduce the CUF. Four of the five analyses used NB-3600 piping methods. A detailed finite analysis of the regions with high CUFs, and, if needed, plastic analyses, could be used to reduce the CUF. The $\mathrm{B} \& W$ plant's analysis already has incorporated an NB-3200 plastic analysis. Probably the best way to reduce the CUF is more precise monitoring of the individual surge lines. The stratification transients used in the analyses are mainly based on owners group submittals that conservatively define a set of enveloping stratification transients that will apply to several plants.

4. After removing conservative assumptions and using anticipated numbers of cycles, the 40-year CUFs for the stainless steel charging and safety injection nozzles were below 1.0 for 7 of the 10 cases. The other three (two charging and one safety injection nozzle) had CUFs ranging from 1.3 to 4.9 for a 40 year life. The numbers of key transients for these two components (for example, loss of letdown and loss of charging) are not counted on a regular basis as are transient cycles important to overall plant operation (for example, heatups and reactor trips); consequently, it was difficult to estimate anticipated numbers of cycles. It appears that the number and severity of these key cycles are conservative and further studies based on plant operation could be used to reduce the CUF. Based on our results of the CUFs for charging and safety injection nozzles of an older vintage plant using the 1992 ASME Code edition NB-3600 and NB-3200 methods, it appears that by using NB-3200 methods contained in the 1992 ASME Code, the CUFs for all nozzles could be reduced than 1.0 . 
Table 6-1. Summary of component CUFs for 40-year life using NUREG/CR-5999 interim fatigue curves.

\begin{tabular}{|c|c|c|c|c|c|c|c|c|}
\hline \multirow[b]{2}{*}{ Component } & \multicolumn{2}{|c|}{$\mathrm{CE}$} & \multirow[t]{2}{*}{$\mathrm{B} \& W$} & \multicolumn{2}{|c|}{ Westinghouse } & \multirow{2}{*}{ Component } & \multicolumn{2}{|c|}{ General Electric } \\
\hline & New & Old & & New & Old & & New & Old \\
\hline RV Shell/Head & 0.014 & 0.013 & 0.742 & 0.018 & 0.891 & RV Shell/Head & 0.628 & 0.079 \\
\hline RV Nozzle & 0.475 & 0.554 & 0.469 & 0.658 & 0.496 & FW Nozzle & 1.881 & 3.168 \\
\hline Surge Line & $3.476^{\mathrm{a}}$ & $1.345^{\mathrm{a}}$ & $2.005^{a, b}$ & $2.458^{\mathrm{a}}$ & $5.860^{\mathrm{a}}$ & Recirc Line & 0.830 & 3.898 \\
\hline Charging Nozzle & 0.774 & 0.666 & $1.263^{c}$ & $4.859^{d}$ & 0.349 & CS Nozzle & 0.436 & 2.305 \\
\hline SI Nozzle & 0.457 & 0.414 & $0.632^{\mathrm{e}}$ & $1.511^{\mathrm{f}}$ & 0.410 & RHR line & $11.260^{\mathrm{a}}$ & 0.523 \\
\hline RHR line & $0.502^{g}$ & $0.139 \mathrm{~g}$ & $0.610^{\mathrm{h}}$ & $2.371^{\mathrm{a}, \mathrm{i}}$ & 0.286 & Feedwater Line & 3.688 & 6.980 \\
\hline
\end{tabular}

a. Includes thermal stratification transients.

b. Detailed analysis unavailable. Estimate based on B\&W design basis CUF for this plant and change in other four PWR (Westinghouse and Combustion Engineering) surge line CUFs.

c. High pressure injection/makeup nozzle.

d. NB-3600 analysis. Other PWR plants used NB-3200 analysis for charging nozzle.

e. Core flood nozzle.

f. Boron injection tank nozzle. No thermal sleeve. NB-3600 analysis.

g. Shutdown cooling line.

h. Decay heat removal line.

i. Only PWR plant to include postulated thermal stratification transients for RHR line. 
5. The 40-year CUFs for RHR lines were less than 1.0 for four of the five plants. The fifth plant included cycles for thermal stratification in the RHR line, which were not considered for the other four plants. Excluding thermal stratification, the CUF for the fifth plant would have been comparable to the other four plants. The analysis of the fifth plant used NB-3600 piping methods. A detailed finite analysis using NB-3200 methods, and, if needed, a plastic analysis, could be used to reduce the CUF. Probably the best way to reduce the CUF is fatigue monitoring of the RHR line. The stratification transients may conservatively define a set of enveloping stratification transients or valve leakage.

6. For carbon and low-alloy steel components, the NUREG/CR-5999 interim fatigue curves increased the CUF by an average factor of 2.2 times the design basis CUF. This was before any adjustments based on conservative assumptions removal and anticipated cycles were made. For stainless steel and Alloy 600 , the average multiplication factor is 9.2.

\subsection{Applications to BWR Plants}

1. The anticipated number of cycles exceed the design basis numbers of cycles for some transients, notably startup and shutdowns. However, the anticipated number of cycles is less than the design basis number of cycles for other transients such as power changes (the design analyses accounted for load following whereas the plants are being operated as base-loaded.)

2. After removing conservative assumptions and using anticipated numbers of cycles, the CUFs for the reactor vessel shell and lower head were less than 1.0 for 40 - and 60 -year lives. The core spray nozzle CUF was less than 1.0 for the 40 - and 60-year lives of the newer vintage BWR plant, but was greater than 1.0 (2.305) for the safe end of the older vintage BWR plant for 40 years. Although
CUFs for the recirculation nozzles were not calculated using NUREG/CR-5999, the design basis CUFs were 0.002 for the newer vintage plant and 0.300 for the older vintage plant (using very conservative lumped transients). No problem would be expected in reducing the CUFs below 1.0 .

3. The 40-year CUF for the feedwater nozzle exceeded 1.0 for both plants. The CUF range was from about 1.9 to 3.2. (The CUF for the thermal sleeve on the BWR/6 plant was about 5). Although we incorporated transient definitions, anticipated cycles, strain rates, and temperatures according to the information available, there remains a great deal of uncertainty concerning these values. There also remain conservative assumptions that could be used to reduce the CUFs. Two studies based on fatigue monitoring of BWR feedwater nozzles in other plants showed that the monitored CUF was a factor of 30 to 50 less than the design basis CUF.

4. The 40-year CUF for the recirculation system is less than 1.0 for the newer vintage BWR, and slightly exceeds 1.0 for 60 years (1.245). The CUF for the older vintage BWR is 3.898. Both CUFs were calculated using NB-3600 methods, and were for tees. Based on our experience with comparing NB-3200 and NB-3600 methods for nozzles, we believe that an NB-3200 analysis and fatigue monitoring would reduce the CUF below 1.0 .

5. The CUF for the feedwater lines are 3.688 and 6.980 (at tee locations). The CUF for the tee was calculated using NB-3600 methods. Based on our experience with comparing NB-3200 and NB-3600 methods for nozzles, we believe that an NB-3200 analysis and fatigue monitoring would reduce the CUFs below 1.0.

6. The CUF for the BWR/6 RHR line is $\mathbf{1 1 . 2 6}$ in a straight run of piping. All transients that contributed to the CUF involved thermal stratification. The analysis used NB-3600 
piping methods. A detailed finite analysis using NB-3200 methods, and, if needed, a plastic analysis, could be used to reduce the CUF. Probably the best way to reduce the CUF is more precise monitoring of the RHR line. The stratification transients may conservatively define a set of enveloping stratification transients.

\subsection{CUF Evaluations for Piping Components Designed to the B31.1 Piping Code}

1. The design of PWR components and the transients to which they are subjected to are similar for older and newer vintage plants. An exception is the Westinghouse 3- and 4-loop plants that we studied, which had different safety injection piping configurations. Consequently, we reviewed transients from both the newer vintage Westinghouse and the Combustion Engineering plants to ensure that the transients we used were representative for the older vintage Westinghouse plant.

The design of some of the BWR systems were not similar for the older vintage (BWR/4) and newer vintage (BWR/6) plants that we reviewed. Several key locations of hot and cold coolant mixing, which on the BWR/4 plant are on piping that would be considered Class 1 today, are included in the Class 2 portions of the BWR/6 piping. We reviewed transients from both a BWR $/ 6$ and another BWR/4 plant to ensure that the transients we used were representative for the older vintage BWR plant.

2. While we did not perform additional fatigue evaluations of PWR surge lines because the licensees had already analyzed these lines for fatigue in response to NRC Bulletin $88-11$, the results of the fatigue evaluations and CUFs for older and newer vintage plants appear comparable.
3. The charging and safety injection nozzles for one older vintage PWR were analyzed using detailed finite element models (both contained thermal sleeves). The CUF using both the ASME Code and NUREG/ CR-5999 curves were less than 1.0.

4. The design basis CUFs for two older vintage PWR RHR lines that we analyzed, including representative transients from other PWRs, were low and comparable to the other PWRs (not including thermal stratification effects).

5. The design basis CUFs for the older vintage BWR plant recirculation, RHR, and feedwater lines that we analyzed, including representative transients from other BWRs, were less than 1.0. The 40-year CUFs using the NUREG/CR-5999 curves were above 1.0 for the recirculation and feedwater lines. The comparable CUFs were above 1.0 for the newer vintage BWR, also, but only about half those computed for the older vintage BWR.

6. The older vintage plants' piping typically has thicker walls than do newer vintage plants. This causes higher thermal stresses in the older vintage plants' piping. Thermal stresses were found to be the major type of stress contributor to the CUF. Some stress indices are a function of the pipe diameter and thickness, but this is expected to have only a minor effect on the CUF.

\subsection{Revised Interim Fatigue Curves for Stainless Steel}

Subsequent to the issue of NUREG/CR-5999, Argonne National Laboratory developed a bestestimate $\mathrm{S}-\mathrm{N}$ equation for stainless steel in air and water environments. The fatigue life is dependent on both the applied strain and the strain rate for stainless steels other than Type $316 \mathrm{NG}$ in a water environment. The equation was converted to ASME Code-type curves by applying factors of 1.5 on stress or 20 on cycles, whichever is less. The CUFs using the revised curves were reduced by an average of about $20 \%$ from the 
CUFs computed using the NUREG/CR-5999 curve. Application of the revised interim curves reduced the CUF for the newer vintage Combustion Engineering plant charging nozzle safe end to below 1.0 for 60 years; reduced the CUF for the older vintage Combustion Engineering plant surge line to below 1.0 for both 40 and 60 years; reduced the $B \& W$ plant lower head penetration weld CUF to below 1.0 for 60 years; and reduced the $\mathrm{B} \& W$ plant makeup/high pressure injection nozzle CUF to slightly above $1.0(1.051)$ for 40 years.

\subsection{Overall Conclusion}

We were able to show that by removing conservative assumptions and using anticipated numbers of cycles, the CUF could be reduced to below 1.0 for most components using the NUREG/CR-5999 interim fatigue curves, both for older and newer vintage plants. Representative CUFs for components on older vintage plants designed to the B31.1 piping code, for which no fatigue analyses were required, were determined to be less than 1.0 using the current ASME Code.

For components which we were not able to reduce the CUF below 1.0 using the NUREG/ CR-5999 interim fatigue curves, several additional steps that could be taken to further reduce the CUF were listed. The two major remaining steps mentioned were (1) more detailed finite ele- ment analyses or (2) fatigue monitoring of the transients. Whereas using ASME Code NB-3200 versus NB- 3600 analysis methods will assist with regions of axial thermal gradients, we did not find that the CUF could be reduced when the majority of the stress was caused by radial thermal gradients. A problem with NB-3200 analyses is that minimal guidance is provided by the ASME Code regarding fatigue strength reduction factors for welds. Analysts typically do not apply fatigue strength reduction factors for welds on nozzles made in the shop. For field welds, the NB-3600 stress indices can be used, but they may be too conservative. A plastic analysis in which the strains are computed, rather than using the $\mathrm{K}_{\mathrm{e}}$ factor to adjust the elastic stresses, will lower the CUF.

The best method to lower the CUF for the few worst locations appears to be fatigue monitoring. For most of the cases where the CUF exceeded 1.0 , neither actual numbers of cycles that the plant is experiencing nor the magnitude of temperature differences or thermal shocks were known. Therefore, worst-case design assumptions were used. By using realistic numbers of cycles and severity of transients, we believe that the CUF could be reduced sufficiently without resorting to more detailed analysis methods. However, in some cases, for example where thermal stratification exists, a combination of fatigue monitoring and more refined analyses may be needed. 


\section{REFERENCES}

American Society of Mechanical Engineers, 1992, "Boiler \& Pressure Vessel Code," Section III, Division I, 1992 edition.

American Society of Mechanical Engineers, 1969, "USA Standard Code for Pressure Piping, Nuclear Power Piping," USAS B31.7, 1969 edition.

American Society of Mechanical Engineers, 1967, "USA Standard Code for Pressure Piping, Power Piping," USAS B31.1, 1967 edition.

American Society of Mechanical Engineers, 1963, Boiler and Pressure Vessel Code, Section III, Nuclear Vessels, 1963 edition.

Chopra, O. K. (ANL), 1994, letter to C. Hrabel (NRC), "Monthly Business Letter Report for program GI-78,Statistical Analysis of Fatigue Data," October 19.

Cooper, W. E., 1992, "The Initial Scope and Intent of the Section III Fatigue Design Procedures," Pressure Vessel Research Committee Workshop on Environmental Effects on Fatigue Performance, Clearwater Beach, FL, January 20, 1992.

Deardorff, A. F., and D. Rosario, 1993, Comparison of Piping Designed to ANSI B31.1 and ASME Section III, Class 1, TR-102901, Electric Power Research Institute.

Deardorff, A. F., and J. K. Smith, 1994, Evaluations of Conservatisms and Environmental Effects in ASME Code Section III, Class 1 Fatigue Analysis, SAND-94-0187, UC-523, Sandia National Laboratories.

Harvey, J. E., 1980, Pressure Component Construction, Van Nostrand Reinhold Company, New York, NY.

Jaske, C. E. and O'Donnell, W. J., 1977, "Fatigue Design Criteria for Pressure Vessel Alloys," Journal of Pressure Vessel Technology, November 1977, pp. 584-592.

Kooistra, L. F. E., E. A. Lange, and A. C. Pickett, 1961, "Full Size Pressure Vessel Testing and Its Approach to Fatigue," ASME Journal of Engineering for Power 86, 4, pp. 419-428.

Majumdar, S., Chopra, O. K., and Shack, W. J., 1993, Interim Fatigue Design Curves for Carbon, Low-Alloy, and Austenitic Stainless Steels in LWR Environments, NUREG/CR-5999.

Manjoine, M. J., and Tome, R. E., 1983, "Proposed Design Criteria for High Cycle Fatigue of Austenitic Stainless Steel," ASME Pressure Vessel and Piping Conference, Portland, OR, ASME H00255, pp. 51-57.

Porowski, J. S., et al., 1988, "Fatigue Criteria for Remaining Life Assessment of Shell Structures Program Plan," submitted to the Subcommittee on Shells and Ligaments of the Pressure Vessel Research Committee, May Meeting.

Sakai, T., et al., 1993, "Implementation of Automated, On-Line Fatigue Monitoring in a Boiling Water Reactor, ASME Pressure Vessel and Piping Conference, Denver, CO, July 25-29, 1993, PVP Volume 252, pp. 67-74.

Snaider, R., 1980, BWR Feedwater Nozzle and Control Rod Drive Return Line Nozzle Cracking, NUREG-0619. 